\title{
DESIGN \& DEVELOPMENT OF A NOVEL GLASS POLYALKENOATE CEMENT FOR STERNAL FIXATION AND REPAIR, IN THE EVENT OF MEDIAN STERNOTOMY SURGERY
}

\author{
by
}

\begin{abstract}
Adel MF. Alhalawani
M.Sc.Eng., Biomedical Engineering, University of Malaya, Kuala Lumpur, Malaysia, 2013 B.Eng., Biomedical Engineering, Mehran University of Engineering and Technology, Jamshoro, Pakistan, 2010
\end{abstract}

\author{
A dissertation \\ presented to Ryerson University \\ in partial fulfillment of the \\ requirement for the degree of \\ Doctor of Philosophy \\ in the program of \\ Mechanical and Industrial Engineering
}

Toronto, Ontario, Canada, 2017

(C) Adel Alhalawani 2017 


\section{Author's Declaration}

I hereby declare that I am the sole author of this dissertation. This is a true copy of the dissertation, including any required final revisions, as accepted by my examiners.

I authorize Ryerson University to lend this dissertation to other institutions or individuals for the purpose of scholarly research.

I further authorize Ryerson University to reproduce this dissertation by photocopying or by other means, in total or in part, at the request of other institutions or individuals for the purpose of scholarly research.

I understand that my dissertation may be made electronically available to the public. 


\title{
Abstract
}

\section{Design \& development of a novel glass polyalkenoate cement for sternal fixation and repair, in the event of median sternotomy surgery}

\author{
Adel Alhalawani \\ Doctor of Philosophy, 2017 \\ Mechanical Engineering \\ Ryerson University
}

Median sternotomy surgery is the gold standard for cardiac/thoracic procedures such as open-heart surgery. With over one million median sternotomy surgeries performed worldwide every year, sternal wound complications pose a serious risk to the health of affected patients.

Various techniques have been used for sternal fixation including wiring, plate-screw systems and cementing. The ideal sternal closure device is the one which has mechanical properties suited to the local environment, biocompatibility, radio-opacity, cost-effectiveness and ease of removal when necessary. None of the techniques that have been utilized for sternal fixation to date address all of these requirements.

Glass polyalkenoate cements (GPCs) have a long history of use in restorative and orthodontic dentistry and ear, nose and throat (ENT) surgery but have yet to be indicated for musculoskeletal applications.

This dissertation relates to the development of new GPC-based adhesives for use in sternal closure. A series of novel glasses based on the system $48 \mathrm{SiO}_{2}-(36-\mathrm{X}) \mathrm{ZnO}-6 \mathrm{CaO}-8 \mathrm{SrO}-2 \mathrm{P}_{2} \mathrm{O}_{5}-\mathrm{XTa}_{2} \mathrm{O}_{5}$ with $\mathrm{X}$ varying from 0.0 to 8.0 mole percentage were fabricated and characterized. The structural features as a function of $\mathrm{Ta}_{2} \mathrm{O}_{5}$ content were investigated by network connectivity (NC) calculations, $x$-ray diffraction (XRD), particle size analysis (PSA), scanning electron microscopy-energy dispersive spectroscopy (SEM-EDS), x-ray photoelectron spectroscopy (XPS), Fourier transform infrared spectroscopy (FTIR) and magic angle spinningnuclear magnetic resonance (MAS-NMR). The thermal properties of the glasses were obtained by performing simultaneous thermal analysis (STA). The effect of glass structure on $\mathrm{pH}$ and solubility was also evaluated. The formulated glasses were used to prepare GPC adhesive materials and tested for their suitability for sternal fixation. The data collected has confirmed that substituting up to 0.5 mole percentage of $\mathrm{ZnO}$ with $\mathrm{Ta}_{2} \mathrm{O}_{5}$ in the glass system under study resulted in the formation of adhesives that are deemed suitable for sternal fixation. The formulated cements, based on the use of glasses containing no greater than 0.5 mole percentage of $\mathrm{Ta}_{2} \mathrm{O}_{5}$ have rheology, strength, radiopacity, antibacterial and in-vitro behavior suitable for sternal fixation.

To the best knowledge of the candidate, this dissertation is the first to report the use of tantalumcontaining GPC-based adhesives for sternal closure. Based on the obtained results, the formulated adhesives can be used in conjunction with sternal cable ties (current standard method) to offer optimal fixation for patients and reduce post-operative complications such as bacterial infection and pain from micro-motion. 


\section{Acknowledgments}

I would like to take this opportunity to acknowledge with much appreciation the crucial rule of my supervisor, Professor Mark Towler, who has invested his full effort in guiding me to achieve the goals of this dissertation. I appreciate his keen interest and support during my $\mathrm{PhD}$ program as well as during my master's program which took place in Malaysia. Without Mark's guidance and persistent help this dissertation would not have been possible.

I would like to thank Ryerson University and the Collaborative Health Research Projects (CHPR) (Grant No. 315694) for the financial support during my PhD candidacy.

I would like to thank my committee chair Professor Ahmad Ghasempoor and my committee members, Professor Marcello Papini and Professor Comondore Ravindran, for their time and expertise to better my work. I thank them for their contribution and their continuous support.

My sincere thanks also goes to Dr. Declan Curran (Medtronic, Ireland), Dr. Daniel Boyd (Dalhousie University, Canada), Dr. Anthony Wren (Alfred University, USA), Dr. Stephen Waldman (Ryerson University), and Dr. Wendy Stone (Ryerson University) who have been instrumental in the successful completion of this project. Dr. Curran provided considerable guidance and support during his post-doctoral fellowship position in the years 2013-2015. Dr. Boyd, Dr. Wren, Dr. Waldman and Dr. Stone assisted and supported my research and gave me access to the laboratory and research facilities at their institutions.

I must acknowledge all my fellow lab mates for the stimulating discussions, and for all the fun we have had in the last three years. Thanks also to the many friends and colleagues who have consistently helped me keep perspective on what is important in life and shown me how to deal with reality.

Further, I would like to express my deepest appreciation to all those who provided me the possibility to complete this dissertation report, to the management, lecturers, and staff in Ryerson University, particularly, in the Faculty of Mechanical and Industrial Engineering.

Last not least, I would like to thank my parents, siblings and my wife for their endless love and support.

Thank you all. 


\section{Dedication}

This dissertation is dedicated to my father Moh'd Fawzi, my mother Muna, my siblings Omar, Amer, Ola and Ala'a and to my wife Rania. 
Author's Declaration

Abstract $\quad$ iii

Acknowledgments $\quad$ iv

Dedication

1 INTRODUCTION

1.1 THE SKELETAL SYSTEM: BONES AND BONE TISSUE

1.1.1 FUNCTIONS OF THE SKELETAL SYSTEM 21

1.1.2 CARTILAGE

1.1.3 BONE HISTOLOGY AND ANATOMY

1.1.3.1 Chemical composition of the bone 2

1.1.3.2 Microscopic anatomy of the bone $\quad 2$

1.1.3.3 Bone shapes 3

$\begin{array}{lll}1.1 .4 & \text { BONE REMODELING } & 4\end{array}$

1.1.5 HOMEOSTATIC IMBALANCE OF BONE 4

1.1.5.1 Osteomalacia $\quad 4$

1.1.5.2 Osteoporosis $\quad 5$

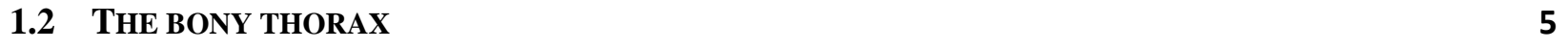

1.2.1 THE STERNUM $\quad 6$

$\begin{array}{lll}1.2 .2 & \text { THORACIC RIBS } & 7\end{array}$

$\begin{array}{lll}1.2 .3 & \text { BIOLOGICAL LOADING } & 7\end{array}$

1.3 MEDIAN STERNOTOMY 9

1.3.1 PROCEDURE $\quad 9$

1.3.2 PRE- AND POST-STERNOTOMY COMPLICATIONS 9

1.3.2.1 Mediastinitis 9

$\begin{array}{lll}\text { 1.3.2.2 } & \text { Dehiscence } & 10\end{array}$

$\begin{array}{lll}1.3 .2 .3 & \text { Osteomyelitis } & 10\end{array}$

1.3.2.4 Wound infections $\quad 10$

$\begin{array}{ll}\text { 1.3.2.5 Sternal displacement/ micro-motion } & 10\end{array}$

1.3.3 MEDIAN STERNOTOMY VS. ALTERNATIVE SURGICAL PROCEDURES 11

1.3.4 STERNAL FIXATION TECHNIQUES 12

$\begin{array}{lll}\text { 1.3.4.1 Wiring techniques } & 12\end{array}$

$\begin{array}{lll}\text { 1.3.4.2 } & \text { Interlocking systems } & 17\end{array}$

$\begin{array}{lll}\text { 1.3.4.3 } & \text { Plate-screw systems } & 19\end{array}$

1.3.4.4 Cementing 23

1.3.4.5 Antimicrobial materials to reduce post-operative complications 25

1.3.4.5.1 Antibiotic incorporation $\quad 25$

$\begin{array}{lll}\text { 1.3.4.5.2 Vacuum assisted closure (VAC) } & 27\end{array}$ 
$\begin{array}{llr}1.4 & \text { RESEARCH SIGNIFICANCE AND LIMITATIONS } & 28\end{array}$

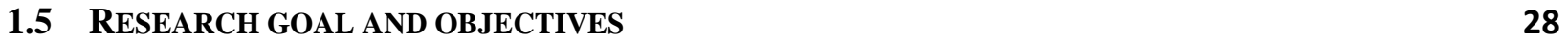

$\begin{array}{llr}1.6 & \text { STRUCTURE OF THESIS } & 29\end{array}$

$\begin{array}{llr}1.7 & \text { STATEMENT OF CO-AUTHORSHIP } & 29\end{array}$

$\underline{2}$ THE ROLE OF POLY(ACRYLIC ACID) IN CONVENTIONAL GLASS POLYALKENOATE CEMENTS: A REVIEW OF THE LITERATURE

2.1 INTRODUCTION

2.2 POLY(ACRYLIC ACID) IN CONVENTIONAL GLASS POLYALKENOATE CEMENTS: HISTORICAL BACKGROUND AND BASIC BEHAVIOR

2.2.1 BACKGROUND AND GENERAL CHARACTERISTICS OF THE PAA COMPONENT OF CGPCS 34

2.2.2 THE ROLE OF PAA IN THE SETTING REACTION OF CGPCS 35

2.2.3 THE ROLE OF PAA DURING CGPC MATURATION

2.3 THE INFLUENCE OF PAA PROPERTIES ON THE PHYSICAL CHARACTERISTICS OF CGPCS 38

2.3.1 THE EFFECT OF THE PAA MOLAR MASS

2.3.2 EFFECT OF THE PAA MOLECULAR WEIGHT

2.3.3 EFFECT OF THE PAA CONCENTRATION 46

2.3.4 EFFECT OF THE PAA POLYDISPERSITY INDEX

2.3.5 EFFECT OF MIXING RATIO OF PAA SOLUTION AND GLASS POWDER 50

2.3.6 EFFECT OF ADDITIVES/CHELATING AGENTS

2.4 THE INFLUENCE OF PAA COMPONENT ON THE CLINICAL PERFORMANCE OF CGPCS 53

2.4.1 BIOCOMPATIBILITY

2.4.2 RHEOLOGICAL AND MECHANICAL PROPERTIES

2.4.3 ADHESION TO SUBSTRATES

2.4.4 ION RELEASE $\quad 58$

2.4.5 ACID EROSION AND CLINICAL DURABILITY $\quad 59$

$\begin{array}{llr}2.5 & \text { SUMMARY } & 59\end{array}$

$\underline{3}$ THE EFFECT OF ZNO $\leftrightarrow \mathrm{TA}_{2} \mathrm{O}_{5}$ SUBSTITUTION ON THE STRUCTURAL AND THERMAL PROPERTIES OF SIO 2 -ZNO-SRO-CAO-P ${ }_{2} \underline{O}_{5}$ GLASSES

$\begin{array}{llr}3.1 & \text { INTRODUCTION } & 61\end{array}$

3.2 MATERIALS AND METHODS $\quad 62$

3.2.1 GLASS SYNTHESIS PROCESS

3.2.1.1 Preparation and determination of glass network connectivity 62

3.2.1.2 Glass firing and powder production $\quad 63$

3.2.2 MATERIAL CHARACTERIZATION

3.2.2.1 X-ray diffraction $\quad 63$

3.2.2.2 Thermal analysis $\quad 63$

3.2.2.3 X-ray photoelectron spectroscopy $\quad 64$

3.2.2.4 Fourier transform infrared spectroscopy study $\quad 64$

$\begin{array}{llr}3.3 & \text { RESUlts } & 64\end{array}$ 
$\begin{array}{lll}\text { 3.3.1 } & \text { GLASS NETWORK CONNECTIVITY } & 64\end{array}$

3.3.2 GLASS STRUCTURAL AND THERMAL CHARACTERIZATION 65

3.3.2.1 X-ray diffraction $\quad 65$

3.3.2.2 Thermal analysis $\quad 65$

3.3.2.3 X-ray photoelectron spectroscopy $\quad 66$

$\begin{array}{lll}\text { 3.3.2.4 Fourier transform infrared spectroscopy study } & 70\end{array}$

$\begin{array}{lll}3.4 & \text { DISCUSSION } & 71\end{array}$

$\begin{array}{lll}3.4 .1 & \text { ROLE OF NETWORK CONNECTIVITY } & 71\end{array}$

3.4.2 GLASS STRUCTURAL AND THERMAL CHARACTERIZATION 73

$\begin{array}{lll}3.5 & \text { SUMMARY } & 77\end{array}$

$\underline{4}$ A NOVEL TANTALUM-CONTAINING BIOGLASS. PART I. STRUCTURE AND

\begin{tabular}{ll} 
SOLUBILITY. & 78 \\
\hline
\end{tabular}

$\begin{array}{lll}4.1 & \text { INTRODUCTION } & 78\end{array}$

\begin{tabular}{ll}
4.2 & EXPERIMENTAL \\
\hline
\end{tabular}

$\begin{array}{lll}\text { 4.2.1 } & \text { GLASS SYNTHESIS } & 79\end{array}$

4.2.2 GLASS STRUCTURAL AND THERMAL CHARACTERIZATION 80

4.2.2.1 X-ray diffraction $\quad 80$

4.2.2.2 Particle size analysis (PSA) $\quad 80$

4.2.2.3 Scanning Electron Microscopy-Energy Dispersive Spectroscopy (SEM-EDS) 81

4.2.2.4 Differential Thermal Analysis (DTA) 81

4.2.2.5 X-Ray Photoelectron Spectroscopy (XPS) 81

4.2.2.6 Magic angle spinning-Nuclear magnetic resonance (MAS-NMR) 81

4.2.3 EFFECT OF GLASS STRUCTURE ON ION RELEASE AND SOLUBILITY 82

4.2.3.1 Disc sample preparation and degradation analysis $\quad 82$

4.2.3.2 $\mathrm{pH}$ analysis $\quad 82$

4.2.3.3 Ion release profiles $\quad 82$

4.3 RESULTS AND DISCUSSION

4.3.1 GLASS STRUCTURAL AND THERMAL CHARACTERIZATION 83

4.3.2 GLASS SOLUBILITY PROPERTIES

4.4 SUMMARY 96

$\underline{5}$ A NOVEL TANTALUM-CONTAINING BIOGLASS. PART II. DEVELOPMENT OF A BIOADHESIVE FOR STERNAL FIXATION AND REPAIR $\quad 97$

$\begin{array}{llr}5.1 & \text { INTRODUCTION } & 97\end{array}$

5.2 MATERIALS AND METHODS
99

$\begin{array}{llr}\text { 5.2.1 } & \text { GLASS SYNTHESIS } & 99\end{array}$

5.2.2 CEMENT PREPARATION 99

5.2.3 EVALUATION OF SETTING CHARACTERISTICS 99

5.2.3.1 Working and net setting (hardening) times 99

5.2.3.2 Fourier transform infrared (FTIR) spectroscopic study 99 
5.2.4 EVALUATION OF PH AND ION RELEASE $\quad 100$

$\begin{array}{lll}\text { 5.2.4.1 Samples preparation } & 100\end{array}$

$\begin{array}{lll}5.2 .4 .2 \mathrm{pH} \text { analysis } & 100\end{array}$

$\begin{array}{lll}\text { 5.2.4.3 } & \text { Ion release studies } & 100\end{array}$

$\begin{array}{ll}\text { 5.2.5 EVALUATION OF MECHANICAL PROPERTIES } & 100\end{array}$

5.2.5.1 Determination of compressive strength 100

$\begin{array}{lll}\text { 5.2.5.2 Determination of Biaxial flexural strength } & 100\end{array}$

5.2.5.3 Determination of Vickers hardness 101

5.2.6 EVALUATION OF RADIOPACITY 102

$\begin{array}{lll}5.2 .7 & \text { ANTIMICROBIAL ANALYSIS } & 102\end{array}$

5.2.8 CYTOTOXICITY TESTING 103

5.2.9 EX-VIVO BOND STRENGTH TESTING 103

$\begin{array}{lll}5.2 .10 & \text { STATISTICAL ANALYSIS } & 104\end{array}$

$\begin{array}{lll}5.3 & \text { RESULTS AND DISCUSSION } & 104\end{array}$

$\begin{array}{lll}\text { 5.3.1 } & \text { EVALUATION OF CEMENT SETTING CHARACTERISTICS } & 104\end{array}$

$\begin{array}{lll}\text { 5.3.1.1 Working and net setting times } & 104\end{array}$

$\begin{array}{lll}\text { 5.3.1.2 } & \text { FTIR spectroscopic study } & 106\end{array}$

$\begin{array}{lll}\text { 5.3.2 PH AND ION RELEASE STUDIES } & 107\end{array}$

$\begin{array}{lll}\text { 5.3.2.1 } & \mathrm{pH} \text { analysis } & 107\end{array}$

$\begin{array}{lll}\text { 5.3.2.2 } & \text { Ion release profiles } & 109\end{array}$

5.3.3 EVALUATION OF MECHANICAL PROPERTIES 110

5.3.3.1 Determination of compressive and biaxial flexural strengths 110

5.3.3.2 Determination of Vickers hardness 111

5.3.4 EVALUATION OF RADIOPACITY 111

5.3.5 ANTIMICROBIAL EVALUATION 112

$\begin{array}{lll}\text { 5.3.6 } & \text { CYTOTOXICITY TESTING } & 117\end{array}$

$\begin{array}{lll}\text { 5.3.7 } & E X \text {-VIVO BOND STRENGTH TESTING } & 118\end{array}$

$\begin{array}{llr}5.4 & \text { SUMMARY } & 119\end{array}$

$\underline{6}$ CONCLUSIONS AND FUTURE WORK 120

$\begin{array}{ll}\text { 6.1 PRACTICAL IMPLICATIONS } & 120\end{array}$

$\begin{array}{llr}\text { 6.2 CONCLUSIONS } & 120\end{array}$

6.3 RECOMMENDATIONS FOR FUTURE WORK 121

\begin{tabular}{lr} 
REFERENCES & 123 \\
\hline
\end{tabular} 


\section{List of Tables}

TABLE 1.1: SUMMARY AND COMPARISON OF THE SIX TESTED WIRING TECHNIQUES ACCORDING TO CASHA ET AL. [15

TABLE 1.2: DISPLACEMENT AT 10 KG LOAD (150TH CYCLE) COMPARING 4 CLOSURE TECHNIQUES WITH STANDARD SS TECHNIQUE (VALUES ARE EXPRESSED IN MEAN \pm STANDARD DEVIATION) [57]

TABLE 1.3: PERCENTAGE CUT-THROUGH THE BONE COMPARING 4 CLOSURE TECHNIQUES WITH STANDARD SS TECHNIQUE (VALUES ARE EXPRESSED IN MEAN \pm STANDARD DEVIATION) [57]

TABLE 1.4: COMPARISON OF SOME PLATING FIXATION TECHNIQUES PUBLISHED FROM 2002 THROUGH 2011 [82-89].22

TABLE 1.5: CHARACTERISTICS OF PERFECT ADHESIVE CEMENT AND/OR FIXATION DEVICE FOR ROBUST STERNAL

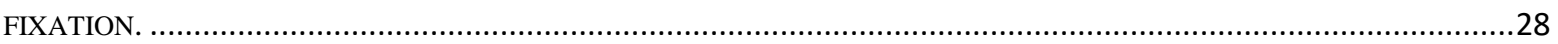

TABLE 2.1: INFLUENCE OF PAA MOLAR MASS ON THE FRACTURE PROPERTIES OF 4.5SIO $\mathrm{S}_{2}-1.5 \mathrm{P}_{2} \mathrm{O}_{5}-3 \mathrm{AL}_{2} \mathrm{O}_{3}-4 \mathrm{CAO}-$ $\mathrm{CAF}_{2}$ GPCS (*E5, E7, E9 AND E11 PAAS HAVE NUMBER AVERAGE MOLAR MASS OF 3.25X103, 6.66X103,

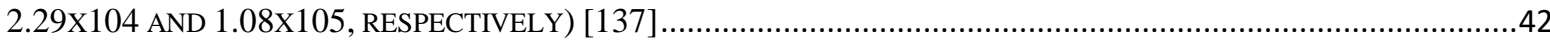

TABLE 2.2: EFFECT OF PAA MW ON RHEOLOGICAL PROPERTIES OF CGPCS ...................................................43

TABLE 2.3: DEPENDENCE OF FRACTURE PROPERTIES AND ACID EROSION OF 12.39SI-16.44AL-7.14CA-10.40F-7.26NA4.54P-41.83O GPCS ON PAA MOLECULAR WEIGHT (*E5, E7, E9, E11, E13 AND E15 PAAS HAVE WEIGHT AVERAGE MOLECULAR WEIGHTS (MW) OF 1.15X104, 2.27X104, 1.14X105, 3.83X10 [127] .........................46

TABLE 2.4: EFFECT OF THE PAA CONCENTRATION (\% W/W) ON RHEOLOGICAL PROPERTIES AND HANDLING

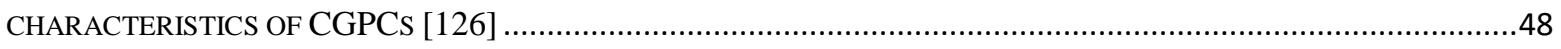

TABLE 2.5: INFLUENCE OF THE PAA CONCENTRATION ON MECHANICAL PROPERTIES OF GPCS [138,139] ................49

TABLE 2.6: PROPERTIES OF CHEMFIL MIXED WITH 100\%, 90\%, 80\% AND 50\% OF THE RECOMMENDED POWDER

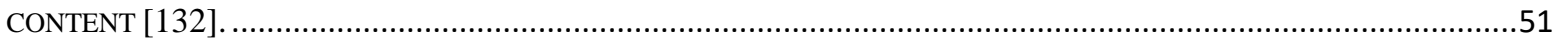

TABLE 3.1: COMPOSITION OF GLASS SERIES IN MOLE PERCENTAGE. ..................................................................63

TABLE 3.2: NETWORK CONNECTIVITY VALUES OF THE GLASS SERIES BEING EVALUATED IN THIS STUDY...................64

TABLE 3.3: THERMAL PROPERTIES $\left({ }^{\circ} \mathrm{C}\right)$ OF THE GLASS SERIES $(\mathrm{N}=1)$ AS A FUNCTION OF $\mathrm{TA}_{2} \mathrm{O}_{5}$ CONTENT

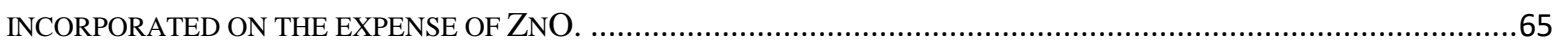

TABLE 3.4: ACTUAL GLASS COMPOSITIONS (AT.\%) AS DETERMINED BY XPS...................................................67

TABLE 3.5: PEAK POSITIONS (EV) FOR THE BO AND THE NBO PEAKS AND THEIR CORRESPONDING AT\%, OBTAINED FROM THE CURVE FITTING OF THE O1S PEAK, OF THE GLASS SERIES.

TABLE 3.6: PEAK POSITIONS (EV) FOR THE CORE LEVELS Si2P3, ZN2P3, CA2P3, SR3D5 AND P2S, OBTAINED FROM HIGH RESOLUTION XPS SPECTRA.

TABLE 3.7: PEAK POSITIONS (EV) FROM THE CURVE FITTING OF THE TA4D3 AND TA4D5 PEAKS AND THEIR CORRESPONDING AT\%, OF THE TA-CONTAINING GLASSES. ...............................................................70

TABLE 3.8: FTIR TRANSMITTANCE BANDS FOR THE GLASS SERIES ....................................................................

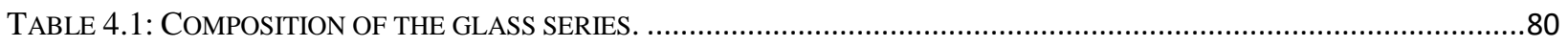

TABLE 4.2: PARTICLE SIZE ANALYSIS DATA FOR THE GLASS SERIES. ................................................................83

TABLE 4.3: ELEMENTAL COMPOSITION (WT\%) OF THE GLASS SERIES AS DETERMINED BY XPS. ................................90

TABLE 4.4: PEAK POSITIONS (EV) FOR THE BO AND THE NBO PEAKS AND THEIR CORRESPONDING AT\%, OBTAINED FROM THE CURVE FITTING OF THE O1S PEAK, OF THE GLASS SERIES. ........................................................91

TABLE 4.5: GLASS SOLUBILITY STATISTICS (WITH RESPECT TO AGING TIME) .....................................................96

TABLE 4.6: GLASS SOLUBILITY STATISTICS (WITH RESPECT TO TA2O5 CONTENT) ............................................96

TABLE 5.1: CHARACTERISTIC VIBRATION FREQUENCIES (CM-1) IN FTIR SPECTRA OF THE CEMENT SERIES. ..............107

TABLE 5.2: MEANS COMPARISON OF $\mathrm{ZN}^{2+}$ AND $\mathrm{SR}^{2+}$ ION RELEASE WITH RESPECT OF TA $\mathrm{O}_{5}$ CONTENT .....................109 


\section{List of Figures}

FIGURE 1.1: SCHEMATIC OVERVIEW OF BONE, DEPICTING GROSS OVERVIEW, AND CELLULAR DISTRIBUTION [3] ............3

FIGURE 1.2: ILLUSTRATION OF NORMAL AND OSTEOPOROTIC SPONGY BONE [10] ……..........................................

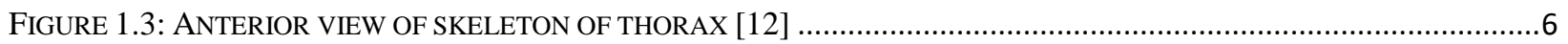

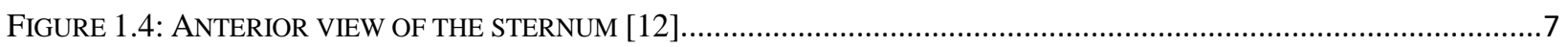

FIGURE 1.5: DIFFERENT STERNAL LOADING CONDITIONS - A) TRANSVERSE SHEAR B) LATERAL DISTRACTION C)

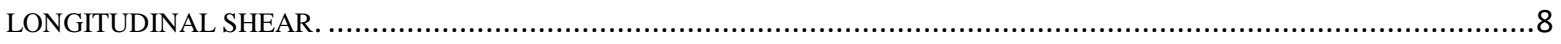

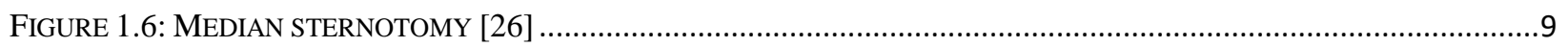

FIGURE 1.7: ILLUSTRATION OF (A) THORACOTOMY AND (B) PORT-ACCESS SURGERY [53]........................................12

FIGURE 1.8: CABLED BUTTERFLY CLOSURE BY PULLING AND TWISTING CONJOINED WIRES [30]...............................16

FIGURE 1.9: THE PROCESS STARTS FROM THE XIPHOID AND CONTINUES UPWARD [30]............................................16

FIGURE 1.10: TALON STERNAL FIXATION DEVICES- A) DOUBLE LEGGED AND B) SINGLE LEGGED [74] ........................18

FIGURE 1.11: H-SHAPED PLATE FOR STERNAL FIXATION. (A) HOLES WITH DIFFERENT ANGELS OF DIRECTION TO COUNTER-BALANCE THE MULTIDIRECTIONAL FORCES IMPOSED ON THE STERNUM (B) STANDARD STABLE

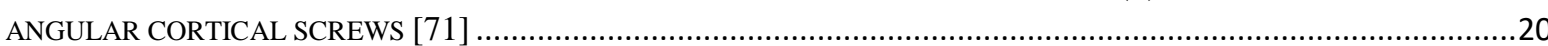

FIGURE 1.12: COMPUTERIZED TOMOGRAPHY SCAN FOR THE MASSIVE AORTIC PSEUDOANEURYSM FOR A 58 YEAR OLD

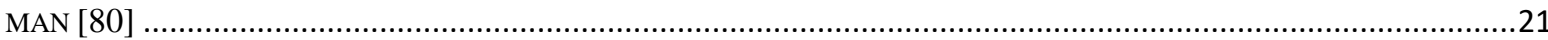

FIGURE 1.13: CASES PROFILE IN THE DURATION BETWEEN JUNE 2009 AND JUNE 2010 IN THE WÜRZBURG UNIVERSITY

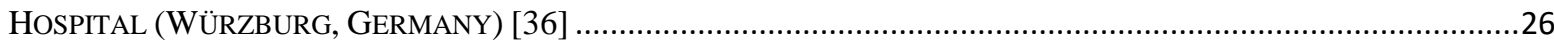

FigURE 1.14: PLACEMENT OF VAC SPONGE ON THE MEDIASTINUM. (A) RIGHT EDGE OF THE STERNUM (B) LEFT EDGE

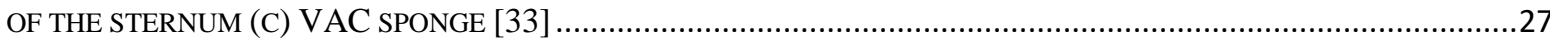

FIGURE 2.1: GENERAL STRUCTURE OF THE REPEATING UNIT FOR PAA (ADAPTED FROM [109]) ...............................33

Figure 2.2: (A) ACRYLIC ACID; (B) MALEIC ACID; (C) ITACONIC ACID; (D) METHACRYLIC ACID; (E) 3-BUtENE-1,2,3-

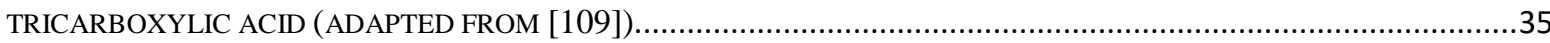

FigURE 2.3: A.) REPTATING ENTANGLED CHAIN, B.) CHAIN SCISSION (REPRINTED WITH PERMISSION FROM REF. [143]).

FIGURE 2.4: (A) CEMENT VOLUME; (B) EFFECT OF INCREASING MOLECULAR WEIGHT; (C) EFFECT OF INCREASING

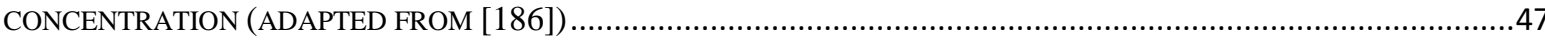

FIGURE 2.5: (A) (+) TARTARIC ACID; (B) (-) TARTARIC ACID; (C) MESO- TARTARIC ACID (ADAPTED FROM [109]).......53

FIGURE 2.6: A SCHEMATIC DIAGRAM ILLUSTRATING THE PROPERTIES OF THE ACR YLIC ACID MONOMER IN THE COPOLYMER AND ITS ABILITY TO FORM HYDROGEN BONDS RESULTING IN EFFECTIVE ADHESION .......................56

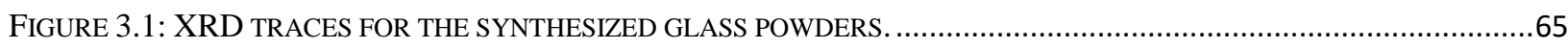

FIGURE 3.2: WIDE SCAN XPS SPECTRA FROM THE SURFACE OF THE GLASS SERIES BEING INVESTIGATED.....................67

FIGURE 3.3: THE HIGH RESOLUTION O1S CORE LEVEL SPECTRA FOR THE GLASS SERIES..........................................68

FIGURE 3.4: CURVE FITTING OF THE O1S SPECTRUM FOR TA0 GLASS WITH RESPECT TO BO AND NBO CONTRIBUTIONS.

FIGURE 3.5: TA4D CORE LEVEL SPECTRA FOR TA-CONTAINING GLASSES (TA1, TA2, TA3 AND TA4) ..........................69

FIGURE 3.6: CURVE FITTING OF THE TA4D3 AND TA4D5 SPECTRUM FOR TA1 GLASS. ..............................................70

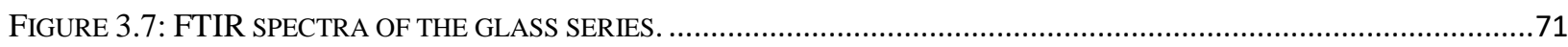

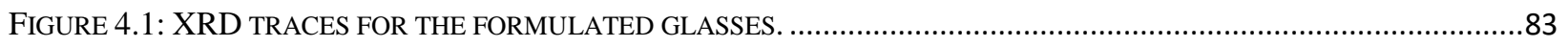

FIGURE 4.2: SEM IMAGES OF THE GLASS SERIES AND THE CORRESPONDING EDS QUALITATIVE SPECTRA AND

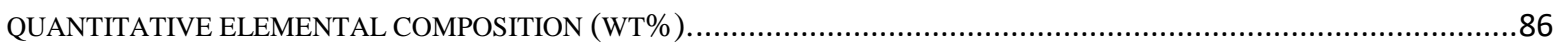

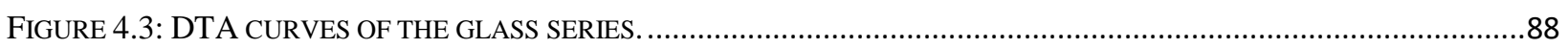

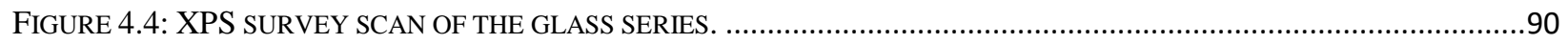


FIGURE 4.5: CURVE FITTING OF THE O1S SPECTRA FOR THE GLASS SERIES WITH RESPECT TO BO AND NBO CONTRIBUTIONS.

FIGURE 4.6: ${ }^{29}$ SI MAS-NMR SPECTRA OF THE GLASS SERIES.

FIGURE 4.7: CURVE FITTING OF THE 29SI NMR SPECTRA: (A) EXPANDED SPECTRUM OF TA0; (B) EXPANDED SPECTRUM OF TA1; (C) EXPANDED SPECTRUM OF TA2; (D) SIMULATED (CURVE FITTED) SPECTRUM OF (A); (E) SIMULATED SPECTRUM OF (B) AND (F) SIMULATED SPECTRUM OF (C).

FigURe 4.8: (A) PERCENTAGE WEIGHT LOSS OF THE GLASS SERIES IN DEIONIZED WATER AS A FUNCTION OF TIME, (B) PH MEASUREMENTS DURING GLASS SOLUBILITY IN DEIONIZED WATER. ERROR BARS REPRESENT STANDARD DEVIATION FROM THE MEAN.

FIGURE 4.9: ION RELEASE PROFILES OF (A) ZN2+ AND (B) SR2+ IONS DURING GLASS SOLUBILITY IN DEIONIZED WATER.

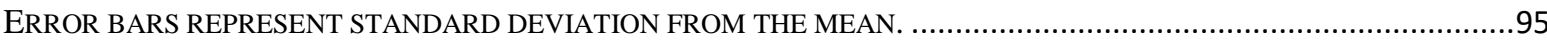

FIGURE 5.1: INDENTATION GEOMETRY OF HARDNESS TEST. [349]. 101

FIGURE 5.2: CROSS-SECTIONAL VIEW (LEFT) AND SIDE VIEW (RIGHT) OF THE BOVINE CORTICAL BONE SAMPLE USED FOR EX-VIVO ADHESION TESTING. 104

FIGURE 5.3: WORKING AND SETTING TIMES FOR TA-CONTAINING SILICA BASED GPCS. ERROR BARS REPRESENT STANDARD DEVIATION FROM THE MEAN $(\mathrm{N}=5)$. .105

FIGURE 5.4: FTIR SPECTRUM OF CEMENT SERIES OVER 1 AND 7 DAY, POST CEMENT PREPARATION AND AGING IN DI WATER

FIGURE 5.5: PH MEASUREMENTS DURING CEMENT SOLUBILITY IN DI WATER FOR 1, 7 AND 30 DAYS, POST CEMENT PREPARATION. ERROR BARS REPRESENT STANDARD DEVIATION FROM THE MEAN ( $\mathrm{N}=5$ ) 108

FigURE 5.6: RELEASE PROFILES OF (A) $\mathrm{ZN}^{2+}$ AND (B) $\mathrm{SR}^{2+}$ IONS DURING CEMENT AGING IN DI WATER. ERROR BARS (TOO SMALL TO SEE) REPRESENT STANDARD DEVIATION FROM THE MEAN ( $\mathrm{N}=3$ ).

FIGURE 5.7: COMPRESSIVE (A) AND BIAXIAL FLEXURAL (B) STRENGTHS OF THE CEMENT SERIES WHEN AGED IN DI WATER FOR 1, 7 AND 30 DAYS. ERROR BARS REPRESENT STANDARD DEVIATION FROM THE MEAN (N=5)..........110

FIGURE 5.8: VICKERS HARDNESS OF THE CEMENTS WHEN MATURED FOR 1, 7 AND 30 DAYS, POST CEMENT PREPARATION. ERROR BARS REPRESENT STANDARD DEVIATION FROM THE MEAN (N=5).

FIGURE 5.9: (A) RADIOGRAPHIC IMAGES OF CEMENT DISCS AND THE ALUMINUM STEP WEDGE. (B) THE RADIOPACITY OF THE DISCS RECORDED IN MM AL. ERROR BARS REPRESENT STANDARD DEVIATION FROM THE MEAN (N=5)..112

FIGURE 5.10: INHIBITION ZONES OF S. AUREUS LAWN ON AGAR MEDIA, IN RESPONSE TO TA0, TA1 AND TA2, EVALUATED AFTER 1 DAY OF MATURATION AND INCUBATED AT $37^{\circ} \mathrm{C}$.

FIGURE 5.11: INHIBITION ZONES OF A) E. COLI, B) S. EPIDERMIDIS AND C) S. AUREUS LAWNS ON AGAR MEDIA, IN RESPONSE TO TA0, TA1 AND TA2, EVALUATED AFTER 1, 7 AND 30 DAYS MATURATION AND INCUBATED AT 37 ${ }^{\circ} \mathrm{C}$. ERROR BARS REPRESENT STANDARD DEVIATION FROM THE MEAN ( $\mathrm{N}=3$ ).

FIGURE 5.12: COLONY MORPHOLOGY OF FUSARIUM SOLANI FUNGUS AGED WITH NO SAMPLES (CONTROL) AND TESTED WITH TA0, TA1 AND TA2 OVER A PERIOD OF 1 (A AND B), 7 (C AND D) AND 30 DAYS (E AND F), RESPECTIVELY.

FIGURE 5.13: CELL VIABILITY RESULTS OF THE CONTROL FIBROBLAST CELLS AND THE FORMULATED CEMENTS OVER 1, 3 AND 7 DAYS, POST CEMENT PREPARATION AND INCUBATION. ERROR BARS REPRESENT STANDARD DEVIATION FROM THE MEAN (N=3). 118

FIGURE 5.14: MECHANICAL TESTING RESULTS OF THE BOVINE FEMUR CORTICAL BONES ADHERED USING THE FORMULATED CEMENTS AND AGED IN DI WATER FOR 1 DAY AT $37^{\circ} \mathrm{C}$. ERROR BARS REPRESENT STANDARD DEVIATION FROM THE MEAN ( $\mathrm{N}=3$ ). 


\section{Nomenclature}

3D

AAS

At $\%$

BO

$\mathrm{Ca}$

CBC

CGPC

$\mathrm{cm}$

$\mathrm{CNC}$

$\mathrm{COOH}$

$\mathrm{CPC}$

CT

DETA

DI

DMTA

DSWI

FDA

FTIR

$G_{1}$

GCS

GIC

$\mathrm{GPa}$

$\mathrm{Hrs}$

HV

HVR

ICU

IR

$K_{1}$

$\mathrm{KPa}$

$\mathrm{lb} / \mathrm{ft}^{3}$

$M c$

$\mathrm{Mi}$

Min

$\mathrm{mm}$

$\mathrm{M}_{\mathrm{n}}$

$\mathrm{MPa}$

MRI

MTT

$\mathrm{M}_{\mathrm{w}}$

MWD

$n$

$\mathrm{NaCl}$

$\mathrm{NBO}$
Three dimensional

Atomic absorption spectroscopy

Atomic percentage

Bridging oxygen

Calcium

Cabled butterfly closure

Conventional glass polyalkenoate cement

Centimeter

Computer numerical control

Carboxylic acid

Calcium phosphate cement

Computerized tomography

Dielectric thermal analysis

Deionized water

Dynamic mechanical thermal analysis

Deep sternal wound infection

Food and Drug Administration

Fourier transform infrared spectroscopy

Toughness

Gentamicin collagen sponge

Glass ionomer cement

Giga pascals

Hours

Vickers hardness

Heart valve replacement

Intensive care unit

Infrared

Fracture toughness

Kilo Pascals

lb per cubic feet

Critical molar mass

Mass of a specific isotope

Minutes

Millimeter

Number average molecular weight

Mega pascals

Magnetic resonance imaging

Methyl thiazol tetrazolium

Weight average molecular weight

Molecular weight distribution

Number of samples

Sodium chloride

Non bridging oxygen 


\begin{tabular}{|c|c|}
\hline $\mathrm{NC}$ & Network connectivity \\
\hline NMR & Nuclear magnetic resonance \\
\hline $\mathrm{P}$ & Phosphorous \\
\hline $\mathrm{P}: \mathrm{L}$ & Powder:liquid \\
\hline PAA & Poly(acrylic acid) \\
\hline PDI & Polydispersity index \\
\hline PMMA & Poly(methyl methacrylate) \\
\hline $\mathrm{PO}_{4}^{3-}$ & Orthophosphates \\
\hline PSA & Particle size analysis \\
\hline $\mathrm{Pt}$ & Platinum \\
\hline$R_{p}$ & Plastic zone size \\
\hline RPM & Rounds per minute \\
\hline SBF & Simulated body fluid \\
\hline SD & Standard deviation \\
\hline $\mathrm{Sec}$ & Seconds \\
\hline SEM-EDS & Scanning electron microscopy-energy dispersive spectroscopy \\
\hline $\mathrm{Si} \quad$ & Silicon \\
\hline Spect & Single photon emission computed tomography \\
\hline $\mathrm{Sr}$ & Strontium \\
\hline SS & Stainless steel \\
\hline SSD & Sternal synthesis device \\
\hline STA & Simultaneous thermal analysis \\
\hline SWC & Sternal wound complication \\
\hline Та & Tantalum \\
\hline $\mathrm{T}_{\mathrm{c}}$ & Glass crystallization temperature \\
\hline ТCP & Tricalcium phosphate \\
\hline$T_{g}$ & Glass transition temperature \\
\hline TGA-DTA & Thermal gravimetric analysis-differential thermal analysis \\
\hline THR & Total hip replacement \\
\hline $\mathrm{T}_{\mathrm{m}}$ & Glass melting temperature \\
\hline TSA & Tryptic soy agar \\
\hline USA & United States of America \\
\hline UV & Ultraviolet \\
\hline VAC & Vacuum assisted closure \\
\hline $\mathrm{Wt} \%$ & Weight percentage \\
\hline XPS & X-ray photoelectron spectroscopy \\
\hline XRD & $\mathrm{X}$-ray diffraction \\
\hline YMA & Yeast malt agar \\
\hline $\mathrm{Zn}$ & Zinc \\
\hline$\%$ & Percentage \\
\hline${ }^{\circ} \mathrm{C}$ & Degrees Celsius \\
\hline$\mu \mathrm{m}$ & Micro meter \\
\hline$\alpha$ & Directly proportional \\
\hline$\sigma_{c}$ & Compressive strength \\
\hline$\sigma_{\mathrm{f}}$ & Biaxial flexural strength \\
\hline
\end{tabular}




\section{Introduction}

\subsection{The skeletal system: bones and bone tissue}

\subsubsection{Functions of the skeletal system}

The skeleton, a structural framework of the body, is essential for our daily activities such as walking, sitting and breathing. Besides helping the body move and breathe, the skeletal system supports and protects the soft tissues and internal organs. The skeleton is composed of complex and dynamic living tissues, made-up of cells, minerals and proteins, that are able to grow, adapt to multi-directional stresses and undergo rehabilitation post-surgery [1].

The skeletal system, consisting of bones, tendons, ligaments and cartilage, has the following main functions [1-3]:

1. Support: rigid bone is a strong supporting tissue of the body that is well suited for bearing loads. Tendons are strong bands of connective tissue attaching bones to skeletal muscles. Ligaments are strong bands of fibrous connective tissue attaching to bones and holding them together. Cartilage provides a flexible support with certain structures, such as the external ear, nose, trachea and thoracic cage.

2. Protection: bones enclose and protect the organs of the body. Examples include the rib cage protecting the lungs, heart and other organs and structures of the thorax. The skull, is another example, protects the brain.

3. Movement: the contraction of skeletal muscles results in the movement of the body which is facilitated through joints such as the elbow, ankle and knee joints. However, excessive movements of bones are restricted by the ligaments. Cartilage allows bones to move freely.

4. Storage: various minerals, with specific concentration levels, are present in blood. Calcium (Ca) and phosphorous $(\mathrm{P})$ are the two essential minerals. Bones store some minerals within their tissues and release them when there is a decrease in the concentration level of the stored minerals.

5. Blood cell production: blood makes-up about $8 \%$ of the total body weight. The process of blood cell production is called hematopoiesis. For the embryo and fetus, this process occurs in tissues such as spleen, liver, thymus and red bone marrow. After birth and for adults, the process is mainly confined to red bone marrow. Stem cells called hemocytoblasts, located in the red bone marrow, are the main cells that divide to produce daughter cells that differentiate and produce formed elements of the blood. 


\subsubsection{Cartilage}

Skeletal cartilage, made of connective tissues, is more flexible than bone. It consists mainly of water and has no nerves or blood vessels. The high concentration of water in the cartilage structure accounts for its resilience, that is, its ability to be compressed and return to its original shape upon release of the compressive forces. There are three main types of cartilage, which are hyaline, elastic and fibro cartilage. Hyaline cartilage consists of specialized cells called chondroblasts that become chondrocytes when they are surrounded by a matrix produced by themselves. Hyaline cartilage includes a) articular cartilage; covering the ends of most bones at movable joints such as elbow, wrist, and shoulder joints; b) costal cartilage; connecting the breastbone (sternum) to the thorax ribs; c) respiratory cartilages; supporting the respiratory passageways and forming the larynx (voicebox); and d) nasal cartilage; supporting the external nose $[1,2,4]$.

\subsubsection{Bone histology and anatomy}

\subsubsection{Chemical composition of the bone}

Bones are strong, durable and non-brittle due to the proper combination of organic (35 wt\%) and inorganic (65 wt\%) matrix elements [5]. Therefore, the characteristics of bone depends on the composition of the bone matrix [1,2]. Organic materials of the bone consist of cells (osteoblasts, osteoclasts and osteocytes) and osteoid (one third of the organic matrix including collagen and proteoglycans). The inorganic material of the bone consists primarily of hydroxyapatite (HA), which has the molecular formula $\mathrm{Ca}_{10}\left(\mathrm{PO}_{4}\right)_{6}(\mathrm{OH})_{2}$. The structural collagen fibers provide flexible strength to the bone matrix whereas the mineral components (inorganic material) provides the weight-bearing strength to the bone structure $[1,2]$.

\subsubsection{Microscopic anatomy of the bone}

Bone can be classified according to the amount of space relative to the amount of matrix within its structure into spongy (cancellous) and compact (cortical) bones (Figure 1.1). The cancellous bone has more space and less bone matrix than compact bone. Spongy bone consists primarily of plates of bone or interconnecting rods called trabeculae. Trabeculae contain irregularly arranged osteocytes and lamellae (matrix tube) interconnected by canaliculi. No blood vessels penetrate the trabeculae and hence nutrients reach the osteocytes by diffusing through the canaliculi from the endosteum capillaries surrounding the trabeculae. In spongy bone, trabeculae are oriented along the bone stress lines. This natural ability of trabeculae to align themselves helps in resisting more stresses imposed on the bone. In contrast to spongy bone, compact bones 
are supplied with blood vessels while the lamellae are oriented around those blood vessels. The structural unit of compact bone is the osteon (cylinder-like structure and oriented parallel to the long axis of the bone) or Haversian system. Compact bones are often called lamellar bone for the reason that the osteon is a group of hollow matrix tubes. Within the structure of the compact bone, the collagen fibers in one lamella always run in opposite directions to those in the adjacent lamella. However collagen fibers in any lamella always run in the same direction. This alternating pattern within the structure of the compact bone gives them the ability to withstand torsion stresses; each lamella reinforce the adjacent lamella to resist twisting $[1,2,6]$. Figure 1.1 shows a schematic view of the bone structure, depicting gross overview and cellular distribution.

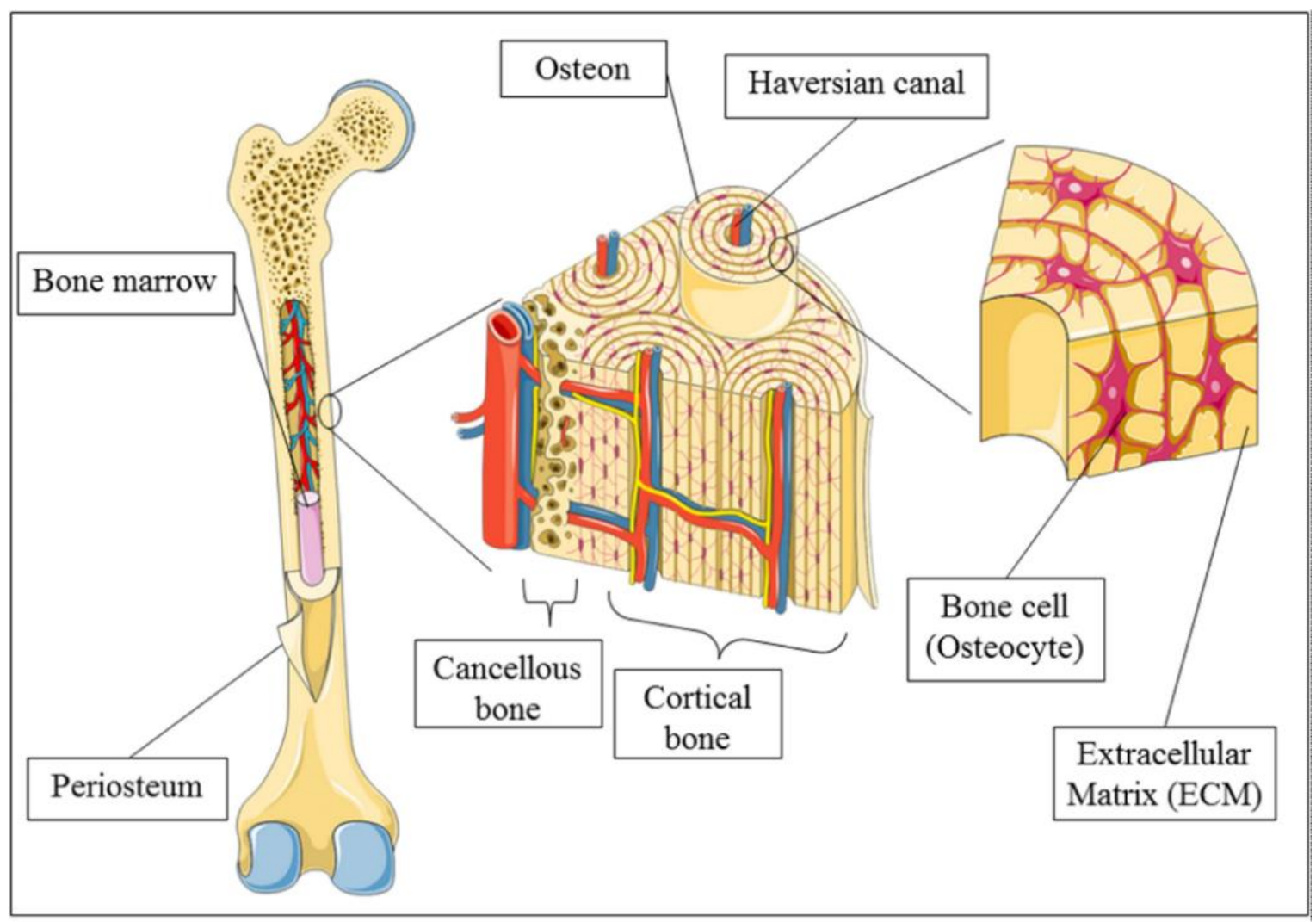

Figure 1.1: Schematic overview of bone, depicting gross overview, and cellular distribution [3]

\subsubsection{Bone shapes}

Bones can also be classified according to their shape into flat, short, long and irregular. Flat bone have a relatively thin, flattened shape and are usually curved; such as the sternum, the ribs and scapulae (shoulder blades). Short bones are nearly cube or round shaped; such as carpal bones (the bones of the wrist) and tarsal (ankle) bones [4]. Long bones are longer than they are wide and are subjected to most of the load during daily activities; such as the femur (thighbone) 
and tibia (shank) bones. Irregular bones are those that do not fit into the other three categories; such as facial and vertebral bones. Nevertheless, it is worth mentioning that all bone shapes share the same design; they all consist of compact and spongy bones. The outer compact bone is covered with periosteum whereas the inner spongy bone is covered with endosteum $[1,2]$.

\subsubsection{Bone remodeling}

Bone is an active dynamic tissue that undergoes small-scale changes continually. 5 to $7 \%$ of bone mass is recycled every week, whereas a $0.5 \mathrm{~g}$ of Ca may leave or enter the skeleton every day [5]. The compact bone is fully replaced nearly every 10 years; spongy bone, every 3 to 4 years. Bones undergo a remarkable self-repair process when they are broken [1]. Bone remodeling is the process through which osteoclasts resorb bone tissue and osteoblasts deposit new bone tissue. Osteoclast activation is the initial step in the bone remodelling process [7]. The activation of the osteoclast may occur due to stimulatory signals produced by local cells in the osteoclast microenvironment such as immune cells. Osteoclast activation may also be due to interactions between integral membrane proteins in the bone matrix [2,7]. This resorptive phase has been estimated to last 10 days. This period is followed by osteoblastic activity. In this phase, a team of osteoblast cells are attracted to the site of the resorption defect and then proceed to repair and make new bone. This 'repair' phase has been estimated to take approximately 3 months $[1,7]$. Bone remodeling is also involved in several important functions; bone growth and repair, $\mathrm{Ca}$ ion $\left(\mathrm{Ca}^{2+}\right)$ regulation and adjustment of the bone to stress [5]. Bone's behavior differs depending on the amount of stress applied on the bone. Osteoblast activity in bone tissue increases as a result of mechanical stress applied, and decreases upon removal of the stress. According to Wolff's law, bones become less dense under conditions of reduced stress (when a person is paralyzed or bedridden). Reduced stresses on bones keep the osteoclast activity at a normal rate but decreases the osteoblast activity $[1,2]$.

\subsubsection{Homeostatic imbalance of bone}

The adult skeleton is affected by various diseases due to imbalances between bone resorption and bone deposit. Examples include osteomalacia and osteoporosis.

\subsubsection{Osteomalacia}

Osteomalacia is the softening of the bone, typically through the deficiency of Ca or vitamin D [8]. In other words, the bone is inadequately mineralized (Ca salts are not deposited, however osteon is produced). The main symptom of osteomalacia is pain when load is applied to the 
affected bone and can usually be cured by increasing the sources of vitamin $\mathrm{D}$ in food and exposing the skin to sunlight [2].

\subsubsection{Osteoporosis}

Osteoporosis is defined as "a progressive systemic skeletal disease characterized by low bone mass and micro-architectural deterioration of bone tissue, with a consequent increase in bone fragility and susceptibility to fracture" [9]. Osteoporosis is a major public health issue, affecting a large proportion of the population $>50$ years of age [10]. It occurs most often in postmenopausal women. Other causes of osteoporosis could be insufficient intake of protein and calcium, smoking, insufficient exercise, diabetes mellitus and abnormal vitamin D receptors. Osteoporosis leads to increased mortality and morbidity associated with fragility fractures [10]. In general, maintaining the normal levels of $\mathrm{Ca}$ and vitamin $\mathrm{D}$ and performing load-bearing exercise will result in higher levels of bone mass and provide further defense against the agerelated bone loss [2,11]. Figure 1.2 shows the difference between the normal and osteoporotic trabecular bone.

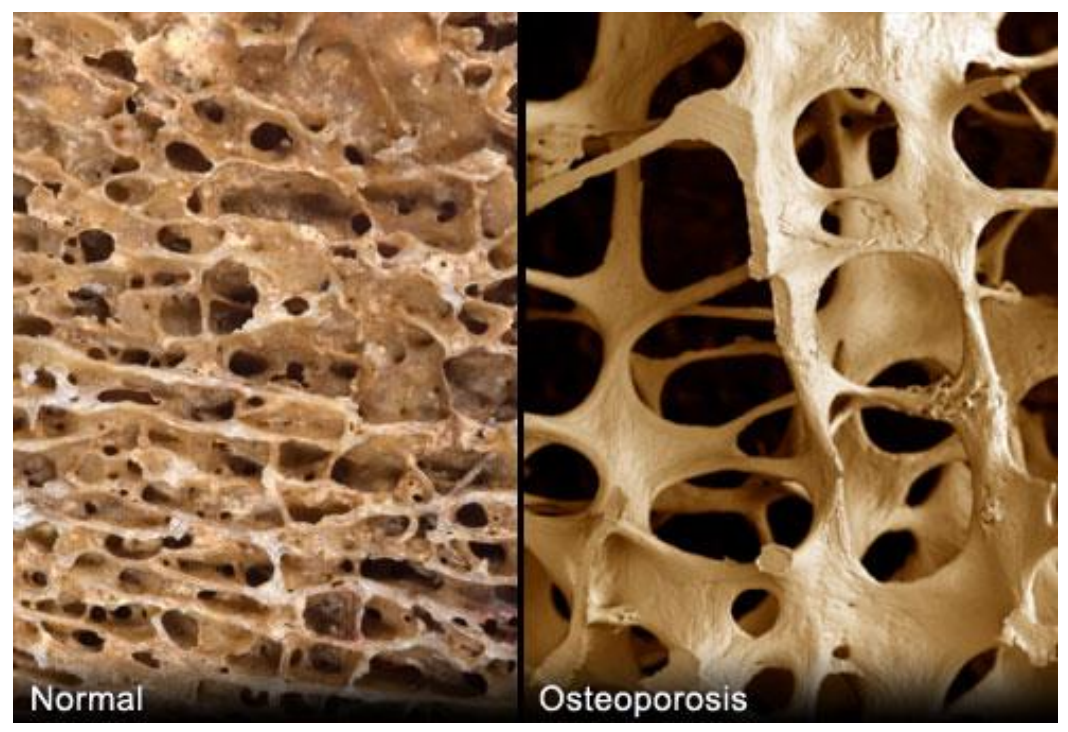

Figure 1.2: Illustration of normal and osteoporotic spongy bone [10]

\subsection{The bony thorax}

The bony thorax, also called as the rib cage or thoracic cage, consists of the thoracic vertebrae, the sternum, the ribs and the costal cartilages (Figure 1.3). The rib cage forms a semirigid chamber that protects the underpinning vital organs and structures (lungs, heart and great blood vessels). The rib cage also supports respiration cycles by increasing and decreasing the volume [12]. 


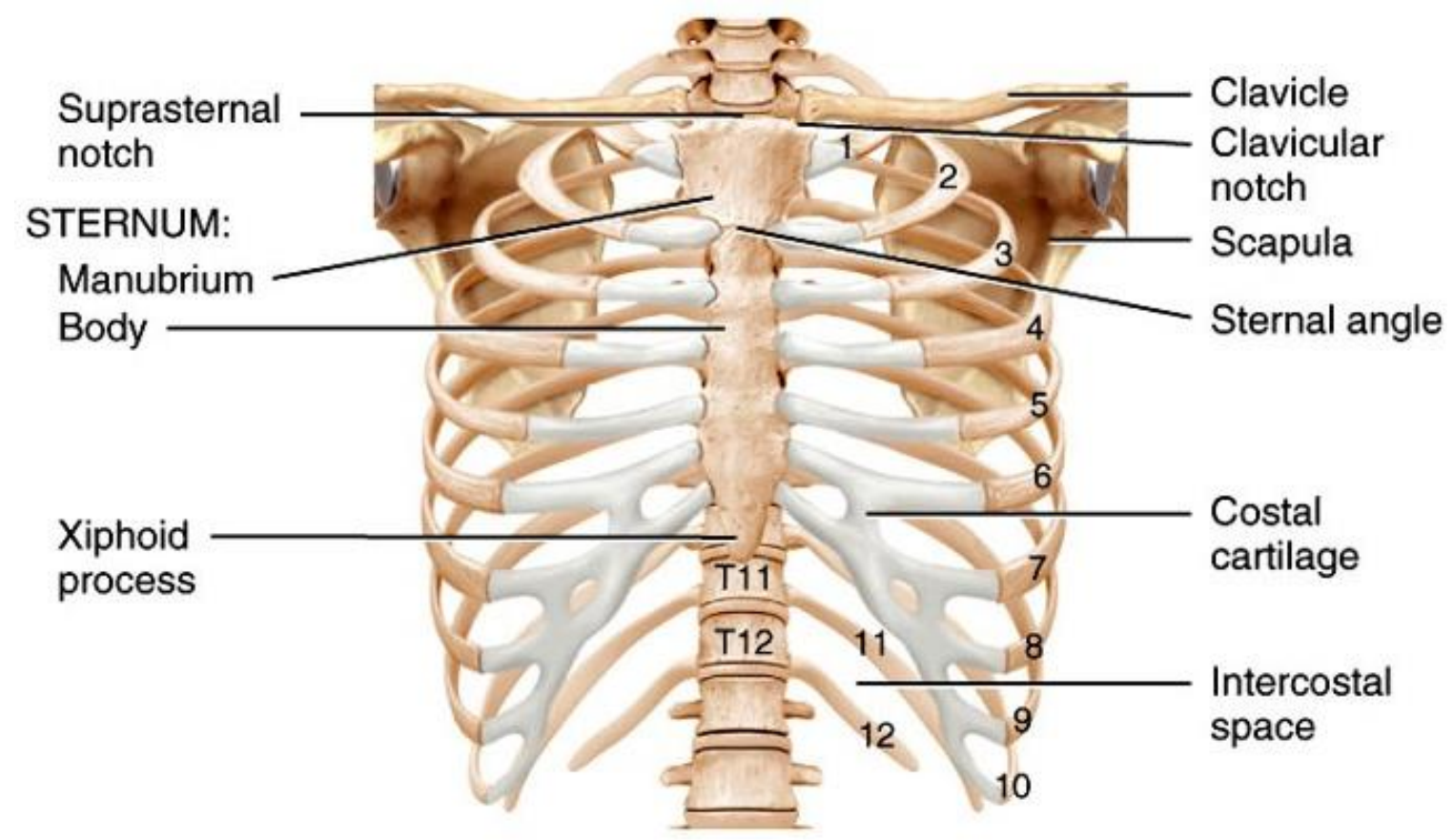

Figure 1.3: Anterior view of skeleton of thorax [12]

\subsubsection{The sternum}

The sternum is a long flat bony plate shaped like a capital T. It is located anteriorly to the heart in the center of the anterior wall of the thorax. The sternum is approximately $15 \mathrm{~cm}$ long, resulting from the fusion of three bones: the manubrium, the body, and the xiphoid process (Figure 1.4). The manubrium is the superior portion which articulates with the first two pairs of ribs; the body is the longest portion that forms the bulk of the sternum, articulating with the cartilages of the $2^{\text {nd }}$ to $7^{\text {th }}$ ribs; the xiphoid process is the smallest and inferior portion of the sternum articulating only with the body of the sternum and serving as an attachment point for some abdominal muscles. The sternum has three main anatomical landmarks: the suprasternal or jugular notch, in the midline, appears as an indentation in the superior border of the manubrium; the sternal angle, the point where the manubrium joins the body of the sternum, is a cartilaginous joint acting like a hinge and allowing the body of the sternum to swing forward during inhalation; and the xiphisternal joint is the point where the sternal body and xiphoid process fuse $[1,2]$. 


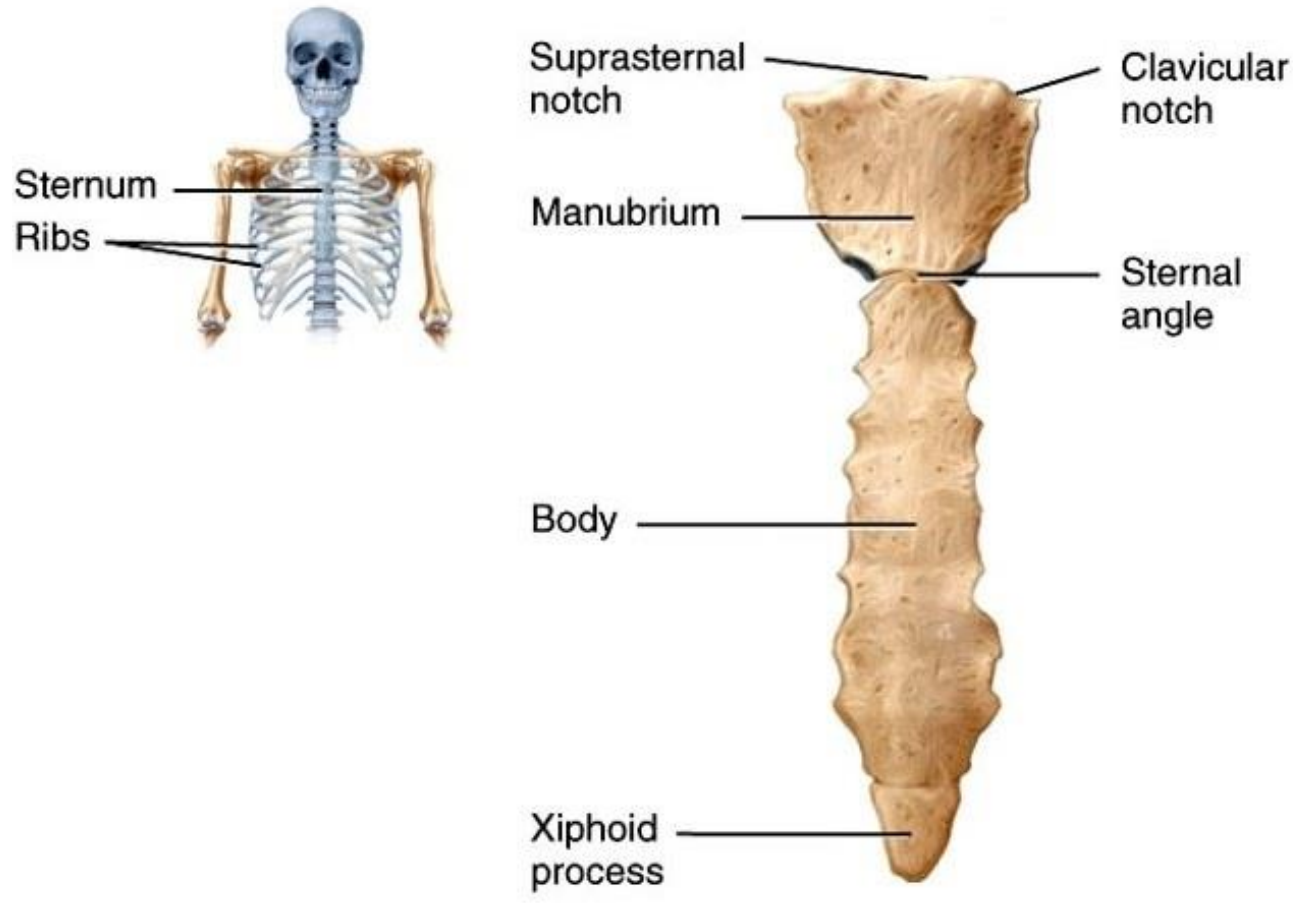

Figure 1.4: Anterior view of the sternum [12]

\subsubsection{Thoracic ribs}

There are twelve pairs of ribs forming the flaring sides of the thoracic cage (Figure 1.3). Ribs are classified as true or false ribs. True or vertebrosternal ribs are the superior seven rib pairs that attach directly to the sternum by individual costal cartilages. False or vertebrochondral ribs are the remaining five pairs of ribs that either attach indirectly to the sternum or lack a sternal attachment $[1,2]$.

\subsubsection{Biological loading}

Loading on the thorax arises from the thorax cavity in response to pulmonary ventilation. Inspiration and expiration are the main cycles of breathing through which the thorax volume changes to maintain stable pressure with respect to the surrounding atmospheric pressure. Boyle's law (Eq. 1.1) presents the relationship between the volume and pressure of a gas. That is "at constant temperature, the pressure of a gas varies inversely with its volume" [2].

$$
P 1 V 1=P 2 V 2
$$

Where $\mathrm{P}$ is the gas pressure $(\mathrm{mm} \mathrm{Hg})$ and $\mathrm{V}$ is its volume $\left(\mathrm{mm}^{3}\right)$.

Four studies [13-16] analyzed the biomechanics of sternal fixation techniques from three loading perspectives which are transverse shear, lateral distraction and longitudinal shear (Figure 1.5). The transverse shear mimics the use of arm's assistance to pull the body upright, 
lateral distraction mimics the forces imposed due to coughing or breathing and longitudinal shear mimics the use of one extended arm to support the body (also called lateral flexion stretching).

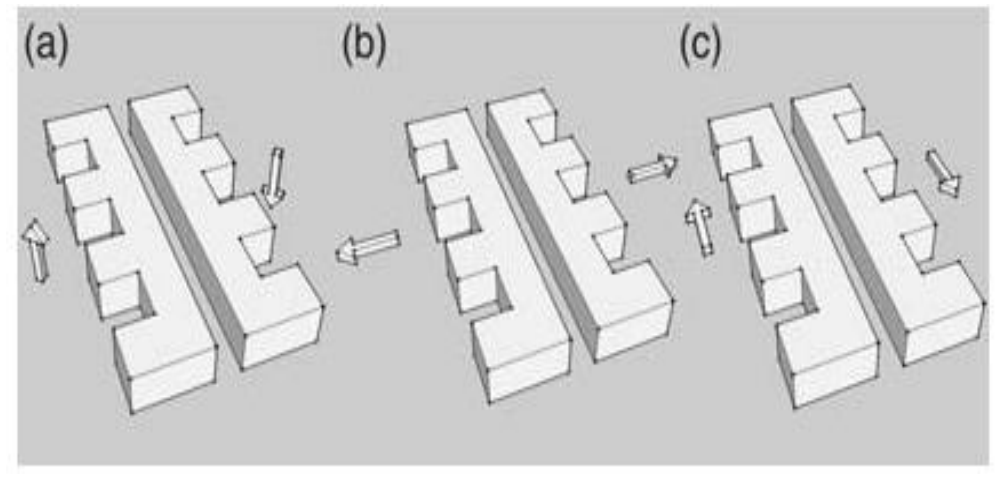

Figure 1.5: Different sternal loading conditions - a) transverse shear b) lateral distraction c) longitudinal shear.

According to the indirect measurements presented by Casha et al., a force of $260 \mathrm{~N}(\sim 26 \mathrm{Kg})$ is imposed on the sternum during a $42 \mathrm{~mm} \mathrm{Hg}(\sim 5.6 \mathrm{kPa})$ pressure generating cough, while their developed mathematical model called as Laplace law (Eq. 1.2) showed that a pressure of $5.6 \mathrm{kPa}$ results in a force of $24 \mathrm{Kg}$ in comparison with the $26 \mathrm{Kg}$ indirect measurement [15].

$$
T=R L P=0.17 * 0.25 * 5.6=238 \mathrm{~N}(\sim 24 \mathrm{Kg})
$$

Where $\mathrm{T}$ is the tension $(\mathrm{N}), \mathrm{R}$ is the sternal radius $(\mathrm{m}), \mathrm{L}$ is the chest's height $(\mathrm{m})$ and $\mathrm{P}$ is the distending pressure $(\mathrm{kPa})$.

Additionally, Casha et al. [15] demonstrated that the distending pressure of normal cough is $100 \mathrm{~mm} \mathrm{Hg}(\sim 13.3 \mathrm{kPa})$; imposing a force of $555.3 \mathrm{~N}$, whereas the distending pressure of maximal cough reaches to $300 \mathrm{~mm} \mathrm{Hg}(39.9 \mathrm{kPa})$; imposing a force of $1666 \mathrm{~N} \mathrm{[17].} \mathrm{Other}$ studies [18,19] presented that according to the Laplace law; forces ranging between $160 \mathrm{~N}$ to 400 $\mathrm{N}$ and $550 \mathrm{~N}$ to $1650 \mathrm{~N}$ are imposed on the sternal midline during breathing and coughing respectively [16]. These results match with the results presented by [15]. Later in 2014, a prospective non-randomized study [20] was conducted on 41 healthy volunteers that evaluated the force exerted during bench press resistance exercise and while sneezing. In their study [20], they found no statistically significant difference between the mean force exerted on the sternum during a sneeze $(402 \mathrm{~N})$ and that exerted during moderated intensity bench press resistance exercise with breathing (406 N) suggesting that patients who undergo sternotomy surgery can withstand a sneeze and the forces from more sternous activities if the sternal fixation device can resist forces of up to $\sim 402 \mathrm{~N}$. These results were found similar to the findings of the same group [21] in which they showed that the maximum force imposed on the sternum by a cough was significantly greater than the force imposed by lifting $2.3 \mathrm{Kg}$. 


\subsection{Median sternotomy}

\subsubsection{Procedure}

Median sternotomy has been widely used since its introduction in 1957 and it is the preferred choice by surgeons to reach the thorax structures, particularly the heart $[22,23]$. The median sternotomy procedure starts with the separation of superficial sternal tissues. Then, along the center of the sternum; a longitudinal bisection/incision is performed using a high frequency saw. Surgeons will then have the ability to perform the cardiac surgery while the bisected halves of the sternum are held by a sternal retractor (Figure 1.6). Finally, the surgeon fixes the sternal halves using one of the techniques which will be discussed later (section 1.3.4). Sternal closure plays a significant role in minimizing the complications after any thoracic operation $[22,24,25]$.

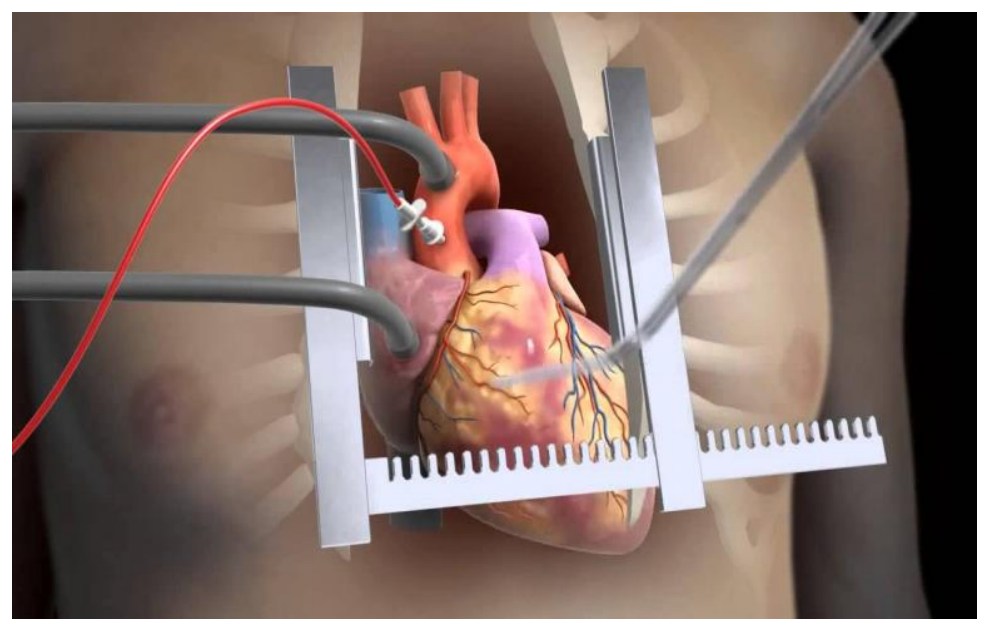

Figure 1.6: Illustration of median sternotomy surgery

\subsubsection{Pre- and post-sternotomy complications}

Major sternal complications such as dehiscence, mediastinitis, osteomyelitis, sternal wound infection (SWI), and/or non-union/displacement are infrequent after cardiac surgery [26,27]. However, such complications, when they do occur, result in considerable morbidity, mortality, and resource utilization [26]. A study [15] showed that major sternal complications occur due to osteoporosis in $2 \%$ of sternal closure procedures.

\subsubsection{Mediastinitis}

The region between the right and left pleural cavities is known as the mediastinum. It covers mainly the trachea, the heart, and the esophagus [2]. Mediastinitis is the invasion of the anterior mediastinum with pus; it is one of the most feared complications in patients undergoing cardiac surgery which begins as an infectious syndrome with an incidence rate of 1-5\%. Despite the advances in prevention and treatment of this type of infectious disease, mediastinitis contributes 
to morbidity and life-threatening events, in $10-25 \%$ of cases. Major consequences of mediastinitis are chronic infection and inflammation on both the mediastinum structures and the surface of the sternum $[6,28]$.

\subsubsection{Dehiscence}

Sternal dehiscence is directly related to SWI and occurs due to sternal fracture, osteoporosis, coughing, obstructive pulmonary disease, and other force-imposing activities. It is the cause of up to $40 \%$ mortality and morbidity after median sternotomy with an incidence rate of $0.3-8 \%$ [29,30]. The delayed treatment of dehiscence leads to further events requiring surgical procedures, often involving the association of mediastinitis or osteomyelitis. It has been reported that rigid sternal fixation (reinforced osteosynthesis) could reduce the rate of dehiscence and directly related sternal wound complications [30].

\subsubsection{Osteomyelitis}

Osteomyelitis is caused by a bacterial infection [31]. It usually occurs within two to three weeks after the initial surgery [32]. The treatment of osteomyelitis may start with antibiotics, but in most cases surgical intervention is required to remove necrotic tissue so that the wound can granulate. Irrigation with an antiseptic and/ or antibiotic follows. The delayed treatment of osteomyelitis can result in chronic infection and may lead to mediastinitis $[32,33]$.

\subsubsection{Wound infections}

Deep sternal wound infection (DSWI) has been identified as one of the main sternotomy complications that contributes to high mortality and morbidity, despite antibiotic advances [3436]. It was reported [35] that DSWI contributes to 14-47\% of total mortality with an occurrence rate of $0.5-8 \%$. Further studies [37,38] reported an occurrence of up to $4 \%$ of patients undergoing median sternotomy. SWIs are considered rare but are still the major post-sternotomy complications following open heart surgery.

\subsubsection{Sternal displacement/ micro-motion}

The abnormal or non-physiologic motion of the sternum is known as sternal instability [39]. It occurs after the disruption of reuniting wires or fracture of the surgically fixed sternum. Instability is associated with elderly patients, osteoporotic sterna, and in those suffering from mediastinitis [40]. It has been reported that sternal displacement/instability may result in serious injury to other structures and organs around the sternum, particularly to the heart and lungs [39]. Further, patients who undergo median sternotomy may also experience pain with certain 
movements of the upper back and chest including twisting, bending forward or arching backwards, and with certain movements of the upper limb including heavy lifting, pushing, pulling, or with overhead activities [41]. This pain is postulated to result from micro-motions between the two sides of the fixed sternum [26,39]. Therefore, prevention of sternal displacement and the associated pain is achieved through rigid sternal approximation $[39,40]$.

\subsubsection{Median sternotomy Vs. alternative surgical procedures}

Median sternotomy is associated with deep sternal infection and incomplete resection [42]. Therefore other techniques for sternal fixation have been considered by researchers and clinicians in this field. Thoracotomy and port-access are two alternative techniques that were discussed in the literature as minimally invasive techniques for approaching the chest cavity [4345]. Thoracotomy refers to approaching the chest cavity by intercostal incision in the pleural space of the chest (Figure 1.7a) [44]. Port-access, on the other hand, is a catheter-based system that provides effective cardiopulmonary bypass, and ventricular decomposition through an incision $(8.1+/-2.5 \mathrm{~cm})$ in the fourth intercostal space (Figure 1.7b) [44].

Cooper and associates [46] first described resecting primary pulmonary cancer through a median sternotomy in 1978. They demonstrated that median sternotomy and thoracotomy were both associated with marked loss of measured lung function, but recovery occurred notably sooner after median sternotomy than after lateral thoracotomy. In 1980, Urschel and Razzuk [47] presented their experience with median sternotomy for resecting primary lung tumors; they predicted that cardiac surgery through median sternotomy appears to cause less incisional pain and fewer pulmonary complications compared with thoracotomy, however lateral thoracotomy provided better results in certain pulmonary procedures such as superior sulcus carcinoma, pulmonary resection with posterior chest wall extension, and left lower lobe resection in patients who demonstrate cardiomegaly, obesity or an elevated diaphragm. Others [48] have also shown that median sternotomy was associated with lower incidence of respiratory complications and lesser pain when compared to thoracotomy. The three techniques; median sternotomy, portaccess and thoracotomy, were compared in a single study for patients who had undergone mitral surgery after prior median sternotomy surgery [44]. The study [44] has shown that port-access technique can be an alternative to median sternotomy or thoracotomy in re-operation for mitral valve disease, with potential advantages of avoiding revision sternotomy and reducing the 
surgical incision. These benefits, however may come at the expense of more incisional pain and longer hospital stay and cardiopulmonary bypass time.

It can be therefore concluded that alternative techniques such as thoracotomy and port-access can be utilized for a revision mitral surgery to avoid the increased risk associated with revision median sternotomy [49-51]. These alternative techniques however, are associated with more post-operative pain and longer hospital stays resulting in higher costs and increased mortality rate, when compared to conventional median sternotomy [44,45]. Hence, median sternotomy remains the best choice for open-heart surgery with lesser associated pain and better access to the thoracic cavity. This explains why this research is important and provides a strong evidence that new novel sternal fixation device is required.

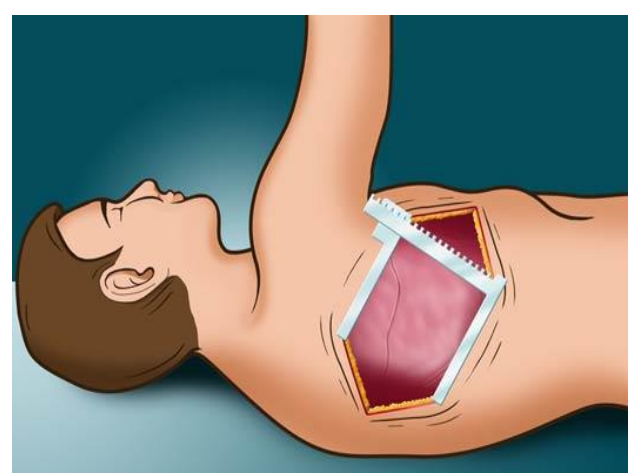

(a)

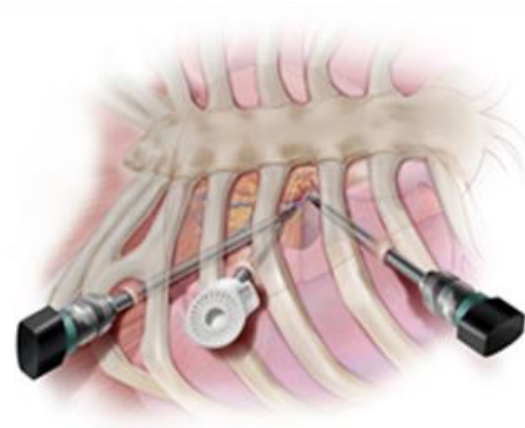

(b)

Figure 1.7: Illustration of (a) thoracotomy and (b) port-access surgery [52]

\subsubsection{Sternal fixation techniques}

Different techniques for improving sternal rigidity and reducing the complications associated with sternal fixation are discussed in this section.

\subsubsection{Wiring techniques}

Wiring using stainless steel (SS) has been the standard technique for sternal closure since 1957 due to its simplicity, strength, short healing time and rigidity [53]. Casha et al. [15] investigated 6 different sternal wiring/suturing techniques using Ethicon no. 5 SS wire (Ethicon, UK), Ethibond no. 5 suture (Ethicon, UK) and Sternaband (StonyBrook Surgical Innovations, Stony Brook, NY) and produced force-displacement curves. Wire closure types involved straight, Ethibond, 'repair' of straight, figure of eight, multi-twist and sternaband SS wires. They used a "steel jig" as a sternal model. Computerized material testing equipment (Autograph ASG$10 \mathrm{KN}$, Shimadzu, Japan) was used to pre-tension the wires around the model up to $10 \mathrm{~N}$. A data 
capture card (Amplicon PC20G, Amplicon, UK) was used to record the displacement data every quarter-second based on the separation of the two halves of the jig model at a velocity of 2 $\mathrm{mm} / \mathrm{min}$. Table 1.1 summarizes the comparison between the 6 wiring techniques.

Table 1.1: Summary and comparison of the six tested wiring techniques according to Casha et al. [15]

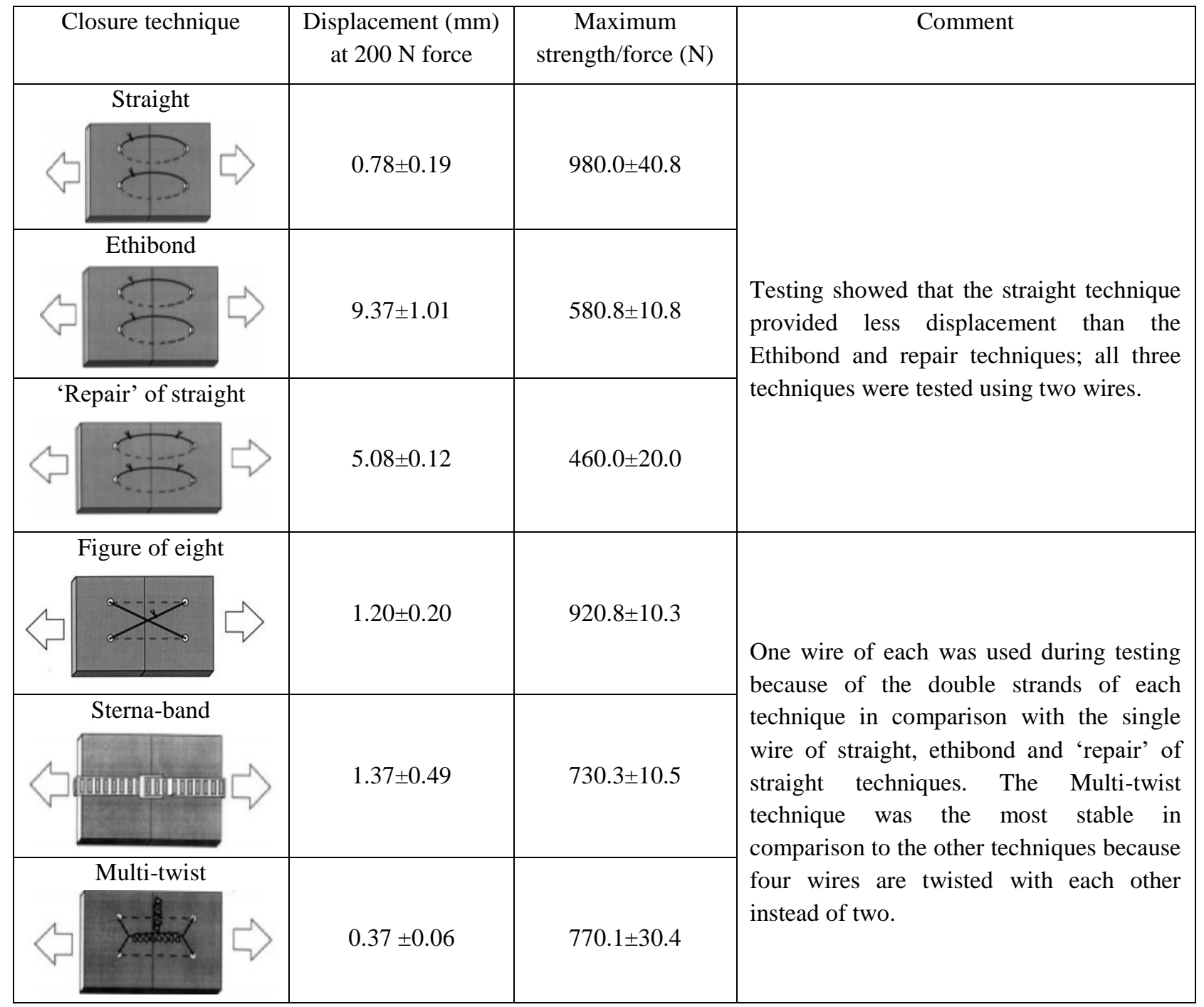

For the six wiring techniques, the maximum force applied was $200 \mathrm{~N}$ because the no.5 SS untwists in the range of 200 to $220 \mathrm{~N}$, hence the displacement was measured at the starting-point of material deformation [15]. The Laplace law was employed to measure the maximum coughing force on the sternum after median sternotomy as results indicated that all wires may untwist under severe coughing forces; usually considered $1500 \mathrm{~N}$, although they may reach $1680 \mathrm{~N}$ [17]. Thus, Casha et al. [15] demonstrated that the closure device is expected to have a safety margin able to withstand double the maximum force applied. This study also recommended the use of at 
least eight straight wires; four figure-of-eight wires or four multi-twist wires. Limitations of this study involved the analysis of wire fracture only and the use of a steel sternal model which differs from the biological or cadaver sternum. Despite these shortcomings, they demonstrated that the multi-twisted technique is useful in bleeding-fractured sterna as it appears to be able to stop the bleed by the lateral part of the closure. Also, the Ethibond technique was determined as the best technique for patients with a small chest who do not generate high forces on the sternum through coughing and those having high risk of dehiscence and osteoporosis; pediatric and elderly patients, respectively. The advantageous use of interlocking multi-twisted wires over conventional or figure-of-eight sternal closures was also evident from a further study performed by the same group [54]. The same group also performed fatigue testing on various closure techniques (polyester, figure-of-eight, steel wire, sternal bands, peristernal) using sheep sterna [55] to assess the rates of wire cutting through the bone. The sheep sternal samples were used because bovine bone was not allowed in the United Kingdom at that time and the porcine sternum differs from the human sternum in being keel shaped [55]. They tested peristernal, figure-of-eight, sternal bands and polyester closure techniques against standard SS closure (control group) eight times using adjacent paired samples. Additionally, fatigue cycles between 1 and $10 \mathrm{~kg}$ were applied on all models and displacements measured at minimum and maximum loads (Table 1.2). They further calculated the percentage cut-through of each closure as the displacement at the maximum load between the 1st and 150th cycles (Table 1.3).

Table 1.2: Displacement at $10 \mathrm{~kg}$ load (150th cycle) comparing 4 closure techniques with standard SS technique (values are expressed in mean \pm standard deviation) [55]

\begin{tabular}{|l|c|c|}
\hline \multirow{2}{*}{ Closure type } & \multicolumn{2}{|c|}{ Displacement (mm) } \\
\cline { 2 - 3 } & Test closure technique & Control technique \\
\hline Polyester & $1.01 \pm 0.17$ & $0.22 \pm 0.11$ \\
\hline Figure-of-eight & $0.52 \pm 0.36$ & $0.22 \pm 0.17$ \\
\hline Sternal band & $0.66 \pm 0.26$ & $3.27 \pm 2.84$ \\
\hline Peristernal & $0.72 \pm 0.51$ & $2.14 \pm 1.46$ \\
\hline
\end{tabular}

Table 1.3: Percentage cut-through the bone comparing 4 closure techniques with standard SS technique (values are expressed in mean \pm standard deviation) [55]

\begin{tabular}{|l|c|c|c|}
\hline \multirow{2}{*}{ Closure type } & \multicolumn{3}{|c|}{ Number of cycles } \\
\cline { 2 - 4 } & 25 & 75 & 150 \\
\hline Steel wire & 100 & 100 & 100 \\
\hline Polyester & $427 \pm 157$ & $454 \pm 109$ & $453 \pm 137$ \\
\hline Figure-of-eight & $234 \pm 72$ & $196 \pm 37$ & $232 \pm 35$ \\
\hline Sternal band & $51 \pm 29$ & $34 \pm 14$ & $23 \pm 8$ \\
\hline Peristernal & $43 \pm 22$ & $40 \pm 14$ & $34 \pm 7$ \\
\hline
\end{tabular}


Table 1.2 and Table 1.3 show that the sternal band and peristernal techniques are superior to SS controls. Additionally, the use of the figure-of-eight or polyester technique requires caution since it is associated with faster cut-through in comparison with the control model [55]. The results also showed different rates of cutting through the sternum for the five types of technique. The superiority of sternal bands over SS wires was contradicted by Cheng et al. [56] who compared the biomechanical stability of No. 5 SS wire closure with 3 types of band closure techniques ( $5 \mathrm{~mm}$ Mersilene ribbon, $5 \mathrm{~mm}$ plastic band, $5 \mathrm{~mm}$ SS band) and concluded that SS wire closure is superior to sternal band techniques on cadaver sterna.

Considering post-operative complications, Dogan et al. [57] reported that the use of standard steel wires is associated with osteomyelitis, dehiscence, prolonged hospitalization and increased morbidity and mortality. They proposed the use of sternal approximation using a suture anchor device (made of titanium) that can overcome major complications associated with steel wires and wire-cut through the sternal bone. Based on the tests performed on a cadaver model, they indicated that the suture device is recommended for patients with metabolic bone disease as it was associated with less post-operative complications and facilitated magnetic resonance imaging (MRI) due to the compatibility of titanium with MRI. Major limitations of their study were the small sample size, an absence of biomechanical analysis of the proposed device and lack of clinical trials. The outcome of this study succeeded previous work by Kalush and Bonchek [58] who reported the success of SS bands by peristernal closure especially for obese patients.

Several other studies [59-69] considered different wiring and cabling techniques for sternal fixation. However, this was contradicted by Gunja et al. [23] who reported complications from SS sutures including poor sternal healing, dehiscence, SWI and sternal separation in $0.5-2.5 \%$ of cases. Schulz et al. [70] also indicated that the wiring techniques usually fail to achieve the required level of rigidity. It has been suggested that rigid sternal fixation using more than 6 wires would reduce the incidence of SWI [71]. Jolly et al. [29] developed a new technique called "cabled butterfly closure (CBC)" which consists of 12 equally spaced wires made from SS (no. 6) and are conjoined together in order to hold both halves of the sternum (Figure 1.8). 


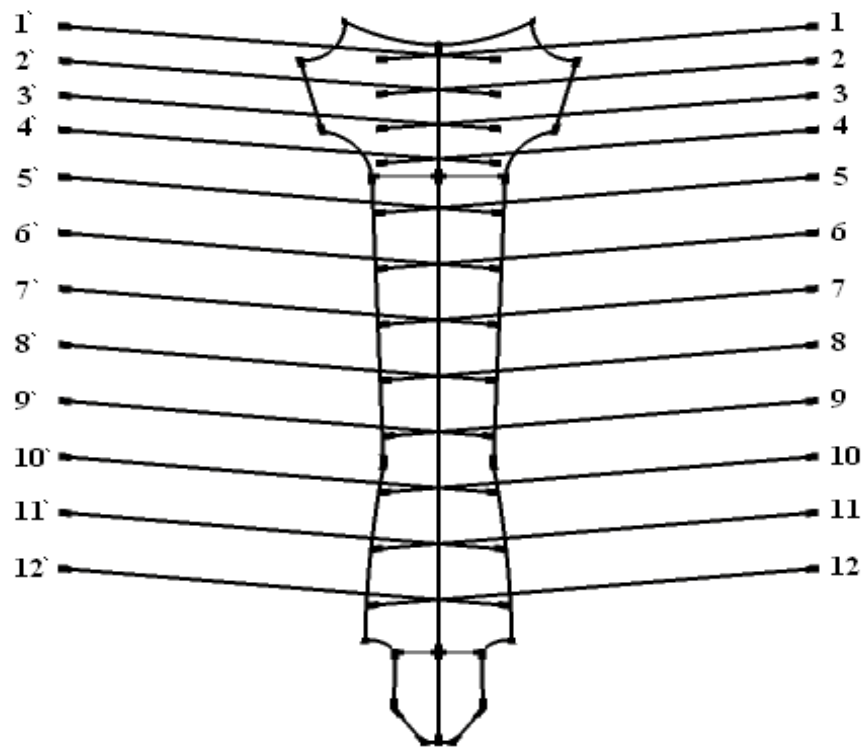

Figure 1.8: Cabled butterfly closure by pulling and twisting conjoined wires [29]

The wires are then twisted together in the middle of the sternum, so forming the final cabled bond. The procedure starts from the xiphoid and continues upward as can be seen in Figure 1.9. The wires are then tightened from both sides; the completed bond should not lose against the sternum so that ensuring rigid sternum fixation [29].

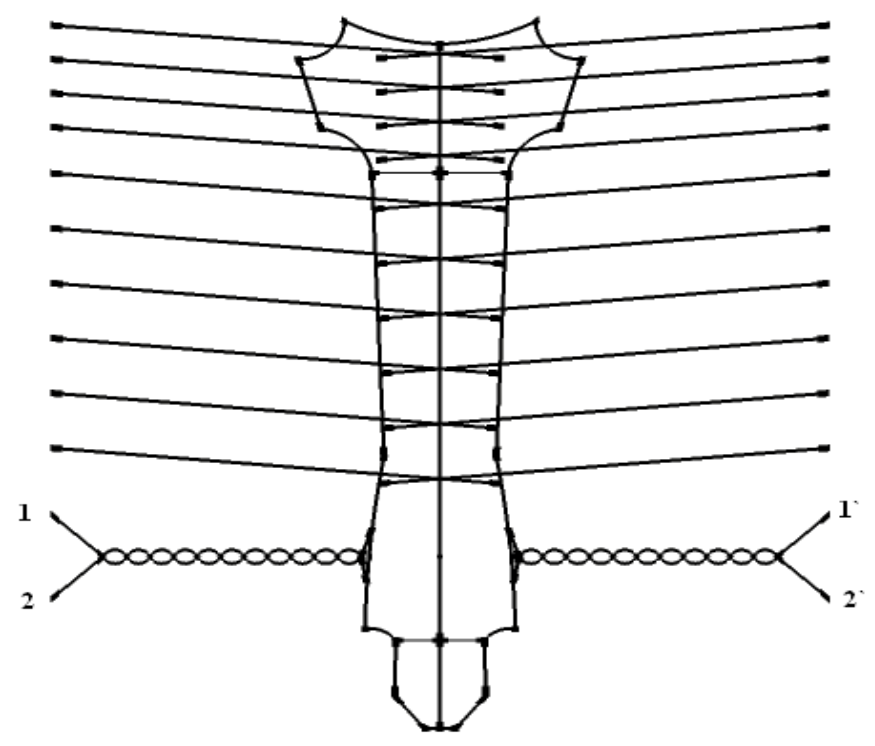

Figure 1.9: The process starts from the xiphoid and continues upward [29]

This technique was reported to be superior to simple wiring as it provides the required stability against coughing and other imposed forces by dissipating them over a broader area. 
Additionally, this cabling design minimises dehiscence in contrast to the 8 wires closure technique. The effectiveness of this technique was confirmed when four of six cables (butterflies) failed due to coughing while the sternum remained stable. Other advantages include cost effectiveness and suitability for osteoporosis sufferers and for both light and heavy patients [29].

Cadaver sterna provide better results than animal models (porcine, cow and sheep), however their use is associated with various limitations such as availability, price and the inability to consider the clinical challenges such as bleeding, osteoporosis, obesity and direction of applied forces. Cow and sheep sterna are more preferred than the porcine sternum due to its different anatomical structure being keel shaped. Clinical trials must take place for further comparison between SS wires, bands and sutures. Furthermore, more investigation is required to evaluate the associated post-operative complications, especially, with high risk patients who suffer from osteoporosis, obesity, diabetes, previous sternotomy, and/or old age. On the other hand, different closure techniques were discussed in the literature, while no studies are considering the development of a new material with improved mechanical and biological properties.

\subsubsection{Interlocking systems}

Zeitani et al. [72] and Levin et al. [73] studied the biomechanical properties of two sternal reinforcement devices. Zeitani et al. proposed the use of a Sternal Synthesis Device (SSD) [Mikai SpA, Vicenza, Italy] whereas Levin et al. proposed the use of a Sternal Talon device (KLS Martin Group, Jacksonville, FL).

The SSD consists of two clips made of $0.7 \mathrm{~mm}$ titanium sheet that can slide into each other. Both clips are located on either side of the sternum. The significant advantage of SSD is that the $5 \mathrm{~mm}$ wide horizontal segments can interlock at different lengths, permitting the surgeon to fit the device according to the size of the sternum [72]. The study [72] was subdivided into two sections; mechanically testing 22 artificial polyurethane sterna (formed from $20 \mathrm{lbs} / \mathrm{ft}^{3}$ dense polyurethane foam) to determine the forces that cause implant failure and, subsequently, a clinical trial to test the SSD on 45 patients. For further support during the first stage of testing, wiring (2-3 No. 5 SS wires) was also applied around the sternum. The clinical trial involved 45 patients who were submitted to median sternotomy for valve replacement $(n=4)$ or coronary artery bypass grafting $(n=41)$; all patients had at least three preoperative risk factors of SW complications (diabetes mellitus, depressed left ventricular function, chronic obstructive 
pulmonary disease, obesity, peripheral vascular disease) and a faulty paramedian sternotomy. The trial aimed to test sternal reinforcement with the SSD. The maximum forces $(1200 \mathrm{~N})$ at which the artificial models failed during mechanical testing are below the maximum severe coughing force $(\sim 1600 \mathrm{~N})$ [17-19]. Although displacement was seen in all models, the displacement was less for the SSD when compared with the wired control [72,74]. The device implantation for each sternal half took approximately 4 to 6 minutes and patients were followedup during the first three post-operative months. Results from the clinical trials showed no interoperative complications associated with implantation. However, post-operative respiratory failure was realized in 3 patients requiring prolonged mechanical ventilation and, of those, 1 patient experienced superficial dehiscence. It was determined that reinforced SSD is a promising technique in terms of preventing the sternal wound instability especially for patients who are at high risk of dehiscence [72].

The Sternal Talon (Figure 1.10) is made of titanium and is available in both single legged and double legged form which increases flexibility for placement. The study on the talon device [73] is similar to that performed on the SSD [72], with the distinction that it considers the use of the device as an alternative to the wiring technique. Clinical trials of the device involved 42 patients (26 male and 16 female; aged 34 to 84 years) who underwent sternal stabilization after median sternotomy [73]. Similar to the study performed by Zeitani et al. [72], Levin et al. [73] performed the procedure only on patients with three or more risk factors in order to determine safety and efficacy of the device. Their study reported a reduced placement time, from 30 minutes to between 8 to 10 minutes; longer than the 4 to 6 minutes required to place the SSD [72]. The trial resulted in successful placement of the Talon in all cases with no reports of death, dehiscence or instability. However, superficial post-operative infection was reported in a single patient and was treated using oral antibiotics [73].

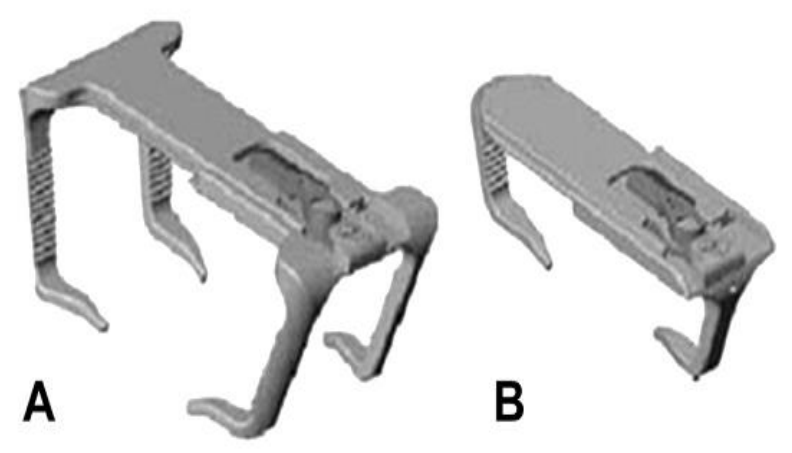

Figure 1.10: Talon sternal fixation devices- a) double legged and b) single legged [73] 
Interlocking sternal fixation devices provided better sternal fixation in comparison with wiring techniques. However, these systems require long term follow-up. Further studies performed by Baskett [75] and Gandy and Moulton [76] revealed that interlocking fixation techniques reduce the major post-sternotomy complications, especially for patients with high risk factors such as diabetes, pulmonary diseases, obesity and wound dehiscence. Nevertheless, further clinical investigations are required to consider the post-operative complications, especially, for high risk patients.

\subsubsection{Plate-screw systems}

The introduction of the plate-screw system was mainly based on the need for a new sternal fixation technique to provide more stability than that of the wiring or interlocking closure systems, particularly with high-risk patients, facilitating faster sternal healing and decreasing the incidence rate of post-operative complications associated with median sternotomy [23]. Most of the plating techniques for sternal fixation had not been evaluated mechanically $[23,70,77]$, thus there is little data directly comparing plating and wiring techniques. Gunja et al. [23] conducted a study to determine the optimal configuration for an X-shaped sternal plate system in terms of the number, type and location of the metal plates. They used a commercial sternum model made of Polyurethane (Sawbones, Pacific Research Laboratories, Vashon, WA), and a midline sternotomy was treated with $3 \mathrm{X}$-shaped plates (Walter Lorenz Surgical, Jacksonville, FL). Uniaxial lateral loading was applied to both halves of the sternum to measure the relative distraction. The model was tested such that each side of the sternum is loaded at 8 locations with equal forces. During the test, ten distraction measurements were taken by the four $5 \mathrm{~mm}$ calibration markers (placed on different sternal regions) and the average distraction was calculated at each location [23]. Ford et al. [78] considered various associated complications and deficiencies such as wobbling and loosening of the screw within the plate. They reported that there is no fixation device capable of supplying locking and subsequently withstanding compressive forces for fixation of the two halves of the sternum. In response to this, they presented a new device consisting of one screw in another screw (an "anti-wobble" device) to reduce post-operative displacement. The inner screw is a flat head screw made of SS which penetrates the bone plate, while the outer screw, also made of SS is tightened into the inner screw. 
Schulz et al. [70] tested the application of pure titanium H-shaped 8 holes plates (Figure 1.11) on a 28-year old male who underwent a horizontal fracture in the sternum during a motorbike accident. The procedure started with an $8 \mathrm{~cm}$ incision (longitudinal) over the non-union sternum, then removal of fibrous tissue and grafting of the cancellous bone. The device was then placed and locked by screwing into the sternum.

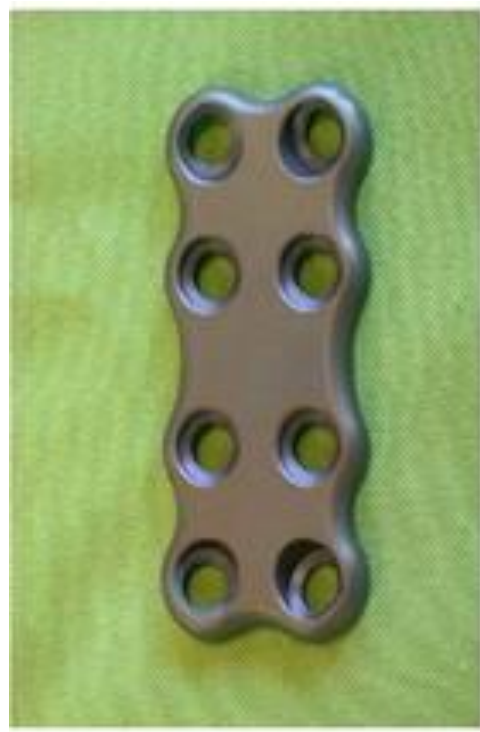

(a)

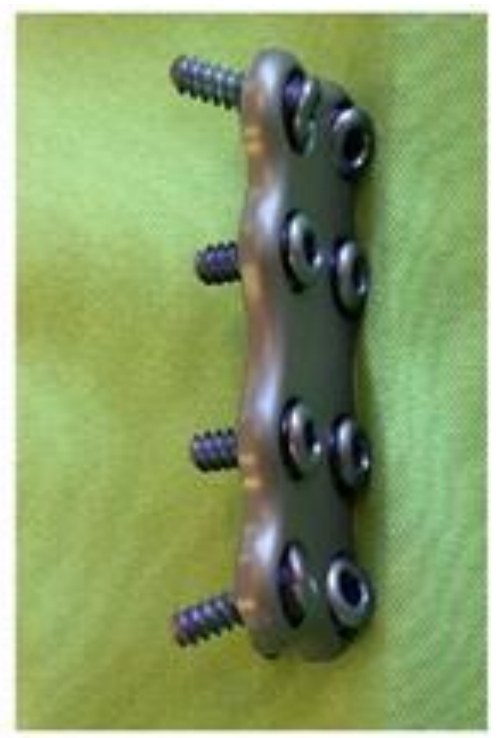

(b)

Figure 1.11: H-shaped plate for sternal fixation. (a) holes with different angels of direction to counter-balance the multidirectional forces imposed on the sternum (b) standard stable angular cortical screws [70]

Shifrin et al. [79] applied a sternal-lock (Lorenze) plate fixation to a 58 year old man who had a pulsatile, enlarging mediastinal mass $(16 \times 14 \times 14 \mathrm{~cm})$ following a massive aortic pseudoaneurysm surgical operation (Figure 1.12). Thoracic surgery aimed to reconstruct the aortic arch, and involved direct approximation of the sternal edges using forceps. Subsequently, Lorenze plate fixation was used; by applying two X-shaped plates to the centre of the sternum and 3 curved plates in the caudal (inferior) and cephalad (superior) bones. The construct remained stable with no signs of sternal infection at the 3 month follow up. 


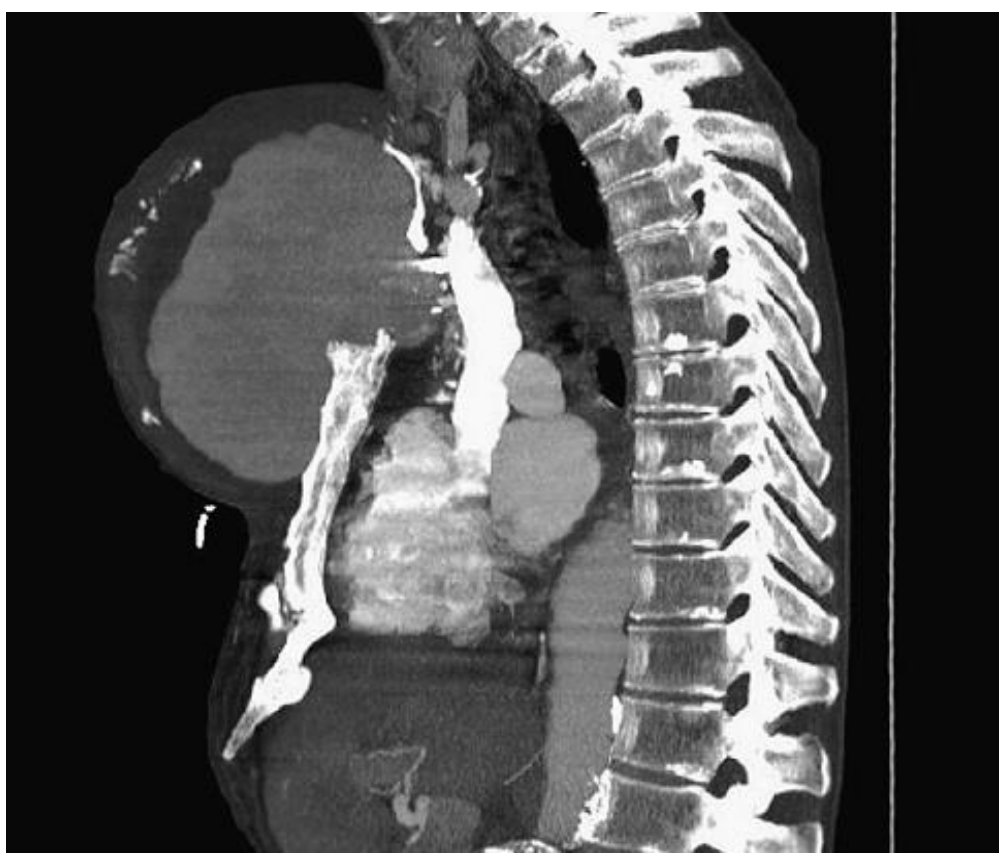

Figure 1.12: Computerized tomography scan for the massive aortic pseudoaneurysm for a 58 year old man [79]

López et al. [34] and Huh et al. [77] discussed transverse plate sternal fixation; known as "Sternal Sparing". The design consists of two titanium plates $(2.4 \mathrm{~mm}$ thick) connected using emergency release pin and titanium unilock screws (Synthes GmbH, Solothurn, Switzerland). López et al. [34] proposed rigid fixation by placing 3 plates on 3 thoracic ribs (rib-to-rib fixation [Synthes CMF, Paoli, PA]) and a single star plate on the manubrium in 2 patient cases with DSWI while Huh et al. [77] employed 3 to 5 plates along the sternum with a single star plate on the manubrium in 14 patient cases with major post-sternotomy complication including chronic dehiscence (9 cases), acute dehiscence ( 3 cases), previous mediastinitis ( 2 cases).

Other studies [80-87] have considered different plating techniques for rigid sternal fixation and reduced incidence rate of SWIs. Table 1.4 compares some of the clinical plating techniques performed between 2004 and 2011. 
Table 1.4: Comparison of some plating fixation techniques published from 2002 through 2011 [80-87]

\begin{tabular}{|c|c|c|c|c|}
\hline Authors & Fixation technique & Clinical cases & $\begin{array}{r}\text { Post-operative } \\
\text { complications }\end{array}$ & Comment \\
\hline $\begin{array}{l}\text { Elahi et al. } \\
\text { [80] }\end{array}$ & $\begin{array}{l}2.4 \text { mm fixation plates } \\
\text { (Synthes Mandibular } \\
\text { Trauma Set; Synthes, Paoli, } \\
\text { PA), with SS wires. }\end{array}$ & $\begin{array}{l}6 \text { with } \\
\text { complicated } \\
\text { sternal closure. }\end{array}$ & None reported. & $\begin{array}{l}\text { The wire/plate fixation } \\
\text { provides more stability } \\
\text { resulting in no } \\
\text { complications. }\end{array}$ \\
\hline $\begin{array}{l}\text { Song et al. } \\
\text { [81] }\end{array}$ & $\begin{array}{l}\text { Combination of plates } \\
\text { secured by bi-cortical } \\
\text { screws. }\end{array}$ & $\begin{array}{l}45 \text { ( } 26 \text { males } / 19 \\
\text { females); high } \\
\text { risk for sternal } \\
\text { dehiscence. }\end{array}$ & $\begin{array}{l}\text { Post-operative deaths } \\
\text { unrelated to the sternal } \\
\text { fixation technique }(n=4) \text {. } \\
\text { Associated with fixation } \\
(n=18) .\end{array}$ & $\begin{array}{l}\text { Plate fixation resulted in no } \\
\text { incidence of mediastinitis } \\
\text { compared with incidence due } \\
\text { to the wire closure in } 28 \\
\text { cases of the same study } \\
\text { group. }\end{array}$ \\
\hline $\begin{array}{l}\text { Cicilioni } \\
\text { et al. }[82]\end{array}$ & $\begin{array}{l}3 \text { (minimum) Synthes } \\
2.4 \text { mm locking Titanium } \\
\text { plates. }\end{array}$ & 50 & $\begin{array}{l}\text { Seroma formation }(n=5 \\
\text { patients). } \\
\text { Bleeding }(n=2) \text {. } \\
\text { Pectoral muscle } \\
\text { dehiscence }(n=1) \text {. } \\
\text { Incomplete bony union } \\
(n=1) \text {. } \\
\text { Late recurrent infection } \\
(n=1) \text {. }\end{array}$ & $\begin{array}{l}\text { Complete healing in } 98 \% \text { of } \\
\text { patients. }\end{array}$ \\
\hline $\begin{array}{l}\text { Raman et } \\
\text { al. [83] }\end{array}$ & $\begin{array}{l}\text { Sternalock system } \\
\text { (Jacksonville, } \\
\text { Florida) with mono-cortical, } \\
\text { self-tapping screws. }\end{array}$ & $\begin{array}{l}320 \text { with } 3 \text { or } \\
\text { more risk } \\
\text { factors of } \\
\text { DSWI, divided } \\
\text { into group S } \\
\text { ( } n=105, \text { rigid } \\
\text { plate fixation) } \\
\text { and control } \\
\text { group }(n=215) .\end{array}$ & $\begin{array}{l}12 \text { death cases }(3.75 \%) \text { in } \\
\text { group } \mathrm{S} \text { and } 18 \text { death } \\
\text { mediastinitis reported in } \\
13 \% \text { of controls ( } \mathrm{p}< \\
0.05) \text {. No mediastinitis in } \\
\text { group } \mathrm{S} \text {. }\end{array}$ & $\begin{array}{l}\text { Technique suitable for high } \\
\text { risk patients. }\end{array}$ \\
\hline $\begin{array}{l}\text { Plass et al. } \\
\text { [84] }\end{array}$ & $\begin{array}{l}\text { Transverse plating } \\
\text { technique (Synthes }{ }^{\mathrm{TM}} \text {, } \\
\text { Switzerland). }\end{array}$ & $\begin{array}{l}3 \text { cases } \\
\text { suffering from } \\
\text { sternal infection } \\
\text { and instability. }\end{array}$ & - & $\begin{array}{l}\text { Technique resulted in stable } \\
\text { sternal fixation. }\end{array}$ \\
\hline $\begin{array}{l}\text { Voss et al. } \\
\text { [85] }\end{array}$ & $\begin{array}{l}\text { Transverse plating } \\
\text { technique (Synthes }^{\mathrm{TM}} \text {, } \\
\text { Switzerland);self-tapping } \\
\text { unilock screws with } 2.4 \mathrm{~mm} \\
\text { titanium plates. }\end{array}$ & $\begin{array}{l}15 \text { with sternal } \\
\text { non-union }\end{array}$ & $\begin{array}{l}\text { Plate removal in } 3 \text { patients } \\
\text { due to post-operative pain; } \\
\text { one death (not related to } \\
\text { the fixation). }\end{array}$ & $\begin{array}{l}\text { Technique provides stable } \\
\text { fixation with complicated } \\
\text { sternal dehiscence. }\end{array}$ \\
\hline $\begin{array}{l}\text { Chou et } \\
\text { al. [86] }\end{array}$ & $\begin{array}{l}\text { SternaLock (Biomet } \\
\text { Microfixation Inc, } \\
\text { Jacksonville, FL). }\end{array}$ & $\begin{array}{l}2 \text { cases with } \\
\text { unstable sternal } \\
\text { fixation. }\end{array}$ & No complications reported. & $\begin{array}{l}\text { System can provide rigid } \\
\text { sternal fixation following } \\
\text { median sternotomy. }\end{array}$ \\
\hline $\begin{array}{l}\text { Fawzy et } \\
\text { al. [87] }\end{array}$ & $\begin{array}{l}3 \text { rib-plates with a single } \\
\text { manubrial plate (Titanium } \\
\text { Sternal Fixation System }{ }^{\circledR}, \\
\text { Synthes). }\end{array}$ & 40 cases. & 2 cases developed SWI. & $\begin{array}{l}\text { Technique can be used } \\
\text { effectively in cases with } \\
\text { sternal instability. }\end{array}$ \\
\hline
\end{tabular}


The literature discusses various plating techniques for sternal fixation. The investigators presented the superiority of these techniques over the wiring systems in terms of stability and reduction of post-operative complications. They also presented their superiority over the interlocking systems in terms of improved stability and further reduction of post-operative complications [80-84]. Moreover, they showed their suitability for high risk patients. Nevertheless, the literature also showed various challenges associated with the plating techniques. As discussed earlier, the use of an artificial sternum models is considered as a limitation in that the authors [23] were not able to consider the post-operative complications which could be encountered during the clinical situation. On the other hand, the stability of the plating device depends heavily on the location of the plates and the subsequent load. An 'antiwobble' device [78] was developed to reduce the post-operative complications resulting from screw loosening; it was capable of providing both locking and withstanding forces that cause screw loosening or pull-out. Furthermore, development of the $\mathrm{H}$ shaped plating system [70] showed positive performance; however, the authors reported the need for a thinner plate $(<5$ $\mathrm{mm}$ ) to allow for smaller screws.

\subsubsection{Cementing}

Acrylic cement was developed in the 1930s for dental applications [88]. In the 1950s, poly(methyl methacrylate) (PMMA) was utilised in cranioplasty, and in the 1960s, it was used in a total hip replacement (THR) procedure [88-91]. Recent developments of calcium-phosphate cements such as HA and tricalcium phosphate (TCP) have facilitated the integration of cements with bone [90].

Muehrcke et al. [92] studied Callos (Skeletal Kinetics, Cupertino, CA), a calcium phosphate cement (CPC), to control bleeding in severely osteoporotic, fragile sterna. Callos is approved by the Food and Drug Administration (FDA) for bone void filler applications in non-load bearing applications [93,94]. The study identified 11 subjects who had osteoporotic sterna out of 246 patients and selected them for median sternotomy. CPC was applied after wire closure. Patients were followed up for 6 months using computerized tomography (CT) scans. Muehrcke et al. [95] performed a follow-up study on seven patients. They applied the cement directly onto osteoporotic sterna using a spatula. The comparison of preoperative and post-operative CT scans for the majority of patients (15 out of 18) revealed that the application of CPC to the osteoporotic 
sterna resulted in greater bone mineral density. It was also evident that the cement partially reabsorbs.

Kryptonite $^{\mathrm{TM}}$ cement (Doctors Research Group, Inc., USA) has been described as "a polymer comprised of castor oil based polyols, a reactive isocyanate and calcium carbonate powder that cures in situ" [96]. The viscous liquid form of this cement is formed by interoperative mixing of the components which then polymerise to form a putty. Fedak et al. [26] applied Kryptonite ${ }^{\mathrm{TM}}$ bone cement to fresh cadaveric sternal models (part A) and to a selected clinical case series (part B). In part A, four samples were fixed using a conventional wiring technique (seven SS wires) whereas five samples were fixed using wire closure with the addition of $6 \mathrm{cc}$ of Kryptonite ${ }^{\mathrm{TM}}$ as a thin (1-2 mm) coating on each half of the sternum. Constructs were stored at $37^{\circ} \mathrm{C}$ and after 24 hrs, were mounted in an accelerated cyclic biomechanical testing machine at loads 10-100 N (lateral distracting force). Micro-displacement sensors were placed at the mid-sternal region and about 1 inch from the superior and inferior ends of the sternum (manubrium and xiphoid, respectively). $24 \mathrm{hrs}$ post-cementation, the adhesive solidified forming a contiguous core along the interior portion of the cancellous bone. Results on the wire closed construct showed measurable displacement $(\geq 2 \mathrm{~mm})$ in all segments of the sternum at load forces $\geq 400 \mathrm{~N}$, while the cemented constructs showed no displacement at load forces $\leq 600 \mathrm{~N}$. In part B, the wire and cement closure techniques were compared on a selected clinical case series (University of Calgary and Calgary Health Region, Canada). SPECT results indicated that the adhesive, along with the use of conventional wires, can rapidly augment bone strength without compromising the perfusion of the sternum; this is considered as an advantage as successful sternal closure should improve stability without decreasing sternal perfusion, which would limit the healing process [97].

Recently, researchers considered the use of cements for sternal fixation in order to overcome major post-operative complications and to facilitate the short recuperation hospitalization period. The literature $[92,95]$ confirmed that the use of a CPC such as Callos resulted in no evidence of infection, dehiscence or non-union. Callos did not dissolve at blood $\mathrm{pH}$ and is the only CPC capable of accepting pins and screws directly after setting. This gives an indication that this type of cement can replace the use of plates along with providing the biological required materials that will reabsorb during the follow-up period. On the other hand, the clinical use of Kryptonite $^{\mathrm{TM}}$ confirmed that it was chemically adhesive and not associated with infection or 
cement migration [26]. However Kryptonite ${ }^{\mathrm{TM}}$ was discontinued from the market and is no longer available for sternal fixation.

Limitations of cementing techniques involved the small sample size [92], lack of a control group [92,95], lack of animal model testing [26] and the inability to identify the rate of sternal remodeling [92], obtain a preoperative scan for all patients [95] and consider other forces else than the lateral stress [26]. Despite this, the potential of cements in the field of sternal fixation is large. Novelty can be achieved by the development of a material which can provide the required biological response (expected to overcome major post-operative complication) and strength (mimics the physiological imposed forces).

\subsubsection{Antimicrobial materials to reduce post-operative complications}

\subsection{Antibiotic incorporation}

Diefenbeck et al. [98] reported that infection rates range from $0.8-1.2 \%$ in total hip arthroplasty (orthopaedic surgery) and $3.6-8.1 \%$ in closed fracture to $17.5-21.2 \%$ in open fractures (trauma surgery). Infections might necessitate revision surgery and long term hospitalization and can cause mortality [99]. Antibiotics are used to treat bacterial infections. They have the ability to penetrate the soft tissue and bone for healing purposes [100]. The efficacy of antibiotics is limited due to the increased resistance of bacterial agents against their specific targeting drugs [101]. Schimmer et al. [35] performed the first controlled, double blind, single centre and prospectively randomized study for investigating the effective benefit of using gentamicin collagen sponges (GCSs) to reduce the complications associated with the DSWIs. Figure 1.13 shows the trial profile for the cases involved in the study in the duration between June 2009 and June 2010 in the Würzburg University Hospital (Würzburg, Germany). 


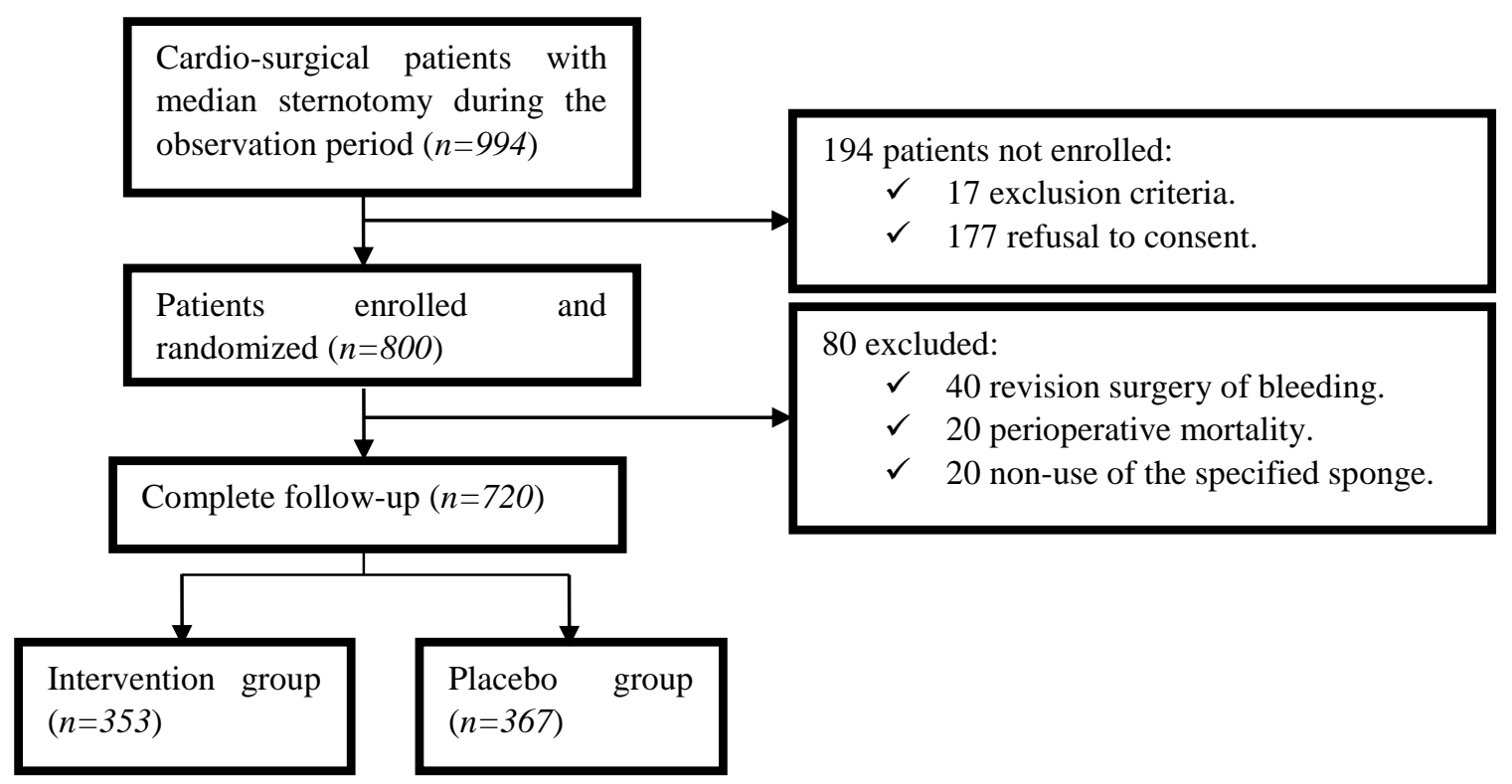

Figure 1.13: Cases profile in the duration between June 2009 and June 2010 in the Würzburg University Hospital (Würzburg, Germany) [35]

The method involved the randomization of 400 GCSs (intervention group) and 400 placebo sponges (control group). All patients were subjected to continuous check-up preoperatively and post-operatively on days 1, 2, 4, 7 and on the day before discharge [35]. DSWI was realized in 13 of 367 cases $(3.52 \%)$ for the control group and 2 of 353 cases $(0.56 \%)$ for the intervention group. This shows significant effect of using GCSs in reducing DSWI for patients undergoing median sternotomy. The conclusions of Friberg et al. [102] supported Schimmer et al. [35]. Friberg and colleagues investigated into the use of GCS (intervention group) and intravenous prophylaxis (control group) in 398 and 967 patients, respectively. The rate of SWI was 9\% in the control group and $4.3 \%$ in the intervention group. A further study [103] confirmed the benefits of GCS in reducing SWI for patients who underwent median sternotomy. 4,863 patients suffered from post-operative bleeding after cardiac surgery due to the sterility issues in the Intensive Care Unit (ICU). They analyzed the data in order to investigate the occurrence of SWI for the cases after re-exploration in the ICU. The use of GCS (after reoperation for bleeding) was effective in reducing the incidence of SWI by placing the sponge between both halves of the sternum. Limitations were that this study was single-institution, it did not consider large randomized populations and there was no control group. A further study [36] investigated the suitability of GCS to prevent wound infection after median sternotomy. Meta analysis of the results suggested GCSs helped the prevention of post-operative SWIs for patients who underwent cardiac surgery. 


\subsection{Vacuum assisted closure (VAC)}

Sternal osteomyelitis is a common consequence of cardiac surgery which requires flap coverage and debridement [32]. A VAC device (KCI Inc, San Antonio, TX) has applicability in situations including wound stabilization (prior to the reconstructive surgery), wound infection management (after the reconstructive surgery) and wound closure. In cases of severe sternal infection, sternal debridement and total sternotomy are suitable for the effective removal of all contaminated bone; this process involves crushing of the pectoralis muscle flaps between both edges of the sternum. The VAC sponge/device is placed on the mediastinum and between both sternal edges (Figure 1.14).

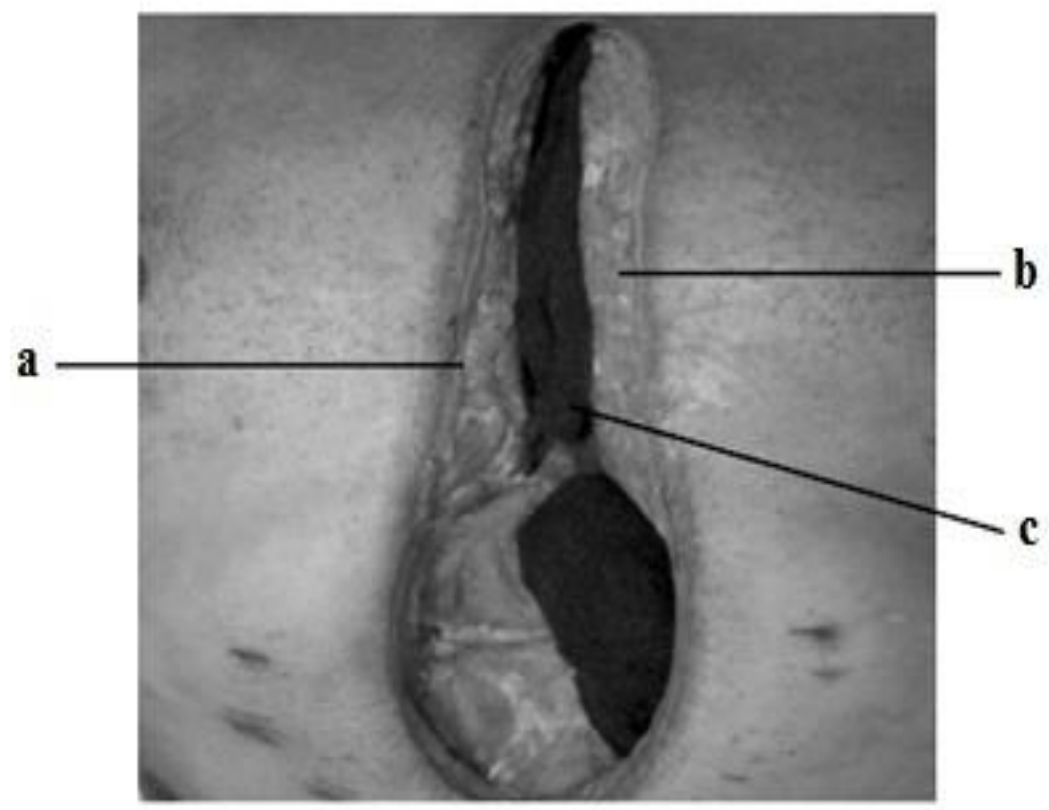

Figure 1.14: Placement of VAC sponge on the mediastinum. (a) right edge of the sternum (b) Left edge of the sternum (c) VAC sponge [32]

The VAC sponge resulted in no erosion or bleeding in the underlying cardiovascular structures [32]. The device was associated with a decreased number of soft tissue flaps and dressing changes required for closure. Moreover, it helps in achieving complete wound healing without extensive flap reconstruction and sternal debridement [104]. Additionally, it is useful when infections appear after muscle flap reconstruction. Post-operative infection occurred in one out of 13 patients [32]. Other studies [34,77] reported some advantages of using the VAC system including shorter hospital stay and reduced number of complications. Re-debridement using VAC avoided the necessity of second flap reconstruction. 


\subsection{Research significance and limitations}

Over a million sternotomies are performed worldwide every year [26]. Statistics showed that over 60,000 patients undergo heart valve replacement (HVR) in the United States of America (USA) every year [105], while another study reported that approximately 470,000 open heart surgeries are performed yearly in the USA [106]. Patients with heart problems are most often old, obese, diabetic, and/or suffering osteoporosis. These factors do not only affect the bone healing process, post-surgery but also reduce the rate of success of this surgery [69]. postoperative complications following sternotomy result in remarkable mortality, morbidity and resource utilization [26]. There have been numerous innovations and efforts to improve the sternal closure technique, but the ideal conditions for sternal closure have yet to be met. An ideal procedure should consider a device that imparts suitable mechanical properties, radiopacity, biocompatibility, removability when necessary, and cost-effectiveness. Table 1.5 summarizes the criteria for such a device. Hence, innovation is required not only to develop a sternal closure technique which eliminates displacement but also to reduce the rate of mortality and morbidity caused by post-operative complications.

Table 1.5: Characteristics of perfect adhesive cement and/or fixation device for robust sternal fixation.

\begin{tabular}{ll}
\hline Criteria & \multicolumn{1}{c}{ Purpose } \\
\hline Mechanical properties & $\begin{array}{l}\text { To withstand the maximum forces imposed during coughing and sneezing and } \\
\text { to prevent micro-motions between the sternal halves. } \\
\text { To observe sternal displacement. }\end{array}$ \\
Radiopacity & To avoid inflammations and reduce the need for a revision surgery. \\
Antibacterial & To avoid infection, rejection or inflammatory reaction. \\
Biocompatibility & To reduce operation time and achieve rigid fixation. \\
Handling properties & To facilitate revision surgery if necessary. \\
Removable when necessary & To avoid limitations on use and supply. \\
Cost effective &
\end{tabular}

\subsection{Research goal and objectives}

The research will focus on the development of a novel bioadhesive, based on glass polyalkenoate cement (GPC) chemistry, specifically the glass and acid phases, in order to create a wholly new series of therapeutic GPCs for robust sternal fixation. This project has the following interrelated objectives:

- Synthesize tantalum-containing bio-glasses using melt/quench fabrication process. 
- Mix the formulated glasses with poly(acrylic acid) (PAA) and deionized (DI) water to obtain cement pastes with handling properties in line with industry standards (ISO-9917 for dental based cements).

- Resultant GPCs must possess mechanical properties comparable to the bone that they are replacing.

- GPCs must provide supreme handling and mechanical properties for rigid fixation of the sternum, post sternotomy surgery.

- GPCs should release therapeutic ions, reducing the post-operative complications and stimulating bone formation, thus increasing the rate of success of sternotomy surgery and minimize the need for revision surgeries.

\subsection{Structure of thesis}

Following this introduction, chapter 2 provides a detailed historical background of PAA and the effect of its chemistry on the rheological and mechanical properties and the clinical performance of GPCs. Chapter 3 describes the synthesis and characterization of a wholly new series of $\mathrm{SiO}_{2}-\mathrm{ZnO}-\mathrm{CaO}-\mathrm{SrO}-\mathrm{P}_{2} \mathrm{O}_{5}-\mathrm{Ta}_{2} \mathrm{O}_{5}$ glasses in which $\mathrm{ZnO}$ was substituted with up to 8 mole percentage $\mathrm{Ta}_{2} \mathrm{O}_{5}$. The glasses formulated and discussed in chapter 3 have rheology that are deemed unsuitable for sternal applications, therefore Chapter 4 expands the understanding of this particular glass system where a new modified series of the glasses was synthesized containing lower $\mathrm{Ta}_{2} \mathrm{O}_{5}$ contents ( 0 to 0.5 mole percentage), replacing $\mathrm{ZnO}$. Chapter 5 provides a complete characterization of the physical, mechanical and biological properties of new adhesive materials based on mixing the glasses containing lower $\mathrm{Ta}_{2} \mathrm{O}_{5}$ contents (chapter 4) with PAA and DI water. Chapter 6 provides a summary, practical implications and recommendations for future work.

\subsection{Statement of co-authorship}

The following people and institutions contributed to the publications of the work undertaken as part of this thesis: Adel Alhalawani, Ryerson University = Candidate

Dr. Declan Curran, Medtronic, Ireland = Author 1

Dr. Daniel Boyd, Dalhousie University $=$ Author 2

Cina Mehrvar, Ryerson University $=$ Author 3

Dr. Wendy Stone, Ryerson University = Author 4

Dr. Stephen Waldman, Ryerson University = Author 5

Dr. Mark Towler, Ryerson University = Author 6 . 
Author details and their roles:

Paper 1, The role of poly(acrylic acid) in conventional glass polyalkenoate cements: A review of the literature:

Located in chapter 2.

Candidate was the primary author who collected the data and wrote the article. Authors 1, 2 and 6 helped with drafting the work or revising it critically for publication.

Paper 2, The effect of $\mathrm{ZnO} \leftrightarrow \mathrm{Ta} 2 \mathrm{O} 5$ substitution on the structural and thermal properties of $\mathrm{SiO} 2-\mathrm{ZnO}-\mathrm{SrO}-\mathrm{CaO}-\mathrm{P} 2 \mathrm{O} 5$ glasses:

Located in chapter 3.

Candidate was the primary author who performed the lab work, data analysis and writing. Author 6 contributed to the idea, its formalization and development and supervised the lab work of the candidate.

Paper 3, A novel tantalum-containing bioglass. Part I. Structure and solubility:

Located in chapter 4.

Candidate was the primary author who performed the lab work, data analysis and writing. Author 6 contributed to the idea, its formalization and development and supervised the lab work of the candidate.

Paper 4, A novel tantalum-containing bioglass. Part II: Development of a bioadhesive for sternal fixation and repair:

Located in chapter 5.

Candidate was the primary author. Author 3 helped, during his summer internship, in collecting data related to rheological and mechanical properties. Author 4 helped with evaluating the antibacterial properties of the adhesive materials and with revising the manuscript for publication. Author 5 offered laboratory assistance with evaluating the cytotoxicity of the adhesive materials and with revising the manuscript for publication. Author 6 is the supervisor who contributed the idea, its formalization and development and supervised the lab work of the candidate. 
We the undersigned agree with the above stated "proportion of work undertaken" for each of the above published (or submitted) peer-reviewed manuscripts contributing to this thesis:

Signed:

Dr. Mark Towler

Department of Mechanical \& Industrial Engineering

Ryerson University

Date:

Signed:
Adel Alhalawani
Department of Mechanical \& Industrial Engineering
Ryerson University

Date: 


\section{The role of poly(acrylic acid) in conventional glass polyalkenoate cements: A review of the literature}

\section{This chapter is based on the following published paper:}

Alhalawani, A.M.F.; Curran, D.J.; Boyd, D.; and Towler, M.R. The role of poly(acrylic acid) in conventional glass polyalkenoate cements: A review of the literature. J Poly. Eng., 2015, 36(3), 221-237.

\subsection{Introduction}

Conventional glass polyalkenoate cements (CGPCs), commonly referred to as the glass ionomer cements (GICs), were developed in the early 1970s at the laboratory of the Government Chemist in London, England [107]. These adhesive materials have been subjected to continuous improvement and diversification [108]. CGPCs are acid-base cements typically formed by the reaction of an organic aqueous solution of polyalkenoic acid, mainly a copolymer of PAA (Figure 2.1) with an inorganic acid-degradable fluoro-alumino-silicate glass. The reaction between both components results in a composite cement material consisting of reacted and unreacted glass particles embedded in a polysalt matrix [108-110]. CGPCs are used in dentistry due to a selection of clinical advantages, as follows:

(a) Single-step adhesion characteristics to both enamel and dentine [111].

(b) Biocompatible and considered bioactive [112-114].

(c) High dimensional stability [115].

(d) Harden and form a cement and exhibit good resistance to cohesive failure, upon aging [116].

(e) Satisfactory aesthetics and have negligible shrinkage upon setting $[117,118]$.

These features have made them attractive candidates for expanded applications in hard tissue repair. However, whilst their use in orthopedic applications has long been mooted, their nondental, clinical use has been limited to ear, nose and throat applications [119-121]. This is due to certain challenges in their properties including:

(a) Clinical literature supporting defective osteoneogenesis and fatal encephalopathy arising from aluminum ions $\left(\mathrm{Al}^{3+}\right)$ release in-vivo [122].

(b) Relatively poor mechanical properties versus conventional acrylic bone cements [123]. 
(c) Sensitivity to ambient room conditions, such as temperature and humidity, during mixing [124].

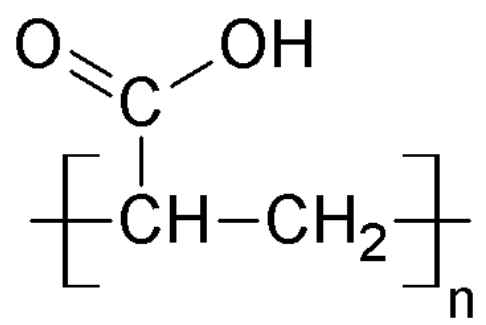

Figure 2.1: General structure of the repeating unit for PAA (Adapted from [108])

The majority of research into CGPCs has focused on changing the glass composition because it is capable of controlling both setting chemistry, strength $[125,126]$ and ion release. However, the polyacid phase also plays a major role in controlling rheological (working and setting times) and mechanical properties, chemical adhesion to substrates, ion release and durability [127]. These characteristics can be influenced by altering the molar mass [128,129], concentration [130], molecular weight [131,132] and polydispersity index [133] of the polyacid alongside other factors such as the powder:liquid ratio [134-136], and the addition of surface conditioners and chelating agents [111].

Moshaverinia et al. [137] have reviewed the literature describing the trends of modifying the polymer phase in GPCs. They focused on the advantages and disadvantages of various PAA based polymers currently used in GPC systems (including new acrylic acid copolymers, amino acid containing polyelectrolytes, $\mathrm{N}$-vinylpyrrolidone and $\mathrm{N}$-vinylcaprolactam modified terpolymers). This review however, focuses on the chemistry and properties of PAA and their subsequent effect on the early performance, characteristics and clinical applicability of CGPCs. The aim of this review is to complement existing works by evaluating three important questions:

(a) How does the chemistry of PAA influence setting and maturation reactions of CGPCs?

(b) To what extent can the different properties of PAA (molar mass, molecular weight, concentration, polydispersity index and content and incorporation of chelating agents) affect the mechanical and rheological properties of CGPCs?

(c) How does the PAA phase of CGPCs influence their clinical performance? 
Following this brief introduction to CGPCs, section 2.2 aims to answer the first research question by providing a historical background of PAA and the effect of its chemistry on the setting and maturation reactions of CGPCs. The main objective of section 2.3 was to answer the second research question by providing a detailed evaluation as to how different properties of the PAA component may influence the characteristics of CGPCs, particularly mechanical and rheological properties. Section 2.4 provides a critical evaluation of the role of PAA in the clinical performance of CGPCs and thus answering the third research question.

\subsection{Poly(acrylic acid) in conventional glass polyalkenoate cements: historical background and basic behavior}

\subsubsection{Background and general characteristics of the PAA component of CGPCs}

Poly(acrylic acid) was patented in 1966 by Gene Harper of Dow Chemical and Carlyle Harmon of Johnson \& Johnson and has been used in a range of healthcare applications including diapers, cosmetics and paint, ion exchange resins and adhesives, and as a thickening, dispersing, suspending and emulsifying agent in pharmaceuticals [138]. The most commonly used polymeric materials for GPC formulations are PAA and copolymers of acrylic and itaconic acid [poly(AAco-IA], or acrylic and maleic acid [poly(AA-co-MA)] with other monomers such as 3-butene 1,2,3-tricarboxylic acid (Figure 2.2) also being employed from time to time [109]. Each repeat unit of PAA has an ionizable group; carboxylic acid $(\mathrm{COOH})$. Partially neutralized PAA has a sufficient charge density making it a superabsorbent (water soluble) polymer. In the presence of water at neutral $\mathrm{pH}$, the PAA chains will lose their protons and acquire a negative charge, giving them the ability to absorb and retain water molecules $[108,139,140]$; as shown in Eq. 2.1.

$$
\boldsymbol{n} \mathrm{CH}_{2}=\mathrm{CH}-\mathrm{CO}_{2} \mathrm{H}+\mathrm{H}_{2} \mathrm{O} \stackrel{p H=7.0}{\longrightarrow} \boldsymbol{n} \mathrm{CH}_{2}=\mathrm{CH}-\mathrm{H}_{2} \mathrm{O}+\mathrm{COOH}
$$

Commercial PAA solutions are usually prepared by free-radical polymerization of the polymer/monomer (such as acrylic acid) in aqueous solution and concentrated to 40-50\% for clinical use [108]. Depending on the production process of PAA, the final product can be either in liquid or anhydrous (freeze-dried) form. Although the PAA used in the formation of early GPC compositions was in aqueous form and almost all CGPCs available from suppliers utilize liquid polyacid, Hill et al. [141] reported the advantage of using powdered, anhydrous PAA over aqueous PAA. Anhydrous PAA is better suited for prolonging the setting time of CGPCs. The finely ground PAA will have to dissolve in the water first and then attack the glass particles; this slows the setting reaction to some extent, allowing for the use of high molecular weight PAA and 
consequently, improved strength of the GPC matrix [141]. The majority of available studies [131,141-144] are detailing anhydrous CGPC systems which contained anhydrous PAAs; confirming the theory presented by Hill et al. [141].<smiles>C=CC(=O)O</smiles>

(a)<smiles>C=C(CC(=O)O)C(=O)O</smiles>

(c)<smiles>O=C(O)/C=C\C(=O)O</smiles>

(b)<smiles>C=C(C)C(=O)O</smiles>

(d)<smiles>C=C(C(=O)O)C(CC(=O)O)C(=O)O</smiles>

(e)

Figure 2.2: (a) Acrylic acid; (b) Maleic acid; (c) Itaconic acid; (d) Methacrylic acid; (e) 3-butene-1,2,3-tricarboxylic acid (adapted from [108])

\subsubsection{The role of PAA in the setting reaction of CGPCs}

CGPCs set by an acid-base reaction between a polyelectrolyte such as PAA and an aciddegradable glass. The cement-forming reaction consists of a number of overlapping stages including $[108,145,146]$ :

a) The attack by the PAA protons on the glass cations.

b) The release and migration of the liberated ions from the glass into the aqueous phase.

c) Neutralization and ionization of the polyacid resulting in unwinding, or relaxation, of the 'twisted' polymer chains contributing to increasing the cement viscosity.

d) Ion binding between the charged polyacid chains and glass cations.

e) Gelation due to an increase in the $\mathrm{pH}$ of the pre-formed cement.

f) Continuous ion binding leading to the hardening phase. 
The PAA component of CGPCs plays a significant role in the cement forming reaction. Additionally, changes in the cement properties, ranging from molecular transport to mechanical properties, result from several physio-chemical processes including, but not restricted to $[108,147]$ :

a) Conformational changes in the polymer chain (changes in their ordered structure): PAA is a conformation changing polymer that undergoes unwinding/relaxation processes during the cement forming reaction. This may modulate ion release and control the network properties [148].

b) Binding of the polymer chains to the glass cations: as cations become bound along the polymer chain, the polymer becomes in effect a polyelectrolyte. Cations already bound to the polymer chains may introduce charge repulsions reducing the cation binding. These repulsions may be decreased by counterions in the vicinity of the polymer shielding the charges. Further, dipole-dipole interactions in the polymer domain between cation pairs on the chain and cation pairs in solution may also influence cation binding to the polymer [108,149]. In effect, changes in GPC properties would be expected.

c) Hydration surrounding polyanion and cation regions: as mentioned earlier in this chapter, PAA is a superabsorbent polymer that has the ability to absorb and retain water molecules at neutral $\mathrm{pH}$. The extent and rate of interaction between hydrated cations and polyanions disrupts the hydration regions surrounding both, therefore changing the setting reaction of the CGPC and probably its long-term strength.

The extent of ion binding (between PAA anions and glass cations) depends on a number of characteristics of the polyion including, but not restricted to [108,132,150]:

a) Polymer structure: longer chain PAA results in long-range entanglements and hence stronger cation-anion bonds. Further discussions will be provided later in the current chapter.

b) Acid strength: strength of the PAA refers to its ability to ionize and lose protons in a solution, i.e stronger PAAs will provide more sites for cations to bind resulting in stronger bonds.

c) Degree of dissociation: PAA neutralizes in water due to its ability to dissociate. Degree of dissociation refers to the fraction of the original polymer structure that 
have dissociated. Higher degree of PAA dissociation will result in higher rates of cation attack for binding. Further, the quicker is the PAA dissociation in the GPC matrix, quicker is the setting reaction and stronger is the structure.

d) Degree of conformation: the polymer conformational changes can determine the proximity of binding sites to one another and hence effecting the binding process [149].

The ability of PAA to bind to basic cations released from the glass is determined largely by the ionic radius and complexation constant (the strength of the cation-releasing base, in interacting with the acid polyion, for the formation of a complex in aqueous solution) of the cations involved. Put another way, the smaller the ionic radius of the glass cation, the greater the binding strength. Similarly, the greater the complexation constant, the stronger the acid-base complex. For example, zinc ions $\left(\mathrm{Zn}^{2+}\right)$ are likely to be more stable than calcium ions $\left(\mathrm{Ca}^{2+}\right)$ when bonded to PAA, because zinc has a smaller ionic radius and greater complexation constant. Apart from its ability to bond to bone, the main advantages of PAA are low toxicity coupled with high solubility in water which allows solutions of $50 \%$ by mass to be produced $[108,109,151,152]$. Some of the PAA factors proportionally affect the rate of the setting reaction of GPCs (Eq. 2.2).

Setting reaction $\alpha(\mathrm{M}, \mathrm{C}, \mathrm{R}, \mathrm{H})$

Where $\mathrm{M}$ is the molar mass or molecular weight of the polyacid, $\mathrm{C}$ is the concentration of the polymeric solution, $\mathrm{R}$ is the powder:liquid ratio, and $\mathrm{H}$ is the presence of additives or chelating agents.

\subsubsection{The role of PAA during CGPC maturation}

The setting reaction of CGPCs is regarded as continuous and the extent to which the ionic network develops has a direct impact on mechanical properties with strengths usually developing rapidly in the first 24 hrs $[108,153,116,154]$. Strength of CGPCs increases quickly in the early stages of the reaction, within the first few days maturation, and then increases at a slower rate over the following year [155,156]. It was first postulated by Crisp and Wilson [154] that this hardening process is based on the gelation of the polymeric acid by cross-linking, or forming inter- and intramolecular salt bridges, of the polymeric carboxyl groups with $\mathrm{Al}^{3+}$ and $\mathrm{Ca}^{2+}$ from the glass phase. Later in 1976, Crisp et al. [156] attributed the increase in strength with time up to one year, to an increase in cross-link density. Crisp's conclusions were later confirmed by Matsuya et al. [155] who used infrared (IR) spectroscopy and nuclear magnetic resonance 
(NMR) to show that an increase in cross-link density was the reason for increased strength. Wasson and Nicholson, have otherwise found that the strength of the cement increased with time even when the glass powder was mixed with acetic acid which did not form insoluble salts with $\mathrm{Al}^{3+}$ and $\mathrm{Ca}^{2+}$ ions. Meanwhile, they attributed the hardening reaction to the silica component which leached from the glass powder and formed a hydrated silicate in the matrix $[145,146]$. These results were supported by Cattani-Lorente et al. [157] and Hatton and Brook [158] who concluded that the strengthening of CGPCs during maturation resulted from additional crosslinking and the development of a silica gel phase. It is presumed that restricted chain pull-out and increased cross-linking are the most likely causes of increased strength while the inorganic phase acts as a reinforcing phase in the strength of CGPCs [108,142]. Maturation of a CGPC does not always result in increased strength in all modalities [157]. The literature has considered the effect of maturation on both compressive and biaxial flexural strength. Pearson and Atkinson [159] have shown that the flexural strength increased with maturation up to a period of about 3 months but decreased thereafter. The flexural strength of Opus-fil (Davis, Schottlander and Davis, UK), a conventional restorative GPC, increased to $73 \mathrm{MPa}$ at 56 days, then decreased to $53 \mathrm{MPa}$ after 100 days maturation. This phenomenon of decreasing strength of some GPC formulations with maturation has been attributed to hydration of the ionic bonds within the cement matrix resulting in the loss of matrix forming ions into solution, and consequently decreasing the integrity of the GPC [160,161]. This phenomenon has also been attributed to the erosion and the plasticizing

effect of water on these materials and to the slower rate of the reaction, as the cement ages in aqueous solution, resulting from the lesser number of $\mathrm{COOH}$ groups available to form ionic bonds $[146,162]$.

\subsection{The influence of PAA properties on the physical characteristics of CGPCs}

\subsubsection{The effect of the PAA molar mass}

Hill et al. [163] have shown, using dynamic mechanical thermal analysis (DMTA) and dielectric thermal analysis (DETA), that GPCs exhibit sharp loss peaks similar to thermoplastics. Berry [164] demonstrated that the fracture surface energy of a thermoplastic polymer was much greater than the energy required to break all the polymer chains crossing the crack plane. Hence, GPCs may be classed as thermoplastic polymer composites with ionic crosslinks liable to continual breaking and reforming. The strength of thermoplastic polymers is related to longrange entanglements that serve to restrict chain motion. Originally these entanglements were 
viewed as physical knots. However most polymer chains are too inflexible to form a physical knot and a model has been developed that views a chain as being trapped in a tube of entanglements formed by neighboring chains, as shown in Figure 2.3(a). This model, known as the reptation model, assumes that a polymer chain only crosses the fracture plane once. This theory was first proposed in 1986 by Doi and Edwards [165] and was based on the theories postulated previously by Edwards [166] that polymer chains were contained within a hypothetical tube constructed by the forces imposed by the chain's nearest neighbors. By calculating simple Brownian motion of a polymer chain within this hypothetical tube, Edwards proposed a mathematical expression of the rate of motion of the chain along its tube and postulated that the long chain polymers become solid once a certain cross-link density is exceeded [165-169]. This proved to fit for many thermoplastics and explained the variation of chain interaction with temperature. Several studies have elaborated on Edwards model and variations are still being produced for specific applications [170,171].

In 1998, Griffin and Hill [142] derived an equation (Eq. 2.3), based on a previous study by Prentice [169], relating molar mass of the PAA $(M)$ to the fracture surface energy per unit area of fracture plane $(\tau), \tau$ can be also identified as the work that needs to be done to remove chains from a unit area of crack plane, whereas $M_{c}$ is the critical molar mass required for entanglements to occur. Detailed derivation of Eq. 2.3 can be found in the literature [142,169].

$$
\tau \propto\left(M-M_{c}\right)^{2} \text {. }
$$

Further, based on the reptation theory, as the molar mass increases, a critical molar mass (typically about $10^{5}$, however its value is generally lower) will be reached where the stress to extract a chain from its tube is greater than that required for homolytic chain scission, depicted in Figure 2.3(b). In other words, for molar masses greater than a critical value, the force required to remove the chain will be greater than the force required to break the carbon-carbon bonds of the polymer backbone, making the surface fracture energy independent of molar mass and hence the matrix toughness is no longer related to the molar mass of the PAA. Similarly, at low molar masses, below approximately $2.7 \times 10^{4}$, chain entanglements will not form, making the fracture surface energy independent of molar mass because the chain length is too short to form entanglements and the tube concept no longer applies. Griffin and Hill [142] conducted a study which evaluated the influence of the PAA molar mass on the mechanical properties of GPCs. Their results are summarized in Table 2.1 which shows that the molar mass of PAA affects a 
range of mechanical properties including compressive strength, flexural strength, fracture toughness, toughness and plastic zone size but will have no significant effect on Young's modulus of the cement matrix. These results (Table 2.1) are in good agreement with those later reported by Fennell and Hill [143,144].

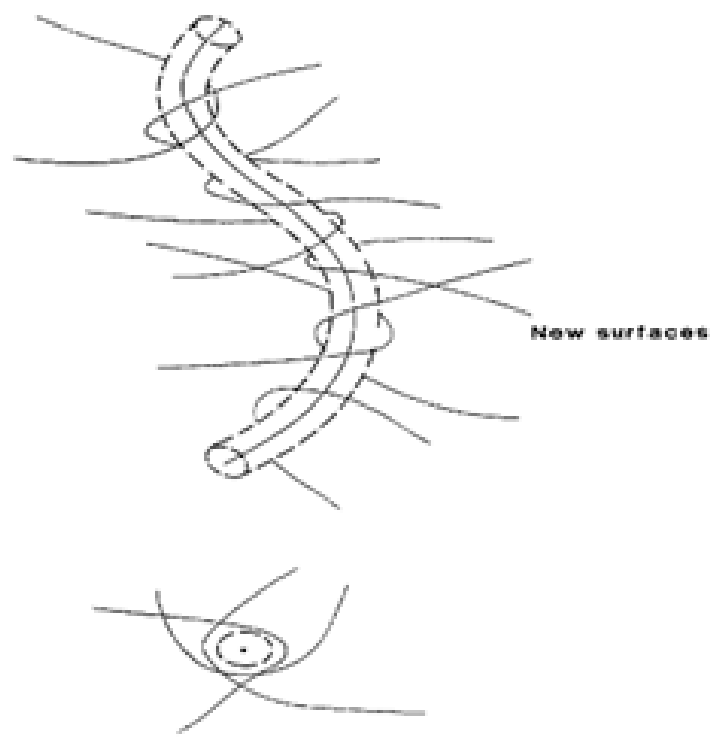

(a)

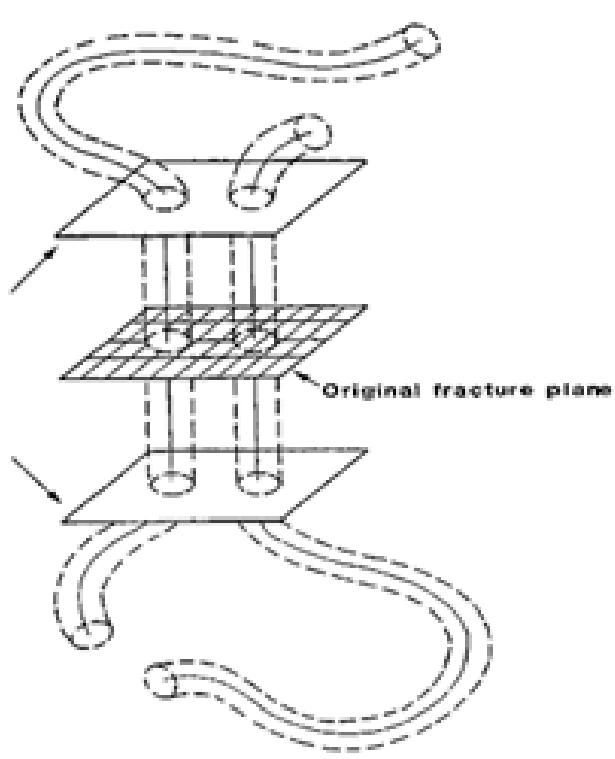

(b)

Figure 2.3: a.) Reptating entangled chain, b.) Chain scission (reprinted with permission from ref. [142]).

Compressive strength of CGPCs increased with increasing PAA molar mass (Table 2.1). This was found to be in good agreement with the literature $[131,156]$. Wilson noted that higher molar mass cements failed with marked plastic deformation, while lower molar mass cements failed in a brittle fashion [131], confirming Edward's model. Additionally, it was postulated [146], and later supported in the literature [155,172,173], that the change in the mechanical properties of GPCs, by changing the molar mass, results from the formation of the silicate network during the maturation period. However other studies have illustrated that the role of the silicate phase is small and confirmed on the significant role of the increased crosslinking of the polyacrylate chains in dominating the fracture behavior of GPCs [142]. Hence, crosslinking reaction of PAA chains is not only important in the early stages of the setting process of GPCs but also in dominating the long-term fracture behavior [142].

Griffin and Hill [142] evaluated the influence of PAA molar mass on the fracture properties of GPCs being investigated (Table 2.1). They have indicated that Young's modulus was 
independent of the molar mass of the polymer phase of GPCs, agreeing with the literature $[141,174]$. Young's modulus is not predicted to rise with increased molar mass, according to the reptation theory $[143,175]$, but is, instead, dominated by the strength and number of interactions in the polymeric phase, in particular the number and strength of ionic cross-links. Altering the molar mass of the PAA will not affect the concentration or number of functional carboxylate groups present for crosslinking $[143,175]$ which provides evidence of why Young's modulus is independent of the molar mass of the polymer phase.

In several studies, flexural strength has been observed to increase with molar mass $[143,175,176]$; evident from the data obtained by Griffin and Hill (Table 2.1). However this increase is more pronounced for GPCs produced using higher molar mass acids [142,175]. This may indicate that, although chain pullout is the predominant mechanism involved in fracture, it may not be the only one. CGPCs produced from PAA with molar masses lower than the critical molar mass result in flexural strengths far lower than predicted by reptation theory, as the carbon-carbon bonding strength determines the overall strength. This may reflect the fact that cements utilizing low molar mass PAA are more brittle and the sensitivity to inherent flaws on the tensile edge of the sample will be increased. However, cements based on PAA with molar masses higher than the critical molar mass have a greater degree of plasticity, which reduces the sensitivity of the samples to surface flaws and consequently increases the flexural strength [143].

Fracture toughness, toughness and plastic zone size have also increased, as the molar mass increased (Table 2.1). This was attributed to the continuing crosslinking reaction of the polymer phase of GPCs, restricting chain motion and/or molecular flow taking place at the crack tip $[142,144]$. The application of reptation theory to GPCs has been criticized but it is capable of making quantitative predictions for analysis of GPC's fracture behavior [142]. 
Table 2.1: Influence of PAA molar mass on the fracture properties of 4.5 $\mathrm{SiO}_{2}-1.5 \mathrm{P}_{2} \mathrm{O}_{5}-3 \mathrm{Al}_{2} \mathrm{O}_{3}-4 \mathrm{CaO}-\mathrm{CaF} 2 \mathrm{GPCs}$ (*E5, E7, E9 and E11 PAAs have number average molar mass of 3.25x103, 6.66x103, 2.29x104 and 1.08x105, respectively) [142]

\begin{tabular}{|c|c|c|c|c|c|c|}
\hline Property & Formula & Cement preparation & "E5 & E7 & E9 & E11 \\
\hline $\begin{array}{l}\text { Compressive } \\
\text { strength }\left(\sigma_{c}\right) \\
(\mathrm{MPa})(\mathrm{SD})\end{array}$ & $\sigma_{c}=\frac{F}{\pi r^{2}}$ & & $\begin{array}{l}42.63 \\
(2.14)\end{array}$ & $\begin{array}{l}53.75 \\
(3.16)\end{array}$ & $\begin{array}{l}54.84 \\
(1.61)\end{array}$ & $\begin{array}{l}70.33 \\
(3.17)\end{array}$ \\
\hline $\begin{array}{l}\text { Young's } \\
\text { modulus } \\
(\mathrm{GPa})\end{array}$ & $E=\frac{\sigma}{\varepsilon}$ & & \multicolumn{4}{|c|}{ Independent of molar mass } \\
\hline $\begin{array}{l}\text { Flexural } \\
\text { strength }\left(\sigma_{\mathrm{f}}\right) \\
(\mathrm{MPa})(\mathrm{SD})\end{array}$ & $\sigma_{f}=\frac{3 P s}{2 b t^{2}}$ & $\begin{array}{l}\text { Cements were prepared by mixing } \\
\text { the glass powder with different } \\
\text { molar mass PAAs concentrated at } \\
40 \% \text { in a weight ratio of } 5: 1 \text { and }\end{array}$ & $\begin{array}{l}10.90 \\
(0.84)\end{array}$ & $\begin{array}{l}14.00 \\
(1.07)\end{array}$ & $\begin{array}{l}14.36 \\
(1.32)\end{array}$ & $\begin{array}{l}22.50 \\
(0.36)\end{array}$ \\
\hline $\begin{array}{l}\text { Fracture } \\
\text { toughness }\left(K_{\mathrm{I}}\right) \\
\left(\mathrm{MPa} \mathrm{m}{ }^{1 / 2}\right) \\
(\mathrm{SD})\end{array}$ & $\begin{array}{l}K_{I} \\
=P_{c} W_{m}\left(\frac{3(1+v)}{W t^{3} t_{n}}\right)^{\frac{1}{2}}\end{array}$ & $\begin{array}{l}\text { then adding this mixture to water } \\
\text { containing } 10 \% \mathrm{~m} / \mathrm{v}(+) \text { tartaric } \\
\text { acid, in a weight ratio of } 4: 1 \text {. } \\
\text { Samples were aged for } 1 \text { day. }\end{array}$ & $\begin{array}{c}0.41 \\
(0.02)\end{array}$ & $\begin{array}{c}0.52 \\
(0.02)\end{array}$ & $\begin{array}{c}0.54 \\
(0.01)\end{array}$ & $\begin{array}{c}0.98 \\
(0.04)\end{array}$ \\
\hline $\begin{array}{l}\text { Toughness }\left(G_{\mathrm{I}}\right) \\
\left(\mathrm{J} \cdot \mathrm{m}^{-2}\right)\end{array}$ & $G_{I}=\frac{K_{I}^{2}\left(1-v^{2}\right)}{E}$ & & 23 & 37 & 49 & 167 \\
\hline $\begin{array}{l}\text { Plastic zone } \\
\text { size }\left(R_{p}\right)(\mu \mathrm{m})\end{array}$ & $R_{p}=\frac{K_{I C}^{2}}{\sigma_{Y S}}$ & & 9.2 & 9.9 & 13.0 & 42.3 \\
\hline
\end{tabular}

\subsubsection{Effect of the PAA molecular weight}

The weight average $\left(\mathrm{M}_{\mathrm{w}}\right)$ and number average $\left(\mathrm{M}_{\mathrm{n}}\right)$ molecular weight of the polyelectrolyte also affects the rheological and mechanical properties of GPCs as shown in Eq. 2.4a. The molecular weight averages are defined mathematically using Eqs. 2.4b and 2.4c:

$$
\begin{aligned}
& M_{w}, M_{n} \propto \frac{\text { Cement strength }}{\text { Rheological properties }} \ldots \ldots \ldots . . . .(2.4 \mathrm{a}) \\
& M_{w}=\frac{\sum N_{i} M_{i}^{2}}{\sum N_{i} M_{i}} \\
& M_{n}=\frac{\sum N_{i} M_{i}}{\sum N_{i}}
\end{aligned}
$$

Where $M_{i}$ is the mass of a specific isotope and $N_{i}$ is the number of molecules whose weight is $M_{i}$. 
The simplicity of Eq. 2.4a has resulted in a number of studies that have found similar trends with regard to the influence of the PAA molecular weight $\left(\mathrm{M}_{\mathrm{n}}\right.$ or $\left.\mathrm{M}_{\mathrm{w}}\right)$ on the mechanical and rheological properties of CGPCs [131,133,141,177]. Increasing the PAA molecular weight, in order to improve cement strength, increases cement viscosity for clinical handling and decreases working and setting times [131,132] (see Table 2.2). In particular, it can be seen that the use of low $\mathrm{M}_{\mathrm{w}}$ PAA results in non-measurable rheological properties. Very low $\mathrm{M}_{\mathrm{w}}(\leq 3.5 \mathrm{~K})$ results in very low viscosity resulting in a weakened cement and, at the same time, very long rheological properties when compared with the minimum requirements noted by ISO 9917-1:2007 for dental based cements. In general, higher $\mathrm{M}_{\mathrm{w}}$ PAA would provide more un-bonded carboxylic (-COO) groups to bind with glass cations resulting in quicker interaction and hence shorter setting time; i.e. this occurs due to the faster ability of cross-linking between the polymer chains and the released cations while the low viscosity allowed for longer working time [132]. In such a case, the resulting cement is expected to be putty like. Results presented by Wilson et al. have been later confirmed by a number of studies in this field [178,179]. In the clinic, a long working time (sufficient for placement of the cement before its workability diminishes) and a sharp setting time (to prevent un-favorable acid-tissue interactions) are desirable properties.

Table 2.2: Effect of PAA Mw on rheological properties of CGPCs

\begin{tabular}{lccc}
\hline PAA $\left(\mathbf{M}_{\mathrm{w}}\right)$ & Viscosity $(\mathbf{c P})$ & Working time (sec) & Setting time (sec) \\
\hline $3.5 \mathrm{~K}$ & 16 & - & - \\
$27 \mathrm{~K}$ & 50 & 555 & 390 \\
$76 \mathrm{~K}$ & 200 & 285 & 300 \\
$230 \mathrm{~K}$ & $3.5 \mathrm{~K}$ & 165 & 195 \\
\hline
\end{tabular}

The effect of the PAA molecular weight on the fracture properties of CGPCs is controlled, to a large extent, by the PAA molar mass. The conceptual framework of reptation theory and the ideas of entanglements help in illustrating the effect of polymer molecular weight on the properties of CGPCs. The application of the reptation model to CGPCs was successful in describing the dependency of fracture properties of CGPCs on the PAA molecular weight. Wilson et al. [131] have conducted a study investigating the influence of the PAA molecular weight on the mechanical properties of GPCs. Table 2.3 brings together their results. As shown (Table 2.3) compressive strength of GPCs increases with molecular weight. In the literature $[130,131,142,143]$, there were little differences in compressive strengths reported with PAA $\mathrm{M}_{\mathrm{w}}$ 
in excess of $100 \mathrm{~K}$ which confirmed the suggestion by Hill et al. [141] that a critical $\mathrm{M}_{\mathrm{w}}$ for PAA was approximately $100 \mathrm{~K}$ when anhydrous PAA investigated. A recent study by Gomes et al. [180] considered $\mathrm{M}_{\mathrm{w}}$ PAA between $50 \mathrm{~K}$ and $1250 \mathrm{~K}$ and observed that the highest compressive strength and compressive elastic modulus (E) were associated with a PAA $\mathrm{M}_{\mathrm{w}}$ of $50 \mathrm{~K}$. Young's modulus was also evaluated by Wilson and co-workers, values (Table 2.3) showed little variation, as expected, with PAA molecular weight, confirming that molecular weight does not influence the chemistry of the setting reaction. In a similar fashion to compressive strength, the flexural strength was markedly increased with increased molecular weight. However, it was realized that the flexural strength ceases to rise at very high $\mathrm{M}_{\mathrm{w}}\left(>5 \times 10^{5}\right)$. This behavior is similar to that of thermoplastics; at $\mathrm{M}_{\mathrm{w}}$ higher than $5 \times 10^{5}$, the flexural strength becomes independent of the molecular weight as a result of reaching a critical stress sufficient to cause chain scission. This explanation agrees with the reptation chain pullout model presented by Prentice [169]. Further, fracture toughness, toughness and flaw size measurements also increased with PAA molecular weight. It was illustrated that the increase in toughness resulted from both PAA crosslinking reactions and the interface between the glassy phase and the polymer matrix. Additional testing included wear and erosion as a function of molecular weight; both decreased with increased molecular weight (values are not tabulated in the original article). Hence, it can be seen that a large number of mechanical properties are dependent on the PAA molecular weight since the longer the polyacid chain is, the larger the number of cross-links are required to be broken to free the chain. It is relatively easier to pull-out a low molecular weight chain than to pull out a high molecular weight chain. In addition, increased strength can be attributed to limited motion of the bonded polyacid molecules due to their long chain entanglements [131,181]. Values in Table 2.3 were compared to other experimental data in the literature $[132,141,182]$ and were found to have similar patterns.

In 2011, Dowling and Fleming [133,177] investigated ways of improving the mechanical properties of GPCs, in particular compressive strength and elastic modulus, using PAA molecular weight mixtures, different blend ratios and different PAA concentrations without impacting viscosity of the PAA solution. The PAAs in their studies were conventional aqueous solutions with $M_{n}$ ranging between $5 \mathrm{~K}$ and $200 \mathrm{~K}$. They have suggested, in line with the observations of Martin et al. [183], that the critical $\mathrm{M}_{\mathrm{w}}$ would be approximately $80 \mathrm{~K}$; lower than that (100 K) suggested by Hill et al. [141] and based on work by Prentice [169]. Additionally, 
Dowling and Fleming [133] suggested the entanglement $\mathrm{M}_{\mathrm{w}}$ for PAA to be below $5 \mathrm{~K}$, for aqueous PAAs, compared with the $7 \mathrm{~K}$ suggested by Hill et al. [141] for anhydrous PAAs. Their results have confirmed the aforementioned discussions by Wilson and Hill groups. By replacing $10-30 \%$ of a lower $\mathrm{M}_{\mathrm{w}}$ PAA $(\sim 15 \mathrm{~K})$ with a higher $\mathrm{M}_{\mathrm{w}}$ PAA $(\sim 80 \mathrm{~K})$, significant increases in compressive strength and elastic modulus were observed with minimal increases in the viscosity of the PAA solutions. It is important to note that although the approach of mixing different molecular weights at different ratios to improve the mechanical properties is encouraging, no marked increases in compressive strength and elastic modulus were observed compared with those for the control cements with highest $\mathrm{M}_{\mathrm{w}}$ PAA ( $\left.~ 80 \mathrm{~K}\right)$ investigated. The use of $50 \mathrm{~K} \mathrm{M}$ PAA with a particle size $<50 \mu \mathrm{m}$ would result in the optimum polymerization and end-use characteristics of GPCs for clinical use. The use of $\mathrm{M}_{\mathrm{w}}$ PAA higher than $50 \mathrm{~K}$ is favorable as it results in marked plastic deformation due to the wider distribution of the polymer chain lengths. It is important, though, to note that the use of $\mathrm{M}_{\mathrm{w}}>500 \mathrm{~K}$ would not improve the mechanical properties since the cement matrix reaches a point of critical stress sufficient to cause chain scission and the mechanical properties become independent of $\mathrm{M}_{\mathrm{w}}$. Attention must also be paid to the use of different molecular weight PAAs as they result in different molecular weight distributions. The short chains in the high molecular weight PAA would contribute to the quick setting reaction with the released cations through faster disentanglement and dissolution and hence resulting in improved mechanical properties, while the long chains in the low molecular weight PAA would contribute to slightly delaying the matrix from quick setting $[108,131,132]$. 
Table 2.3: Dependence of fracture properties and acid erosion of 12.39Si-16.44Al-7.14Ca-10.40F-7.26Na-4.54P-41.83O GPCs on PAA molecular weight (*E5, E7, E9, E11, E13 and E15 PAAs have weight average molecular weights (Mw) of 1.15x104, $2.27 \times 104,1.14 \times 105,3.83 \times 10[131]$

\begin{tabular}{|c|c|c|c|c|c|c|c|}
\hline Property & Cement preparation & ${ }^{*} \mathbf{E 5}$ & E7 & E9 & E11 & E13 & E15 \\
\hline Compressive strength $\left(\sigma_{c}\right)(\mathrm{MPa})$ & & 30.40 & 41.95 & 45.80 & 50.14 & 65.88 & 57.48 \\
\hline (SD) & & $(2.53)$ & $(3.30)$ & $(8.66)$ & $(1.48)$ & $(5.39)$ & $(2.05)$ \\
\hline & & 1750 & 1754 & 1220 & 1313 & 1429 & 1580 \\
\hline Young's modulus (GPa) (SD) & Cements were prepared & $(314)$ & (374) & $(150)$ & (132) & (132) & (145) \\
\hline Flexural strength $\left(\sigma_{\mathrm{f}}\right)(\mathrm{MPa})(\mathrm{SD})$ & & 7.06 & 8.05 & 9.63 & 10.98 & 13.74 & 13.25 \\
\hline & $\begin{array}{l}\text { powder }(50 \mathrm{~g}) \text { with } 7 \mathrm{~g} \text { of } \\
\text { different molecular }\end{array}$ & $(1.05)$ & $(0.61)$ & $(0.41)$ & $(0.78)$ & $(0.57)$ & $(1.90)$ \\
\hline $\begin{array}{l}\text { Fracture toughness }\left(K_{\mathrm{I}}\right)(\mathrm{MPa} \\
\left.\mathrm{m}^{1 / 2}\right)(\mathrm{SD})\end{array}$ & weight anhydrous PAAs & 0.13 & 0.10 & 0.23 & 0.26 & 0.33 & \\
\hline & and then adding $11 \mathrm{~g}$ of & $(0.01)$ & $(0.01)$ & $(0.02)$ & $(0.04)$ & $(0.04)$ & \\
\hline Toughness $\left(G_{\mathrm{I}}\right)\left(\mathrm{J} \cdot \mathrm{m}^{-2}\right)$ & $\begin{array}{l}\text { this mixture to water } \\
\text { containing } 10 \% \text { by mass }\end{array}$ & 10 & 15 & 30 & 38 & 61 & - \\
\hline Plastic zone size $\left(R_{p}\right)(\mu \mathrm{m})$ & $\begin{array}{l}(+) \text { tartaric acid. Samples } \\
\text { were aged for } 1 \text { day. }\end{array}$ & 91 & 106 & 142 & 171 & 155 & - \\
\hline Mechanical wear & & \multicolumn{6}{|c|}{$\begin{array}{l}\text { Both, mechanical wear and acid erosion decreased as } \\
\text { the molecular weight of the PAA increased }\end{array}$} \\
\hline Acid erosion & & & & & & & \\
\hline
\end{tabular}

\subsubsection{Effect of the PAA concentration}

Continuing our earlier discussions on the reptation model, the theory also considers individual polymer chains and states that when the concentration of a polymer solution is high enough to produce dense chain entanglements, each chain is forced to wriggle in an anisotropic curvilinear motion, called 'reptation'. Increasing PAA concentration involves reducing water content, i.e. increasing the relative amount of chemically bonded atoms with stable electronic configuration, alternatively called covalent bonds, or the number of $\mathrm{COOH}$ groups resulting in better distribution of stresses through the structure. In other words, higher concentration PAA results in cements with higher numbers of polyacid chains, thus affecting GPC characteristics. Figure 2.4 illustrates this concept and shows that the strength of the cement depends on the stress transfer between volume elements, which would improve if the PAA molecular weight or concentration were increased [184,185]. 


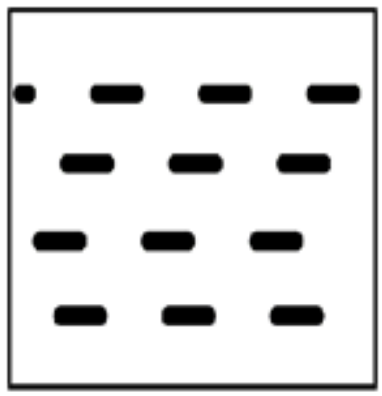

(a)

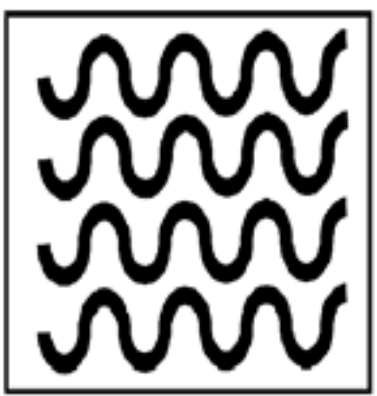

(b)

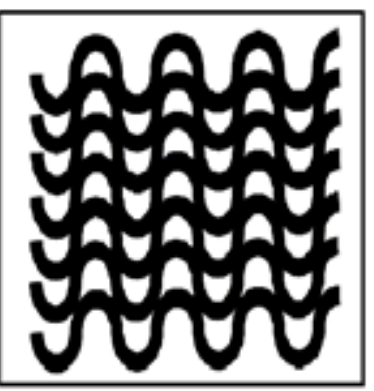

(c)

Figure 2.4: (a) Cement volume; (b) effect of increasing molecular weight; (c) effect of increasing concentration (adapted from [185])

CGPCs have utilized the PAA at a concentration of about $45 \%$ [151]. Since then, various studies have considered the effect of changing PAA concentration on the physical (rheological and mechanical) properties of GPCs. The effect of PAA concentration on rheological properties was studied by Crisp et al. [130]. Table 2.4 provides the active region (a region in which identifying the GPCs' properties is possible), of PAA concentration, for different rheological properties and comments on each. It is clear that increasing PAA concentration increases cement viscosity resulting in a quicker setting reaction. In general, more concentrated PAA results in improved matrix formation through the formation of metallic ions and salt bridges, however this improvement happens at the expense of rheological properties, i.e. limiting the factor is the consistency of the cement paste $[108,130]$. It was also postulated that increasing polymer concentration results in higher polymer conductivity and lower $\mathrm{pH}$. This is expected to increase intra- and inter-molecular interactions resulting in compressed macromolecular chains and hence increased surface reactivity [185-187]. Thus, it can be noted that the concentration of the polymer phase is an important factor affecting the setting reaction whereas a suitable balance is important to allow the cement components to react and to attain optimum properties [130]. These results observed by Crisp and co-workers were confirmed by similar studies in the literature [108,133,146,177]. 
Table 2.4: Effect of the PAA concentration $(\%$ w/w) on rheological properties and handling characteristics of CGPCs [130]

\begin{tabular}{|c|c|c|}
\hline Parameter & $\begin{array}{l}\text { Active } \\
\text { region }\end{array}$ & Comment \\
\hline Viscosity & $28-52$ & $\begin{array}{l}\text { Linear relationship, however, the viscosity increases rapidly at PAA concentrations } \\
>48 \% \mathrm{w} / \mathrm{w} \text {. }\end{array}$ \\
\hline $\begin{array}{l}\text { Powder:liquid } \\
\text { ratio }\end{array}$ & $38-50$ & $\begin{array}{l}\text { Increasing the PAA concentration corresponds to a reduction in the P:L ratio resulting } \\
\text { in increased viscosity maintaining the cement consistency. PAA concentration }<38 \% \\
\text { w/w resulted in no effects on the } \mathrm{P}: \text { L ratio }\end{array}$ \\
\hline Working time & $38-50$ & $\begin{array}{l}\text { Within this active region, increasing the PAA concentration decreased the working } \\
\text { time. This corresponds to the increased viscosity of the cement. Below } 38 \text { per cent } \\
\text { w/w, there is no effect on the working time, while the use of ratios }>50 \text { is not } \\
\text { recommended for clinical purposes. }\end{array}$ \\
\hline Setting time & $28-48$ & $\begin{array}{l}\text { The setting time decreased for PAA concentrations between } 28 \text { and } 38 \% \mathrm{w} / \mathrm{w} \text {. } \\
\text { However, an increase in the setting time was recorded corresponding to concentrations } \\
\text { between } 29 \text { and } 43 \% \mathrm{w} / \mathrm{w} \text {. Subsequently, the setting time drops until a plateau is } \\
\text { reached. }\end{array}$ \\
\hline
\end{tabular}

The literature $[133,142,177,188,189]$ also researched and commented on the effect of PAA concentration on the mechanical properties of GPCs. Table 2.5 brings together the results observed by a series of studies by Fennell and Hill $[143,144]$, which focused on the influence of PAA concentration and molar mass on the fracture properties of GPCs. It can be seen that, generally, cement strength increases with PAA concentration (30\% to 50\%). Further increases in PAA concentration (up to approximately 45\%-50\%) increases the number of chains crossing the fracture plane leading to higher toughness and strength [143]. However, a slight fall and variation in some mechanical properties can be seen for PAA concentrations higher than 50\% offering justification for why a PAA concentration of $45 \%$ is preferred for preparation of GPCs in the dental clinic. This slight fall/variation for cements prepared with PAA concentrations higher than $50 \%$ can be attributed to the deficiency of metal cations in the polysalt matrix present for crosslinking and/or due to incomplete dissolution of the polyacid particles [143]. Moreover, Young's modulus was observed to be independent of PAA molar mass (Table 2.1), however it was found (Table 2.5) to increase with PAA concentration up to approximately 50\%. The increase in Young's modulus was due to the reduced water content as PAA concentration 
increases. Water molecules are likely to cause a plasticizing action, spacing the polymer chains apart, and hence lower chain entanglement density or decreased number of $\mathrm{COOH}$ groups for crosslinking would be expected resulting in lower or unpredictable Young's modulus [143]. Generally, the viscosity, and mechanical properties of GPCs increase with the PAA concentration regardless of the PAA molecular weight. However, an optimum PAA concentration (ranging between 35 and 50\%) exists for each PAA molecular weight, above which the mechanical properties decrease [133].

Table 2.5: Influence of the PAA concentration on mechanical properties of GPCs [143,144]

\begin{tabular}{|c|c|c|c|c|c|c|c|c|}
\hline \multirow{2}{*}{ Property } & \multirow{2}{*}{ Cement preparation } & \multicolumn{7}{|c|}{ PAA concentration } \\
\hline & & $30 \%$ & $35 \%$ & $40 \%$ & $45 \%$ & $50 \%$ & $55 \%$ & $60 \%$ \\
\hline $\begin{array}{l}\text { Compressive } \\
\text { strength }\left(\sigma_{\mathrm{c}}\right) \\
(\mathrm{MPa})(\mathrm{SD})\end{array}$ & & $34(2)$ & $44(3)$ & $50(3)$ & $73(7)$ & $76(6)$ & $88(5)$ & $73(4)$ \\
\hline $\begin{array}{l}\text { Young's } \\
\text { modulus } \\
(\mathrm{GPa})\end{array}$ & $\begin{array}{l}\text { Cements were prepared by mixing } \\
\text { the glass powder }\left(4.5 \mathrm{SiO}_{2^{-}}-1.5\right. \\
\left.\mathrm{P}_{2} \mathrm{O}_{5^{-}} 3 \mathrm{Al}_{2} \mathrm{O}_{3}-4 \mathrm{CaO}-\mathrm{CaF}_{2}\right) \text { with }\end{array}$ & $\begin{array}{c}2.93 \\
(0.23)\end{array}$ & $\begin{array}{c}3.07 \\
(0.28)\end{array}$ & $\begin{array}{l}4.05 \\
(0.47)\end{array}$ & $\begin{array}{c}5.04 \\
(0.75)\end{array}$ & $\begin{array}{c}5.67 \\
(0.59)\end{array}$ & $\begin{array}{c}4.90 \\
(0.37)\end{array}$ & $\begin{array}{c}3.55 \\
(0.27)\end{array}$ \\
\hline $\begin{array}{l}\text { Flexural } \\
\text { strength }\left(\sigma_{\mathrm{f}}\right) \\
(\mathrm{MPa})(\mathrm{SD})\end{array}$ & $\begin{array}{l}\text { E7 PAAs concentrated between } \\
30-60 \% \mathrm{~m} / \mathrm{m} \text { and then adding this } \\
\text { mixture to water containing } 10 \% \\
\mathrm{~m} / \mathrm{v}(+) \text { tartaric acid. Cement were }\end{array}$ & $\begin{array}{c}5.14 \\
(1.28)\end{array}$ & $\begin{array}{c}5.53 \\
(1.14)\end{array}$ & $\begin{array}{c}8.65 \\
(1.31)\end{array}$ & $\begin{array}{l}10.08 \\
(1.83)\end{array}$ & $\begin{array}{l}11.01 \\
(1.38)\end{array}$ & $\begin{array}{l}19.18 \\
(0.65)\end{array}$ & $\begin{array}{l}18.14 \\
(0.72)\end{array}$ \\
\hline $\begin{array}{l}\text { Fracture } \\
\text { toughness }\left(K_{\mathrm{I}}\right) \\
\left(\mathrm{MPa} \mathrm{m}{ }^{1 / 2}\right) \\
(\mathrm{SD})\end{array}$ & $\begin{array}{l}\text { prepared with } 0.4 \text { glass volume } \\
\text { fraction and were aged for } 1 \text { day. }\end{array}$ & $\begin{array}{c}0.25 \\
(0.03)\end{array}$ & $\begin{array}{c}0.27 \\
(0.10)\end{array}$ & $\begin{array}{l}0.40 \\
(0.05)\end{array}$ & $\begin{array}{r}0.42 \\
(0.08)\end{array}$ & $\begin{array}{c}0.52 \\
(0.16)\end{array}$ & $\begin{array}{c}0.50 \\
(0.04)\end{array}$ & $\begin{array}{c}0.51 \\
(0.04)\end{array}$ \\
\hline $\begin{array}{l}\text { Toughness } \\
\left(G_{\mathrm{I}}\right)\left(\mathrm{J}^{-\mathrm{m}^{-2}}\right)\end{array}$ & & 21 & 24 & 39 & 35 & 48 & 51 & 73 \\
\hline
\end{tabular}




\subsubsection{Effect of the PAA polydispersity index}

The polydispersity index (PDI) is a measure of molecular weight distribution (MWD) of the PAA (Eq. 2.5). Molecular weight distribution results from the unequal growth of the polymer chains during polymerization $[133,190]$.

$$
M W D(P D I)=\frac{M_{w}}{M_{n}}
$$

Most studies in the field have considered the effect of changing molecular weight, while less attention is paid to PDI. Studies by Hill et al. [141], Wilson et al. [131] and Dowling and Fleming [133] have shown that increasing PDI results in increased strength. Dowling and Fleming, for example, investigated the influence of PDI of a series of PAA solutions, with number average molecular weights ranging from $5 \mathrm{~K}$ to $200 \mathrm{~K}$ and concentrations ranging from 10 to $60 \%$. PDI values between 1.5 and 2.2 were used in the study of Dowling and Fleming and were considered narrow. Otherwise, high PDI ( $>3)$ is indicative of a wide distribution of PAA chain lengths and can be called 'polydisperse PAA', which is generally advantageous for processing purposes since low molecular weight fractions or low $\mathrm{M}_{\mathrm{n}}$ result in higher viscosities and behave like lubricants $[131,133]$. This behavior was attributed to that longer PAA chains, associated with higher $\mathrm{M}_{\mathrm{w}}$ PAA, have a disproportionate effect on the viscosity while a monodisperse PAA, with a narrower distribution of PAA chain lengths, would provide a proportionate effect on the viscosity when concentrated in solution [142].

Chain length of the polyacid is known to be an important parameter affecting a wide range of clinically relevant parameters such as rheology, acid erosion, solubility, mechanical properties and abrasive wear. Increasing the chain length of the polymer results in lower viscosity and hence higher strength because the narrow distribution of PAA chain length results in larger chain entanglements and hence lower stress cracking sensitivity [131,141].

\subsubsection{Effect of mixing ratio of PAA solution and glass powder}

Variations in the powder:liquid (P:L) ratio can, understandably, influence both mechanical and rheological properties of GPCs. Fleming et al. [136] manipulated the ratio for ChemFil (Dentsply, Germany); a commercially available restorative cement, and examined the effects on rheological and mechanical properties. Using the manufacturer's recommended ratio as a baseline (100\% powder), other formulations were mixed at $90 \%, 80 \%$, and $50 \%$ of the recommended powder content, with a constant volume $(1 \mathrm{ml})$ of aqueous polyacid. Table 2.6 summarizes key results from the literature. Decreasing powder content, while keeping liquid 
content constant, results in reduced strength but longer rheological properties. Xie et al. [191] studied the effect of increasing glass content on the GPC strength and rheological properties. They have shown that increasing P:L ratio in the cement results in increased compressive strength but decreased setting time. Further, they have shown that increasing P:L ratio from 1 to 2 increases compressive strength from $\sim 40$ to $\sim 140 \mathrm{MPa}$, while a non-significant increase resulted when the P:L increased further from 2 to 2.5. Beyond 2.5, the compressive strength dropped significantly. Results of Xie and his group [191] are in good agreement with those presented by Fleming et al. [136].

Table 2.6: Properties of ChemFil mixed with 100\%, 90\%, 80\% and 50\% of the recommended powder content [136].

\begin{tabular}{lcccc}
\hline Property & $\mathbf{1 0 0 \%}$ & $\mathbf{9 0 \%}$ & $\mathbf{8 0 \%}$ & $\mathbf{5 0 \%}$ \\
\hline Compressive strength (MPa) & 102 & 94 & 83 & 56 \\
Working time in seconds (sec) & 90 & 90 & 108 & 120 \\
Net setting time (sec) & 150 & 168 & 186 & 210 \\
\hline
\end{tabular}

The higher the amount of glass powder, the higher the cement strength [192]. This correlation has been explained through the particles of the glass powder that remain unchanged due to the lower level of acid. The 'un-reacted' glass cations, within the cement structure, act as reinforcing filler particles and prevent crack propagation within the cement matrix, resulting in improved strength [134,192]. Reducing the volume of reinforcing glass particles (or increasing the amount of liquid used for a specific formulation) reduces the ability of GPCs to resist compressive forces during loading and consequently failure occurs at lower compressive loads. Variations in the rheology of the cements with P:L ratio can be explained in similar terms. Firstly, increased PAA ratio will inevitably provide a more fluid cement upon mixing, and decreasing the glass volume fraction provides fewer available matrix forming ions relative to active bonding sites on the polyacid chain [108,134,193]. There must be an optimum P:L ratio, providing that the cement has sufficient working and setting times for application of the cement at this optimum ratio.

\subsubsection{Effect of additives/chelating agents}

It has been postulated that the polymer phase is responsible for the strength of the cement while incorporation of chelating agents was assumed to affect various properties of GPCs [194,195]. Tartaric acid (Figure 2.5), as a co-additive to the PAA backbone, is often added to 
GPCs as a rate-controlling additive [108]. Wilson et al. [194] showed that tartaric acid was effective in the extraction of ions from the alumino-silicate glass. The expected effect would be of shortening the setting time and accelerating the rate of cement hardening. However, the paper reported that D-tartaric acid was also an effective complexing agent for improving working and setting times of cement pastes [195] and postulated that the addition of tartaric acid first delays the setting reaction and then enhances ion bridging as a result of withholding cations from the polyanion chains. 5-10 wt.\% (+)-tartaric acid (Figure 2.5a) improves rheological properties of GPCs by extending the working time and sharpening the onset of the setting time [151]. Results of Wilson and his group were confirmed by Prosser et al. [196] who showed by means of ${ }^{13} \mathrm{C}$ Fourier transform nuclear magnetic resonance spectroscopy (FT-NMR) that tartaric acid reacts preferentially with the glass and prevents the early binding of cations to the polyanion chains, resulting in increased working time. Tartaric acid is fully complexed at $\mathrm{pH} \approx 3$ and complexing by PAA then occurs with the $\mathrm{pH}$ of the set cement rising to $\mathrm{pH} \approx 5$ [196]. This change in complexing species occurs due to the stability of calcium and aluminium tartrate compounds at low $\mathrm{pH}(\mathrm{pH} \approx 3-4)$. In the presence of $(+)$-tartaric acid, calcium salts form more slowly and aluminium salts form more rapidly. It has also been noticed that the conformation of the acid is also of paramount importance as neither (-) (Figure 2.5b) or ( \pm )-tartaric acids influence the setting process in the same way as the (+)-isomer (meso form shown in Figure 2.5c) does, whilst their use is contraindicated. A modest increase in strength has also been noticed with the addition of (+)-tartaric acid. These strengthening effects have been attributed to reduction in bulk homogeneities and indirectly improving the surface of the specimen by increasing flow properties [151,195,196].

Other additives including, but not restricted to, phosphoric [197], amino [198], maleic [199], itaconic [200] and oxalic acids [201], have been studied and discussed by other review papers $[109,137,151]$. Yet, they are not the focus of this chapter. 


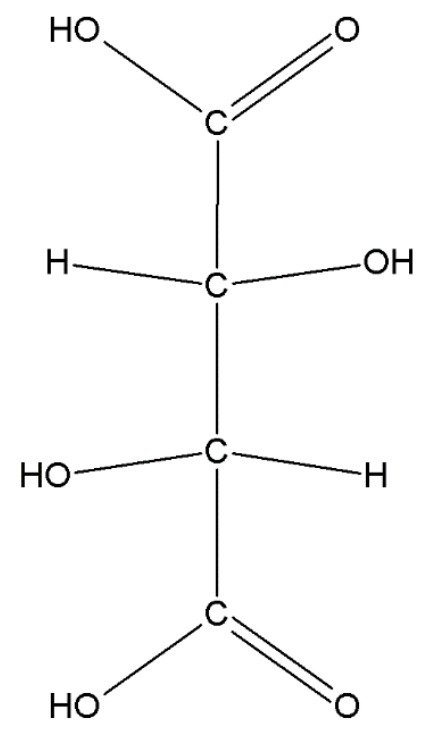

(a)

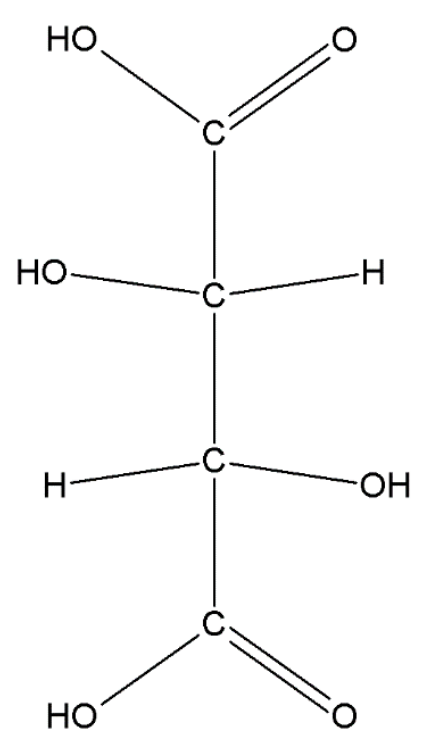

(b)

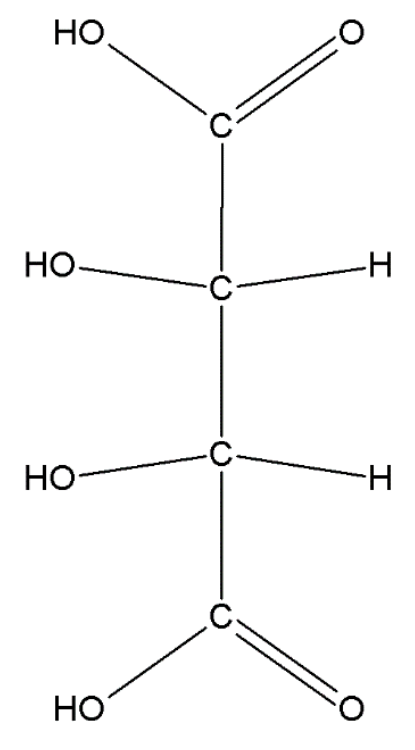

(c)

Figure 2.5: (a) (+) Tartaric acid; (b) (-) Tartaric acid; (c) meso- Tartaric acid (Adapted from [108])

\subsection{The influence of PAA component on the clinical performance of CGPCs}

This review considers the role of PAA in the setting chemistry and maturation of CGPCs and then discusses the effect of changing various aspects of the PAA phase, including molar mass, molecular weight, concentration, polydispersity index, content and inclusion of chelating agents on the mechanical and rheological properties of CGPCs. This section of the review focuses on the clinical aspects of these biomaterials.

\subsubsection{Biocompatibility}

Biocompatibility refers to "the ability of a biomaterial to perform with an appropriate host response in a specific application" [202]. This definition was later modified by Williams who redefined biocompatibility of a biomaterial as "the ability to perform as a substrate that will support the appropriate cellular activity in order to optimize tissue regeneration, without eliciting any undesirable local or systemic responses in the eventual host" [203]. Many studies have been performed in-vitro and in-vivo to evaluate the biocompatibility of PAA-based systems. A study by Brodbeck et al. [204] demonstrated that PAA could prevent failure of implanted biomedical devices by limiting macrophage fusion and monocyte adhesion in-vivo using the rat cage implant system. Other studies $[205,206]$ have also commented on the anti-corrosion performance of the PAA, the ability to functionalize such water-soluble polymers with bioactive molecules and their compatibility towards human osteoblast-like cells. 
The biocompatibility of CGPCs has been investigated and reported over the past several decades. There are no studies reporting the systemic toxicity of CGPCs, attributed to their positive preclinical biocompatibility results [112]. A single study [207] has reported a case of allergy reaction to CGPCs, in which a generalized urticaria occurred after the application of CGPCs. In general, CGPCs do not pose an acute systemic risk or chronic toxic behavior, however it is important to assess their systemic toxicity prior to their market launch. A number of studies [208-212,113] have intensively investigated the cytotoxicity of CGPCs. It was consistently illustrated that the cytotoxic behavior of CGPCs depends on their setting reaction. A freshly mixed cement may exhibit an antibacterial activity or cytotoxicity, both diminishing as the cement matrix hardens [213-216]. The literature has postulated that this behavior could result from the release of metal ions such as aluminum and fluoride and/or free PAAs when freshly mixed [217,218]. The cytotoxic effect of freshly mixed CGPC was also attributed to the high acidity of the freshly mixed cement $(\mathrm{pH}$ 1.6-3.7) when compared to that $(\mathrm{pH} \mathrm{5.4-7.3)} \mathrm{of} \mathrm{the}$ completely set cement [219]. Antimicrobial properties of CGPCs have been investigated in-vitro and in-vivo [220-227]. It was found that freshly mixed CGPCs inhibited bacterial growth, whereas completely set cement samples revealed no antimicrobial effect. In addition to the antimicrobial effect of CGPCs, these adhesive materials have resulted in decreased microbial adhesion when compared with other dental materials, for instance, resin-based composites [112]. A number of clinical studies on CGPCs have questioned their biocompatibility. An implantation study by Steinbrunner et al. [228] revealed that very thin mixes of CGPC, when used as a pit and fissure sealant, generated much more pronounced tissue reactions than a thick mix of the same product when used as a filling material. Other studies [212,113,229] have shown that the exposure of pulp to CGPCs have resulted in severe pulp reactions, including abscess formation. CGPCs used as luting agents caused severe pain in certain cases [230]. The possible causes of these clinical reactions can be the incorrect handling (e.g., pronounced drying of the prepared tooth prior to cementation), insufficient remaining dentin thickness, excessive pressure during cementation or increased solubility resulting from inhibited setting reaction [227,231,232]. Further details on the biocompatibility of CGPCs are presented elsewhere [233,234,114].

\subsubsection{Rheological and mechanical properties}

Mechanical and rheological properties of GPCs are often interrelated. Improving the mechanical properties of GPCs would, in some cases, shorten the rheological properties and vice 
versa. The strength of GPCs increases with time as a result of cross-linking in the polysalt matrix. The previous sections of this chapter have commented on the chemistry of these novel materials and discussed the effect of various properties of PAA on the mechanical and rheological properties of CGPCs. GPCs are not only required to set to give a strong material, but they must also remain viscous for a sufficient time to allow manipulation by the clinician after which they must present a degree of hardness following placement to avoid failure.

\subsubsection{Adhesion to substrates}

CGPCs adhere to both dentin and enamel without prior treatment [108,235]. Many studies have considered the mechanism of adhesion using information from spectroscopic techniques such as infrared spectroscopy. Smith [236] has suggested that PAA carboxylate groups in the GPC chelate $\mathrm{Ca}^{2+}$ ions in hydroxyapatite. Beech [237] has postulated, from infrared absorption spectra, that adhesion is a result of ionic attraction between carboxylate groups and the surface of the tooth. Wilson [238] considered that metal ions could form a salt bridge between pendant carboxylate groups in the cement and the negatively charged apatite surface of enamel. Further, Wilson has indicated that effective adhesion results from excellent wetting which is attributed to the ability of the free $\mathrm{COOH}$ groups present in fluid cement to form hydrogen bonds as shown in Figure 2.6. These hydrogen bonds are replaced by ionic bridges as the cement sets. Belton and Stupp [239] have shown that ionized rather than un-ionized polyacrylate is responsible for adhesion. Another possibility remains, that the polyacrylate chains affect adhesion by crossing the interface and interacting with the surface layer of the enamel apatite. Wilson et al. [240] have shown that the surface layer of the adhering cement becomes enriched in phosphate and calcium ions as these diffuse from the enamel surface. A more recent laboratory study by Van Meerbeek et al. [241] described a micromechanical interlocking mechanism between the self-etching effect of the polyacid component of the glass ionomer and the hydroxyl apatite coated collagen fibril network of dentine. Therefore, it was concluded that ionic bonds are formed between the poly carboxyl groups of the glass ionomers poly acid and the $\mathrm{Ca}^{2+}$ ions of the tooth, confirming the results presented by Smith [236]. Furthermore, a study by Yoshida et al. [242] has shown the capability of using novel biomaterial characterization techniques such as X-ray photoelectron spectroscopy (XPS) in identifying the chemical bonding at biomaterial-hard tissue interfaces. They demonstrated, using XPS, that the PAA component of the glass ionomer system significantly influences the chemical bonding potential. Further, they have shown that a PAA 
based upon 10:1 acrylic/maleic acid units has about two thirds of its carboxyl groups bonded to hydroxyapatite versus half of the carboxyl groups of pure PAA. It is therefore important to note that adhesion is not solely a result of ion bridging, but of interactions between the polyacrylate chains and the enamel surface of the tooth, displacing phosphate for example. In other words, adhesion is dynamic in nature with bond interchange since ion exchange is continually taking place between the oral fluids and the cement interface [111,240].

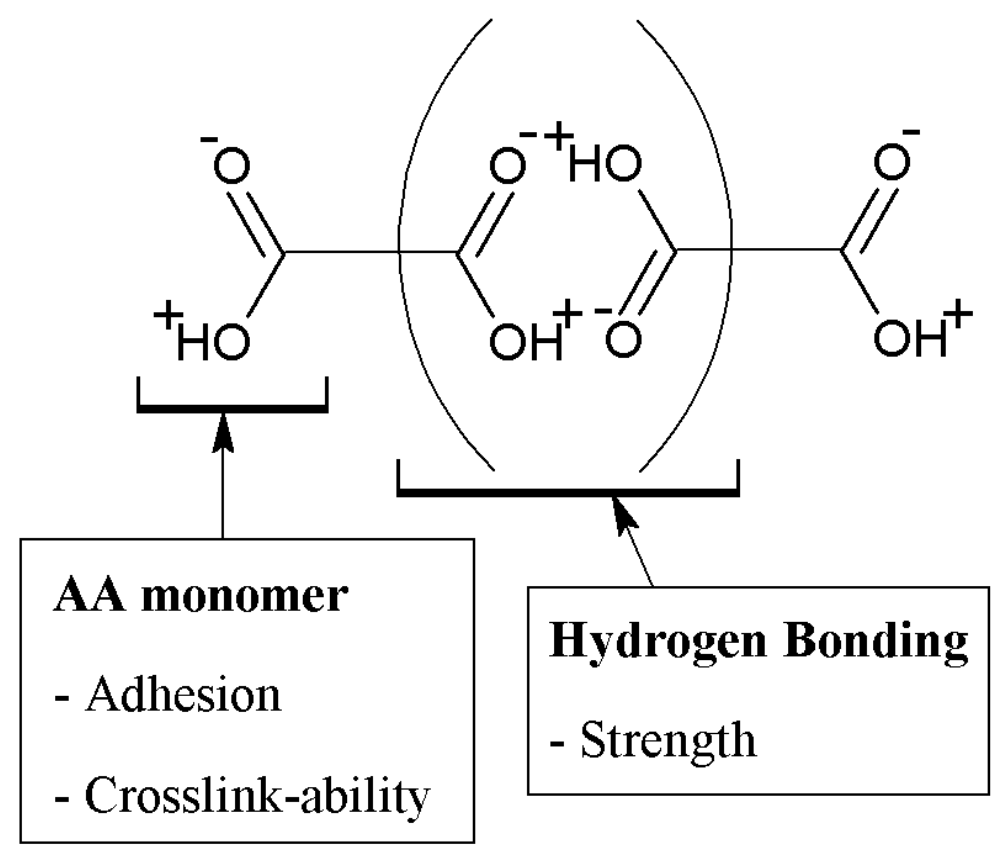

Figure 2.6: A schematic diagram illustrating the properties of the acrylic acid monomer in the copolymer and its ability to form hydrogen bonds resulting in effective adhesion.

Adhesion of CGPCs to surfaces improved through chemical treatment [111]. Although CGPCs can adhere to substrates chemically, surface treatment is of great importance since effective adhesion can only occur when an adhesive and a substrate are brought into molecular contact. Some work on this topic has been reported. Hotz et al. [243] have recommended pretreatment with citric acid. Levine et al. [244] and Causton and Johnson [245] have studied the use of mineralizing solutions. The use of citric acid was found unfavorable as, although it resulted in improved adhesion [243], it also opens up dentinal tubules and causes loss of the smear layer. An experimental study [111] assessed the effectiveness of adhesion of GPCs to substrates pre-treated with chemical reagents that are less aggressive than citric acid, these include PAA, ferric acid and tannic acid. Carboxylic acid hydroxyl containing PAA was found as one of the most effective conditioning solutions, for both enamel and dentin. The functional 
group of the PAA has the ability to form a multiplicity of hydrogen bonds to the substrate surface. These bonds promote wetting, cleansing, and probably, sorption of the conditioning agent by chelation. Enamel treated with 25\% PAA resulted in bond strength of 7.1 MPa that was found significantly higher than that of the untreated enamel (3.2 MPa) [111]. Similar results were achieved for the dentine. There was no significant modification in the morphology of the enamel surfaces. Although, surface modification improves the cement adhesion to the substrate, the substrate surface must be treated with caution. Surface modifications could lead to the creation of air voids, which could act as foci for high stress, hence lowering the strength of the adhesive joint [111].

GPCs have been used in dentistry for over 40 years and have been considered as promising biomaterials in orthopedics. GPCs have been reported to have great potential for use as bone cements as an alternative to the conventional acrylic cements [246,247]. The importance of the adhesion property of CGPCs can not be neglected, it plays an important role in both dental and orthopedic therapies. Hence, the following important factors must be considered for improving the GPCs' adhesion properties [108,248]:

a) Good initial wetting of the surfaces; achieved through a low contact angle, high surface energy and/or low viscosity.

b) Excellent intermolecular and interatomic forces between the adhesive and the substrate to avoid cohesive or adhesive failure in the substrate or within the adhesive, both may compromise the applicability of the material for clinical use.

c) The polymer chain molecules must possess sufficient mobility and be mutually soluble.

d) The material must have comparable strength to the tissue it is replacing to prevent material failure.

e) The solubility of both, the adhesive and the substrate must match to provide stronger interaction.

f) Air voids in cements must be avoided as they act as stress-raisers and result in unsatisfactory adhesive strength attributed to the reduced ability of the adhesive to penetrate into the substrate surface. 


\subsubsection{Ion release}

Physical properties of CGPCs are dominated by the polymer matrix, with the residual glass particles simply acting as a filler [131]. Ion release takes part in the formation of the cement matrix and contributes to the therapeutic activity, giving these materials the potential to be used for various clinical applications. The fluoro-alumino-silicate glass-based CGPCs are known for their sustained release of clinically beneficial amounts of fluoride [161,249,250], as shown by Wilson and co-workers [251] who found that release of fluoride continued for at least 18 months. Fluoride plays an important biological role, particularly in dentistry, and has the effect of improving the resistance of the tooth material to acid attack, decreasing demineralization and increasing re-mineralization, inhibiting dental decays, and making the cement translucent [252254]. Although the therapeutic activity of CGPCs depends mainly on the glass phase [252,255258], the polymer phase plays an important role in attacking the glass cations and releasing them or complexing them within its network. PAA or a copolymer of acrylic and itaconic or maleic acid have been the most commonly used polyacids in the preparation of GPCs. Towler et al. [118] have shown that increasing the concentration of PAA minimizes ion release from GPCs. They have also shown that agitation (sample rotation at 1000 rounds per minute (RPM)) or aging samples at higher temperature $\left(70^{\circ} \mathrm{C}\right)$ significantly increases the release of $\mathrm{Zn}^{2+}$ ions from the cement matrix into the medium, when compared to those aged at $37^{\circ} \mathrm{C}$ in static conditions. Wren et al. [259] investigated titanium-containing glasses and found that the immersion of GPCs based on such glasses into DI water resulted in increased surface area after 1 day which then decreased over the next 29 days of incubation. The increase in the surface area was attributed to the dissolution of PAA within the cement matrix (hydration processes) resulting in open porosity and thus liberating ions bound within the cement structure, which then seek anionic sites. The formation of the siliceous hydrogel, during the hydration processes of GPCs, might be another reason for the increased surface area observed in their study [108]. The release of ions was also influenced by the cross-linked PAA matrix. Studies [259,260] on Ti-containing glasses reported that there was no $\mathrm{Ti}^{4+}$ release. Shen et al. [260] have shown that sodium was dissolved at higher rates than calcium and strontium. These results were attributed to the anion-cation reactions suggesting that $\mathrm{Ca}^{2+}$ and $\mathrm{Sr}^{2+}$ are complexed more strongly by the PAA matrix than $\mathrm{Na}^{2+}$ ions. Ti, on the other hand, is expected to be complexed by the PAA at higher rates than those of the $\mathrm{Na}, \mathrm{Sr}$ and $\mathrm{Ca}$. Further, these results illustrate that the PAA matrix continues its degradation, post 
setting and while immersed into water resulting in selective retention of cations. This is in agreement with the literature [261] where it was indicated that PAA readily complexes alkali metal cations. A study [249] on fluoride release has shown that acidity of the PAA component of a CGPC and/or the P:L mixing ratio may affect the rate of fluoride release from CGPCs. Xu and Burgess [262] have proposed a mathematical equation (Eq. 2.6) to model fluoride release from both conventional and resin modified glass ionomers.

$$
[F]_{C}=[F]_{I}\left(1-e^{-b t}\right)+\beta \sqrt{t}
$$

Where $[\mathrm{F}]_{\mathrm{c}}$ is the cumulative fluoride concentration, $[\mathrm{F}]_{\mathrm{I}}$ is the initial fluoride concentration, $\mathrm{t}$ is the time and $\mathrm{b}$ and $\beta$ are mathematically derived constants.

\subsubsection{Acid erosion and clinical durability}

Clinical durability of a CGPC can be defined as the ability of the cement matrix to withstand long-term clinical use and resist failure [108]. Clinical durability depends on the resistance to acid erosion. CGPCs have generally shown failure rates between $20 \%$ and $30 \%$ after 2 years [263-266]. However, a clinical study by Mount [124] has shown a failure rate of only $2 \%$ over 7 years. The significant difference in the failure rate can be attributed to the fact that the extent of acid erosion varies inversely with the time allowed for the cement to set prior to exposure [267]. It was reported [108] that GPCs based on copolymers of acrylic and maleic acids are less durable than those based on PAA suggesting that the extent of erosion depends on the type of the polyelectrolyte used. Another study by Crisp et al. [162] has performed a chemical study of the erosion of a GPC under acid attack. They found that the chief species eluted were sodium and fluoride ions and silicic acid suggesting that the polyacid attack occurred mainly on the glass

particles rather than on the matrix. It was reported by the same group [162] that GPCs begin to erode at $\mathrm{pH}=4.0$, however a study by Wilson et al. [268] has shown that one brand of GPCs did not erode at all at this $\mathrm{pH}$. In general, the susceptibility of GPCs to acid erosion is low even when the $\mathrm{pH}$ is 2.7 [108].

\subsection{Summary}

PAA has been the most commonly used acid for the preparation of GPCs. This review has critically summarized and evaluated the role of PAA in the performance of CGPCs. Authors suggest that this critical review is crucial for dental material scientists for building proper understanding of the chemistry and properties of the PAA component in GPCs. Hence 
facilitating the development of new cements that may overcome various disadvantages of the commercial GPCs currently used in the clinic.

The current review has shown that PAA, due to its ability to neutralize and ionize in the presence of water, initiates the GPC forming and setting/hardening reactions. This review has also shown that the molar mass, molecular weight, concentration, and polydispersity index of the PAA and the P:L ratio of the GPC system were found to have similar effect on mechanical and rheological properties of the cement being investigated. Increasing any of these factors would increase the cement's strength, however the rheological properties of the material are shortened, representing a challenge in this field. The use of additives such as tartaric acid improves the GPC rheological properties by increasing the workability of the cement. PAA contributes to the biocompatibility of the CGPC system and controls its adhesion to the substrate. It was also found that ion-release is restricted as molecular weight, molar mass, or concentration of the PAA increases. 


\section{The effect of $\mathrm{ZnO} \leftrightarrow \mathrm{Ta}_{2} \mathrm{O}_{5}$ substitution on the structural and thermal properties of $\mathrm{SiO}_{2}-\mathrm{ZnO}-\mathrm{SrO}-\mathrm{CaO}-\mathrm{P}_{2} \mathrm{O}_{5}$ glasses}

\section{This chapter is based on the following published paper:}

Alhalawani, A.M.F.; and Towler, M.R. The effect of $\mathrm{ZnO} \leftrightarrow \mathrm{Ta}_{2} \mathrm{O}_{5}$ substitution on the structural and thermal properties of $\mathrm{SiO}_{2}-\mathrm{ZnO}-\mathrm{SrO}-\mathrm{CaO}-\mathrm{P}_{2} \mathrm{O}_{5}$ glasses. Mater Charact, 2016, 114, 218-224.

\subsection{Introduction}

Bioactive glass systems have osteoinductive, osteoconductive and osteogenic properties that can aid in the reconstruction of damaged bone tissue via exposure of osteoblasts to the ions dissolved from the surface of the glass [269]. These ionic species can form a strong bond with living tissues such as bone [270].

Silicate based bioactive glass systems have been studied because of their potential in various biomedical applications including, but not restricted to, synthetic bone grafts and scaffolds [271]. Silicate bio-glasses mostly contain silicon dioxide $\left(\mathrm{SiO}_{2}\right)$, sodium oxide $\left(\mathrm{Na}_{2} \mathrm{O}\right)$, calcium oxide $(\mathrm{CaO})$, and phosphorous pentoxide $\left(\mathrm{P}_{2} \mathrm{O}_{5}\right)$. Chemical modifications can be made to the silicate bio-glass system by the incorporation of various network forming and modifying cations that offer anabolic effects in bone metabolism [269] and can improve or modify mechanical properties [272-275]. Transition metal oxides form glasses, but generally only in combination with other glass-forming oxides. Tantalum (Ta) is part of the refractory/transition metals group, known as the $d$-block metals. Similar to vanadium pentoxide $\left(\mathrm{V}_{2} \mathrm{O}_{5}\right)$, tantalum pentoxide $\left(\mathrm{Ta}_{2} \mathrm{O}_{5}\right)$ is a conditional glass former that has orthorhombic crystal structure [276]. The basic units of such metals are chains of tetrahedra linked through two corners. Two chains are then linked by placing a fifth oxygen ion from one chain to each Ta ion in the other chain to form a double chain. In this matter, each Ta atom is considered to have five oxygen neighbors [276,277]. Ta has been incorporated into sodium boro-phosphate glass systems (at up to 35 mole percentage), due to its excellent optical and dielectric properties [278] and it has also been found to increasing thermal and chemical stability [278-280]. In the medical field, Ta can increase radiopacity of bone cements [281]. Also, Ta metals were reported to be bioactive and biocompatible due to their ability to form apatite on their surface when soaked in simulated body fluid (SBF). This is due to the formation of Ta-OH groups with calcium and phosphate ions from the SBF [282]. 
The authors have previously replaced $\mathrm{ZnO}$ in bio-glasses with other oxides such as gallium oxide $\left(\mathrm{Ga}_{2} \mathrm{O}_{3}\right)$ [283]. This changed the physical properties of both the precursor ternary $\mathrm{SiO}_{2}$ $\mathrm{ZnO}-\mathrm{CaO}$ glass system and GPCs subsequently prepared from them [284,285]. The adhesive properties of the resultant GPCs, however, deteriorated with increased Ga content in the glass, when evaluated in a bovine sternal model.

In this work, a novel series of $\mathrm{SiO}_{2}-\mathrm{ZnO}-\mathrm{CaO}-\mathrm{SrO}-\mathrm{P}_{2} \mathrm{O}_{5}-\mathrm{Ta}_{2} \mathrm{O}_{5}$ glasses were prepared using melt-quenching at $1550^{\circ} \mathrm{C}$. The structural and thermal properties were investigated as a function of increasing $\mathrm{Ta}_{2} \mathrm{O}_{5}$ content at the expense of $\mathrm{ZnO}$. Simultaneous thermal analysis (STA) was performed on the glasses in the series to obtain the thermal properties for the glass series. Structural analysis was achieved by the use of characterization techniques including network connectivity (NC), x-ray diffraction (XRD), x-ray photoelectron spectroscopy (XPS) and Fourier transform infrared spectroscopy (FTIR).

\subsection{Materials and methods}

\subsubsection{Glass synthesis process}

\subsubsection{Preparation and determination of glass network connectivity}

Five glasses were proposed for this study, a $\mathrm{Ta}_{2} \mathrm{O}_{5}$-free $\mathrm{SiO}_{2}-\mathrm{ZnO}-\mathrm{CaO}-\mathrm{SrO}-\mathrm{P}_{2} \mathrm{O}_{5}$ glass $(\mathrm{TaO})$ and four $\mathrm{Ta}_{2} \mathrm{O}_{5}$-containing glasses, $\mathrm{Tal}$ to $\mathrm{Ta} 4$ (see Table 3.1).

The $\mathrm{NC}$ of the glass series was calculated using Eq. 3.1 considering the molar compositions of the formulated glasses (Table 3.1) where $\mathrm{SiO}_{2}$ and $\mathrm{P}_{2} \mathrm{O}_{5}$ are considered as network formers [286,287], $\mathrm{CaO}$ and $\mathrm{SrO}$ as network modifiers [287] and $\mathrm{Ta}_{2} \mathrm{O}_{5}$ and $\mathrm{ZnO}$ as intermediates [280,288-290]. The authors assume the following conditions for the network intermediates:

$\mathrm{NC}^{1}: \mathrm{Ta}_{2} \mathrm{O}_{5}$ and $\mathrm{ZnO}$ as network formers, $\mathrm{NC}^{2}: \mathrm{Ta}_{2} \mathrm{O}_{5}$ and $\mathrm{ZnO}$ as network modifiers, $\mathrm{NC}^{3}: \mathrm{Ta}_{2} \mathrm{O}_{5}$ as a network former and $\mathrm{ZnO}$ as a network modifier and $\mathrm{NC}^{4}: \mathrm{Ta}_{2} \mathrm{O}_{5}$ as a network modifier and $\mathrm{ZnO}$ as a network former.

$$
N C=2+\left[\frac{B O-N B O}{G}\right]
$$

Where $\mathrm{BO}$ is the total fractional number of bridging oxygen per network-forming ion (for example two per $\mathrm{SiO}_{2}$ or one per $\mathrm{ZnO}$ ), $\mathrm{NBO}$ is the total fractional number of non-bridging oxygen per network-modifier ion (for example two per $\mathrm{Sr}^{2+}$ ), and $\mathrm{G}$ is the total number of glass-forming units (for example two per $\mathrm{Ta}_{2} \mathrm{O}_{5}$ or one per $\mathrm{SiO}_{2}$ ) [291]. 


\subsubsection{Glass firing and powder production}

Appropriate amounts of analytical grade reagents (Fisher Scientific, Ottawa and SigmaAldrich, Oakville, both Canada) were weighed out and mixed into a container. The container was shaken for $15 \mathrm{~min}$ and then sieved through a $<90 \mu \mathrm{m}$ mesh. Silica crucibles and a Lindberg/Blue M model furnace (Lindberg/Blue M, Asheville, NC USA) with a UP550 controller were used for melting the sieved powders $\left(1550^{\circ} \mathrm{C}, 1 \mathrm{hr}\right)$. The melts were shock quenched in water to obtain frit which was then dried in the oven $\left(100^{\circ} \mathrm{C}, 1 \mathrm{hr}\right.$ ), ground using a ball mill (400 RPM, $\left.15 \mathrm{~min}\right)$, and sieved once more through a $45 \mu \mathrm{m}$ mesh. The obtained glass powders of the selected compositions were then used for characterization purposes.

Table 3.1: Composition of glass series in mole percentage.

\begin{tabular}{cccccc}
\hline Oxide & $T a 0$ & $T a 1$ & $T a 2$ & $T a 3$ & $T a 4$ \\
\hline $\mathrm{SiO}_{2}$ & 48 & 48 & 48 & 48 & 48 \\
$\mathrm{ZnO}$ & $\mathbf{3 6}$ & $\mathbf{3 4}$ & $\mathbf{3 2}$ & $\mathbf{3 0}$ & $\mathbf{2 8}$ \\
$\mathrm{CaO}$ & 6 & 6 & 6 & 6 & 6 \\
$\mathrm{SrO}$ & 8 & 8 & 8 & 8 & 8 \\
$\mathrm{P}_{2} \mathrm{O}_{5}$ & 2 & 2 & 2 & 2 & 2 \\
$\mathrm{Ta}_{2} \mathrm{O}_{5}$ & $\mathbf{0}$ & $\mathbf{2}$ & $\mathbf{4}$ & $\mathbf{6}$ & $\mathbf{8}$ \\
\hline
\end{tabular}

\subsubsection{Material characterization}

\subsubsection{X-ray diffraction}

A Bruker D2 Phaser desktop X-ray diffractometer (Bruker AXS Inc., WI, USA) was used to obtain X-ray diffraction patterns at room-temperature $\left(23 \pm 1{ }^{\circ} \mathrm{C}\right)$. Glass powder samples were packed into stainless steel sample holders. With the X-ray generator set at $45 \mathrm{kV}$ and $30 \mathrm{~mA}$, a copper anode was used to produce a divergent beam with an average K $\alpha$ wavelength of 1.541874 $\AA$. The range of $10-80^{\circ} 2 \theta$ with a step size of $0.02^{\circ} 2 \theta$ and a count time of $10 \mathrm{sec}$ per step were used for the measurements. X'Pert Highscore ${ }^{\mathrm{TM}}$ data analysis software version $1.0 \mathrm{~d}$ (PANalytical, Almelo, The Netherlands) was employed to find peak parameters.

\subsubsection{Thermal analysis}

Simultaneous thermal gravimetric analysis-differential thermal analysis (TGA-DTA) was used to study the thermal properties of the formulated glasses. These analyses were performed using a Netzsch STA 449 analyzer (Erich Netzsch GmbH \& Co., Holding KG, Selb, Germany). A heating rate of $20^{\circ} \mathrm{C} / \mathrm{min}$ was employed using air atmosphere with alumina in a matched platinum crucible as a reference and then cooled to room temperature at the same rate. Sample measurements were carried out every $6 \mathrm{sec}$ between $25^{\circ} \mathrm{C}$ and $1000^{\circ} \mathrm{C}$. 


\subsubsection{X-ray photoelectron spectroscopy}

The powders' chemical compositions as well as local chemical environment were analyzed using PHI Quantera X-ray photoelectron Spectroscopy (Scanning X-ray Microprobe, Physical Electronics, Inc., MN) in a vacuum chamber. The XPS data sets were collected with $\mathrm{Al} \mathrm{Ka} \mathrm{X}$ rays (monochromatic, beam size $=100 \mu \mathrm{m}$ ) at an output power of 26.2 watts, with a photon energy of $1486.6 \mathrm{eV}$ and a step size of $\sim 0.025 \mathrm{eV}$. Survey scans $(\sim 0.5 \mathrm{eV}$ step size $)$ were performed with a pass energy of $140 \mathrm{eV}$ to gain qualitative information such as peak identification and peak position. Peaks identified in all survey scans were used to adjust high resolution scan binding energy range, pass energy $(26 \mathrm{eV})$ and beam dwelling time ( $100 \mathrm{~ms})$. The beam sweeps for each high resolution scan was adjusted to yield a signal-to-noise ratio of $>100: 1$. The analyzed area was 1-2 $\mathrm{mm}$ in diameter.

\subsubsection{Fourier transform infrared spectroscopy study}

Infra-red spectra of the powders were recorded using a Fourier transform infrared spectrometer (Spectrum One FTIR spectrometer, Perkin Elmer Instruments, USA). $\sim 0.3 \mathrm{~g}$ of the prepared glass powder was placed on a $\mathrm{NaCl}$ crystal discs of $25 \mathrm{~mm}$ diameter and spread using a spatula to form a thin film. The FTIR spectrum was collected after background correction. The sample and the reference background spectra were collected 400 times for each glass formulation in ambient air $\left(23 \pm 1{ }^{\circ} \mathrm{C}\right)$. Analysis was performed in the wavenumber ranging from 400 to 4000 $\mathrm{cm}^{-1}$ with a spectral resolution of $4 \mathrm{~cm}^{-1}$.

\subsection{Results}

\subsubsection{Glass network connectivity}

The calculated NCs for the glass series (Table 3.2) exhibited a value of 3.2 for all compositions for $\mathrm{NC}^{1}\left(\mathrm{Ta}_{2} \mathrm{O}_{5}\right.$ and $\mathrm{ZnO}$ as network formers), a value of 2.0 for all glasses for $\mathrm{NC}^{2}$ ( $\mathrm{Ta}_{2} \mathrm{O}_{5}$ and $\mathrm{ZnO}$ as network modifiers), an increase from $2.0(\mathrm{Ta})$ to $2.5(\mathrm{Ta} 4)$ for $\mathrm{NC}^{3}\left(\mathrm{Ta}_{2} \mathrm{O}_{5}\right.$ as a network former and $\mathrm{ZnO}$ as a network modifier), and a decrease from 3.2 ( $\mathrm{Ta} 0$ ) to 3.1 (Ta4) for $\mathrm{NC}^{4}\left(\mathrm{Ta}_{2} \mathrm{O}_{5}\right.$ as a network modifier and $\mathrm{ZnO}$ as a network former).

Table 3.2: Network connectivity values of the glass series being evaluated in this study.

\begin{tabular}{cccccc}
\hline & Ta0 & Ta1 & Ta2 & Ta3 & Ta4 \\
\hline $\mathrm{NC}^{1}$ & 3.2 & 3.2 & 3.2 & 3.2 & 3.2 \\
$\mathrm{NC}^{2}$ & 2.0 & 2.0 & 2.0 & 2.0 & 2.0 \\
$\mathrm{NC}^{3}$ & 2.0 & 2.1 & 2.3 & 2.4 & 2.5 \\
$\mathrm{NC}^{4}$ & 3.2 & 3.2 & 3.1 & 3.1 & 3.1 \\
\hline
\end{tabular}




\subsubsection{Glass structural and thermal characterization}

\subsubsection{X-ray diffraction}

$\mathrm{X}$-ray diffraction patterns were recorded for each of the glasses and are presented in Figure 3.1. A single crystalline peak (identified using X'Pert Highscore ${ }^{\mathrm{TM}}$ data analysis software as $\mathrm{SiO}_{2}$, reference code: 00-033-1) was seen in the XRD patterns obtained from Ta2, Ta3 and Ta4.

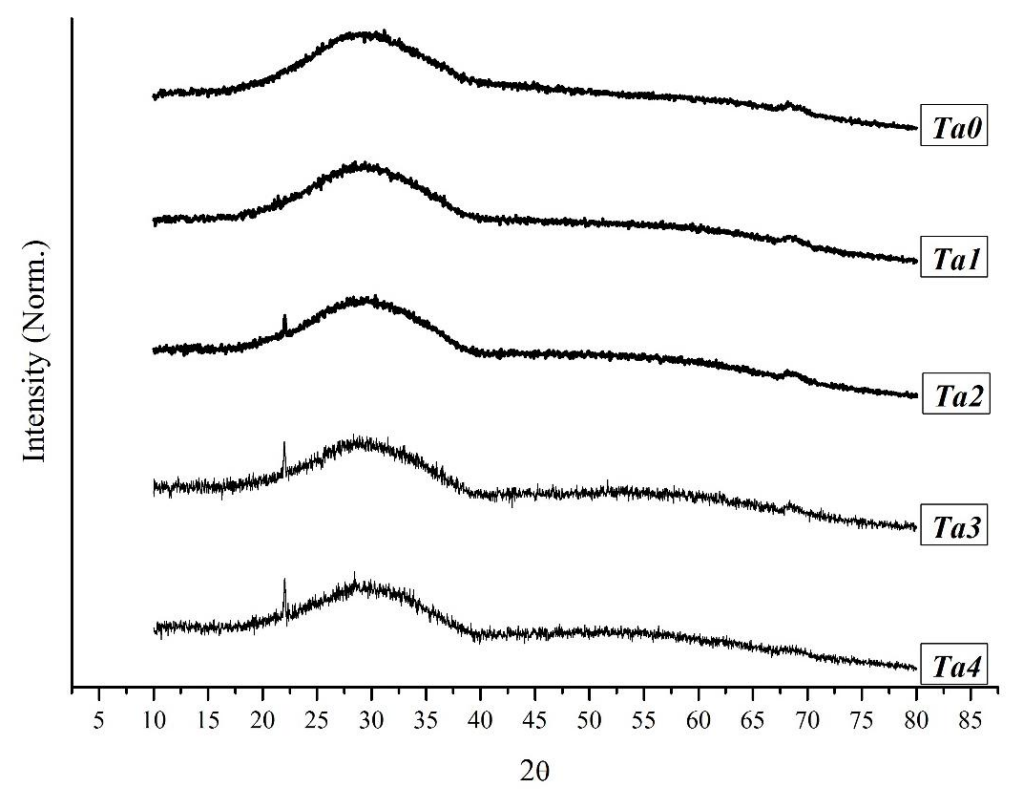

Figure 3.1: XRD traces for the synthesized glass powders.

\subsubsection{Thermal analysis}

Glass transition $\left(T_{g}\right)$ and crystallization $\left(T_{c}\right)$ temperatures were observed for all glasses in the series while the melting temperature $\left(T_{m}\right)$ was observed only for TaO and Tal. The thermal events are reported in Table 3.3 together with the thermal stability values $\left(T_{c}-T_{g}\right)$. It is observed that all temperatures as well as the glass thermal stability increase in function of $\mathrm{Ta}_{2} \mathrm{O}_{5}$ content. Samples $\mathrm{Ta} 2, \mathrm{Ta} 3$ and $\mathrm{Ta} 4$ do not melt under these experimental conditions until temperatures greater than $1000{ }^{\circ} \mathrm{C}$ are reached.

Table 3.3: Thermal properties $\left({ }^{\circ} \mathrm{C}\right)$ of the glass series $(n=1)$ as a function of $\mathrm{Ta}_{2} \mathrm{O}_{5}$ content incorporated on the expense of $\mathrm{ZnO}$.

\begin{tabular}{cccccc}
\hline & TaO & Ta1 & Ta2 & Ta3 & Ta4 \\
\hline$T_{g}\left({ }^{\circ} \mathrm{C}\right)$ & 710 & 716 & 720 & 727 & 739 \\
$T_{c}\left({ }^{\circ} \mathrm{C}\right)$ & 872 & 882 & 910 & 970 & 989 \\
$T_{m}\left({ }^{\circ} \mathrm{C}\right)$ & 968 & 986 & - & - & - \\
$T_{c}-T_{g}\left({ }^{\circ} \mathrm{C}\right)$ & 162 & 166 & 190 & 243 & 250 \\
\hline
\end{tabular}




\subsubsection{X-ray photoelectron spectroscopy}

The XPS survey spectrum of the glass series is shown in Figure 3.2. Besides the expected $\mathrm{Si} 2 \mathrm{p}, \mathrm{Zn} 2 \mathrm{p} 3, \mathrm{Ca} 2 \mathrm{p}, \mathrm{Sr} 3 \mathrm{~d} 5, \mathrm{P} 2 \mathrm{~s}$ and Ta4d and O1s peaks, a C1s peak can be seen in all the samples tested. This relates to 'adventitious carbon', present due to the adsorption of impurities during the glass firing process.

The elemental compositions of the observed electronic configurations including Si2p, Zn2p3, $\mathrm{Ca} 2 \mathrm{p}, \mathrm{Sr} 3 \mathrm{~d} 5, \mathrm{P} 2 \mathrm{~s}$ and Ta4d are presented in Table 3.4, from which it is obvious that the actual glass compositions varied slightly from the proposed formulations.

O1s spectra of the glass series are presented in Figure 3.3. A slight asymmetry in the O1s high resolution spectra is apparent, i.e the O1s peak shifts to a slightly lower binding energy with increasing $\mathrm{Ta}_{2} \mathrm{O}_{5}$ content, replacing $\mathrm{ZnO}$. Thus, two different types of oxygen sites ( $\mathrm{BO}$ and NBO) in these glasses were identified and are shown in Figure 3.4 for $T a 0$ glass. From this, a NBO appears at a lower binding energy than a BO. Table 3.5 provides detailed information obtained from the O1s core level peaks for all glass compositions. As seen in Figure 3.3 and Table 3.5, the O1s spectra show slight composition-dependent changes. The BO peak shifted slightly from $532.3 \mathrm{eV}$ to $532.5 \mathrm{eV}$ whereas the NBO peak exhibited similar binding energies ( 531.3), when the content of $\mathrm{Ta}_{2} \mathrm{O}_{5}$ changes from 0 to 8 mole percentage. The difference in the peak position of the $\mathrm{BO}$ and the NBO peaks $\left(\Delta E_{O 1 s}\right)$ was measured (Table 3.5). Also, it can be seen that the content (atomic \% (at\%)) of NBO peak increased from 51.9 ( $\mathrm{TaO})$ to 63.0 at\% (Ta4) whereas the BO peak decreased in content from $48.1(\mathrm{TaO})$ to 37.0 at\% ( $\mathrm{Ta} 4$ ), with increasing the $\mathrm{Ta}_{2} \mathrm{O}_{5}$ content from 0 to 8 mole percentage.

High resolution spectra were also obtained for each element contained within the synthesized glasses. Table 3.6 presents the relevant peak position (eV) of the Si2p3, Zn2p3, Ca2p3, Sr3d5 and P2s core levels. Figure 3.5 shows the core level spectra of Ta4d for Ta1, Ta2, Ta3 and Ta4. The spectra exhibit spin-orbit components, attributed to Ta4d3 and Ta4d5, at approximately $242 \mathrm{eV}$ and $231 \mathrm{eV}$, respectively. Figure 3.6 exhibits the presence of two separate overlapping contributions for each component of the main Ta4d spectra. Table 3.7 presents the peak positions

of the overlapping curves of the Ta4d3 and Ta4d5 peaks and their corresponding at\%, obtained from curve fitting of the main Ta4d peak of the Ta-containing glasses. 


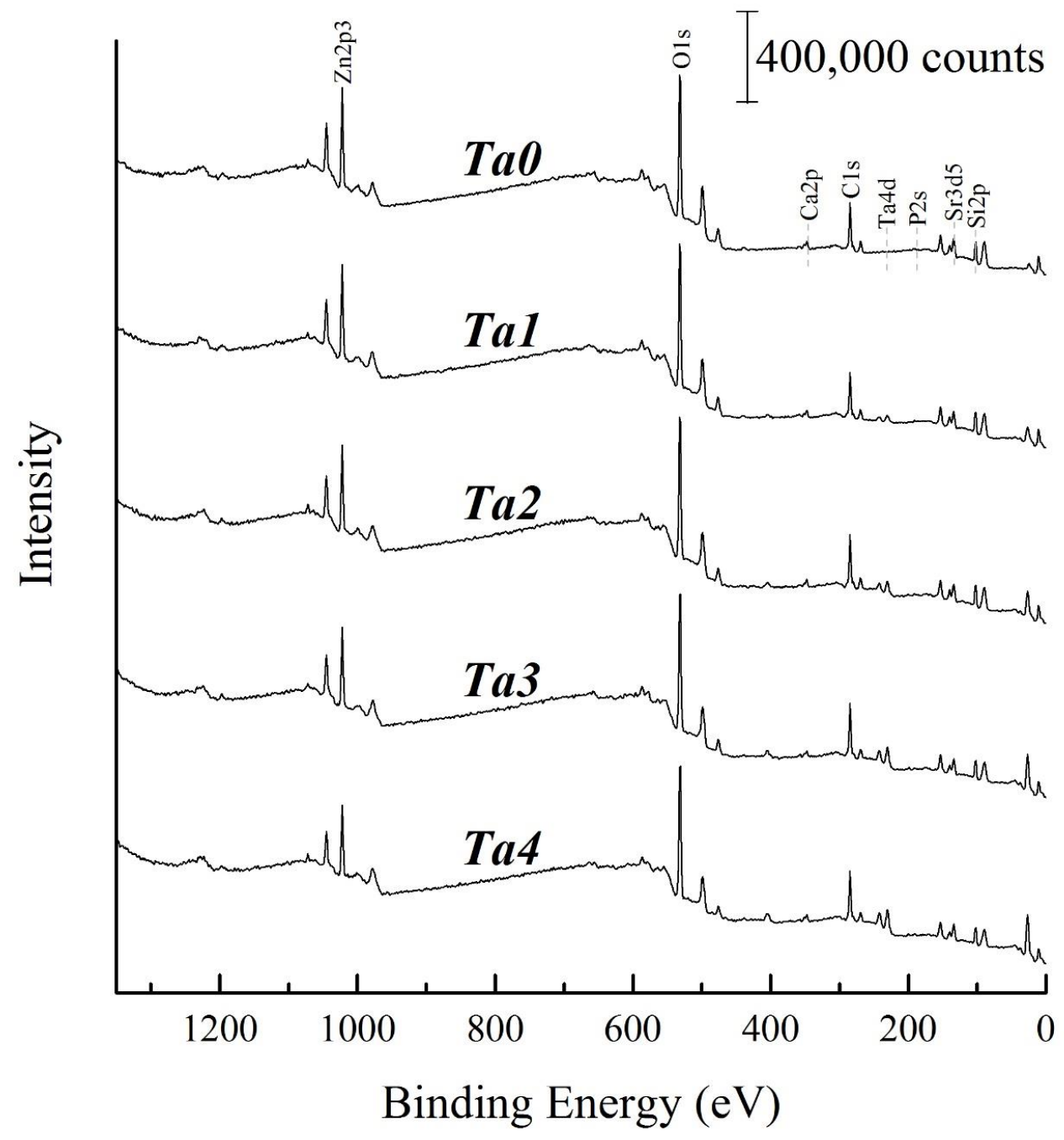

Figure 3.2: Wide scan XPS spectra from the surface of the glass series being investigated.

Table 3.4: Actual glass compositions (at.\%) as determined by XPS.

\begin{tabular}{lccccc}
\hline Peaks & TaO & Tal & Ta2 & Ta3 & Ta4 \\
\hline Si2p & 54.7 & 53.8 & 52.7 & 52.0 & 50.3 \\
Zn2p3 & $\mathbf{2 6 . 0}$ & $\mathbf{2 7 . 0}$ & $\mathbf{2 5 . 8}$ & $\mathbf{2 3 . 3}$ & $\mathbf{2 1 . 7}$ \\
Ca2p & 4.6 & 4.6 & 4.6 & 4.5 & 5.6 \\
Sr3d5 & 6.6 & 6.2 & 6.2 & 6.1 & 6.2 \\
P2s & 8.1 & 5.8 & 5.6 & 6.6 & 6.6 \\
Ta4d & $\mathbf{0 . 0}$ & $\mathbf{2 . 6}$ & $\mathbf{5 . 1}$ & $\mathbf{7 . 5}$ & $\mathbf{9 . 6}$ \\
\hline
\end{tabular}




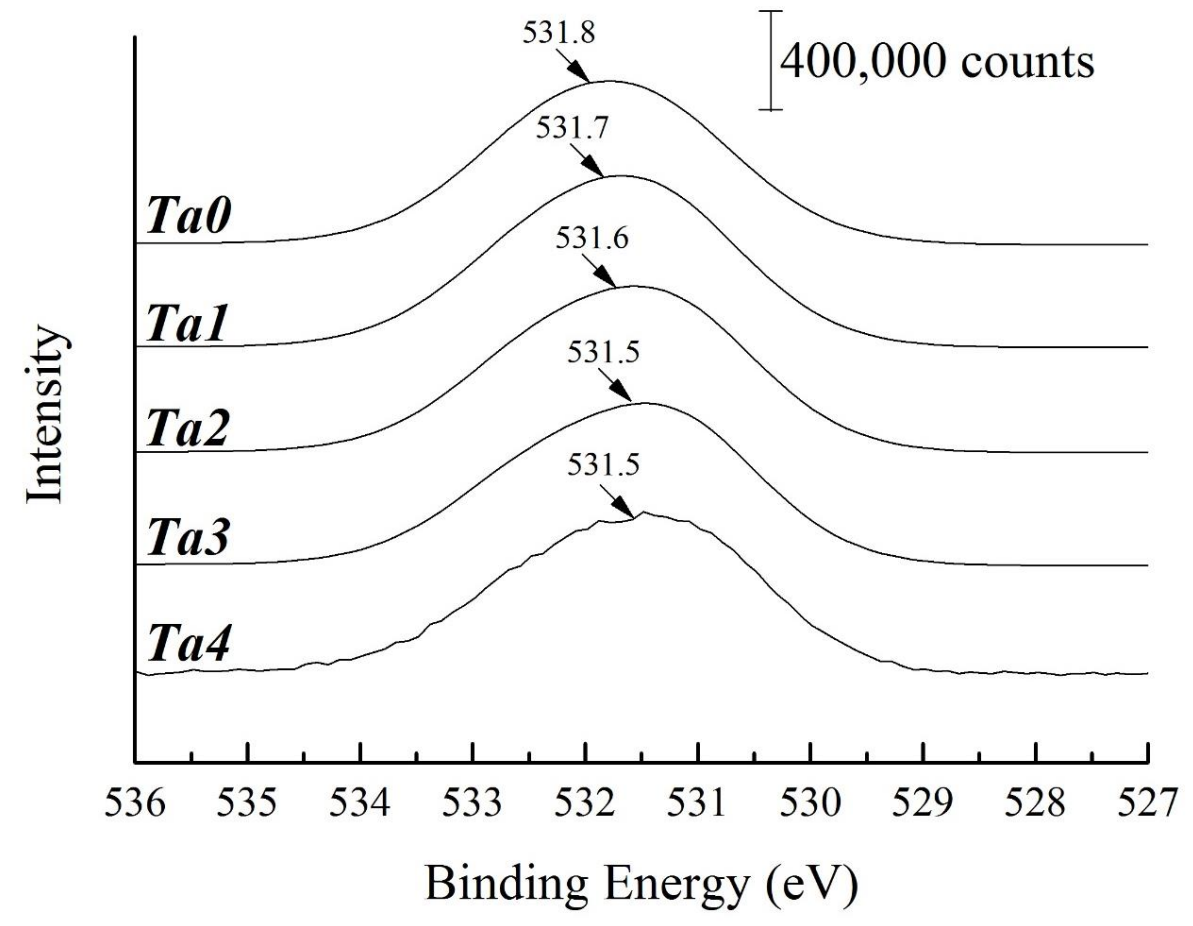

Figure 3.3: The high resolution O1s core level spectra for the glass series.

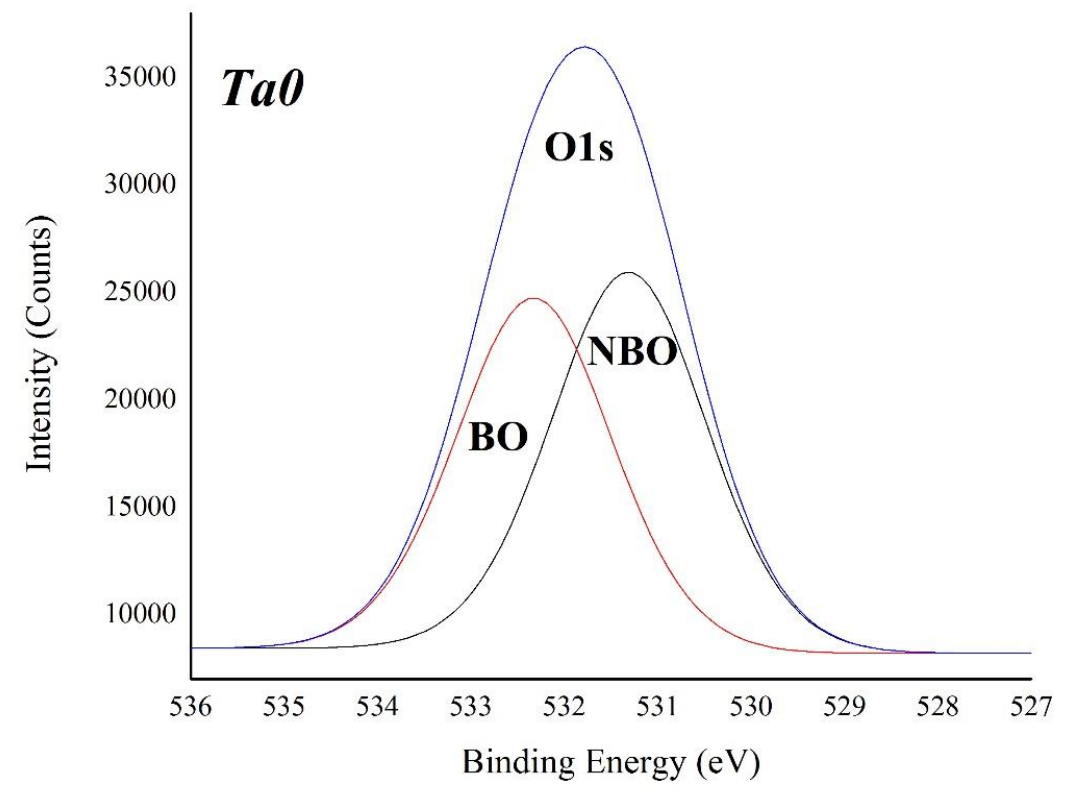

Figure 3.4: Curve fitting of the Ols spectrum for TaO glass with respect to BO and NBO contributions. 
Table 3.5: Peak positions ( $\mathrm{eV}$ ) for the $\mathrm{BO}$ and the NBO peaks and their corresponding at\%, obtained from the curve fitting of the Ols peak, of the glass series.

\begin{tabular}{cccc}
\hline & $\begin{array}{c}\text { O1s (NBO) } \\
\text { at\% }\end{array}$ & $\begin{array}{c}\text { O1s (BO) } \\
\text { at\% }\end{array}$ & $\Delta E_{01 s}$ \\
\hline Ta0 & 531.3 & 532.3 & 1.0 \\
& 51.9 & 48.1 & \\
$T a 1$ & 531.3 & 532.4 & 1.1 \\
& 60.4 & 39.6 & \\
$T a 2$ & 531.2 & 532.4 & 1.2 \\
& 59.4 & 40.7 & \\
$T a 3$ & 531.2 & 532.5 & 1.3 \\
& 62.2 & 37.8 & \\
$T a 4$ & 531.2 & 532.5 & 1.3 \\
& 63.0 & 37.0 & \\
\hline
\end{tabular}

Table 3.6: Peak positions (eV) for the core levels Si2p3, Zn2p3, Ca2p3, Sr3d5 and P2s, obtained from high resolution XPS spectra.

\begin{tabular}{lccccc}
\hline & $T a 0$ & $T a 1$ & $T a 2$ & $T a 3$ & $T a 4$ \\
\hline Si2p3 & 102.2 & 102.2 & 102.2 & 102.2 & 102.2 \\
Zn2p3 & 1022.4 & 1022.4 & 1022.4 & 1022.4 & 1022.4 \\
Ca2p3 & 347.6 & 347.6 & 347.6 & 347.6 & 347.5 \\
Sr3d5 & 133.9 & 133.9 & 133.9 & 133.9 & 133.9 \\
P2s & 191.2 & 191.1 & 191.0 & 190.9 & 190.9 \\
\hline
\end{tabular}

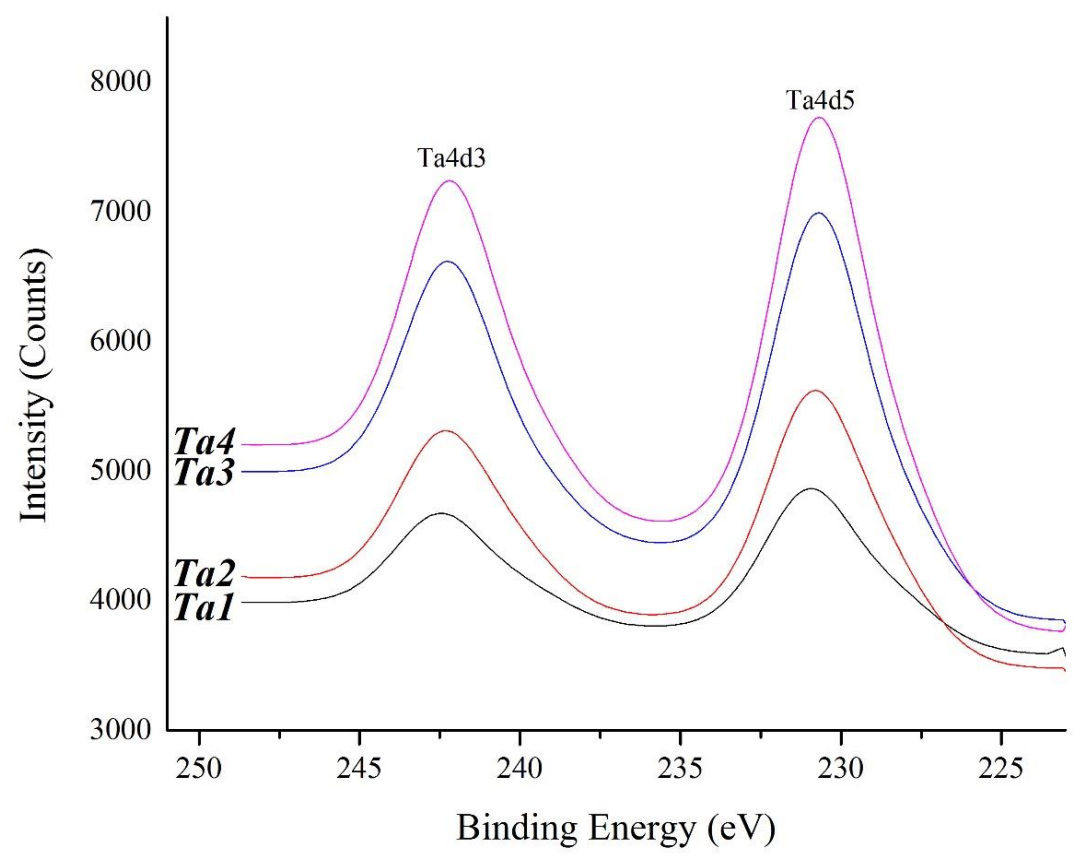

Figure 3.5: Ta4d core level spectra for Ta-containing glasses (Ta1, Ta2, Ta3 and Ta4) 


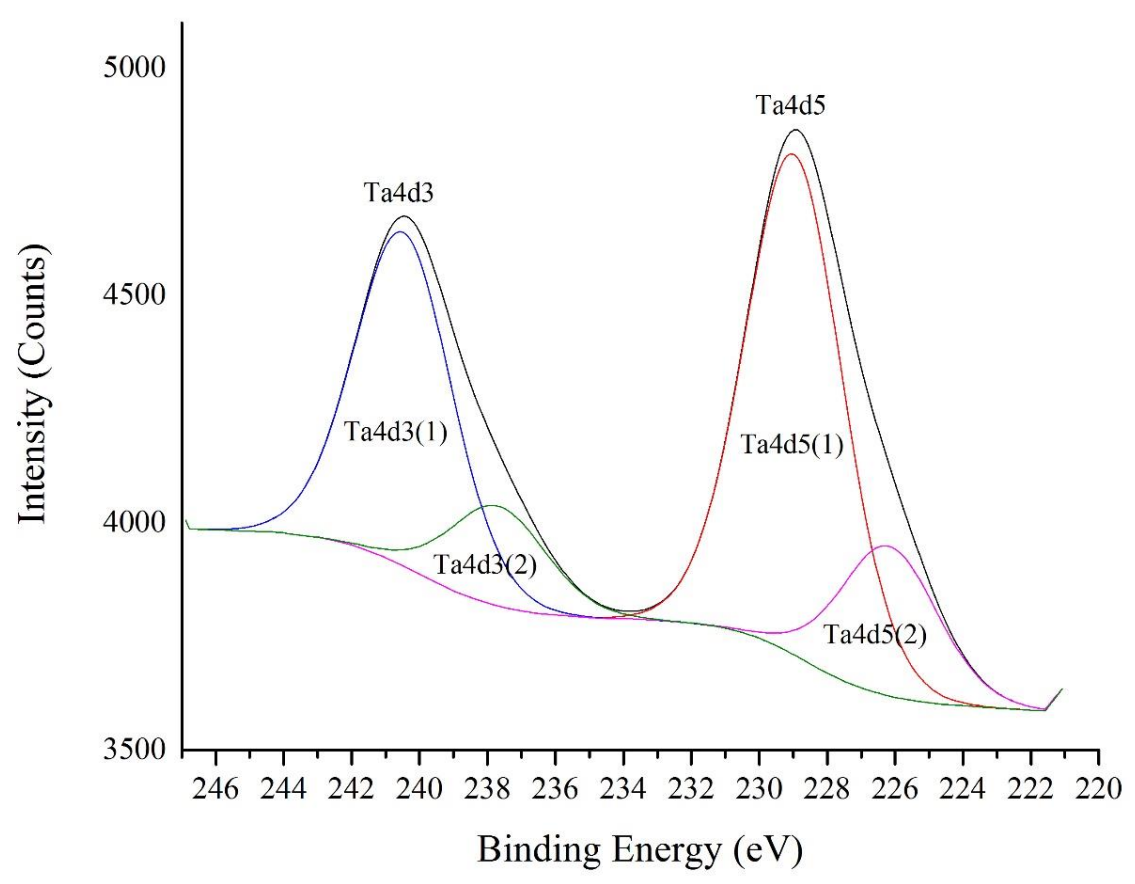

Figure 3.6: Curve fitting of the Ta4d3 and Ta4d5 spectrum for Tal glass.

Table 3.7: Peak positions (eV) from the curve fitting of the Ta4d3 and Ta4d5 peaks and their corresponding at\%, of the Tacontaining glasses.

\begin{tabular}{cccccc}
\hline & $\mathrm{Ta} 0$ & $\mathrm{Tal}$ & $\mathrm{Ta} 2$ & $\mathrm{Ta} 3$ & $\mathrm{Ta} 4$ \\
\hline Ta4d3(1) & - & 242.5 & 242.4 & 242.2 & 242.2 \\
at\% & 0.0 & 0.0 & 0.0 & 0.0 & 0.0 \\
Ta4d3(2) & - & 239.7 & 239.9 & 239.4 & 239.5 \\
at\% & 0.0 & 0.0 & 0.0 & 0.0 & 0.0 \\
Ta4d5(1) & - & 231.0 & 231.0 & 230.7 & 230.7 \\
at\% & 0.0 & 77.0 & 77.0 & 83.1 & 81.2 \\
Ta4d5(2) & - & 228.2 & 228.4 & 227.9 & 228.0 \\
at\% & 0.0 & 23.0 & 23.0 & 16.9 & 18.8 \\
\hline
\end{tabular}

\subsubsection{Fourier transform infrared spectroscopy study}

FTIR transmittance spectra are presented in Figure 3.7 in the range $4000-400 \mathrm{~cm}^{-1}$ and exhibit significant changes with glass composition. Table 3.8 provides a complete list of the obtained vibration frequencies and their assignments. The shoulder peak shown at $1120 \mathrm{~cm}^{-1}$ sharpens and decreases in intensity with increasing $\mathrm{Ta}_{2} \mathrm{O}_{5}$ content. The band centered at $1000 \mathrm{~cm}^{-1}$ broadens, shifts to lower frequencies and decrease in intensity with increasing $\mathrm{Ta}_{2} \mathrm{O}_{5}$ content. The shoulder peak centered at around $540 \mathrm{~cm}^{-1}$ disappears for $T a 3$ and $T a 4$ glasses. The band centered at 470 $\mathrm{cm}^{-1}$ was similar for all glasses but decreases in intensity with increasing $\mathrm{Ta}_{2} \mathrm{O}_{5}$ content. 


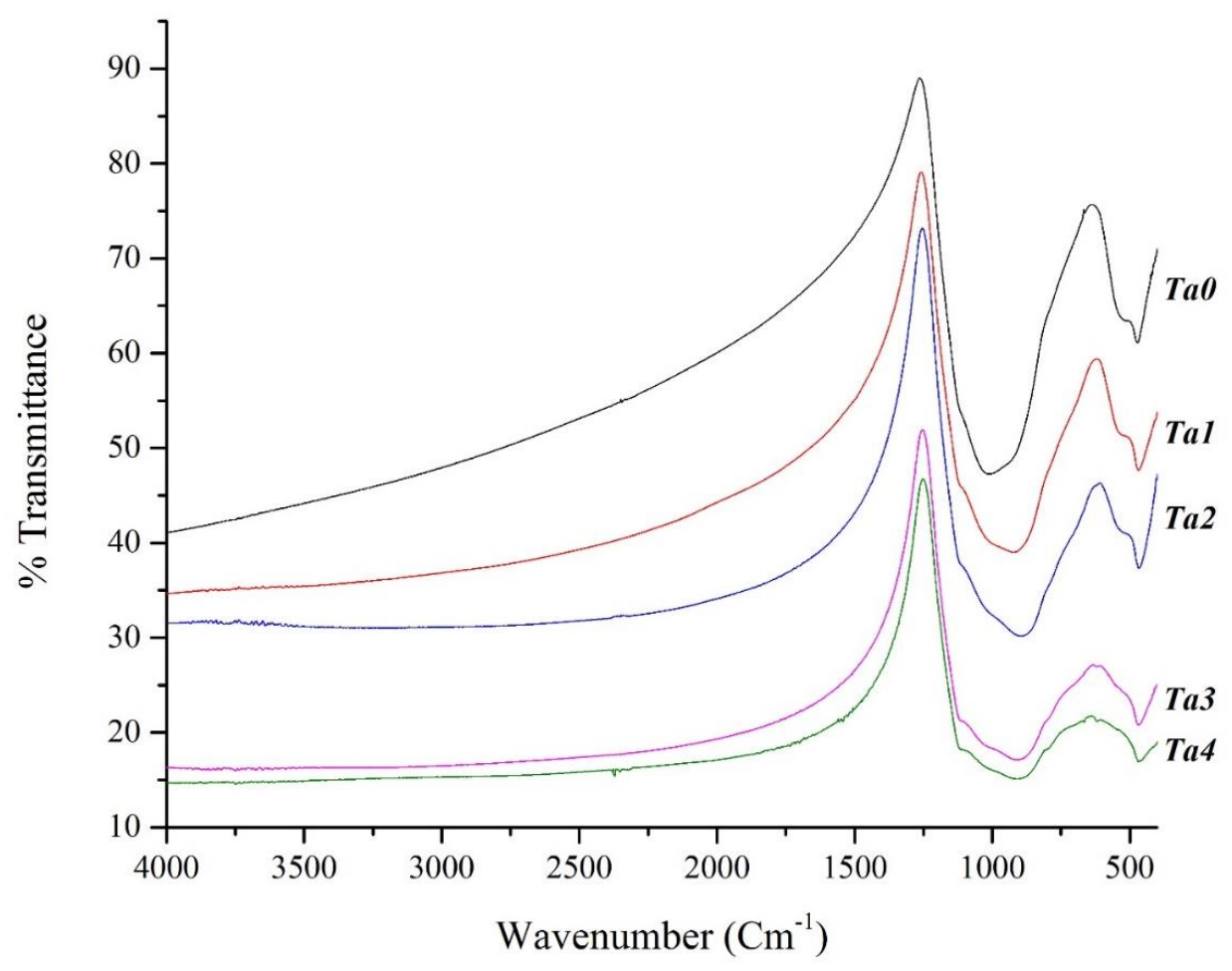

Figure 3.7: FTIR spectra of the glass series.

Table 3.8: FTIR transmittance bands for the glass series

\begin{tabular}{lccccc}
\hline \multirow{2}{*}{ Peak assignments } & \multicolumn{5}{c}{ Wavenumber $\left(\mathrm{cm}^{-1}\right)$} \\
\cline { 2 - 6 } & TaO & Tal & Ta2 & Ta3 & Ta4 \\
\hline Si-O-Si stretching & 1120 & 1120 & 1120 & 1120 & 1120 \\
Si-O stretching & 1000 & 931 & 900 & 908 & 907 \\
$\mathrm{ZnO}_{4}$ & 540 & 545 & 549 & - & - \\
Si-O-Si bending & 470 & 470 & 467 & 470 & 470 \\
\hline
\end{tabular}

\subsection{Discussion}

\subsubsection{Role of network connectivity}

Network connectivity, defined as the average number of bonds that link each repeat unit in the silicate network [292], is based on the relative number of bridging (network forming) and non-bridging (network modifying) species in a glass.

Glasses with NC values < 1.8 may result in high solubility rates, while NC values $>2.4$ results in decreased formation of new bone [291]. An NC value close to 2.0 was recommended by Hill [291] while Edén [293] suggested an NC range between 2.0 and 2.6 for optimum bioactivity. An accepted method of representing $\mathrm{NC}$ in a silica-based glass is by $\mathrm{Q}^{\mathrm{n}}$ units, where $\mathrm{Q}$ represents the $\mathrm{Si}$ tetrahedral unit and $\mathrm{n}$ is the number of $\mathrm{BO}$ ranging from 0 to 4 . $\mathrm{Si}$ is the 
central tetrahedral atom which ranges from $\mathrm{Q}^{0}$ (orthosilicates) $\left[\mathrm{SiO}_{4}\right]^{4-}$ to $\mathrm{Q}^{4}$ (tectosilicates) and $\mathrm{Q}^{1}, \mathrm{Q}^{2}$ and $\mathrm{Q}^{3}$ structures representing intermediate silicates containing modifying oxides such as $\mathrm{Ca}$ and $\operatorname{Sr}[294]$.

Alkaline earth oxides such as $\mathrm{Ca}$ and $\mathrm{Sr}$ offer oxygen for the modification of the glass network formers, such as $\mathrm{Si}^{4+}$ and $\mathrm{P}^{5+}$ ions. Zachariasen's rules for glass formation consider $\mathrm{P}_{2} \mathrm{O}_{5}$ as a network former [295]. Several studies [286,296-298] however have shown that $\mathrm{P}_{2} \mathrm{O}_{5}$ does not form part of the silicate network, but instead forms a separate orthophosphate phase $\left(\mathrm{PO}_{4}^{3-}\right)$. This behavior has been attributed to the key role that phosphate plays in apatite formation onto bioactive glasses. In our study, $\mathrm{P}_{2} \mathrm{O}_{5}$ is added in small amounts (Table 3.1) and, in line with Zachariasen's rules, is assumed to act as a glass network former. During the glass formation process, $\mathrm{PO}_{4}$ is formed and the authors are assuming that the low amounts of phosphate incorporated in our glass system may provide oxygen to form Si-O-P or P-O bonds. However, no "free" $\mathrm{P}^{5+}$ ions would charge balance the NBO ions of the silicate tetrahedra. It has been reported [299] that in glass compositions containing less than $50 \% \mathrm{SiO}_{2}$ and very low $\mathrm{P}_{2} \mathrm{O}_{5}$ amounts (2-5 mole percentage), $\mathrm{PO}_{4}$ groups form and are predominately isolated as orthophosphates $\left(\mathrm{PO}_{4}^{3-}\right)$. Even in the presence of orthophosphates, $\mathrm{P}-\mathrm{O}$ bonds are covalent and $\mathrm{P}$ is a network former.

The role of $\mathrm{Zn}^{2+}$ is intermediary, either as a network former $\left(\mathrm{ZnO}_{4}\right)$ or as a network modifier $\left(\mathrm{ZnO}_{6}\right)$. Transition metals such as $\mathrm{Ta}$ and $\mathrm{Zn}$ vary their coordination number depending on their content and the composition of the glass matrix [289,300-302]. The variation in the coordination number of transition metals is assumed to modify the network structure. It has been reported that when $\mathrm{Ta}_{2} \mathrm{O}_{5}$ is added in small quantities to the glass matrix, it forms isolated $\mathrm{TaO}_{6}$ octahedra $[278,303]$. As the Ta content increases, the octahedral favors corner sharing and the number of Ta-Ta links increases resulting in higher network connectivity, strengthening the glass network [278]. Infrared and Raman spectroscopic studies have shown that Ta can also be inserted in the glass matrix in the form of other coordination numbers such as $\mathrm{TaO}_{4}$ [301], and $\mathrm{TaO}_{7}$ [288]. In general, $\mathrm{Ta}$ is inserted in the glass network in the form of $\mathrm{TaO}_{6}$ clusters with a valence state of 5+ [278,280,288]. Decreasing $\mathrm{ZnO}$ content in a glass system would cause the system to require fewer modifier ions such as $\mathrm{Ca}^{2+}$ and $\mathrm{Sr}^{2+}$ to balance the charge. However, in our system $\mathrm{ZnO}$ is replaced with $\mathrm{Ta}_{2} \mathrm{O}_{5}$ which is assumed to increase the $\mathrm{NC}$ as it requires more network modifiers from the network to balance the charge of the complex, resulting in decreased ion dissolution 
rates. Further discussions will provide more details on the role of $\mathrm{Ta}_{2} \mathrm{O}_{5}$ and $\mathrm{ZnO}$ in our glass series.

\subsubsection{Glass structural and thermal characterization}

A single crystalline peak, contained within the amorphous matrix, was seen in the XRD patterns obtained from $\mathrm{Ta}$, $\mathrm{Ta} 3$ and $\mathrm{Ta} 4$. This peak, identified by the software as $\mathrm{SiO}_{2}$, matched with that found in tantalum alkali-germanate glasses [288] where it was attributed to orthorhombic $\mathrm{Ta}_{2} \mathrm{O}_{5}$. The authors assume that the diffraction peak observed in Ta-containing samples (Ta2, $\mathrm{Ta} 3$ and $\mathrm{Ta} 4$ ) is attributed to $\mathrm{SiO}_{2}$ taking into account the $\mathrm{SiO}_{2}: \mathrm{Ta}_{2} \mathrm{O}_{5}$ ratios, as predicted from Table 3.1.

STA was performed to investigate the effect of replacing $\mathrm{ZnO}$ with $\mathrm{Ta}_{2} \mathrm{O}_{5}$ on the thermal properties of the glass series. Results (Table 3.3) indicate that structural changes are occurring within the glass network as $\mathrm{Ta}_{2} \mathrm{O}_{5}$ replaces $\mathrm{ZnO}$. Similar behavior has been reported in the literature $[280,304,305]$ for bio-glass systems containing transition metal oxides. The oxygen ions of transition metals are usually close-packed with the smaller metal ions situated in the octahedral and tetrahedral holes among the oxygen ions. Therefore, increasing the content of a transition metal such as Ta increases the solubility of the oxide in the glass former and allows for its insertion inside the glass network [305-307]. In general, transition metal ions behave as network intermediates with formation of cross-linking bonds between the covalent chains within the glass network structure. Thus, $\mathrm{Ta}^{5+}$ can be assumed to enter the silicate network in six or seven-fold coordination $\left(\mathrm{TaO}_{6}, \mathrm{TaO}_{7}\right)$. The crosslinking between the $\mathrm{Ta}_{2} \mathrm{O}_{5}$ units and the silicate network of the glasses studied here is evident from the results obtained in Table 3.3 and agrees with our earlier NC discussions. Results in Table 3.3 have also shown increased glass stability $\left(T_{c}-T_{g}\right)$ with increasing $\mathrm{Ta}_{2} \mathrm{O}_{5}$ content which can be attributed to the formation of additional TaO-Ta species, agreeing with the literature [308]. The increase in the glass thermal stability as a function of $\mathrm{Ta}_{2} \mathrm{O}_{5}$ indicates a greater glass forming tendency and a delay in the nucleation process [288]. However, this may be contradicted in the results of our study, where the addition of $\mathrm{Ta}_{2} \mathrm{O}_{5}$ appears to result in a single crystalline peak within an amorphous matrix. The thermal properties reported in this study indicate that the small degree of crystallinity within Ta2, Ta3 and $\mathrm{Ta} 4$ samples can be attributed to the incorporation of $\mathrm{Ta}_{2} \mathrm{O}_{5}$ which may serve to increase the melting temperature required to ensure homogeneity of the melt. 
XPS (Figure 3.2) confirmed the initial glass composition and showed the electronic configurations or the core levels associated with each of the glass cations. It is clear from Table 3.4 that the elemental composition as determined by XPS varied slightly from the precursor glass formulations. An important result extracted from this elemental composition is that the content of $\mathrm{Zn}$, determined by XPS, was reduced by $\sim 10 \%$ for $\mathrm{Ta} 0$, and by $\sim 6-7 \%$ for the Tacontaining glasses ( $\mathrm{Ta1}, \mathrm{Ta}$, Ta3 and Ta4), when compared to the calculated formulations. It seems that $\mathrm{ZnO}$ did not completely melt in the Ta-free glass $(\mathrm{TaO})$, however the incorporation of $\mathrm{Ta}_{2} \mathrm{O}_{5}$ had resulted in better approximation of the glass composition to the initial batch calculation. Further, in the original glass formulations, $\mathrm{ZnO}$ content is highest for $\mathrm{TaO}$ glass. However, there was an unexpected increase in recorded $\mathrm{ZnO}$ content for Tal (27.0 at\%) when compared to $\mathrm{TaO}$ (26.0 at\%), as determined by XPS. This is expected to cause slight changes in the structure of the glass. The reason behind the significant increase in the content of P2s, when comparing its values in Table 3.4 and Table 3.1 is not understood. However it could have resulted from the fact that P2s and Sr3d5 peaks overlap and appear to have similar binding energy ( 134 $\mathrm{eV}$ ) in the XPS high resolution scans. It is important to note that XPS is a surface technique and therefore explanations offered around the actual glass composition are subject to the assumption that the bulk of the glass is similar in composition to the surface. The vacuum cleaved O1s spectrum was also obtained. It is apparent from Figure 3.3 and Table 3.5 that the O1s peak position shifted to slightly lower binding energies (531.8 eV for TaO to $531.5 \mathrm{eV}$ for Ta4) and that the $\mathrm{BO} / \mathrm{NBO}$ ratio decreased, as a function of $\mathrm{Ta}_{2} \mathrm{O}_{5}$ content. This is a result of different variables and can be attributed to one or more of the following reasons:

a) The decreased content of network formers $\left(\mathrm{SiO}_{2}, \mathrm{P}_{2} \mathrm{O}_{5}\right.$ and $\left.\mathrm{ZnO}\right)$ as $\mathrm{ZnO}$ is replaced with $\mathrm{Ta}_{2} \mathrm{O}_{5}$ (Table 3.4).

b) The lower the amount of $\mathrm{ZnO}$ in the system, the higher the number of glass modifying $\mathrm{ZnO}_{6}$ units and the lesser the number of glass forming $\mathrm{ZnO}_{4}$ units.

c) A change in the electronegativity of the bonding environment; i.e., the electron charge density near the oxide atom is changed due to the decrease in the glass forming $\mathrm{ZnO}_{4}$ units and an increase in both the modifying $\mathrm{ZnO}_{6}$ units and the forming $\mathrm{TaO}_{6}$ units. Also this could simply result from the difference in the physical properties of both metals, i.e the higher electronegativity of $\mathrm{Zn}$ (1.65), compared to Ta (1.5), leads to stronger bonds with oxygen. 
Chemical bonding in a compound usually causes a change in the binding energy of several valence states within it [309]. This is called 'chemical shift'. It is obvious from Table 3.6 that $\mathrm{Si} 2 \mathrm{p} 3, \mathrm{Zn} 2 \mathrm{p} 3$ and Ca2p3 did not undergo significant changes in their peak positions. Sr3d5 remained at $133.9 \mathrm{eV}$ regardless of $\mathrm{Ta}_{2} \mathrm{O}_{5}$ content. P2s also presented similar binding energies $(\sim 191 \mathrm{eV})$ for all glasses. It was assumed that $\mathrm{P}$ acts as a glass former and that was based on the fact that very small quantities $(2 \%)$ were added to the glass. However the actual glass composition showed that $\mathrm{P}$ values reached up to $8 \%$. As explained earlier, this may have resulted from the peak overlap of the $\mathrm{P}$ and Sr cations. The peak position of $\mathrm{P}$ (as shown in Table 3.6) may indicate that $\mathrm{PO}_{4}$ groups are available within the glass compositions and are isolated as orthophosphates. This is in good agreement with previous experimental NMR and Raman data for bioactive glasses [286,310], which indicated that the $\mathrm{Q}^{\mathrm{n}}$ distributions for glass structures containing small amounts (2-5 mole percentage) of $\mathrm{P}_{2} \mathrm{O}_{5}$ are predominately $\mathrm{Q}^{2}$.

Analysis of the core level of Ta showed interesting results with respect to $\mathrm{Ta}_{2} \mathrm{O}_{5}$ content. The two doublet peaks attributed to Ta4d3 and Ta4d5 (Figure 3.5), and their corresponding components (shown in Figure 3.6) in the Ta4d spectra have essentially the same binding energies (Table 3.7) for all glass compositions independent of $\mathrm{Ta}_{2} \mathrm{O}_{5}$ content. Thus, it is assumed that Ta is present in all glasses with a stable oxidation state $\left(\mathrm{Ta}^{5+}\right)$. The concentration of both components of the Ta4d3 peak was found to be 0.0 at $\%$. The concentration of Ta4d5(1) peak however, increased from 0 at\% ( $\mathrm{TaO})$ to 81.2 at\% ( $\mathrm{Ta} 4)$ while Ta4d5(2) varied between 0.0 at\% (TaO) and 23.0 at\% (Tal). Results obtained for the Ta4d5 peak and its components of the Ta4d core level may have resulted from changes in the molecular environment within the glass structure.

In general, the glasses being investigated are assumed to have isolated $\mathrm{TaO}_{6}$ units with $\mathrm{Si}-\mathrm{Ta}$ and P-Ta linkages that contribute to the glass network. As $\mathrm{Ta}_{2} \mathrm{O}_{5}$ content increases on the expense of $\mathrm{ZnO}$, the number of $\mathrm{ZnO}_{4}$ units decrease thus introducing more NBOs. The number of Ta-Ta linkages is expected to increase, leading to corner sharing and to more $\mathrm{TaO}_{6}$ units connected to each other. This will result in the formation of a three dimensional network of corner sharing $\mathrm{TaO}_{6}$ octahedra which take the role of a network former, strengthening the network by eliminating NBO atoms that are introduced into the network due to the increase in the $\mathrm{ZnO}_{6}$ glass modifying cations, as $\mathrm{Ta}_{2} \mathrm{O}_{5}$ is replaced with $\mathrm{ZnO}$. The ability of the $\mathrm{Zn}$ cation to accommodate six oxygen neighbors, when more oxygen is available, has been reported in the literature [289]. This explanation indicates that Ta favors glass formation whereas the $\mathrm{Zn}$ atoms 
acts as a network intermediate in the formulated glasses. Further analysis using FTIR is provided to further understand the structural changes within the glass structure as a result of increasing $\mathrm{Ta}_{2} \mathrm{O}_{5}$ content on the expense of $\mathrm{ZnO}$.

FTIR can detect and quantify local changes in glass structural symmetry. The infrared shoulder band centered at $1120 \mathrm{~cm}^{-1}$ in Figure 3.7 is attributed to Si-O-Si stretching mode vibrations [290]. The sharpening and decrease in intensity of this band with increasing $\mathrm{Ta}_{2} \mathrm{O}_{5}$ content suggests a change in the neighborhood of $\mathrm{SiO}_{4}$ units and is attributed to the increased presence of $\mathrm{TaO}_{6}$ units connected to $\mathrm{SiO}_{4}$. This is in good agreement with the assumption of $\mathrm{TaO}_{6}$ insertion in the silicate network resulting in the formation of "cross" Si-O-Ta linkages and "self" Ta-O-Ta linkages. However considering the $\mathrm{SiO}_{2}: \mathrm{Ta}_{2} \mathrm{O}_{5}$ ratio in the formulated glasses, this peak was assigned to Si-O-Si and the observations obtained are attributed to the chemical changes resulting from replacing the $\mathrm{ZnO}$ with $\mathrm{Ta}_{2} \mathrm{O}_{5}$. Similar behavior was observed in the $\mathrm{GeO}_{2}-\mathrm{K}_{2} \mathrm{O}-\mathrm{Ta}_{2} \mathrm{O}_{5}$ glass system in which FTIR and Raman results indicated the insertion of $\mathrm{TaO}_{6}$ units inside the germinate network resulting in the formation of Ge-O-Ta bonds and thus higher network connectivity [288]. These results imply the participation of $\mathrm{Ta}_{2} \mathrm{O}_{5}$ in mixed networks together with $\mathrm{SiO}_{4}$. This is based on the fact that the reactivity between a metal-oxide such as Ta and $\mathrm{Si}$ is more likely than the reaction between $\mathrm{Si}$ and $\mathrm{Si}$ because the oxide-formation energy of Ta is less than that of Si [311].

The transmittance band seen in the $1000-900 \mathrm{~cm}^{-1}$ domain was attributed to $\mathrm{Si}-\mathrm{O}$ stretching mode vibrations. This band exhibits a clear broadening, shifts from higher to lower frequencies and decreases in intensity with $\mathrm{Ta}_{2} \mathrm{O}_{5}$ content. These results indicate that decreasing $\mathrm{ZnO}$ disrupts the amorphous silica structure by requiring more oxygen units to increase the number of its $\mathrm{ZnO}_{6}$ units, thus reducing the number of $\mathrm{BO}$ and facilitating the formation of a higher number of un-polymerized $\mathrm{SiO}_{4}(\mathrm{Si}-\mathrm{O})$ groups.

Observations from both peaks in the $1120-900 \mathrm{~cm}^{-1}$ FTIR domain can imply the creation of several chemical environments for $\mathrm{SiO}_{4}$ as the content of $\mathrm{Ta}_{2} \mathrm{O}_{5}$ increases.

The shoulder peak at around $545 \mathrm{~cm}^{-1}$ was attributed to the $\mathrm{ZnO}_{4}$ group [290] suggesting the presence of these former ions in the glass system. However it is obvious that this peak shifts to higher frequencies, as shown in Table 3.8, and disappears for Ta3 and Ta4 glasses. This behavior can be attributed to our assumptions that reducing $\mathrm{ZnO}$ content would facilitate the formation of higher numbers of $\mathrm{ZnO}_{6}$ units resulting in higher $\mathrm{NBO} / \mathrm{BO}$ ratios as the $\mathrm{Ta}_{2} \mathrm{O}_{5}$ content increases 
on the expense of $\mathrm{ZnO} . \mathrm{ZnO}$ is expected to participate in the formation of mixed networks, together with $\mathrm{SiO}_{4}$. However as its content is replaced with $\mathrm{Ta}_{2} \mathrm{O}_{5}, \mathrm{ZnO}_{4}$ units decrease and the general role of $\mathrm{ZnO}$ changes to participate in disrupting and modifying the glass forming cations and introducing NBO into the glass structure.

The band at $470 \mathrm{~cm}^{-1}$ is assigned to $\mathrm{Si}-\mathrm{O}-\mathrm{Si}$ bending vibrations [312]. This band is similar for all glasses and does not shift to lower or higher frequencies. However, the decrease in intensity of this band confirms our earlier assumptions that replacing the $\mathrm{ZnO}$ with the $\mathrm{Ta}_{2} \mathrm{O}_{5}$ facilitates the insertion of $\mathrm{Ta}$ atoms within the silicate network and the resulting disruption in the neighborhood of the $\mathrm{SiO}_{4}$ units.

\subsection{Summary}

This study has presented for the first time the effect of replacing $\mathrm{ZnO}$ with $\mathrm{Ta}_{2} \mathrm{O}_{5}$ in the glass system $0.48 \mathrm{SiO}_{2}-(0.36-\mathbf{X}) \mathrm{ZnO}-0.06 \mathrm{CaO}-0.08 \mathrm{SrO}-0.02 \mathrm{P}_{2} \mathrm{O}_{5}-\mathrm{XTa}_{2} \mathrm{O}_{5}$ with $\mathbf{X}$ varying from 0 mole percentage $(\mathrm{TaO})$ to 8 mole percentage $(\mathrm{Ta} 4)$. The results obtained in this work suggest a structural model evolution in which the addition of Ta to the Si-Zn-Ca-Sr-P glass system causes a disruption in the network facilitating the insertion of octahedral $\mathrm{TaO}_{6}$ units between the $\mathrm{SiO}_{4}$ tetrahedral units through Si-O-Ta and Ta-O-Ta linkages. This was supported by the increased $\mathrm{NC}$ of the glasses going through the series and an increase in the temperature at which thermal events were recorded, as a function of $\mathrm{Ta}_{2} \mathrm{O}_{5}$ content. Further, the work herein has shown that the $\mathrm{Zn}$ atom behaves as an intermediate. The $\mathrm{Zn}$ atom may act as a network former by disrupting the $\mathrm{Si}-\mathrm{O}-\mathrm{Si}$ and probably the $\mathrm{Si}-\mathrm{O}-\mathrm{Ta}$ bonds and may act as a network modifier by acquiring more oxygen atoms. 


\section{A novel tantalum-containing bioglass. Part I. Structure and solubility.}

\section{This chapter is based on the following published paper:}

Alhalawani, A.M.F.; and Towler, M.R. A novel Tantalum-containing bioglass. Part I. Structure and solubility, Mater Sci Eng C Mater Biol Appl. 2017, 72, 202-211.

\subsection{Introduction}

Bioactive glasses are candidate materials for a wide variety of biomedical applications as they can bond to bone and be formulated to release bioactive ions into the local environment, resulting in antimicrobial activity and enhanced cell response [269,313].

Silicate-glasses are inorganic amorphous solids composed of $\mathrm{SiO}_{4}^{3-}$ tetrahedral units. In other words, silicon is coordinated to 4 oxygen atoms and each oxygen atom is coordinated to 2 silicon units so that the structure is a three-dimensional (3-D) network of corner connected $\left[\mathrm{SiO}_{4 / 2}\right]$ tetrahedra [314]. These $\mathrm{SiO}_{4}^{3-}$ tetrahedral units form the backbone of the glass structure while modifying cations charge balance the silicate chains. The ionicity of the Si-O bond, resulting from the difference in the electronegativity of $\mathrm{Si}$ and $\mathrm{O}$, allows for the formation of Si-O-Si bonds [315], forming the backbone of various bioglass systems. Si can also bond to other atoms depending on the glass composition [316,317]. Indeed, bond formation corresponds to a state of electronegativity equalization stated by Sanderson [318]. When a bond is formed between two atoms, $\mathrm{X}$ and $\mathrm{Z}$, with different electro-negativities, there is an electron flow from the less to the more electronegative atom. Further, it is accepted that silica glasses undergo modification in response to the addition of other cations/atoms [319]. As an example, the alkali ions locate themselves in the structure near the NBO when added to silica glasses resulting in the formation of meta, pyro and ortho-silicates. $\left[\mathrm{SiO}_{4 / 2}\right]^{0},\left[\mathrm{SiO}_{3 / 2} \mathrm{O}\right]^{-},\left[\mathrm{SiO}_{2 / 2} \mathrm{O}_{2}\right]^{2-,}\left[\mathrm{SiO}_{1 / 2} \mathrm{O}_{3}\right]^{3-}$ and $\left[\mathrm{SiO}_{4}\right]^{4-}$, which are present in silicate glasses, are designated as $\mathrm{Q}^{4}, \mathrm{Q}^{3}, \mathrm{Q}^{2}, \mathrm{Q}^{1}$ and $\mathrm{Q}^{0}$ respectively, where the superscripts indicate the number of BOs centered on the given $\mathrm{Si}$ atom through which it is connected to other Si atoms in the glass structure [320].

The solubility of a bioglass network is related to alkali ion content [320]; the addition of glass former cations will result in a systematic decrease in the solubility of these systems. Readers are referred to the work of Hoppe et al. [269] for detailed information on the degradation kinetics of these biomaterials and the specific effect of the released ionic dissolution products, for example $\mathrm{Sr}^{2+}$ and $\mathrm{Zn}^{2+}$ ions, impart on biological performance. 
Transition metals can play a dual role in oxide glasses [321]. In some concentrations the transition metal may enter the network structure while in other concentration amounts, they may allow the oxygen ions of their former cation to break the oxygen bridges in the system, therefore acting as a glass modifier. Ta is a transition metal that has been used as a bone implant [322324] due to its physical and biological properties. The Ta ion is reported to be bioactive and biocompatible due to the formation of a stable tantalum pentoxide $\left(\mathrm{Ta}_{2} \mathrm{O}_{5}\right)$ component on its surface [282,325]. Studies [322,326] have shown that Ta surfaces exhibit lower contact angles and higher surface energies than titanium or HA surfaces offering a favorable biological environment for adhesion, growth and differentiation of human cells. Despite some processing challenges [324,327], the inclusion of Ta and other transition metals into ionomer glasses can improve their thermal and chemical stability [278-280,317].

In chapter 3 [317], the authors synthesized and characterized a wholly new silicate-glass series in which $\mathrm{ZnO}$ was substituted with up to 8 mole percentage $\mathrm{Ta}_{2} \mathrm{O}_{5}$. In that work, Alhalawani and Towler showed that Ta incorporation into silicate-based glasses was possible by the melt-quenching process. They also confirmed that Ta behaved as a glass former whereas $\mathrm{Zn}$ acted as a glass intermediate, depending on its content, in that particular glass system. These novel glasses were designed specifically to formulate a series of GPCs for use in sternal fixation. Initial, unpublished data has confirmed that high Ta-containing glasses have rheology (setting and working times) that are deemed unsuitable for sternal applications. The work herein expands the understanding of this particular bioglass system where a new series of the previously formulated glass (chapter 3 ) was synthesized containing lower $\mathrm{Ta}_{2} \mathrm{O}_{5}$ contents $(0.0$ to 0.5 mole percentage). This chapter also aims to characterize the structural and solubility of the glass system under study.

\subsection{Experimental}

\subsubsection{Glass synthesis}

Three glasses were proposed for this study (Table 4.1), a $\mathrm{Ta}_{2} \mathrm{O}_{5}$-free $\mathrm{SiO}_{2}-\mathrm{ZnO}-\mathrm{CaO}-\mathrm{SrO}-$ $\mathrm{P}_{2} \mathrm{O}_{5}$ glass $(T A O)$ and two $\mathrm{Ta}_{2} \mathrm{O}_{5}$-containing glasses (TA1 and TA2) where Ta incrementally replaced $\mathrm{ZnO}$ in the $T A O$ parent composition. Appropriate amounts of analytical grade silica, zinc oxide, calcium carbonate, strontium carbonate, ammonium dihydrogen phosphate and tantalum oxide (Fisher Scientific, Ottawa, ON, Canada; Sigma-Aldrich, Oakville, ON, Canada) were weighed out and mixed into a container. The container was shaken for $15 \mathrm{~min}$ and then 
sieved through a $<90 \mu \mathrm{m}$ mesh. Platinum (Pt.) crucibles and a Lindberg/Blue M model furnace (Lindberg/Blue M, Asheville, NC USA) with a UP550 controller were used for melting the sieved powders $\left(1650^{\circ} \mathrm{C}, 1.5 \mathrm{hrs}\right)$. The melts were shock quenched in water to obtain frit which was then dried in an oven $\left(100{ }^{\circ} \mathrm{C}, 1 \mathrm{hrs}\right)$, ground using a ball mill (400 RPM, $\left.15 \mathrm{~min}\right)$, sieved once more through a $45 \mu \mathrm{m}$ mesh. TAO, TAl and TA2 were then annealed at $670{ }^{\circ} \mathrm{C}, 666^{\circ} \mathrm{C}$ and $677{ }^{\circ} \mathrm{C}$, respectively for $12 \mathrm{hrs}$ to relieve internal stresses within the glass network. The furnace (Lindberg/Blue M, Asheville, NC USA) was programmed to reach to the annealing temperature in $3 \mathrm{hrs}$ and to cool down to the room temperature $\left(25 \pm 2{ }^{\circ} \mathrm{C}\right)$ in $3 \mathrm{hrs}$. The glass powders of the selected compositions were then sieved through a $45 \mu \mathrm{m}$ mesh and utilised for subsequent characterization.

Table 4.1: Composition of the glass series.

\begin{tabular}{ccccccc}
\hline & \multicolumn{6}{c}{ Mole percentage } \\
\cline { 2 - 7 } & $\mathrm{SiO}_{2}$ & $\mathrm{ZnO}$ & $\mathrm{CaO}$ & $\mathrm{SrO}$ & $\mathrm{P}_{2} \mathrm{O}_{5}$ & $\mathrm{Ta}_{2} \mathrm{O}_{5}$ \\
\hline TAO & 48 & 36 & 6 & 8 & 2 & 0 \\
TA1 & 48 & 35.8 & 6 & 8 & 2 & 0.2 \\
$T A 2$ & 48 & 35.5 & 6 & 8 & 2 & 0.5 \\
\hline \multicolumn{6}{c}{ Weight } & percentage \\
\hline TAO & 35.8 & 36.4 & 7.5 & 14.7 & 5.7 & 0.0 \\
TA1 & 35.5 & 35.8 & 7.4 & 14.5 & 5.7 & 1.1 \\
TA2 & 35.0 & 35.1 & 7.3 & 14.3 & 5.6 & 2.7 \\
\hline
\end{tabular}

\subsubsection{Glass structural and thermal characterization}

\subsubsection{X-ray diffraction}

Refer to section 3.2.2.1.

\subsubsection{Particle size analysis (PSA)}

The particle size distribution (PSD) of each glass series was recorded using a Multisizer 4 Particle size analyzer (Beckman Coulter, Fullerton, CA, USA). The glass powder samples $(n=$ 5) were evaluated in the range of 2 to $60 \mu \mathrm{m}$ with a run length of $60 \mathrm{sec}$. A background analysis was performed and subtracted for accurate results. The fluid used in this case was a sodium chloride $(\mathrm{NaCl})$ electrolyte solution at a temperature range of $10-37{ }^{\circ} \mathrm{C}$. The relevant volume statistics were calculated on each glass composition. The average diameters $(n=5)$ at the $10 \%$, $50 \%$, and $90 \%$ of the cumulative volume distribution ( $\mathrm{d}_{10}, \mathrm{~d}_{50}$ and $\mathrm{d}_{90}$, respectively) were recorded. 


\subsubsection{Scanning Electron Microscopy-Energy Dispersive Spectroscopy (SEM-EDS)}

Sample imaging was carried out with an FEI Co. Quanta 200F Environmental Scanning Electron Microscope equipped with an EDAX Genesis Energy-Dispersive Spectrometer (Oxford Instruments X-max, Netherlands). Secondary electron (SE) and backscattered electron (BSE) images were taken on glass particles and polished disc surfaces. All EDS spectra were collected at $20 \mathrm{kV}$ using a beam current of $26 \mathrm{nA}$. Quantitative EDS spectra was subsequently converted into relative concentration data $(n=3)$.

\subsubsection{Differential Thermal Analysis (DTA)}

A combined differential thermal analyzer-thermal gravimetric analyzer (DTA-TG; SDT 2960 Simultaneous DSC-TGA, TA Instruments, DW, USA) was used to study the thermal properties of the glasses. A heating rate of $20^{\circ} \mathrm{C} / \mathrm{min}$ was employed using an air atmosphere with alumina in a matched platinum crucible as a reference and then cooled to room temperature at the same rate. Sample measurements were carried out every $6 \mathrm{sec}$ between $30{ }^{\circ} \mathrm{C}$ and $1200{ }^{\circ} \mathrm{C}$. Data analysis was performed using NETZSCH Proteus software, V. 6 (Netzsch-Gerätebau $\mathrm{GmbH}$, Selb, Germany).

\subsubsection{X-Ray Photoelectron Spectroscopy (XPS)}

Refer to section 3.2.2.3.

\subsubsection{Magic angle spinning-Nuclear magnetic resonance (MAS-NMR)}

${ }^{29} \mathrm{Si}$ MAS-NMR spectra were recorded at $7.05 \mathrm{~T}$ (tesla) on a Varian Unity Inova $300 \mathrm{FT}$ NMR spectrometer (Palo Alto, CA, USA), equipped with a cross polarization-magic angle spinning (CP-MAS) probe. The glass samples were placed in a zirconia sample tube with a diameter of $7 \mathrm{~mm}$. The sample spinning speed at the magic angle to the external magnetic field was $5 \mathrm{kHz}$. 29Si MAS NMR spectra were taken at $59.59 \mathrm{MHz}$ with 7.0-ls pulse length (pulse angle, p/2), 100-second recycle delays, where the signals from 2126, 1837 and 1880 pulses were accumulated for $T A-0, T A-1$ and $T A-2$, respectively. ${ }^{29} \mathrm{Si}$ NMR chemical shifts are reported in ppm, with PDMS (polydimethyl silane) as the external reference (-34 ppm vs. TMS 0 ppm). All NMR spectra were recorded in a room for exclusive use of NMR, where the room temperature was kept at $300 \mathrm{~K}$ by means of an air-conditioner. Data analysis of the NMR spectra was performed by nonlinear curve-fitting using ORIGIN software (Microcal Software Inc., Northhampton, MA, USA). 


\subsubsection{Effect of glass structure on ion release and solubility}

\subsubsection{Disc sample preparation and degradation analysis}

Disc samples were prepared by weighing $0.1 \mathrm{~g}$ powder into a stainless steel die (sample diameter $1.5 \times 6 \phi \mathrm{mm}$ ) which was pressed under 2.5 tons of pressure for $30 \mathrm{sec}$. Disc samples were kept amorphous by annealing at $\mathrm{T}_{\mathrm{g}} \pm 10^{\circ} \mathrm{C}$ for $12 \mathrm{hrs}$. The surface area of each glass disc was then calculated from the dimensions measured using an electronic precision caliper (Cedarlane Laboratories Ltd., Hornby, ON, Canada). Disc samples were then weighed and immersed in measured quantities $(10 \mathrm{ml})$ of DI water. All samples were maintained at $37^{\circ} \mathrm{C}$. At various time points (1, 7 and 30 days), the DI water was removed for $\mathrm{pH}$ and ion release analysis. Then the discs were removed, dried in an incubator for $24 \mathrm{hrs}$, and weighed before being immersed in fresh volumes of DI water. This study was conducted in triplicate, and the data plotted as cumulative degradation (percentage weight loss per unit area, as a function of time). Eq. 4.1 was then used to obtain the \% weight loss per unit area:

$$
\% \text { of weight loss }=\frac{M_{o}-M_{t}}{A} \times 100
$$

Where $\mathrm{M}_{\mathrm{o}}$ is the initial weight in $\mathrm{g}, \mathrm{M}_{\mathrm{t}}$ is the weight at time $\mathrm{t}$ in $\mathrm{g}$ and $\mathrm{A}$ is the surface area in $\mathrm{cm}^{2}$.

\subsubsection{2 pH analysis}

The $\mathrm{pH}$ measurements were collected using a Corning $430 \mathrm{pH}$ meter (Corning Life Sciences, Acton, MA). Prior to testing, the $\mathrm{pH}$ electrode was calibrated using $\mathrm{pH}$ buffer solutions $4.00 \pm$ 0.02 and $7.00 \pm 0.02$ (Fisher Scientific, Pittsburgh, PA). Sterile DI water $(\mathrm{pH}=6.0)$ was used as a control and was measured at each time period.

\subsubsection{Ion release profiles}

Each sample $(n=3)$ was immersed in $10 \mathrm{ml}$ of DI water for 1, 7 and 30 days prior to testing. The ion release profile of each specimen was measured using atomic absorption spectroscopy (AAS) on a Perkin-Elmer Analyst 800 (Perkin Elmer, MA, USA). AAS calibration standards for $\mathrm{Sr}$ and $\mathrm{Zn}$ elements were prepared from a stock solution (Sigma-Aldrich, Oakville, ON, Canada) on a gravimetric basis. Three target calibration standards were prepared for each ion and DI water was used as a control. Owing to the much greater expected concentration of ions, samples were diluted in DI water at 1:10 ratio. The final cumulative concentration was calculated from the results of the measurements taking into account the dilution factor. 


\subsection{Results and discussion}

\subsubsection{Glass structural and thermal characterization}

$\mathrm{X}$-ray Diffraction patterns were recorded for each of the formulated glasses and are presented in Figure 4.1. XRD confirmed that all fired glasses were fully amorphous; that no crystalline species are present in either TAO,TAI or TA2 during glass forming. The results presented herein indicate that any changes in the properties of the glasses will be attributed to $\mathrm{Ta}_{2} \mathrm{O}_{5}$ incorporation rather than phase changes/separation in the glasses.

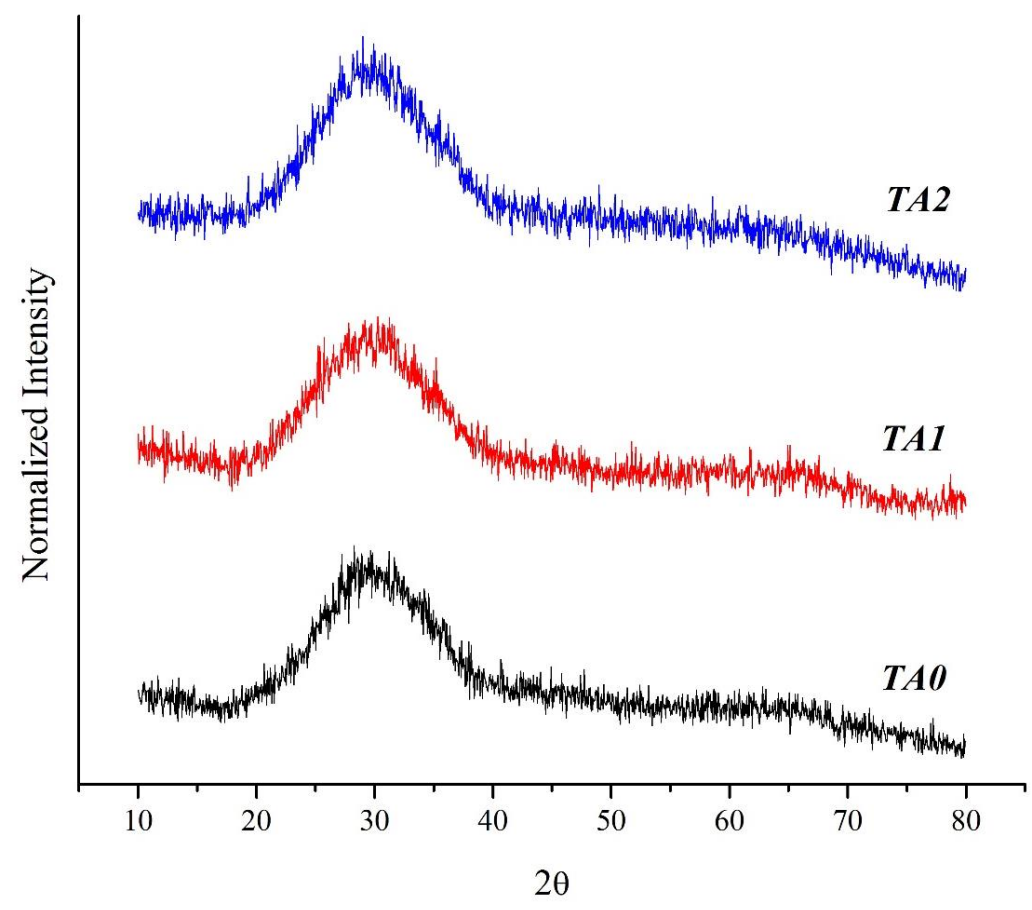

Figure 4.1: XRD traces for the formulated glasses.

Particle size analysis (PSA) was conducted for each glass composition and the results are presented in Table 4.2. The PSA results were comparable for all glasses under study implying that any changes through the series would be related to chemistry, not physicality, of the glasses.

Table 4.2: Particle size analysis data for the glass series.

\begin{tabular}{ccccc}
\hline & Average $(\mu \mathrm{m})$ & $\mathrm{d}_{10}(\mu \mathrm{m})$ & $\mathrm{d}_{50}(\mu \mathrm{m})$ & $\mathrm{d}_{90}(\mu \mathrm{m})$ \\
\hline TAO & 11.5 & 6.4 & 8.8 & 20.2 \\
TA1 & 11.1 & 6.4 & 8.6 & 18.9 \\
TA2 & 10.3 & 6.4 & 8.4 & 16.1 \\
\hline
\end{tabular}

SEM was employed to provide compositional contrast images that result from different atomic number elements and their distribution within the glasses. EDS analysis was also performed to provide qualitative spectra and quantitative relative proportions (wt\%) of the 
particular elements from the SEM backscattered images. SEM-EDS results of the glass series are presented in Figure 4.2a-c which show similar morphology for the glasses through the series. Thus, the incorporation of $\mathrm{Ta}_{2} \mathrm{O}_{5}$ did not cause any obvious changes in the morphology or the mean particle size of the glass series. The white square in the SEM images (Figure 4.2a-c) indicate the interfacial regions used to identify the corresponding EDS spectra as well as the chemical composition $(n=3)$ of the glass series. Qualitative EDS spectra showed that TAO contains $\mathrm{Si}, \mathrm{Zn}, \mathrm{Ca}, \mathrm{Sr}$, and $\mathrm{P}$, while TA1 and TA2 were found to have the same elements but with the addition of Ta, thus confirming the starting formulation of each glass. Further, it was found, as expected, that Ta increases from 0.0 to $1.9 \mathrm{wt} \%$ while $\mathrm{Zn}$ decreases from 31.8 to 29.9 wt $\%$, with increasing $\mathrm{Ta}_{2} \mathrm{O}_{5}$ content from 0.0 to $2.7 \mathrm{wt} \%$, respectively. The $\mathrm{Si}$ fraction however show a significant discrepancy. Si:Zn ratio is $\sim 1: 1$ in the original glass (wt\%, Table 4.1), however the EDS results show a 1:2 rate. This could be attributed to the high signal present for $\mathrm{O}$ and/or the ion diffusion through the glass. Initial quantitative analysis of the glass composition by using EDS can lead to the following assumptions:

- The EDS results are usually collected at low vacuum, therefore the oxygen content recorded by EDS represents BO and NBO and may also represent oxygen in the surrounding environment. This may result in a significant discrepancy in predicting the elemental bulk composition.

- EDS provides the quantitative relative proportions of the particular elements but not the oxides, therefore EDS results cannot be solely used for comparing the chemical composition of the processed and formulated glass.

- The penetration depth of the EDS is $\sim 2-5 \mu \mathrm{m}$, hence the results also include bulk composition data. This advantage of EDS analysis may however be associated with masking and overlapping issues resulting in significant discrepancy and compositional heterogeneity. 
(a) TAO

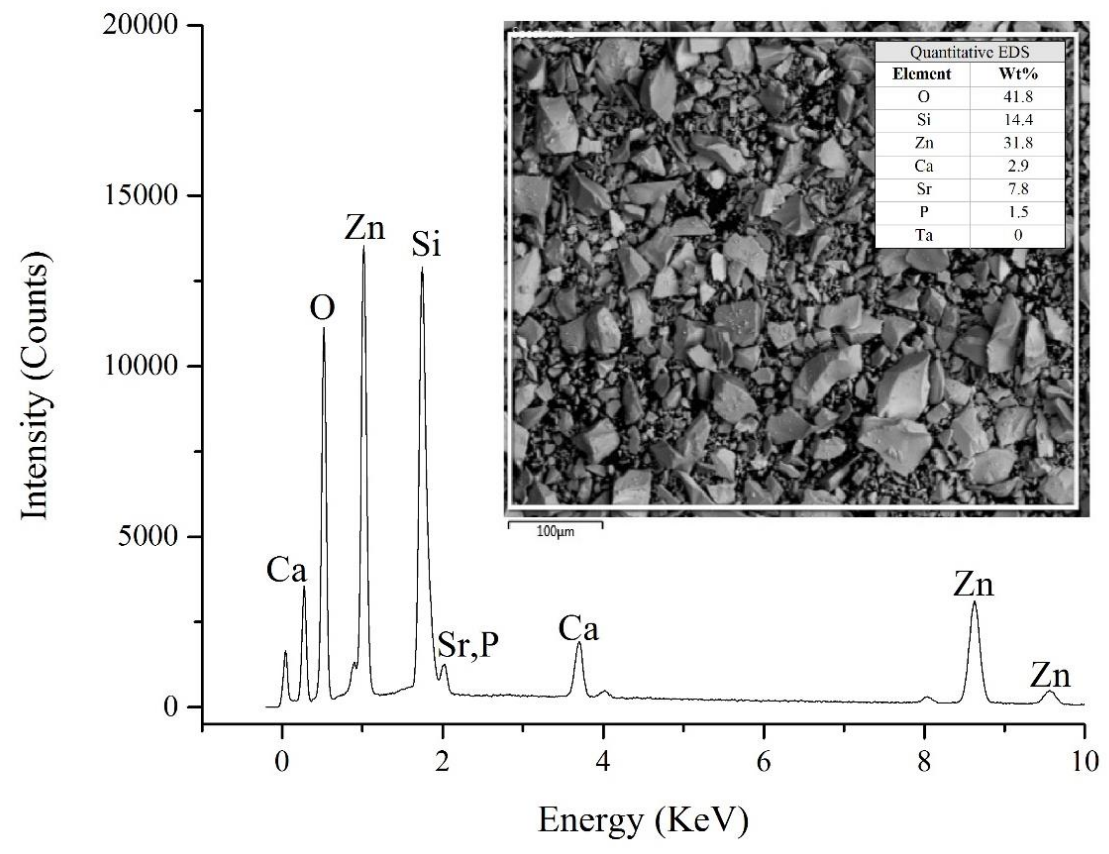

(b) $T A 1$

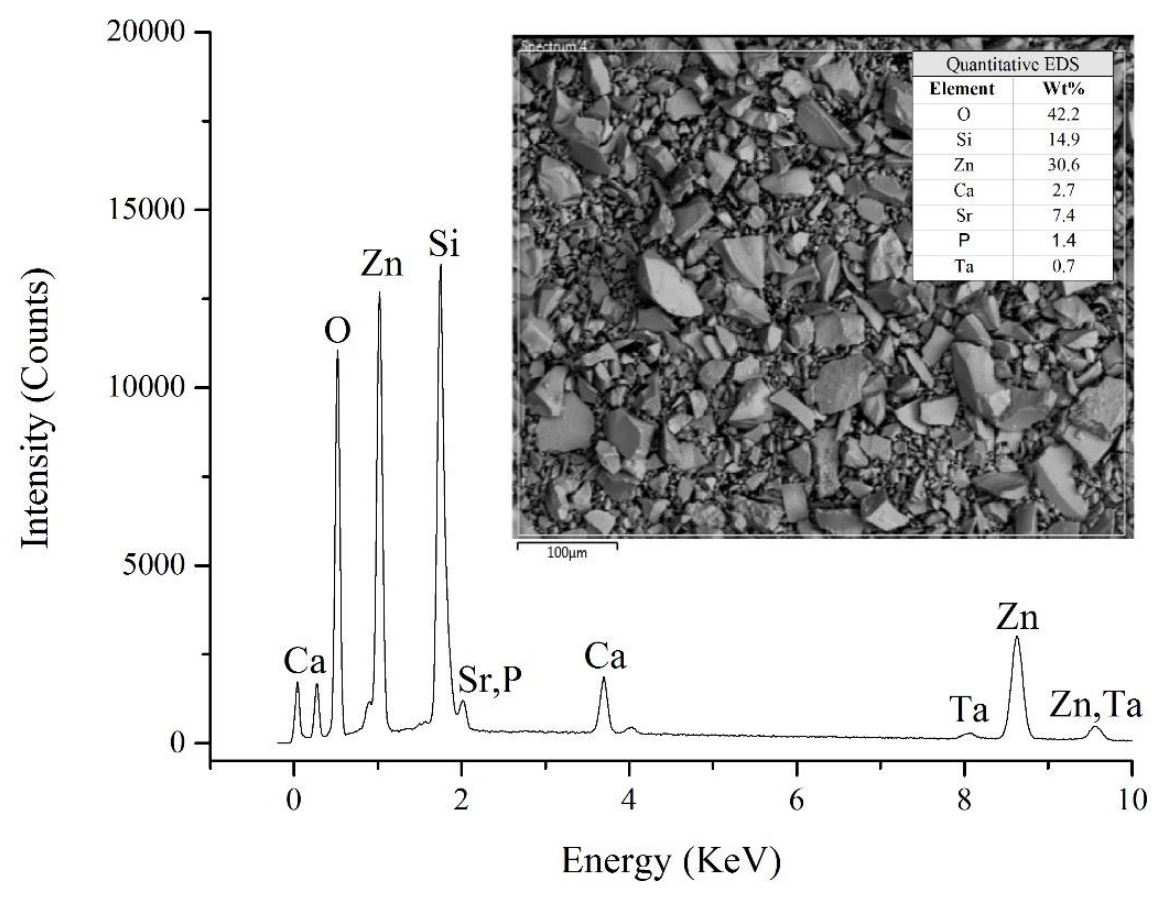


(c) $T A 2$

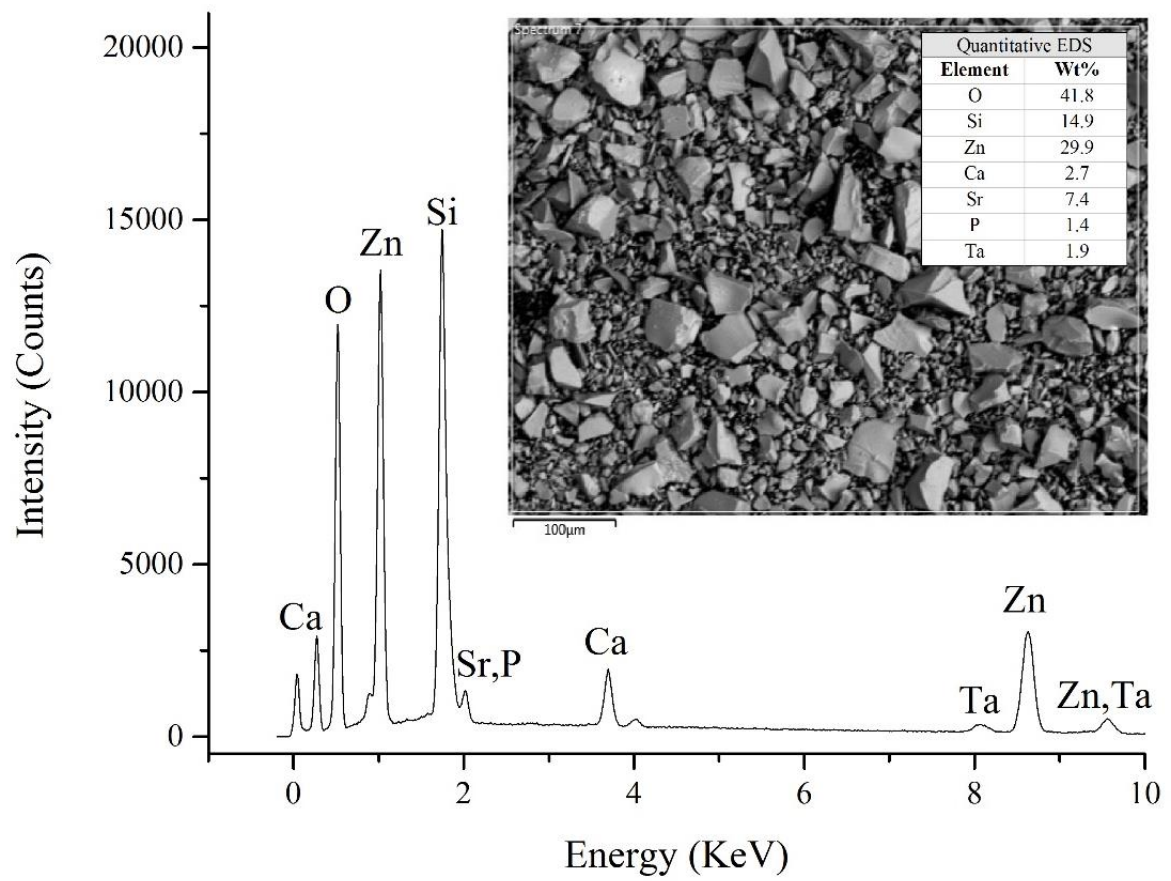

Figure 4.2: SEM images of the glass series and the corresponding EDS qualitative spectra and quantitative elemental composition (wt\%).

Thermal profiles of the glasses are presented in Figure 4.3. DTA curves also show the recorded thermal events and their assignments. The glass transition temperature was observed at $670{ }^{\circ} \mathrm{C}, 666^{\circ} \mathrm{C}$ and $677^{\circ} \mathrm{C}$ for $T A 0, T A 1$ and $T A 2$, respectively. Previous studies [307,317] have shown that the addition of transition metals, such as $\mathrm{Ta}_{2} \mathrm{O}_{5}$, to bio-glasses increases the glass transition temperature and facilitates incorporation of the transition metal oxide inside the glass network. The shift in $\mathrm{T}_{\mathrm{g}}$ implies increased glass stability, which may be attributed to the formation of BO groups. The glass transition is followed by an exothermic peak caused by glass crystallization. TA1 and TA2 show an ideal exothermic crystallization reaction at $874{ }^{\circ} \mathrm{C}$ and 866 ${ }^{\circ} \mathrm{C}$, respectively while $T A O$ shows a broad peak around that region, observed at $897^{\circ} \mathrm{C}$. The slow crystallization of $T A O$ can be attributed to 'interfering' nucleation and oxidation transitions as well as the slow diffusion rates of the reactants in TAO. This is in good agreement with our previous study where higher levels of $\mathrm{Ta}_{2} \mathrm{O}_{5}$ resulted in a greater glass forming tendency and a delay in the nucleation process [317]. Finally the melting temperature for TAO appears at 1094 ${ }^{\circ} \mathrm{C}$. For TA1 and TA2, endothermic peaks appeared at $1098{ }^{\circ} \mathrm{C}$ and $1100{ }^{\circ} \mathrm{C}$, respectively. This last endothermic process for $T A 1$ and $T A 2$ was assigned to initial decomposition and melting of some of the glass elements since the temperature difference does not decrease significantly, 
compared to that of TAO at $1094{ }^{\circ} \mathrm{C}$, over the course of the peak. The glass melting temperature of TA1 and TA2 was not observed in this study, agreeing with explanations in chapter 3 which indicated that substituting $\mathrm{ZnO}$ with $\mathrm{Ta}_{2} \mathrm{O}_{5}$ increased melting temperature [317]. This may indicate increased stability and homogeneity of the glass reactants. This assumption agrees with the previous study on similar glass compositions (chapter 3). In chapter 3, results from STA showed that increasing $\mathrm{Ta}_{2} \mathrm{O}_{5}$ content at the expense of $\mathrm{ZnO}$ resulted in higher glass stability resulting from increased glass transition, crystallization and melting temperatures.

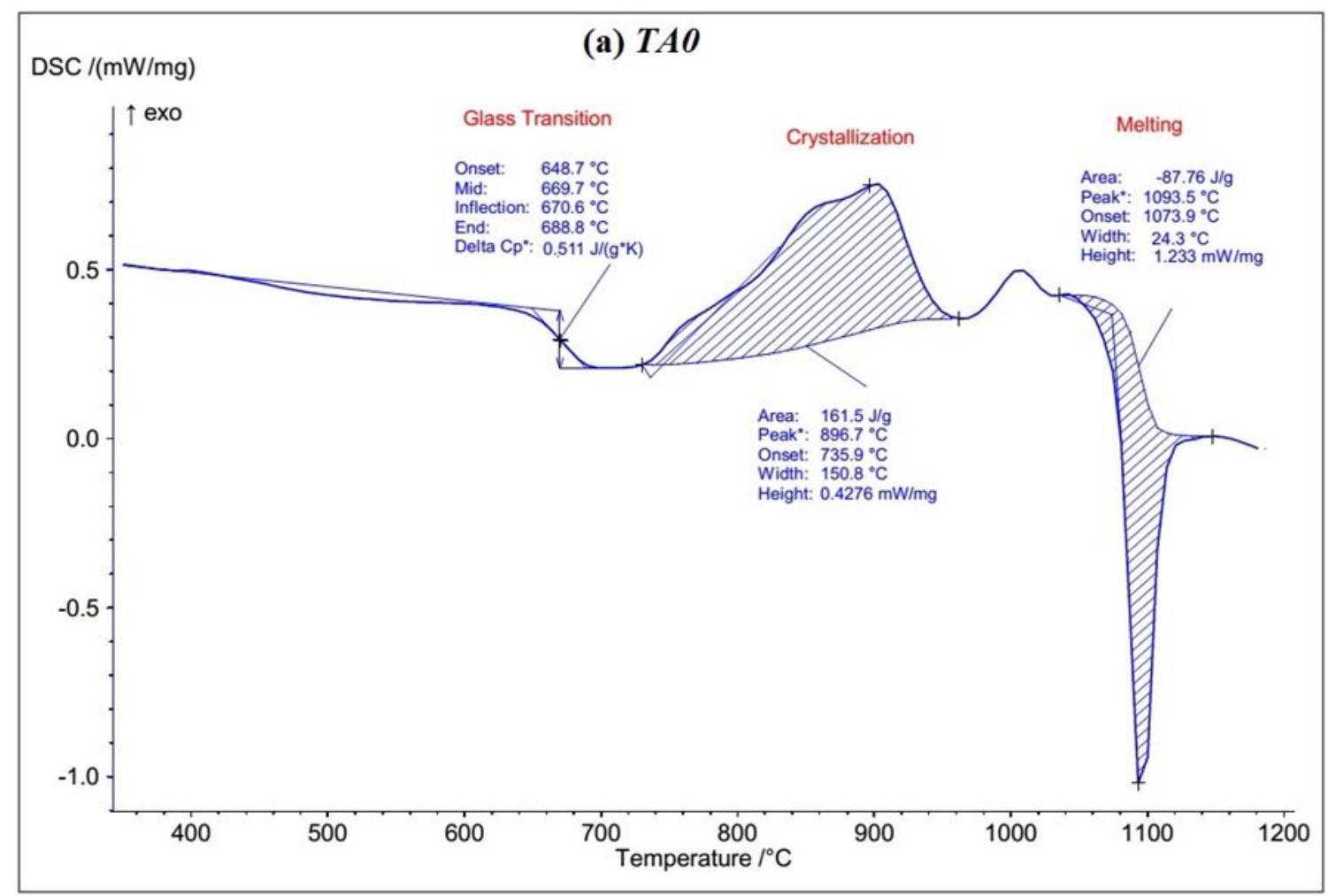




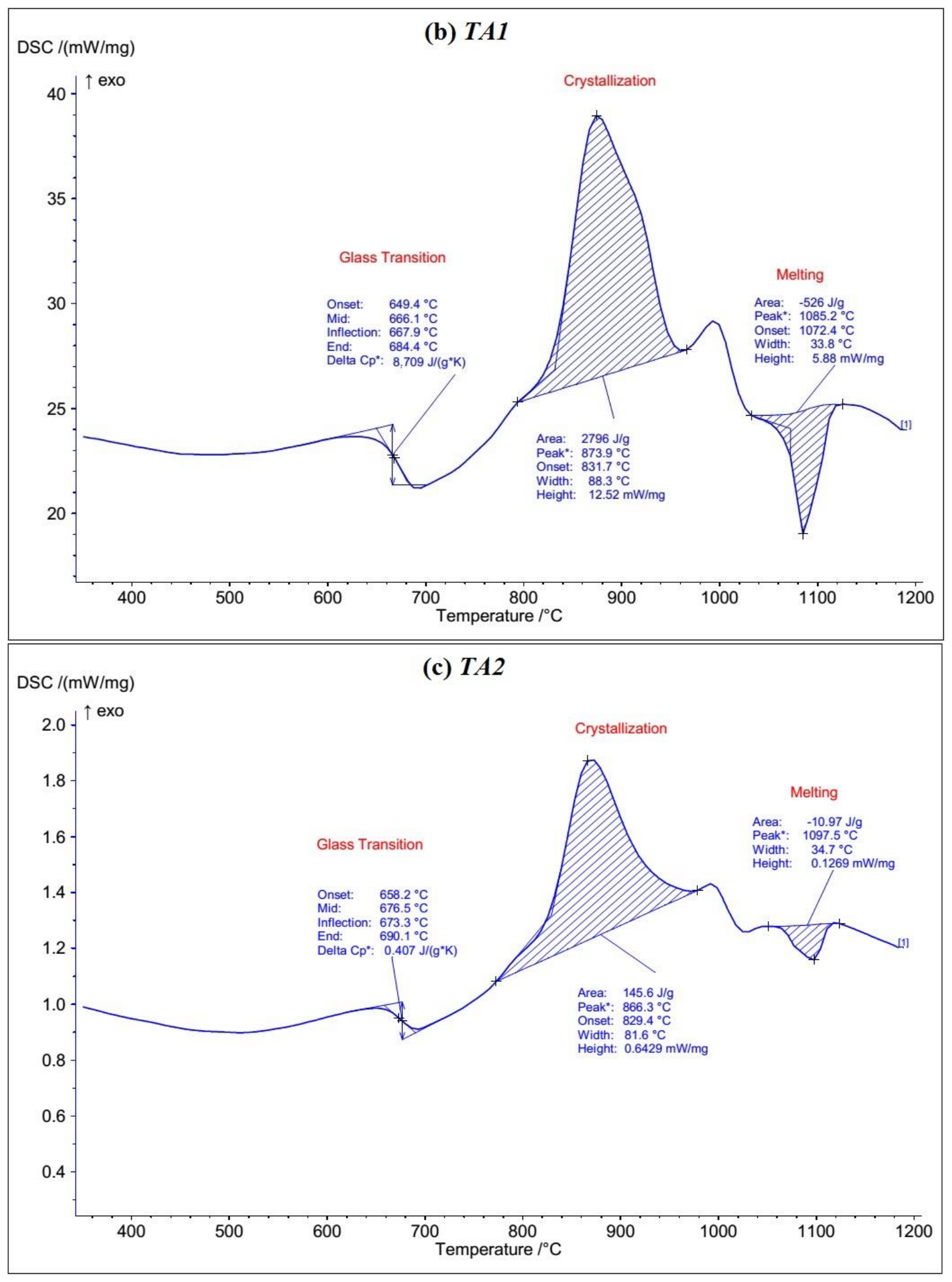

Figure 4.3: DTA curves of the glass series. 
X-ray photoelectron spectroscopy was employed to derive information on the elemental composition and speciation of matter by assessing the electronic structure of the atoms residing within the surface region of the matter being analyzed. The survey spectrum of the glasses formulated is shown in Figure 4.4. Besides the expected Si2p, Zn2p3, P2p, Ca2p, Sr3d5, Ta4d and O1s peaks, a C1s peak can be seen in the survey scans which is attributed to 'adventitious carbon' present due to the adsorption of impurities during the glass firing process. It is, however, important to note that the presence of this peak is common and does not affect the interpretation of our results. The XPS survey scan results (Figure 4.4) are in good agreement with EDS data. TAO was found to contain Si2p, Zn2p3, P2p, Ca2p, Sr3d5, and O1s, while TA1 and TA2 contain each of these elements in addition to Ta4d, reflecting the initial glass formulation.

Elemental compositions of the O1s, Si2p, Zn2p3, P2p, Ca2p, Sr3d5, and Ta4d peaks are presented in Table 4.3. Presenting the elemental composition of the $\mathrm{C} 1 \mathrm{~s}$ peak can make it difficult to compare relative changes between EDS and XPS results, therefore the elemental composition of the $\mathrm{C} 1 \mathrm{~s}$ peak is not presented. The elemental composition of all other peaks was adjusted accordingly. Comparing the glass composition obtained from both EDS and XPS with the initial batch formulation (Table 4.1), it is clear that XPS gives better approximation, particularly when comparing the $\mathrm{Ta}, \mathrm{Zn}$ and $\mathrm{Si}$ content. The wt\% of $\mathrm{Si}$ and $\mathrm{Zn}$ are almost equal in the expected glass compositions (Table 4.1) to those from the XPS results whereas the EDS quantitative analysis showed a $\mathrm{Zn}$ content that is almost twice as large as that of the Si. Further, EDS and XPS show that Ta and $\mathrm{O}$ content increases while the content of $\mathrm{Zn}$ decreases as a function of $\mathrm{Ta}_{2} \mathrm{O}_{5}$, thus they present a similar trend to the precursor glass formulations. It is important to note that XPS is a surface technique and therefore explanations offered around the glass composition are subject to the assumption that the bulk of the glass is similar in composition of the surface. However, although EDS quantitative analysis considers the bulk composition of the glass, XPS results record compositions closer to those from the initial batch calculation.

High resolution O1s spectra were also obtained from XPS to determine the effect of $\mathrm{Ta}_{2} \mathrm{O}_{5}$ substitution. The O1s spectra were curve fitted with respect to BO and NBO contributions and are presented in Figure 4.5. It is clear from Figure 4.5 that the binding energy of the O1s spectrum shifts slightly from 531.8 to $532.1 \mathrm{eV}$, as a function of $\mathrm{Ta}_{2} \mathrm{O}_{5}$ content. This is indicative of increasing the BO content in the glass, further suggesting that tantalum acts as a network former in these glasses. Table 4.3 presents the peak positions for the BO and the NBO and their 
corresponding at\%. $\mathrm{BO}$ and $\mathrm{NBO}$ remained at $531.3 \mathrm{eV}$ and $532.5 \mathrm{eV}$ regardless of $\mathrm{Ta}_{2} \mathrm{O}_{5}$ content. However increasing $\mathrm{Ta}_{2} \mathrm{O}_{5}$ content was found to increase the at $\%$ of $\mathrm{BO}$ peaks on the expense of $\mathrm{NBO}$ content, thus increasing the $\mathrm{BO} / \mathrm{NBO}$ ratio. This aligns with our explanations in chapter 3 [317], in which we show that Ta acts as a glass former, resulting in increased network connectivity. These results also suggest decreased bioactivity, as the $\mathrm{Ta}_{2} \mathrm{O}_{5}$ content increases, resulting from the formation of additional $\mathrm{Si}-\mathrm{O}-\mathrm{BO}$ that are known to have a negative effect on the ion exchange process. The solubility section of this chapter will provide more detailed information with regards to this hypothesis.

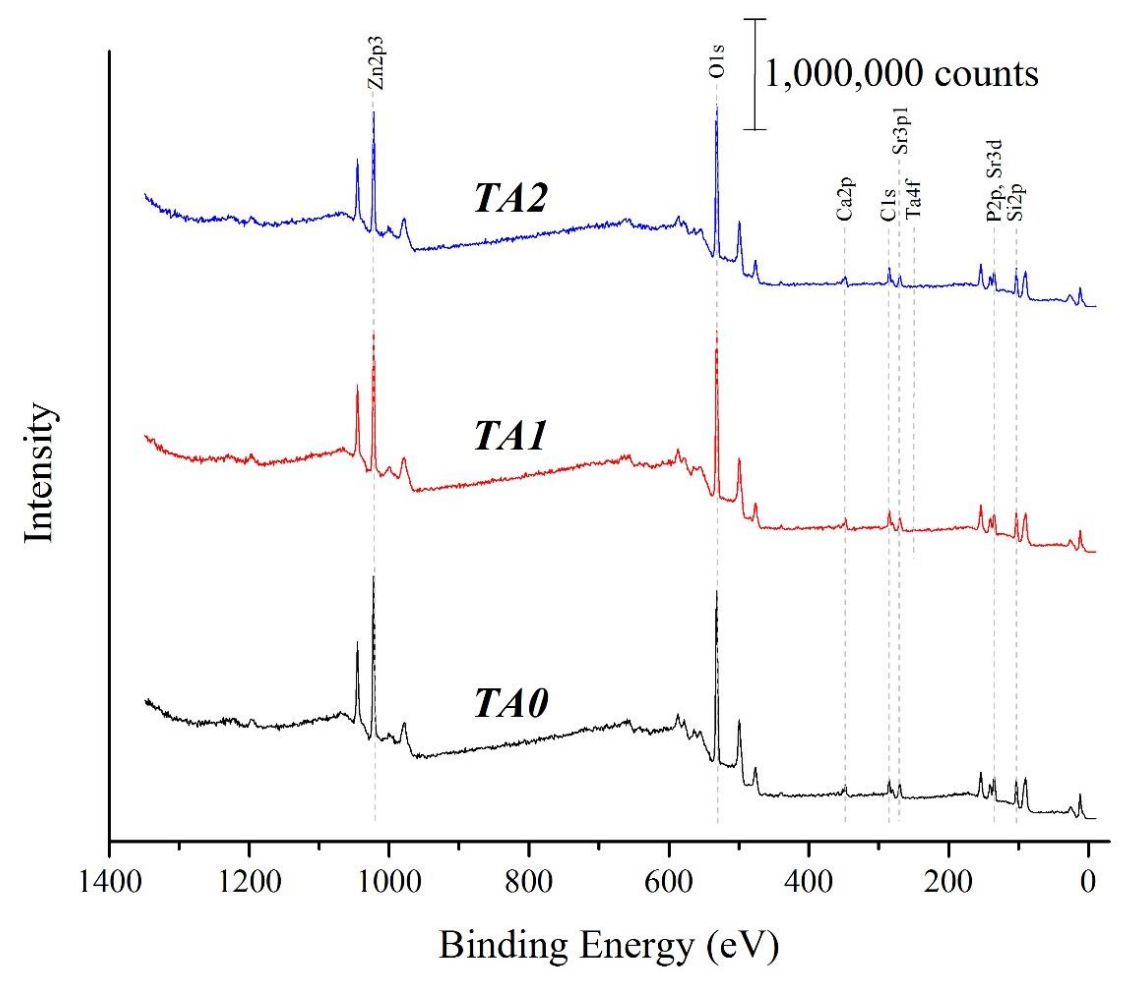

Figure 4.4: XPS survey scan of the glass series.

Table 4.3: Elemental composition (wt\%) of the glass series as determined by XPS.

\begin{tabular}{cccccccc}
\hline & O1s & Si2p & Zn2p3 & Ca2p & Sr3p1 & P2p & Ta4d \\
\hline TAO & 37.7 & 23.3 & 26.9 & 3.0 & 7.8 & 1.4 & 0.0 \\
TA1 & 38.1 & 23.5 & 24.9 & 2.9 & 7.5 & 1.1 & 1.6 \\
TA2 & 38.3 & 23.9 & 23.2 & 2.8 & 7.1 & 1.1 & 3.0 \\
\hline
\end{tabular}




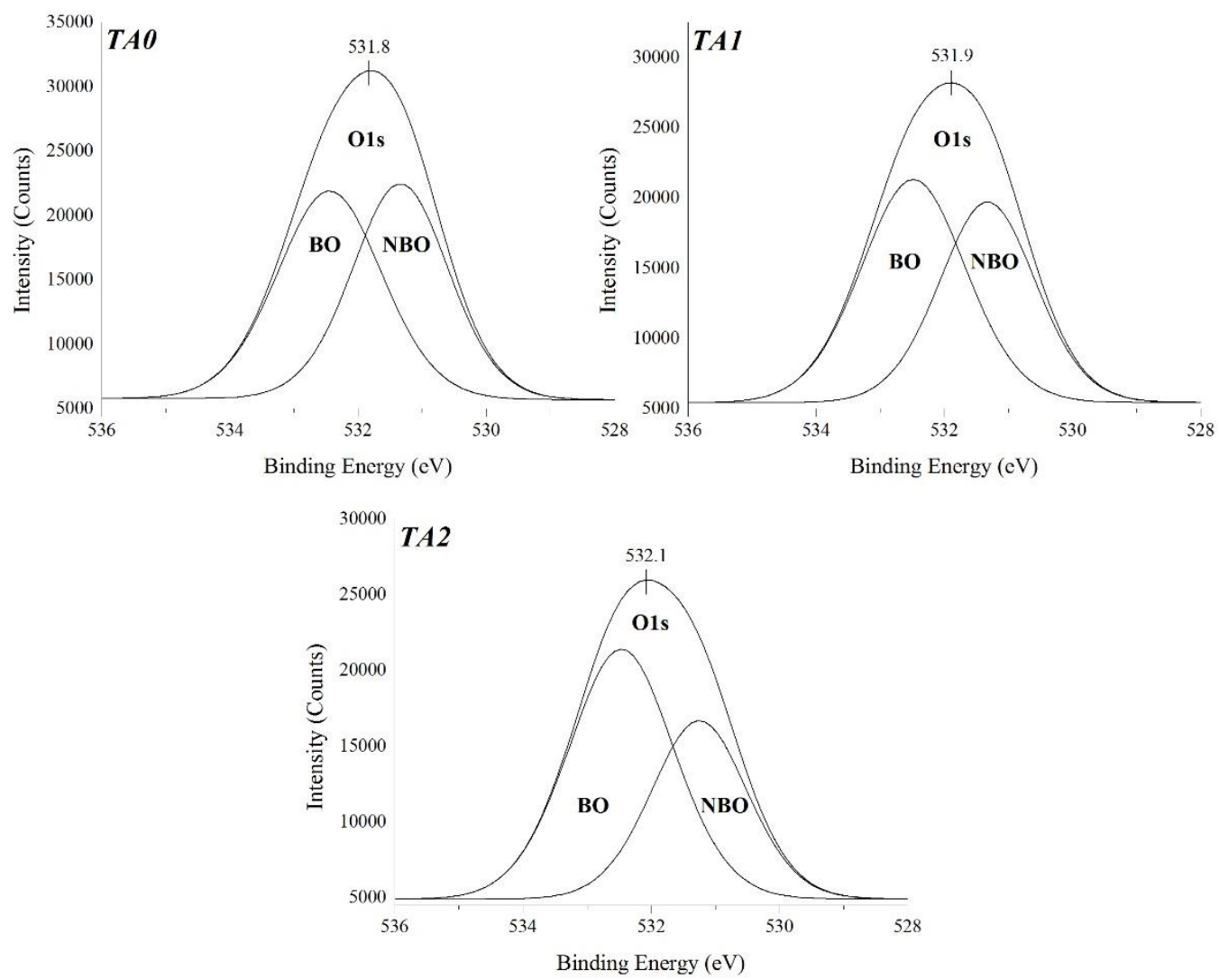

Figure 4.5: Curve fitting of the O1s spectra for the glass series with respect to BO and NBO contributions.

Table 4.4: Peak positions (eV) for the BO and the NBO peaks and their corresponding at\%, obtained from the curve fitting of the Ols peak, of the glass series.

\begin{tabular}{cccc}
\hline & $T A O$ & $T A 1$ & $T A 2$ \\
\hline O1s (NBO) & 531.3 & 531.3 & 531.3 \\
at\% & 45.2 & 45.2 & 39.6 \\
O1s (BO) & 532.5 & 532.5 & 532.5 \\
at\% & 54.8 & 54.8 & 60.4 \\
\hline
\end{tabular}

MAS-NMR was employed to further investigate the structural effects of $\mathrm{Ta}_{2} \mathrm{O}_{5}$ incorporation. Chemical shifts in MAS-NMR represents structural changes around the $\mathrm{Si}$ atom which lie in the region of -60 to $-120 \mathrm{ppm}$ for $\mathrm{SiO}_{4}$ tetrahedra [328]. Figure 4.6 shows the MAS-NMR spectra of the glass series (TAO, TAl and TA2). Figure 4.7a,b,c are the expanded versions of the NMR spectra of the glass series shown in Figure 4.6. Figure 4.7d,e,f are the corresponding curve fitted (simulated) spectra. All glass samples showed similar broad resonances at $\sim-80 \mathrm{ppm}$. It can be seen that there are slight chemical shift differences with the chemical shift of TAO $(-80.1)>T A 1$ 
$(-82.4)>T A 2(-83.5)$. A shift in ppm in a negative direction, as presented with TA1 and TA2, is indicative of an increase in BO species attached to the silicon, within the glass. Thus confirming with the XPS results presented earlier in this chapter. Previous studies have indicated that chemical shifts in the region between -60 and -120 ppm represent structural changes around the $\mathrm{Si}$ atom in a four coordinate state and suggested the presence of $\mathrm{Q}^{1}, \mathrm{Q}^{2}$ and $\mathrm{Q}^{3}$ species at -78, -85 and -95 ppm respectively [328]. All glasses show a broad peak around $-80 \mathrm{ppm}$. This suggests that the formulated glasses contain both $\mathrm{Q}^{1} / \mathrm{Q}^{2}$. However the broadness of the spectral envelope in all peaks suggests the presence of multiple Q-species and indicates that silicon is present in distorted environments within the glass structure.

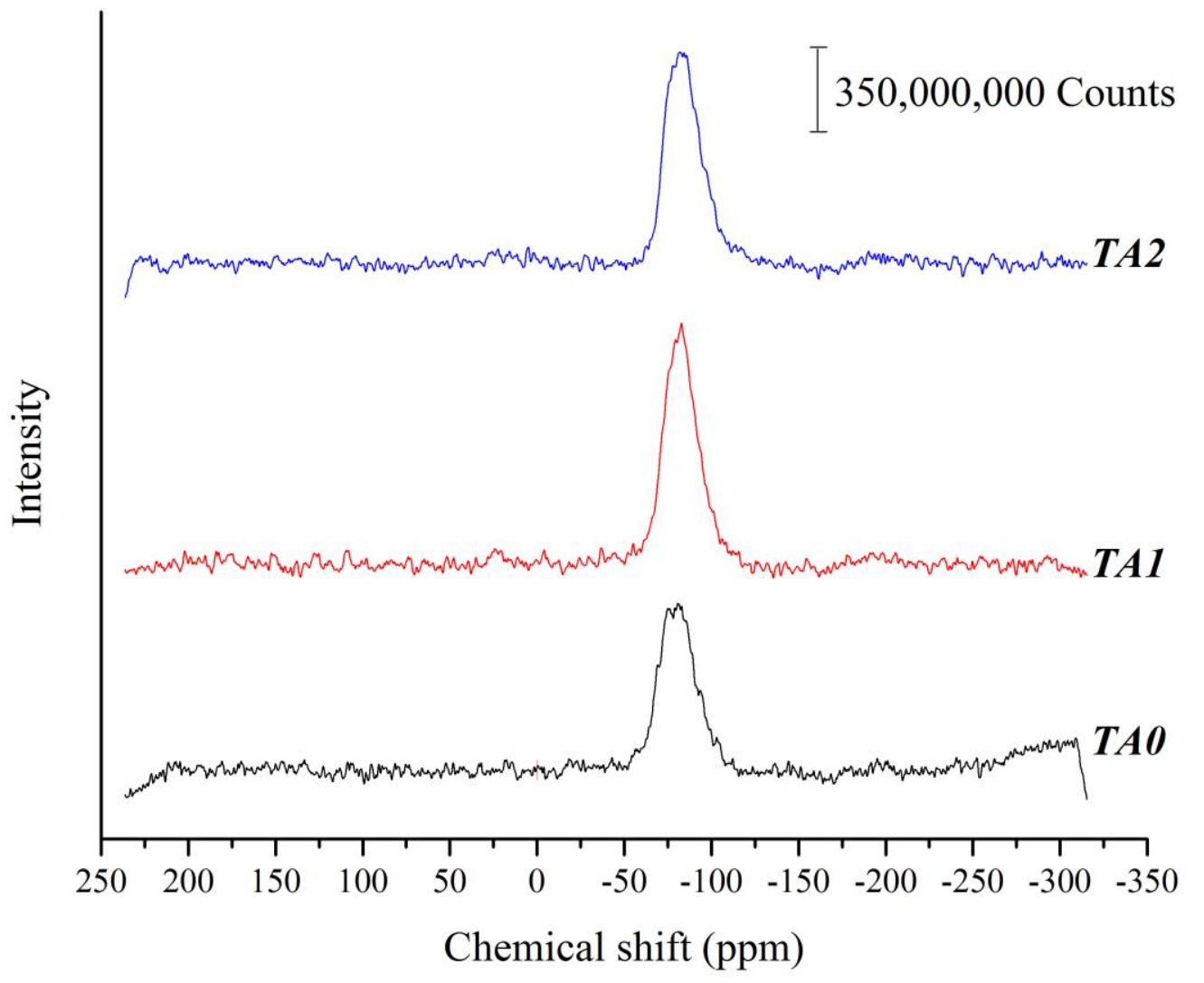

Figure 4.6: ${ }^{29}$ Si MAS-NMR spectra of the glass series. 

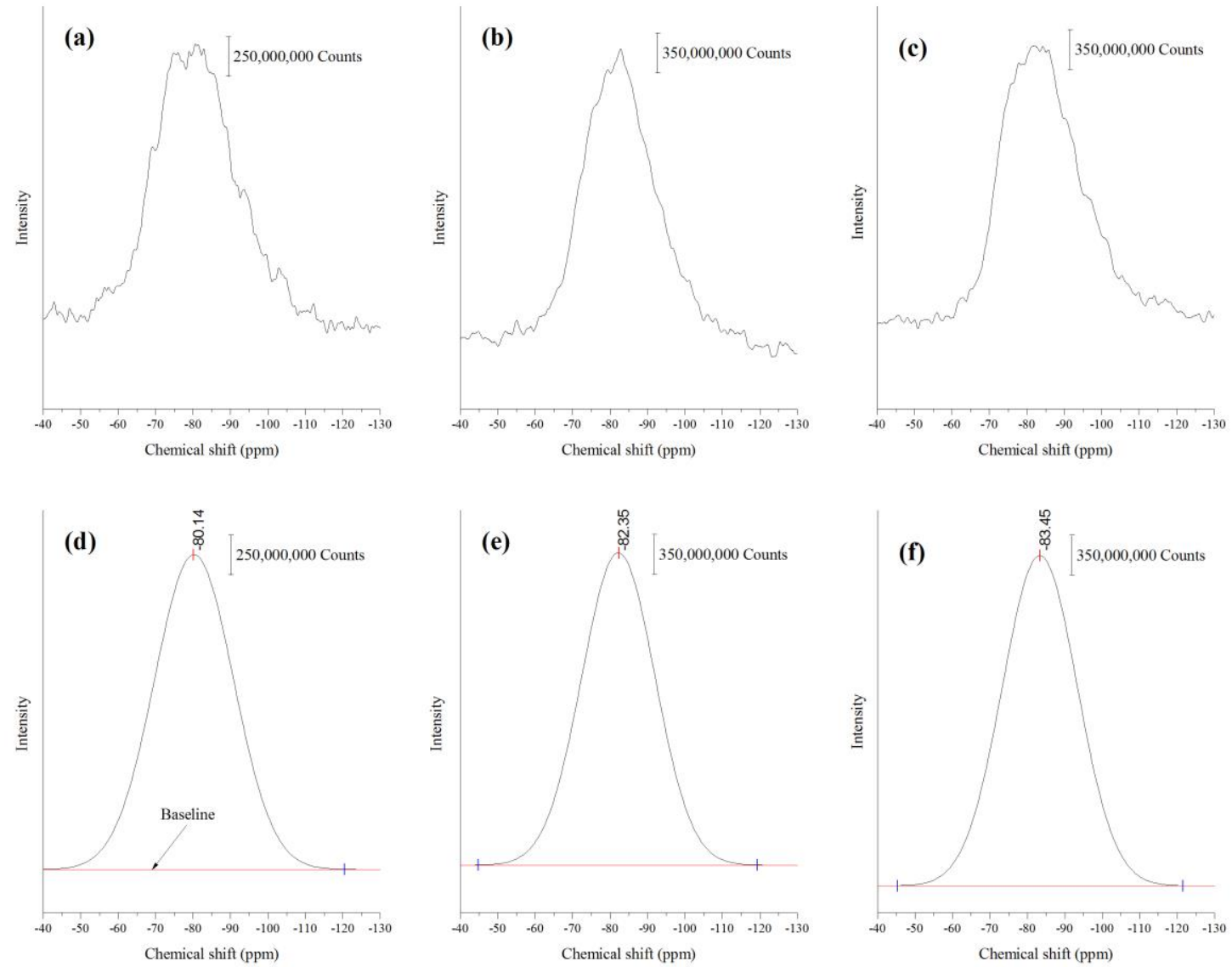

Figure 4.7: Curve fitting of the 29Si NMR spectra: (a) expanded spectrum of TA0; (b) expanded spectrum of TA1; (c) expanded spectrum of TA2; $(d)$ simulated (curve fitted) spectrum of $(a) ;(e)$ simulated spectrum of $(b)$ and $(f)$ simulated spectrum of $(c)$.

\subsubsection{Glass solubility properties}

As discussed, substituting $\mathrm{Ta}_{2} \mathrm{O}_{5}$ with $\mathrm{ZnO}$ resulted in increased $\mathrm{BO} / \mathrm{NBO}$ ratio which correlated with a shift in the thermal events in these glasses to higher temperatures. However, incorporation of $\mathrm{Ta}_{2} \mathrm{O}_{5}$, replacing $\mathrm{ZnO}$, was found to increase the cumulative $\%$ weight loss per unit area of the glasses under study (see Figure 4.8a). The results of $\mathrm{pH}$ measurements (Figure 4.8b) as well as ion release studies of $\mathrm{Zn}^{2+}$ and $\mathrm{Sr}^{2+}$ ions (Figure 4.9a,b) reflected the degradation behavior of the glasses. It can be noted that the $T A 2$ formulation exhibits greater cumulative \% weight loss, $\mathrm{pH}$ values and cumulative $\mathrm{Zn}^{2+}$ and $\mathrm{Sr}^{2+}$ ion concentration over a period of 30 days of maturation, when compared to TAl and/or TAO glasses. Table 4.5 and Table 4.6 show the statistics around these studies, which consider both the effect of $\mathrm{Ta}_{2} \mathrm{O}_{5}$ content and aging on the obtained results. Significant differences (Table 4.5, $p<0.05$ ) in the cumulative 
$\%$ weight loss could only be observed when comparing 1 day with 30 day results for TAO and TA2 samples. However, no significant difference (Table 4.6, $p>0.05$ ) in the cumulative $\%$ weight loss was observed when results were compared with respect to $\mathrm{Ta}_{2} \mathrm{O}_{5}$ content. Significant changes (Table 4.5, $p<0.05$ ) in the $\mathrm{pH}$ measurements were obtained when results were compared with respect to all time modalities. With regards to $\mathrm{Ta}_{2} \mathrm{O}_{5}$ content, there were significant differences in $\mathrm{pH}$ measurements (Table 4.6, $p<0.05$ ) between TAO and TA1 measured at day 7 and between TAO and TA2 measured at 7 and 30 days. Ion release studies of both $\mathrm{Zn}^{2+}$ and $\mathrm{Sr}^{2+}$ showed significant differences $(p<0.05)$ when results were compared with respect to aging time as well as $\mathrm{Ta}_{2} \mathrm{O}_{5}$ content (see Table 4.5 and Table 4.6).

Considering the former role of $\mathrm{Ta}_{2} \mathrm{O}_{5}$ and its substitution with $\mathrm{ZnO}$ in the formulated glasses, the solubility properties were expected to decrease. This assumption can be attributed to the fact that dissolution rates must decrease with additional cross-links formed between the silicate groups and tantalum ions. The solubility behavior of the glasses under study however shows that water can diffuse into the glass structure causing some cations to release into the surrounding medium, resulting in increased \% weight loss and consequently higher $\mathrm{pH}$ and ion release profiles. Previous studies [329,330] have shown that solubility of a glass system strongly depends on the glass composition. It can be generalized that the addition of network modifiers disrupts bonds within the glass network resulting in increased number of NBOs and subsequently increased hydration/solubility when aged in a medium such as water or SBF. Vice versa, the addition of a glass former results in the formation of additional cross-linking within the glass structure resulting in increased network connectivity, reducing solubility. In this study, the results obtained give a basis for assuming that increasing the $\mathrm{Ta}_{2} \mathrm{O}_{5}$ content in the formulated silica-based glasses is accompanied by a rapid dissolution of the unstable residual glass phase at the initial stage of the interaction. This could happen due to the physical and chemical chatacteristics of Ta, which is a basic metal that has a highly reactive surface. The surface of the $\mathrm{Ta}_{2} \mathrm{O}_{5}$ is protected by a thin oxide layer [331], thus preventing its reaction with water. The authors assume that when $\mathrm{Ta}_{2} \mathrm{O}_{5}$ is incorporated in a bioglass system and soaked in water, Ta acts in the same way as $\mathrm{Ca}$ or $\mathrm{Sr}$, meaning that it acts as an unstable residual glass particle. This results in its quick dissolution in the water upon immersing. Further, the solubility behaviour of the glass system under study could have resulted from the fact that Ta is more electropositive than $\mathrm{Zn}$, as predicted from the periodic table of elements. According to the generalized solubility 
rules, the more electropositive the central atom, the more basic the oxide. The results obtained herein confirm with the general rules of solubility and show that Ta when compared to $\mathrm{Zn}$ is a more electropositive metal that increases $\mathrm{pH}$ of the medium in which it is immersed due to its rapid dissolution in the surrounding medium. This initial burst of the cations could be favorable for both cell viability and osseo-integration as well as for fighting against bacterial species.

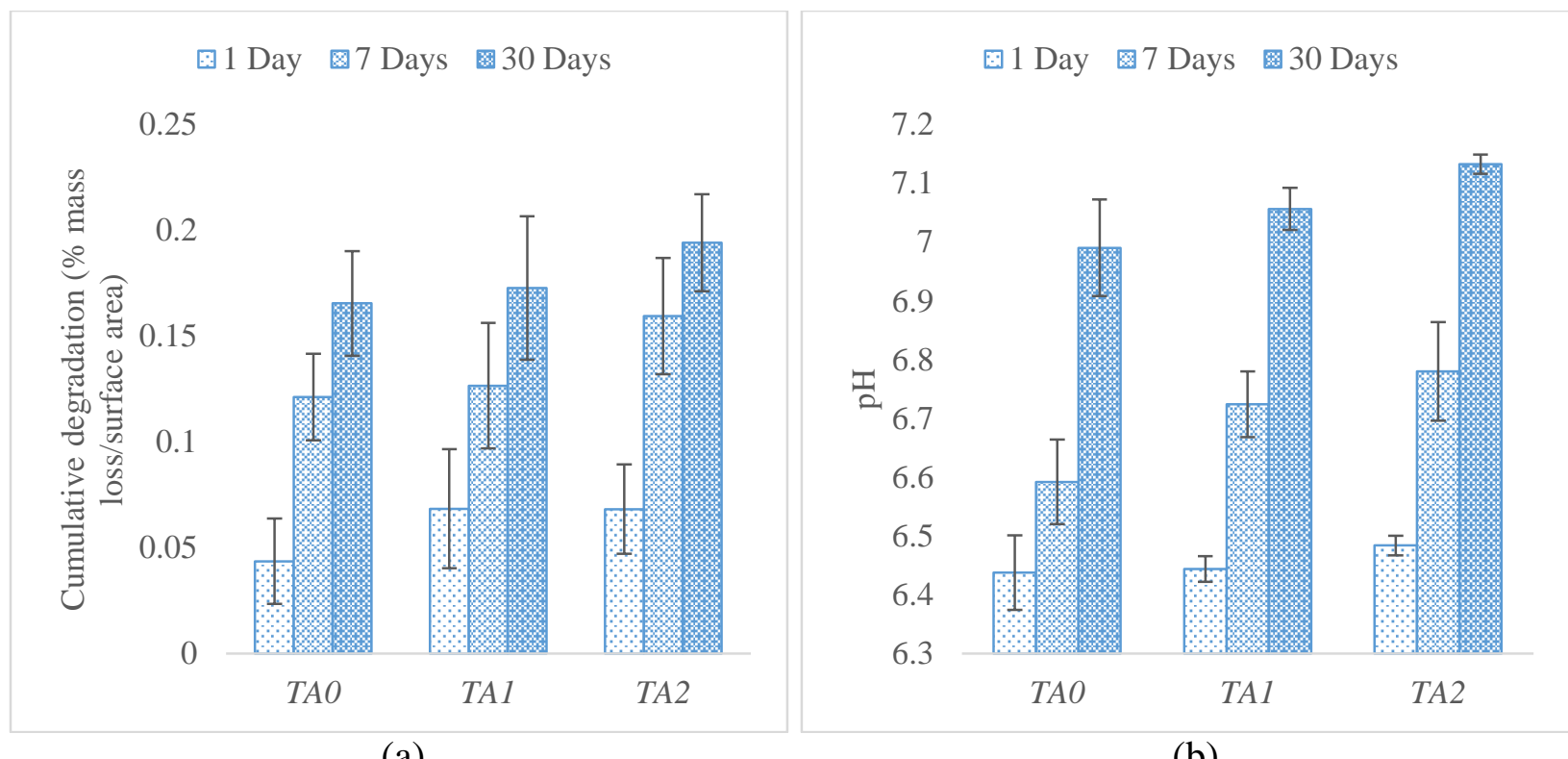

(a)

(b)

Figure 4.8: (a) Percentage weight loss of the glass series in deionized water as a function of time, (b) pH measurements during glass solubility in deionized water. Error bars represent standard deviation from the mean.

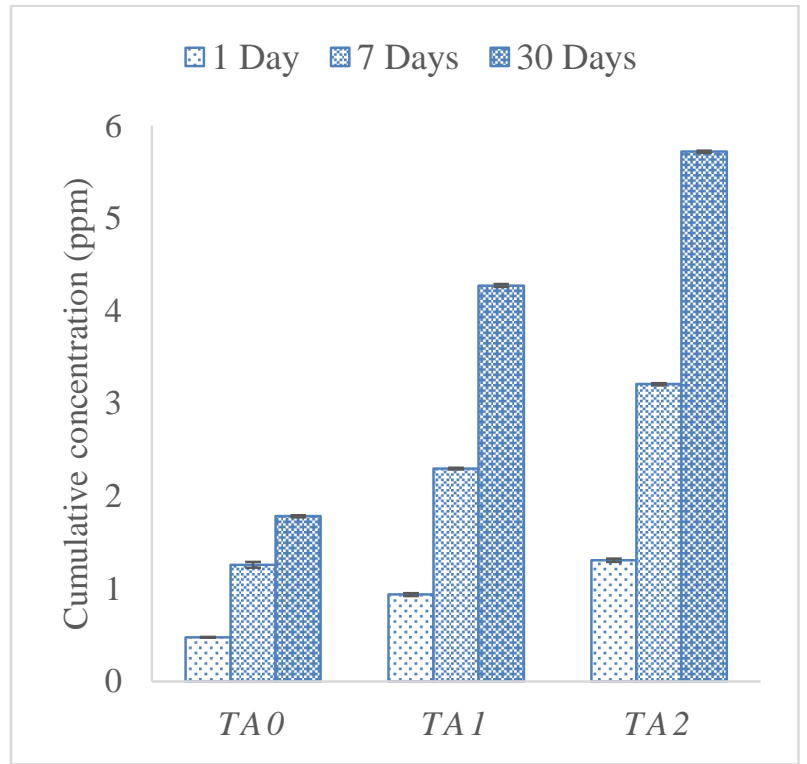

(a)

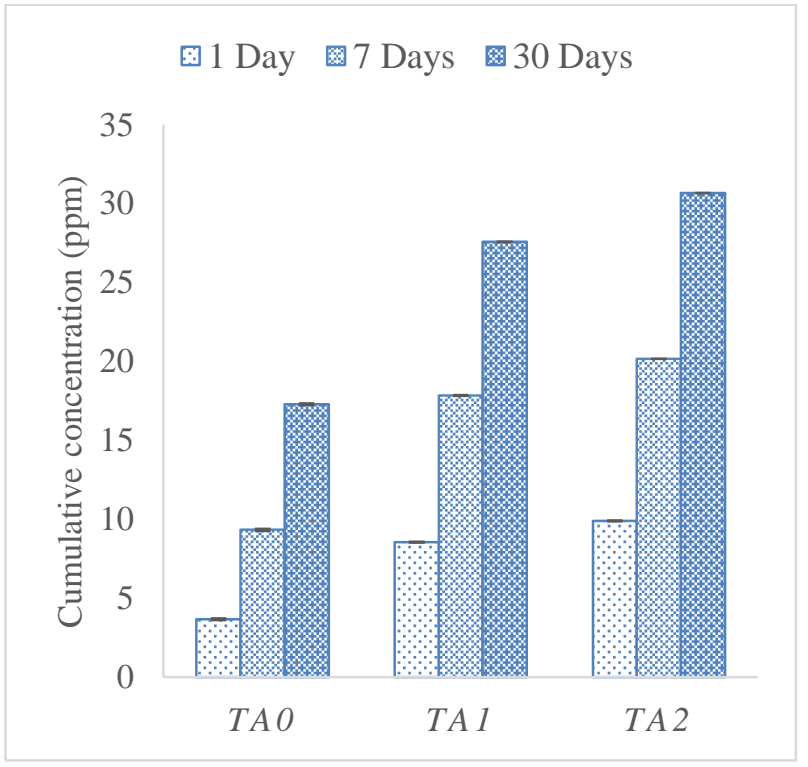

(b)

Figure 4.9: Ion release profiles of (a) Zn2+ and (b) Sr2+ ions during glass solubility in deionized water. Error bars represent standard deviation from the mean. 
Table 4.5: Glass solubility statistics (with respect to aging time)

\begin{tabular}{clccc}
\hline & & TAO & TA1 & TA2 \\
\hline \% weight loss & 1 day vs. 7 day & 0.082 & 0.615 & 0.059 \\
& 7 day vs. 30 day & 0.536 & 0.921 & 0.984 \\
pH & 1 day vs. 30 day & $0.006^{*}$ & 0.099 & $0.009^{*}$ \\
& 1 day vs. 7 day & $0.018^{*}$ & $0.000^{*}$ & $0.000^{*}$ \\
& 7 day vs. 30 day & $0.000^{*}$ & $0.000^{*}$ & $0.000^{*}$ \\
Sr ion release & 1 day vs. 30 day & $0.000^{*}$ & $0.000^{*}$ & $0.000^{*}$ \\
& 1 day vs. 7 day & $0.000^{*}$ & $0.000^{*}$ & $0.000^{*}$ \\
& 7 day vs. 30 day & $0.000^{*}$ & $0.000^{*}$ & $0.000^{*}$ \\
Zn ion release & 1 day vs. 30 day & $0.000^{*}$ & $0.000^{*}$ & $0.000^{*}$ \\
& 1 day vs. 7 day & $0.001 *$ & $0.000^{*}$ & $0.000^{*}$ \\
& 7 day vs. 30 day & $0.018^{*}$ & $0.000^{*}$ & $0.000^{*}$ \\
& 1 day vs. 30 day & $0.000^{*}$ & $0.000^{*}$ & $0.000^{*}$ \\
\hline
\end{tabular}

* The mean difference is significant at the 0.05 level.

Table 4.6: Glass solubility statistics (with respect to Ta2O5 content)

\begin{tabular}{clccc}
\hline & & TAO vs. TAI & TAl vs. TA2 & TAO vs. TA2 \\
\hline \% weight loss & 1 day & 1.000 & 1.000 & 1.000 \\
& 7 day & 1.000 & 1.000 & 0.965 \\
30 day & 1.000 & 1.000 & 1.000 \\
pH & 1 day & 1.000 & 0.417 & 0.280 \\
Sr ion release & 7 day & $0.038^{*}$ & 0.716 & $0.004^{*}$ \\
& 30 day & 0.212 & 0.124 & $0.003^{*}$ \\
& 7 day & $0.000^{*}$ & $0.000^{*}$ & $0.000^{*}$ \\
Zn ion release & $0.000^{*}$ & $0.001^{*}$ & $0.000^{*}$ \\
& 30 day & $0.000^{*}$ & $0.001^{*}$ & $0.000^{*}$ \\
& 1 day & $0.001^{*}$ & $0.005^{*}$ & $0.000^{*}$ \\
& 7 day & $0.000^{*}$ & $0.000^{*}$ & $0.000^{*}$ \\
& 30 day & $0.000^{*}$ & $0.000^{*}$ & $0.000^{*}$ \\
\hline
\end{tabular}

* The mean difference is significant at the 0.05 level.

\subsection{Summary}

The work herein has shown that the synthesis of amorphous $\mathrm{Ta}_{2} \mathrm{O}_{5}$-containing glasses was possible via the melt-quenching process. The incorporation of up to 0.5 mole percentage $\mathrm{Ta}_{2} \mathrm{O}_{5}$ at the expense of $\mathrm{ZnO}$ resulted in structural changes resulting from the insertion of $\mathrm{TaO}$ units into the silicate network. Glass solubility experiments showed that minor amounts of Ta incorporation altered the glass solubility. The ability to control glass solubility by minor compositional modifications offers great promise for the clinical applications of such bioglasses where the coordination of material solubility with bone remodelling/formation are of paramount importance. 


\section{A novel Tantalum-containing bioglass. Part II. Development of a bioadhesive for sternal fixation and repair}

\section{This chapter is based on the following published paper:}

Alhalawani, A.M.F.; Mehrvar, C; Stone, W.; Waldman, S.D.; and Towler, M.R. A novel Tantalum-containing bioglass. Part II. Development of a bioadhesive for sternal fixation and repair, Mater Sci Eng C Mater Biol Appl., 2017, 71, 401-411.

\subsection{Introduction}

Glass polyalkenoate cements were developed in the late 1960s. They consist primarily of an organic aqueous solution of polyalkenoic acid (PAA) and an inorganic acid-degradable fluoroalumino-silicate glass [332]. By mixing these constituents together, the glass component degrades to release cations which are responsible for crosslinking the PAA chains to form a polysalt matrix [151]. The acid component facilitates the adhesion of the GPC to bone and plays an instrumental role in controlling the setting reaction and the resultant physical and mechanical properties [332,333].

GPCs have been used in dentistry for over 40 years. They adhere to tooth structure and are both biocompatible and bioactive [248,334]. They do not set with an exotherm nor do they undergo significant volumetric shrinkage with maturation [335]. However, all commercial GPCs contain, and subsequently release, $\mathrm{Al}^{3+}$ ions from the glass phase during setting which can have a deleterious effect on the recipient of the cement. To address this issue, attempts have been made to modify the chemistry of the glass phase in order to increase their utility in orthopedic applications [336-338] including vertebroplasty and kyphoplasty [339], arthroplasty [340] and sternal fixation [284,341]. These amendments to the glass reagent can also impart an antibacterial effect to the resultant cements as they mature, due to the release of ions such as zinc and strontium $[129,118] . \mathrm{Zn}$ is the second most prevalent trace element in the human body and is required for correct functioning of the immune system, healthy bone metabolism, growth and repair, as well as effective wound healing and antibacterial efficacy [342]. Sr is involved in bone metabolism and plays a physiological role in growth and mineralization of bone tissue [343], therefore up-regulating osteoblastic bone formation. The incorporation of such elements into an Al-free GPC offers the possibility of their slow release at the implant site to facilitate antibacterial and bone regenerating effects. 
Tantalum is used for orthopedic devices [322-324] due to its excellent physical and biological properties. The Ta ion, itself, is reported to be both bioactive and biocompatible due to the formation of a stable $\mathrm{Ta}_{2} \mathrm{O}_{5}$ component on its surface [282,325]. Previous studies [322,326] have shown that Ta surfaces exhibit lower contact angles and higher surface energy than titanium or HA surfaces. Their wettability, high surface energy and enhanced cell-material interactions have confirmed that $\mathrm{Ta}$, as a metallic bio-inert material, offers a favorable biological environment for adhesion, growth and differentiation of human cells. Further, the incorporation of Ta into acrylic bone cements has been reported to increase radiopacity [281]. Despite some processing challenges [324,327], the inclusion of Ta and other transition metals into ionomer glasses can improve their thermal, optical and chemical stability [278-280,317].

Median sternotomy surgery is the gold standard for cardiac procedures. Various techniques have been used for sternal fixation, post sternotomy, including wiring [14,30,71], plate-screw systems [34,78] and cementation [26,344,345]. All such techniques were critiqued in a review authored by Alhalawani \& Towler (refer to chapter 1). Generally speaking, the techniques utilized for sternal fixation have complications restricting their widespread adoption. Sternal wound complications (SWC) occur in $0.4-5 \%$ of patients undergoing cardiac surgery, and pose a serious risk to affected patients. In particular, deep SWCs (osteomyelitis and mediastinitis) are associated with a mortality rate between 14-47\% [34-36]. Dehiscence causes up-to 40\% mortality and morbidity after median sternotomy with an incidence rate of $0.3-8 \%$ [29,30]. The authors previously reported on the potential of Gallium-containing GPCs for sternal fixation [284,283,285]. However, the adhesive properties of the GPCs, deteriorated with increased Ga content, when evaluated in a bovine sternal model [284].

Ta containing GPCs could provide clinicians with an adhesive applicable for sternal fixation and repair. The objective of this chapter is to characterize the physical, mechanical and biological properties of new adhesive materials based on Ta-containing GPCs, with the intent to optimize these materials for sternal fixation and repair. 


\subsection{Materials and methods}

\subsubsection{Glass synthesis}

Refer to section 4.2.1.

\subsubsection{Cement preparation}

Cement samples were prepared by thoroughly mixing the annealed glass with PAA (Mw, $\sim 213,000$ and median particle size $<90 \mu \mathrm{m}$, Sigma-Aldrich, St. Louis, MI, USA) and DI water on a glass plate. The cements were formulated in a P:L ratio of 1:1, where $1 \mathrm{~g}$ of glass was mixed with $0.50 \mathrm{~g}$ PAA 200 and $0.50 \mathrm{ml}$ DI water. Complete mixing was undertaken within $30 \mathrm{sec}$ in ambient room temperature $\left(23 \pm 1{ }^{\circ} \mathrm{C}\right)$. Cements are subsequently named (TAO, TA1 and TA2) after the glasses that they were fabricated from.

\subsubsection{Evaluation of setting characteristics}

\subsubsection{Working and net setting (hardening) times}

The working time of the cements was measured in ambient air $\left(23 \pm 1{ }^{\circ} \mathrm{C}\right)$ using a stopwatch, and was defined as the period of time from the start of mixing during which it was possible to manipulate the material without having an adverse effect on its properties. The setting time of cements was measured in accordance with ISO 9917-1:2007 for dental based cements. An empty mould with internal dimensions $10 \mathrm{~mm}$ x $8 \mathrm{~mm}$ was placed on aluminum foil and filled to a level surface with mixed cement. Sixty sec after mixing commenced, the entire assembly was placed on a metal block ( $8 \mathrm{~mm} \times 75 \mathrm{~mm} \times 100 \mathrm{~mm}$ ) in an oven maintained at $37{ }^{\circ} \mathrm{C}$. Ninety sec after mixing, a Vicat needle indenter (mass $400 \mathrm{~g}$ ) was lowered onto the surface of the cement. The needle was allowed to remain on the surface for $5 \mathrm{sec}$, the indent it made was then observed and the process was repeated every $30 \mathrm{sec}$ until the needle failed to make a complete circular indent when viewed at $\mathrm{x} 2$ magnification. The net setting time of the three tests was recorded.

\subsubsection{Fourier transform infrared (FTIR) spectroscopic study}

Three cement cylinders ( $6 \mathrm{~mm}$ high, $4 \mathrm{~mm}$ diameter) of each composition were prepared and aged for 1 and 7 days in DI water. $\sim 0.3$ g powdered versions ( $<90 \mathrm{um}$ ) of each cement were spread onto $\mathrm{NaCl}$ crystal discs of $25 \mathrm{~mm}$ diameter. Spectra were collected using a Fourier transform infrared spectrometer (Spectrum One FTIR spectrometer, Perkin Elmer Instruments, USA) and background contributions were removed. The sample and the reference background spectra were collected 16 times for each cement formulation in ambient air $\left(23 \pm 1^{\circ} \mathrm{C}\right)$. Analysis 
was performed in the wavenumber ranging from 900 to $3750 \mathrm{~cm}^{-1}$ with a spectral resolution of 4 $\mathrm{cm}^{-1}$.

\subsubsection{Evaluation of $\mathrm{pH}$ and ion release}

\subsubsection{Samples preparation}

GPC cylinders (6 $\mathrm{mm}$ high and $4 \mathrm{~mm}$ diameter) were prepared from each glass type for $\mathrm{pH}$ testing and ion release studies. Sample solutions were prepared by exposing cylindrical samples $(n=3)$ in calculated quantities $(10 \mathrm{ml})$ of sterile DI water and incubated $\left(37^{\circ} \mathrm{C}\right)$ for 1,7 and 30 days.

\subsubsection{2 pH analysis}

Refer to section 4.2.3.2.

\subsubsection{Ion release studies}

Refer to section 4.2.3.3.

\subsubsection{Evaluation of mechanical properties}

\subsubsection{Determination of compressive strength}

The compressive strength $\left(\sigma_{\mathrm{c}}\right)$ of the cements $(n=5)$ were evaluated in ambient air $\left(23 \pm 1{ }^{\circ} \mathrm{C}\right)$ as described by ISO 9917-1:2007. Within $60 \mathrm{sec}$ after mixing of the cement, the moulds (4 mm $\emptyset, 6 \mathrm{~mm}$ height) were filled to excess with cement. The moulds were then sandwiched between 2 $3 \mathrm{D}$ printed polymer plates, clamped, and incubated $\left(37^{\circ} \mathrm{C}, 1 \mathrm{hr}\right)$. Following incubation the samples were de-moulded and flash around the moulds was removed using 1200 grit siliconcarbide paper. Samples were then placed in DI water and incubated for 1, 7 and 30 days. The dimensions of each sample were measured using digital Vernier calipers. The test jig was fixed to an Instron Universal Testing Machine (Instron Corp., Massachusetts, USA) using a $\pm 2 \mathrm{kN}$ load cell at a crosshead speed of $1 \mathrm{~mm} \cdot \mathrm{min}^{-1}$. The fracture load was noted for each sample. Compressive strength was calculated according to Eq. 5.1.

$$
C=\frac{4 \rho}{\pi d^{2}}
$$

Where $\rho$ is the fracture load $(\mathrm{N})$ and $\mathrm{d}$ is the sample diameter $(\mathrm{mm})$.

\subsubsection{Determination of Biaxial flexural strength}

The biaxial flexural strengths $\left(\sigma_{\mathrm{f}}\right)$ of the cements $(n=5)$ were evaluated using the method as described by Williams et al. [347] using three support bearings on the test jig. Within $60 \mathrm{sec}$ after mixing of the cement, rubber moulds $(12 \mathrm{~mm} \varnothing, 2 \mathrm{~mm}$ thick) were filled to excess with cement. The moulds were then sandwiched between 2 SS plates, clamped, and incubated $\left(37^{\circ} \mathrm{C}\right.$, 
$1 \mathrm{hr}$ ). Following incubation the samples were de-moulded and flash was removed from the edges of each disc using 1200 grit silicon-carbide paper. Samples were then placed in DI water and incubated for 1, 7 and 30 days. The thickness of each sample was measured using digital Vernier calipers. The test jig was fixed to an Instron Universal Testing Machine (Instron Corp., Massachusetts, USA) using a $\pm 2 \mathrm{kN}$ load cell at a crosshead speed of $1 \mathrm{~mm} \cdot \mathrm{min}^{-1}$. The fracture load was noted for each sample. Biaxial flexural strength was calculated according to Eq. 5.2.

$$
B F S=\frac{\rho(N)}{t^{2}}\left\{0.63 \ln \left(\frac{r}{t}\right)+1.156\right\}
$$

Where $\rho$ is the fracture load $(\mathrm{N}), \mathrm{t}$ is the sample thickness $(\mathrm{mm})$ and $\mathrm{r}$ is the radius of the support diameter (mm).

\subsubsection{Determination of Vickers hardness}

Hardness testing was performed on cement discs $(12 \mathrm{~mm} \varnothing, 2 \mathrm{~mm}$ thick) with ten measurements taken per disc and three discs used for each glass composition. Samples were tested after 1, 7 and 30 days immersion in sterile DI water at $37^{\circ} \mathrm{C}$. A Shimadzu HMV-2000 micro hardness testing machine (Shimadzu Corporation, Kyoto, Japan) was used. Discs were mounted in epoxy resin and polished using 600 grit silicon carbide polishing paper. Ten Vickers indentations at a load of $500 \mathrm{~g}$ and a dwelling time of $15 \mathrm{sec}$ were made on each disc by indenting the test material with a diamond indenter as shown in Figure 5.1. Using the attached light microscope and computer, the diagonals created by the indenter were measured and VHN was calculated using Eq. 5.3.

$$
H v=\frac{\frac{2 F \sin 136^{\circ}}{2}}{d^{2}}=1.854 \frac{F}{d^{2}}
$$

Where $\mathrm{F}$ is the applied load (kgf) and d is the diagonal length (mm).

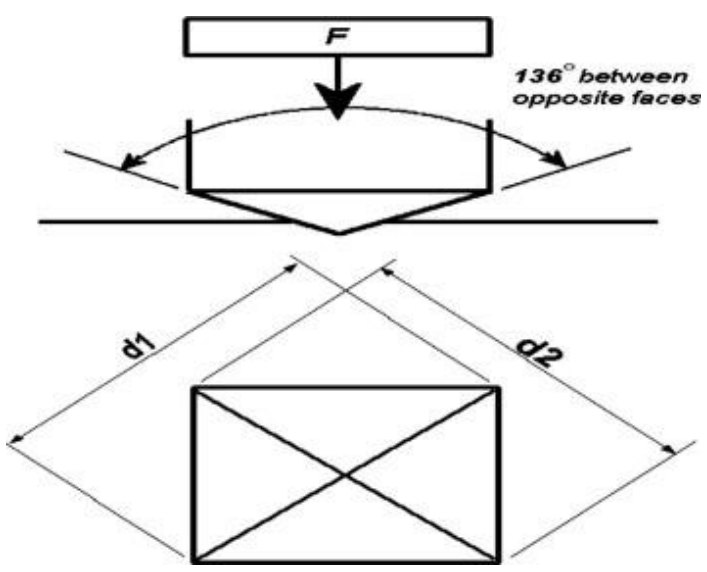

Figure 5.1: Indentation geometry of hardness test. [348] 


\subsubsection{Evaluation of radiopacity}

Cements discs $\left(12 \mathrm{~mm}\right.$ diameter, $1 \mathrm{~mm}$ thick) were prepared and incubated $\left(37^{\circ} \mathrm{C}\right)$ for $1 \mathrm{hr}$. Once removed from their moulds, the samples were ground using 1200 grit silicon carbide paper until, they were $1 \mathrm{~mm}$ thick in accordance with ISO 9917-1:2007 [346]. For the test, the three GPC discs were positioned on dental x-ray film, between an aluminum step wedge (10 steps from thickness from $1.35 \mathrm{~mm}$ to $12.62 \mathrm{~mm}$ ) and an $18 \mathrm{~mm}$ thick lead plate. Film was exposed to $70 \mathrm{kV}$ at $7 \mathrm{~mA}$ for $0.16 \mathrm{sec}$ from the X-ray source (Phot-X II, Belmont Equipment, Somerset, NJ, USA). Optical densities were measured using a QAS Densitometer (Picker International, Highland Heights, OH, USA). Manipulation of results was completed as per the procedure outlined in ISO9917:2007 part 1.

\subsubsection{Antimicrobial analysis}

The antimicrobial properties of the cement discs ( $10 \mathrm{~mm}$ in diameter, $2 \mathrm{~mm}$ thick, $n=3)$ were evaluated on agar plates, against both prokaryotic and eukaryotic species. Prokaryotic species were one Gram-negative bacterium (Escherichia coli) and two Gram-positive bacteria (Staphylococcus aureus and Streptococcus epidermidis) while the eukaryotic species was a fungus (Fusarium solani). Bacterial lawns were spread on Tryptic Soy Agar (3 g/L Tryptic Soy Broth, $15 \mathrm{~g} / \mathrm{L}$ agar). The antimycotic properties of the disks were assessed on Yeast Malt Agar plates (10 g/L Dextrose, $5 \mathrm{~g} / \mathrm{L}$ Peptone, 3g/L Malt Extract, $3 \mathrm{~g} / \mathrm{L}$ Yeast Extract, $15 \mathrm{~g} / \mathrm{L}$ agar, $\mathrm{pH}$ 8.0). All chemicals were purchased from Fisher Scientific (Ottawa, ON, Canada). Bacterial cultures were grown to an exponential phase (12 - 16 hrs), diluted in Physiological Saline Solution $(9 \mathrm{~g} / \mathrm{L} \mathrm{NaCl})$ to $10^{6}$ cells $/ \mathrm{mL}$ and spread onto TSA. Fungal cultures were grown on YMA for 1 month prior to the experiment, and blocks $(1 \mathrm{~cm} \mathrm{x} 1 \mathrm{~cm})$ excised from the outside of the radial colony and transferred to the center of the YMA test plate. Antimicrobial properties were quantified on the bacterial lawns by measuring and comparing the zones of growth inhibition, whereas antimycotic properties against the fungal colonies were compared by measuring the radial growth of the culture.

Samples were sterilized by spreading them in sterile petri dishes and exposing them to ultra violet (UV) light in a biological safety cabinet for 16 hrs (Bio Klone 2 Series, Class II, Type A2 Biological Safety cabinet, equipped with one integral UV light, Microzone Corporation, Napean, Ontario, Canada). 
One disk of each cement ( 3 disks per plate) was added to each bacterial and fungal plate, evenly spaced on the lawn or around the central fungal colony. Each plate (3 disks per plate) had a single microbial species, and each species was repeated in triplicate for statistical comparisons. The diameters of the inhibition zones, as well as the diameters of the fungal colonies, were measured (mm) using digital Vernier Caliper.

\subsubsection{Cytotoxicity testing}

Cytotoxicity of the cement discs (10 $\mathrm{mm}$ in diameter, $2 \mathrm{~mm}$ thick, $n=3$ ) was evaluated using chondrocytes for up to 7 days in culture. Cement discs were first sterilized by soaking in $70 \%$ ethanol overnight, followed by exposure to UV light for $16 \mathrm{hrs}$. Primary bovine articular chondrocytes were then isolated from the metacarpal-phalangeal joints of skeletally mature cattle (12-18 months old) from local slaughter houses by sequential enzymatic digestion. Harvested cartilage slices were incubated in a $0.5 \%$ protease (w/v) (Sigma Aldrich Ltd., Oakville, ON, Canada) for $1.5 \mathrm{hrs}$ at $37{ }^{\circ} \mathrm{C}$ followed by $0.15 \%$ collagenase A (w/v) (Sigma Aldrich) for $18 \mathrm{hrs}$ at $37{ }^{\circ} \mathrm{C}$. Chondrocytes were then separated by passing the digest through a 200 -mesh filter (Sigma Aldrich). Viable cells (determined by Trypan dye exclusion [349]) were re-suspended in DMEM culture media without phenol red and supplemented with $10 \%$ fetal bovine serum and

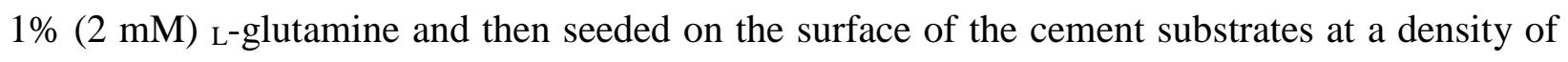
9500 cells per disc. After 1, 3 and 7 days of culture, cell viability was assed using a Methyl Tetrazolium (MTT) assay kit (Sigma Aldrich) according to the manufacturer's instructions. As the presence of the cement discs would interfere with the absorbance measurements, aliquots of the precipitate solution (without cells) were analyzed separately. All results were compared to control cultures of the same number of cells seeded directly onto tissue culture plastic.

\subsubsection{Ex-vivo bond strength testing}

Samples cut from femur cortical bone and reduced to cylindrical bone samples were utilized to study the ability of the developed materials to adhere bovine cortical bones. Bone samples were machined to their final geometries using a computer numerical control (CNC) machine (Figure 5.2). The dimension of the samples was measured accurately using digital Vernier caliper. Fresh bone samples shortly after machining were sterilized and then kept in a protector tube at -4 ${ }^{\circ} \mathrm{C}$. Prior to testing, the samples were left for $0.5 \mathrm{hr}$ at ambient temperature before applying the adhesive. The adhesive of each material (TAO, TA1 and TA2) was prepared as discussed in section 5.2.2 and applied directly on the circular end of both sides of the bovine bone $(n=3)$. 
Both sides were held together for one minute, post cementing, to allow for attachment before it was placed in DI water and incubated $\left(37^{\circ} \mathrm{C}, 1\right.$ day) prior to testing. Testing was undertaken on an Instron Universal Testing Machine (Instron Corp., Massachusetts, USA) using a $\pm 2 \mathrm{kN}$ load cell at a crosshead speed of $1 \mathrm{~mm} \cdot \mathrm{min}^{-1}$. The fracture strength $(\mathrm{N})$ was noted for each sample in tension mode.

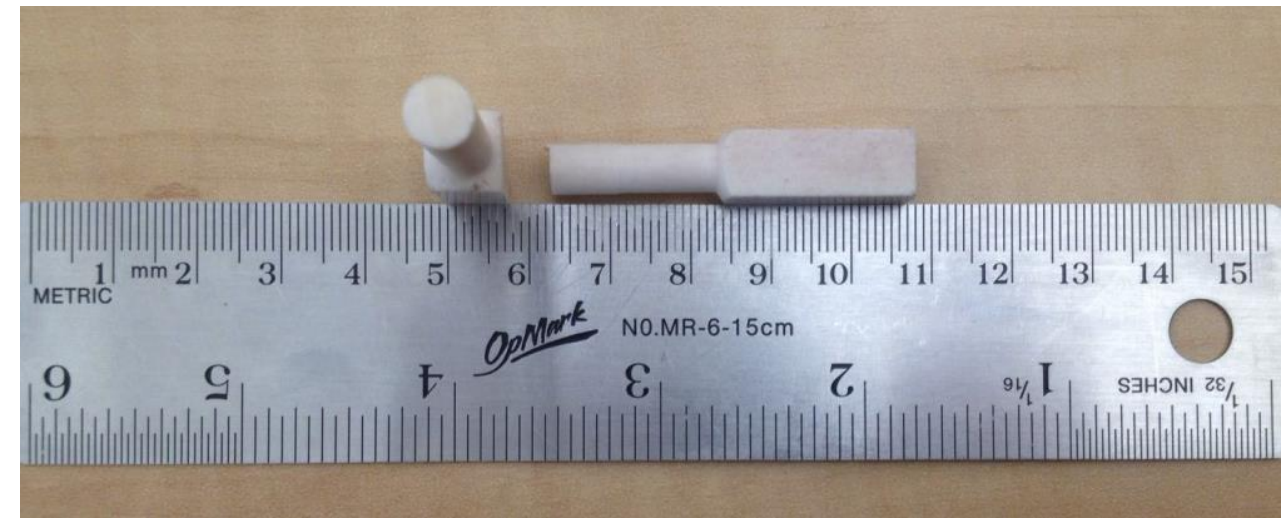

Figure 5.2: Cross-sectional view (left) and side view (right) of the bovine cortical bone sample used for ex-vivo adhesion testing.

\subsubsection{Statistical analysis}

Non-parametric Kruskal-Wallis H Test was used to analyze the data. The Mann-Whitney U test was used to compare the relative means and to report the statistically significant differences when $P \leq 0.05$. Statistical analysis was performed on all groups where $n \geq 3$. Statistical analysis was performed using SPSS software (IBM SPSS statistics 21, IBM Corp., Armonk, NY, USA).

\subsection{Results and discussion}

\subsubsection{Evaluation of cement setting characteristics}

\subsubsection{Working and net setting times}

The working and setting times of the cement series were evaluated with respect to the increasing concentration of $\mathrm{Ta}_{2} \mathrm{O}_{5}$ in the glass phase, and are presented in Figure 5.3. Working times were recorded as 40, 48 and $63 \mathrm{sec}$ for TAO,TA1 and TA2, respectively (Figure 5.3a). There is a statistical significant difference $(P=0.008)$ among all groups. The setting times are also recorded (Figure 5.3b). The $\mathrm{Ta}_{2} \mathrm{O}_{5}$-free GPCs (TAO) presented a setting time of 197 sec which decreased significantly $(P=0.007)$ to $156 \mathrm{sec}$ for $T A l$ and then increased significantly $(P$ $=0.008$ ) to $202 \mathrm{sec}$ for $T A 2$. There is no information on the setting chemistry of Ta-containing GPCs in the literature that can be referenced for comparative purposes. Working and setting times were dependent on the concentration of $\mathrm{Ta}_{2} \mathrm{O}_{5}$ incorporated into the glass. The workability 
of TAO and TAl cements is too short to be considered suitable for sternal fixation application. $T A 2$, however, is more suitable for clinical use due to its longer working and setting times, when compared to those of Ta-free cements. The setting time of all cement formulations lies within the limits outlined by ISO9917-1:2007 for dental based materials/cements, where a minimum of 90 sec and a maximum of $360 \mathrm{sec}$ is required [346]. The setting and working times of Ta-containing cements can be extended/shortened, by changing the P:L ratios and/or by slightly increasing the Ta content within the glass matrix, to meet the requirements of orthopedic surgeries such as sternal fixation. Pre-clinical feedback from cardiac surgeons has confirmed that the incorporation of Ta (up to 0.5 mole percentage) has resulted in adhesive materials suitable for sternal fixation. $\mathrm{Ta}^{5+}$ acts as a network former by adopting six-fold coordination $\left(\mathrm{TaO}_{6}\right)$. $\mathrm{Zn}$ however may either adopt four-fold coordination in oxygen polyhedron and act as a network former, or adopt six-fold coordination and act as a network modifier [317]. Substituting $\mathrm{Ta}^{5+}$ with $\mathrm{Zn}^{2+}$ is expected to result in a better glass structure in terms of stability and electro-neutrality. $\mathrm{Ta}^{5+}$ provides a larger number of positive charges when compared to $\mathrm{Zn}^{2+}$ and therefore acts as a charge-efficient network former. This results in a delay in the gelation process between the $\mathrm{COOH}$ groups and $\mathrm{Ta}^{5+}$ ions resulting in longer handling times. The un-expected decrease in the $\mathrm{T}_{\mathrm{s}}$ of $T A l$ can be attributed to the glass particle size, or to slight changes in the glass compositions. The cements with the highest amounts of $\mathrm{Ta}_{2} \mathrm{O}_{5}$ (TA2) exhibited longer working times and similar setting times than the $\mathrm{Ta}_{2} \mathrm{O}_{5}$-free GPCs and are preferable when compared to TAO and TA1, as clinical materials.

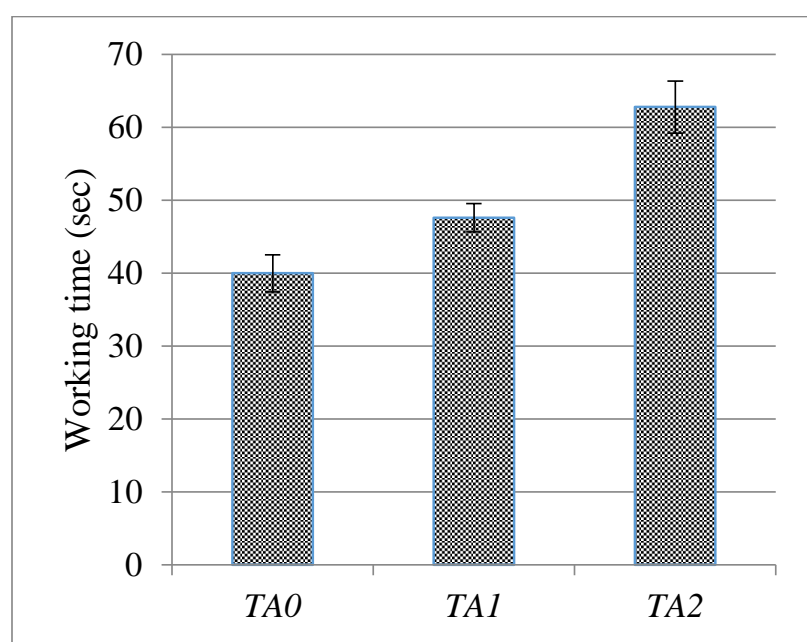

(a)

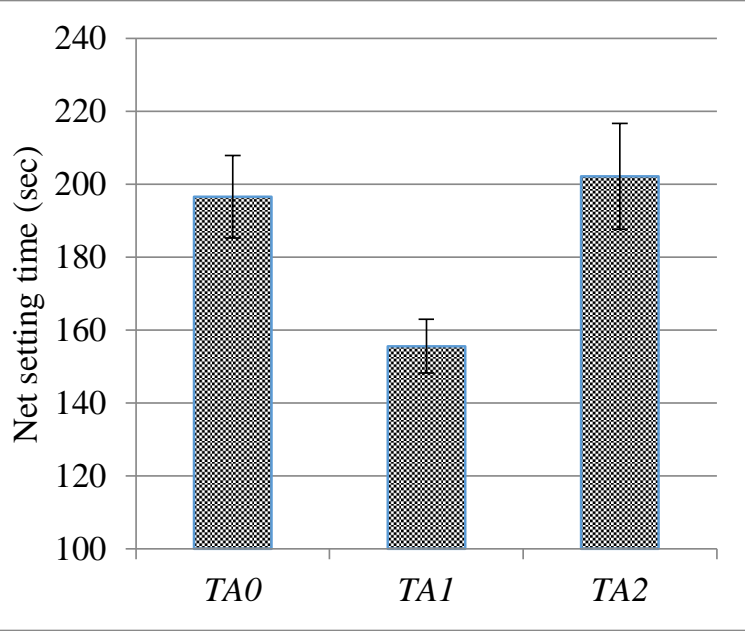

(b)

Figure 5.3: Working and setting times for Ta-containing silica based GPCs. Error bars represent standard deviation from the mean $(n=5)$. 


\subsubsection{FTIR spectroscopic study}

FTIR can provide characteristic information on the setting kinetics of GPCs. FTIR transmittance spectra of the cement series, obtained at days 1 and 7, post cement preparation and maturation in DI water, are shown in Figure 5.4 in the range $3750-900 \mathrm{~cm}^{-1}$. The obtained bands are centered at $3254,1555,1455,1408,1320,1083$, and $965 \mathrm{~cm}^{-1}$. Table 5.1 shows a complete list of the obtained vibration frequencies and their assignments. The broad peak centered at 3254 $\mathrm{cm}^{-1}$ was observed for all spectra and is assigned to the O-H stretch of adsorbed/embedded water within the poly-salt matrix. This $\mathrm{O}-\mathrm{H}$ peak broadens at 7 days, particularly for TAO and TAl. However, the peak intensity does not change significantly for TA2 indicating that TA2 retains the absorbed water for longer times, when compared to TAO and TA1. This results from the former role of Ta in these materials and indicates that the gelation/hardening reactions within TA2 are longer, resulting in longer setting times. The peaks centered at 1555, 1455, 1408 and $1320 \mathrm{~cm}^{-1}$ are assigned to the asymmetric/symmetric stretching vibrations of the carboxyl COO, which could be assumed to be an asymmetrically/symmetrically bonded $\mathrm{COO}-\mathrm{X}$ molecule, where $\mathrm{X}$ represents a possible metal cation. Both $\mathrm{COO}-\mathrm{Ca}^{2+}$ and $\mathrm{COO}-\mathrm{Sr}^{2+}$ groups were identified within the range $1630-1540 \mathrm{~cm}^{-1}$ [99] and within the range $1490-1460 \mathrm{~cm}^{-1}$ [350]. Small shifts to lower wavenumber/frequency were observed for the transmittance bands at 1555, 1455, 1408 and 1320 $\mathrm{cm}^{-1}$ with time. This small shift is caused by the increase in cross-linking (bonding) between the dissociated $\mathrm{COO}-$ group and metal cations, such as the $\mathrm{Ca}^{2+}, \mathrm{Sr}^{2+}$ and $\mathrm{Zn}^{2+}$, to form a metal carboxylate in the cements. Alternatively, the small shifts in frequency of these bands can confirm the complexation of glass cations to the $\mathrm{COOH}$ and the consequent changes within the glass structure, resulting from the insertion of $\mathrm{Ta}_{2} \mathrm{O}_{5}$ within the glass network. This is in good agreement with the literature [284,351-353] [155] which also confirms that the $1083 \mathrm{~cm}^{-1}$ peak represents the $\mathrm{Si}-\mathrm{O}-\mathrm{Si}$ bridges of the cements and as such its relative increase or decrease in intensity correlates to an increase or decrease in the formation of bridging oxygens. The peak at $1083 \mathrm{~cm}^{-1}$ could also represent the Si-O-Ta bridges within the glass structure. The peak at 965 $\mathrm{cm}^{-1}$ is assigned to the $\mathrm{Si}-\mathrm{OH}$ bridges within the glass network. The peaks obtained from samples matured for 1 and 7 day samples do not show a trend in relation to the $\mathrm{Ta}_{2} \mathrm{O}_{5}$ content, however the TA2 peak was observed at the highest \%transmittance $(83 \% \mathrm{t})$ for 1 day samples. This could possibly be due to the changes within the glass network in relation to the insertion of $\operatorname{Ta}_{2} \mathrm{O}_{5}$ metallic ions into the silicate network, hence disrupting the network and resulting in longer 
setting times. TA2 experiences a drop in \%transmittance for the 7 day sample $(65 \% \mathrm{t})$ and this may be attributed to the formation of stronger bonds between the glass cations and acidic anions during maturation in DI water indicating that $T A 2$ results in stronger cements upon immersion in a medium such as DI water.

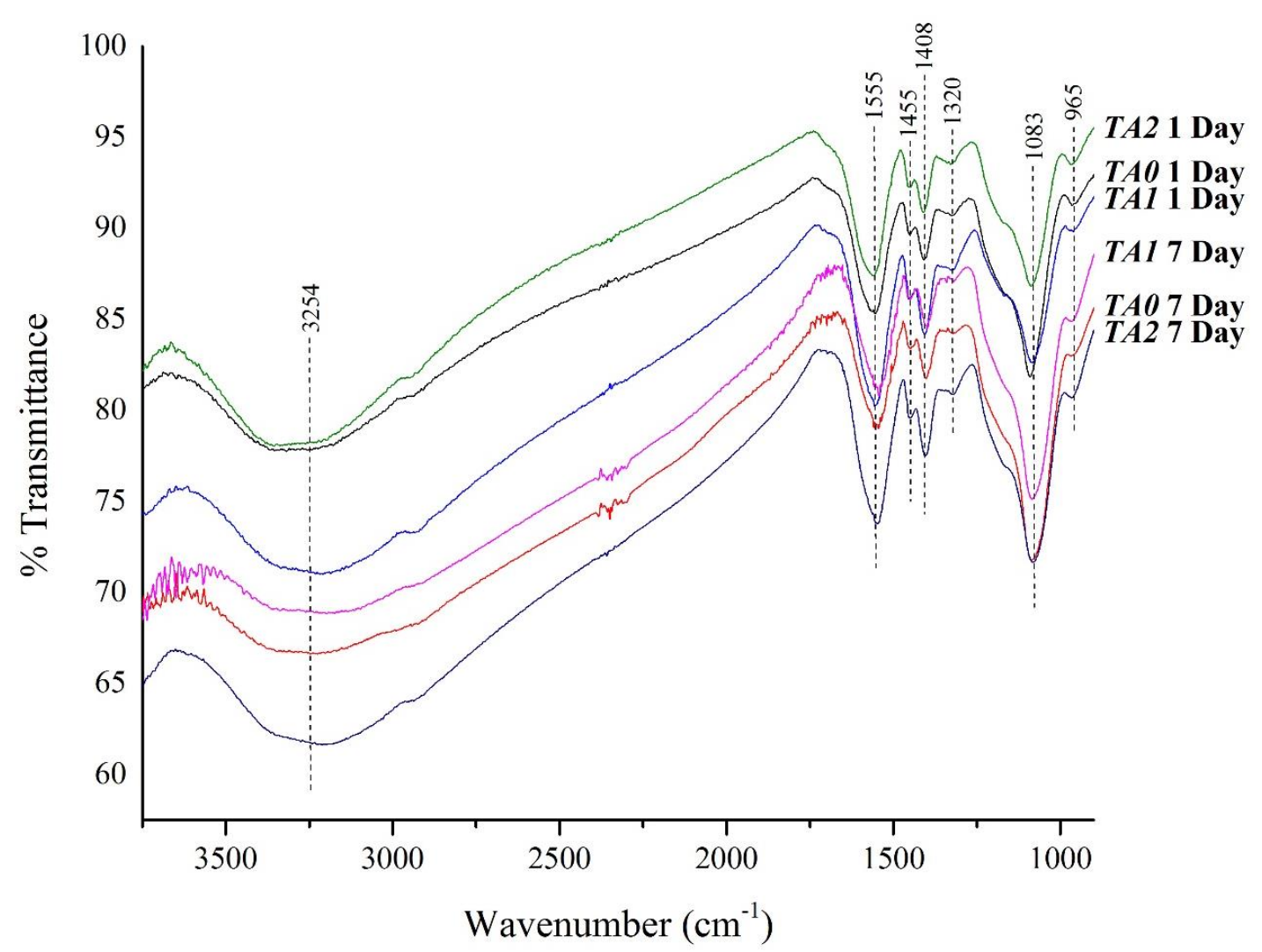

Figure 5.4: FTIR spectrum of cement series over 1 and 7 day, post cement preparation and aging in DI water.

Table 5.1: Characteristic vibration frequencies (cm-1) in FTIR spectra of the cement series.

\begin{tabular}{lcc}
\hline Infrared band position $\left(\mathrm{cm}^{-1}\right)$ & Peak assignment & Ref. \\
\hline 3254 & O-H stretching & {$[284,354]$} \\
$1555-1320$ & Asymmetrical $\mathrm{COO}-\mathrm{X}$ bonding, where $\mathrm{X}$ represents a possible metal & {$[284]$} \\
& cation $\left(\mathrm{Ca}^{2+}, \mathrm{Sr}^{2+}, \mathrm{Zn}^{2+}\right)$ & \\
1083 & $\mathrm{Si-O}-\mathrm{Si} / \mathrm{Si}-\mathrm{O}-\mathrm{Ta}$ stretchig vibration & {$[155]$} \\
965 & $\mathrm{Si}-\mathrm{OH}$ deformation vibration & {$[155]$} \\
\hline
\end{tabular}

\subsection{2 $\mathrm{pH}$ and ion release studies}

\subsubsection{1 pH analysis}

The changing $\mathrm{pH}$ values of the DI water $(\mathrm{pH}=6.0)$ as a function of $\mathrm{Ta}_{2} \mathrm{O}_{5}$ content are plotted in Figure 5.5. Comparing TAO with TA2, there was a significant increase in $\mathrm{pH}(\sim 6.0-6.6$, 
$P=0.008)$ for 1 day samples, a significant decrease in $\mathrm{pH}(\sim 6.9-6.6, P=0.008)$ for 7 day samples and almost identical $\mathrm{pH}$ values $(\sim 6.82, P=0.310)$ for 30 days samples. Further, there was a statistically significant difference $(P<0.05)$ in the $\mathrm{pH}$ values when comparing TAO and TAl for 1 day $(P=0.032)$ and 30 day $(P=0.016)$ groups. However, there was no significant difference $(P=0.421)$ between $T A O$ and $T A 1$ for 7 day samples. The $\mathrm{pH}$ was dependent on immersion time with values varying between $\sim 6$ and $\sim 6.9$ for all cement formulations. However, it is important to note that slight or no change in $\mathrm{pH}$ values $(P>0.05)$ were obtained when comparing 7 and 30 days samples for all cement formulations.

When a GPC sample is aged in DI water, hydrogen ions diffuse and dissociate the polycarboxylic chains within the GPC structure and prompt the glass particles to release cations into the environment. This process is controlled by the concentration of hydrogen ions in both the immediate environment (DI water) and the GPC matrix (COOH groups) [145]. In this study, TA2 exhibited the longest working and setting times of the three cement compositions. This resulted in higher $\mathrm{pH}$ values, when compared to TAO and TA1. The decrease in the $\mathrm{pH}$ of TA2 samples at day 7, when compared to that of $T A 1$, indicates that the incorporation of $\mathrm{Ta}_{2} \mathrm{O}_{5}$ facilitates the formation of a stronger network during ageing. Further, identical $\mathrm{pH}$ for TAO and $T A 2$ at day 30 shows that the incorporation of $\mathrm{Ta}_{2} \mathrm{O}_{5}$ at the expense of $\mathrm{ZnO}$ does not 'negatively' affect the setting reaction.

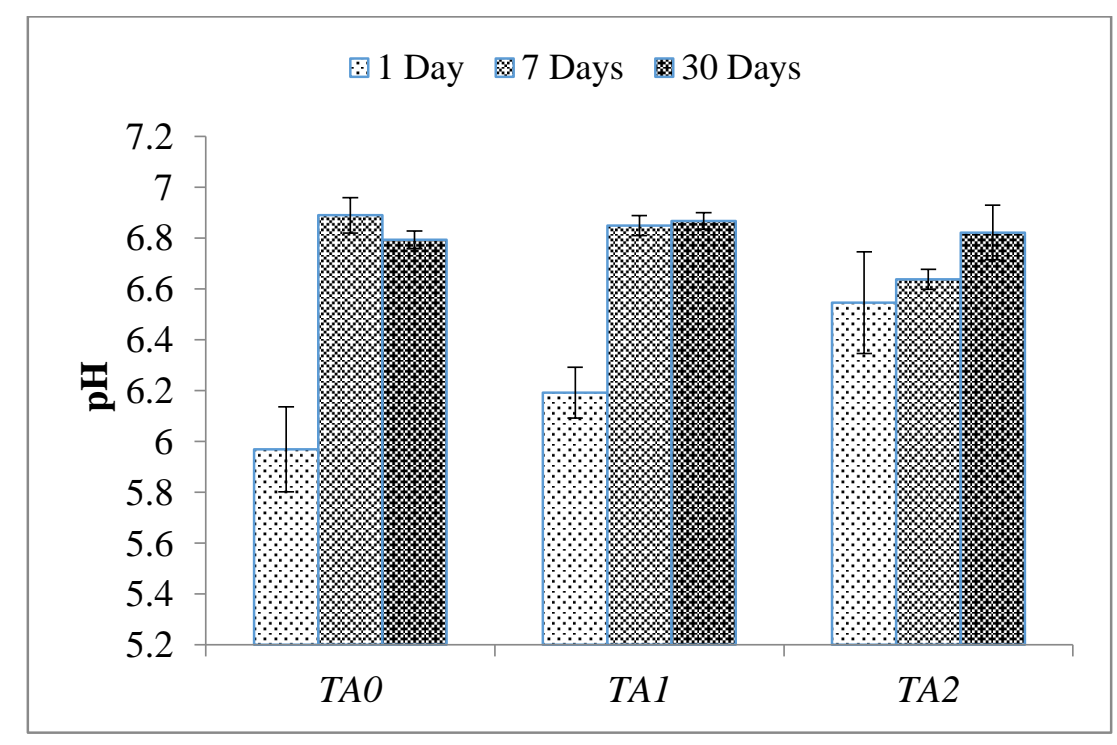

Figure 5.5: pH measurements during cement solubility in DI water for 1, 7 and 30 days, post cement preparation. Error bars represent standard deviation from the mean $(n=5)$. 


\subsubsection{Ion release profiles}

The changing ion release profiles for $\mathrm{Zn}^{2+}$ and $\mathrm{Sr}^{2+}$ ions as a function of maturation are plotted in Figure 5.6. Statistical analysis was performed with respect to $\mathrm{Ta}_{2} \mathrm{O}_{5}$ content (Table 5.2). This study considers the release of $\mathrm{Zn}^{2+}$ and $\mathrm{Sr}^{2+}$ only due to their content in the precursor glasses and their therapeutic importance in the clinical field. The release of $\mathrm{Zn}^{2+}$ decreased with $\mathrm{Ta}_{2} \mathrm{O}_{5}$ content (Figure 5.6a) and was also dependent on immersion time. This was expected as $\mathrm{Ta}_{2} \mathrm{O}_{5}$ was substituted with $\mathrm{ZnO}$ in $T A 1$ and $T A 2$. Figure $5.6 \mathrm{~b}$ represents the release of $\mathrm{Sr}^{2+}$ ions with both $\mathrm{Ta}_{2} \mathrm{O}_{5}$ content and maturation, peaking at $\sim 11.7$ ppm for TA2 cements after 30 days of immersion. Again, this is attributed to the longer setting reaction of TA2 cements, which retards initial cross-linking after the attack of the PAA on the glass structure. This phenomenon can also be attributed to the slow reaction of the $\mathrm{Ta}^{5+}$ ions with the carboxylic groups.

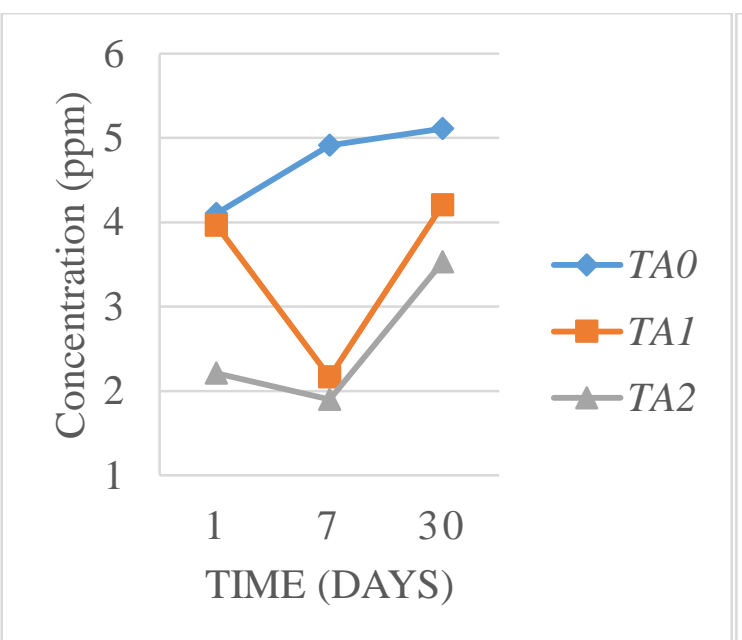

(a)

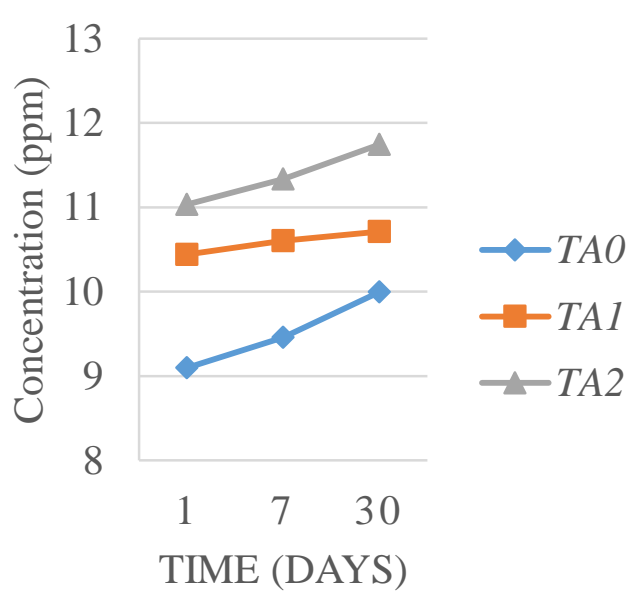

(b)

Figure 5.6: Release profiles of (a) $\mathrm{Zn}^{2+}$ and (b) $\mathrm{Sr}^{2+}$ ions during cement aging in DI water. Error bars (too small to see) represent standard deviation from the mean $(n=3)$.

Table 5.2: Means comparison of $\mathrm{Zn}^{2+}$ and $\mathrm{Sr}^{2+}$ ion release with respect of $\mathrm{Ta}_{2} \mathrm{O}_{5}$ content

\begin{tabular}{llccc}
\hline & Groups & 1 day & 7 day & 30 day \\
\hline \multirow{3}{*}{ Zn ion release } & TAO versus $T A 1$ & 0.690 & $0.008^{*}$ & 0.310 \\
& $T A O$ versus $T A 2$ & $0.032^{*}$ & $0.008^{*}$ & 0.095 \\
& $T A 1$ versus $T A 2$ & $0.008^{*}$ & 0.222 & 0.151 \\
\multirow{5}{*}{ Sr ion release } & $T A O$ versus $T A 1$ & $0.008^{*}$ & $0.008^{*}$ & $0.032^{*}$ \\
& $T A O$ versus $T A 2$ & $0.008^{*}$ & $0.008^{*}$ & $0.008^{*}$ \\
& $T A 1$ versus $T A 2$ & $0.008^{*}$ & $0.008^{*}$ & $0.008^{*}$ \\
\hline
\end{tabular}

*Significant at $P \leq 0.05$ 


\subsubsection{Evaluation of mechanical properties}

\subsubsection{Determination of compressive and biaxial flexural strengths}

Compressive $\left(\sigma_{\mathrm{c}}\right)$ and biaxial flexural $\left(\sigma_{\mathrm{f}}\right)$ strength results of the cement series tested over 1 , 7 and 30 days are presented in Figure 5.7. The highest $\sigma_{\mathrm{c}}$ and $\sigma_{\mathrm{f}}$ are $21 \mathrm{MPa}$ and $22 \mathrm{MPa}$, respectively and are obtained for $T A l$ after 7 days maturation. $T A l$ had the shortest setting time (Figure 5.3b) and is assumed to have higher strength resulting from the quicker cation-anion reactions within the matrix. However this behavior was only noted for 7 day results. There was no significant difference $(P>0.05)$ in $\sigma_{c}$ with respect to either maturation or $\mathrm{Ta}_{2} \mathrm{O}_{5}$ content among the groups. $\sigma_{\mathrm{f}}$, however, showed variation with respect to both Ta content and maturation.

With respect to $\mathrm{Ta}_{2} \mathrm{O}_{5}$ content, there was a significant increase in the $\sigma_{\mathrm{f}}(P=0.008)$ increasing from 16 (TAO) to $21 \mathrm{MPa}(T A 2)$, when tested at day 30 . With respect to ageing, the $\sigma_{\mathrm{f}}$ of a) TAO decreased significantly ( $P=0.005$ ) from 21 (day 1) to $16 \mathrm{MPa}$ (day 30), b) TAl increased signifcanlty $(P=0.035$ ) from 18 (day 1$)$ to $21 \mathrm{MPa}$ (day 30) and c) TA2 increased with no statistical significance ( $P=0.062$ ) from 19 (1 day) to $21 \mathrm{MPa}$ (30 days). The incorporation of Ta has a long-term effect on $\sigma_{\mathrm{f}}$ of the cements prepared from them. This can be attributed to 1) the slow reactions between Ta and the PAA chains as Ta is impervious to acid attack, 2) the dissolution of the glass particles, i.e Ta increases the dissolution of the glass particles within the cement matrix resulting in the release of ions that further crosslink PAA chains [355].

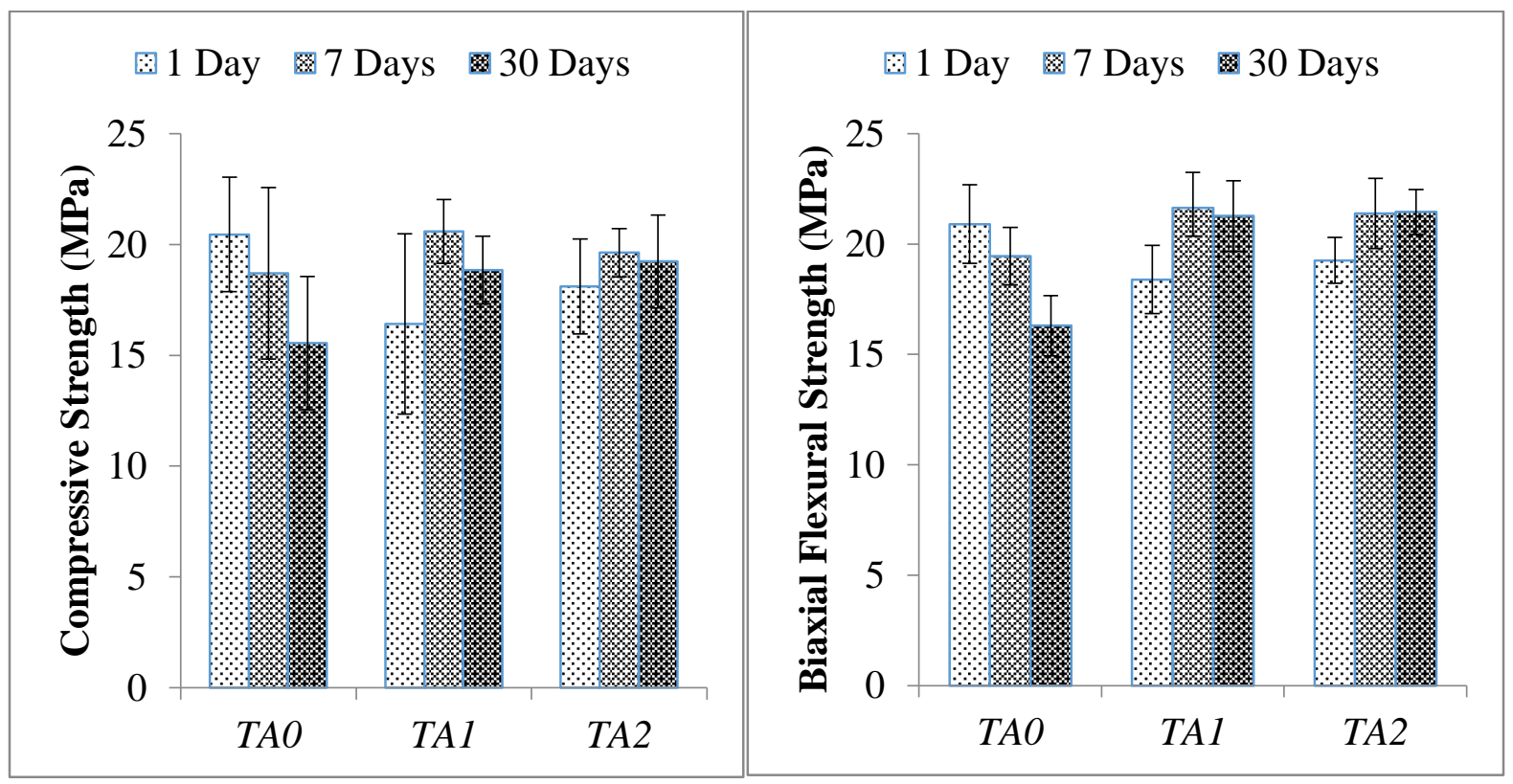

(a)

(b)

Figure 5.7: Compressive (a) and biaxial flexural (b) strengths of the cement series when aged in DI water for 1, 7 and 30 days. Error bars represent standard deviation from the mean $(n=5)$. 


\subsubsection{Determination of Vickers hardness}

The Vickers hardness of the cement series is shown in Figure 5.8. Hardness varied with $\mathrm{Ta}_{2} \mathrm{O}_{5}$ content and exhibited a similar trend to the compressive and biaxial flexural strength results. Hardness of TAO decreased with maturation, from 14 to $9 \mathrm{HV}$. Hardness of TAl and TA2 however, increased with maturation from 11 to $18 \mathrm{HV}$ and from 13 to $18 \mathrm{HV}$, respectively. The incorporation of $\mathrm{Ta}_{2} \mathrm{O}_{5}$ presented higher hardness values and exhibited a significant increase during cement maturation. Statistical significant differences were observed for TAO versus TAl for 30 day samples $(P=0.008)$ and for TAO versus TA2 for 7 and 30 day samples $(P<0.05)$. There is no difference among the TA1 and TA2 groups. These results follow the same trend as those of the the $\sigma_{\mathrm{f}}$, therefore the $\sigma_{\mathrm{f}}$ discussions, provided earlier, may hold true for the hardness results.

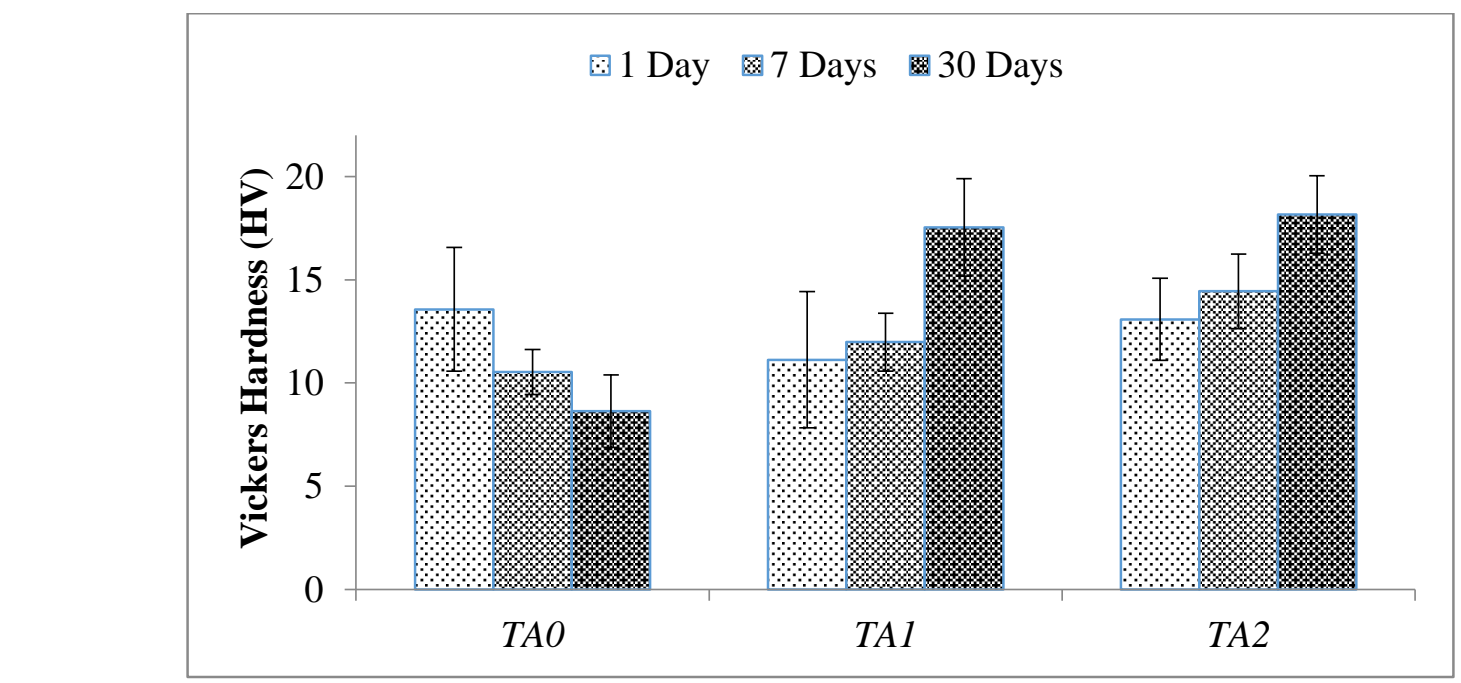

Figure 5.8: Vickers hardness of the cements when matured for 1, 7 and 30 days, post cement preparation. Error bars represent standard deviation from the mean $(n=5)$.

\subsubsection{Evaluation of radiopacity}

Radiopacity results are shown in Figure 5.9. All cements exhibited radiopacity higher than that of $\mathrm{Al}(280 \%, 290 \%$ and $300 \%$ of that of $\mathrm{Al}$ for TAO, TA1 and TA2, respectively). TA2 was the most radiopaque cement tested while the $\mathrm{Ta}_{2} \mathrm{O}_{5}$-free cement $(T A O)$ had a similar radiopacity $(P>0.05)$, when compared to that of TA2. The materials developed in this study are more radiopaque than the $\mathrm{Zn}$-GPCs previously produced by the authors [339]. The high radiopacity of $\mathrm{Zn}$-based cements was previously attributed to both the $\mathrm{ZnO}$ and $\mathrm{SrO}$ content [356,357]. Here, it can be seen that replacing the $\mathrm{ZnO}$ with the $\mathrm{Ta}_{2} \mathrm{O}_{5}$ has increased radiopacity, presumably because the density of $\mathrm{Ta}_{2} \mathrm{O}_{5}\left(8.2 \mathrm{~g} / \mathrm{cm}^{3}\right)$ is higher than that of $\mathrm{ZnO}\left(5.61 \mathrm{~g} / \mathrm{cm}^{3}\right)$ [288]. Increased radiopacity allows for easier subcutaneous monitoring of the implant. 


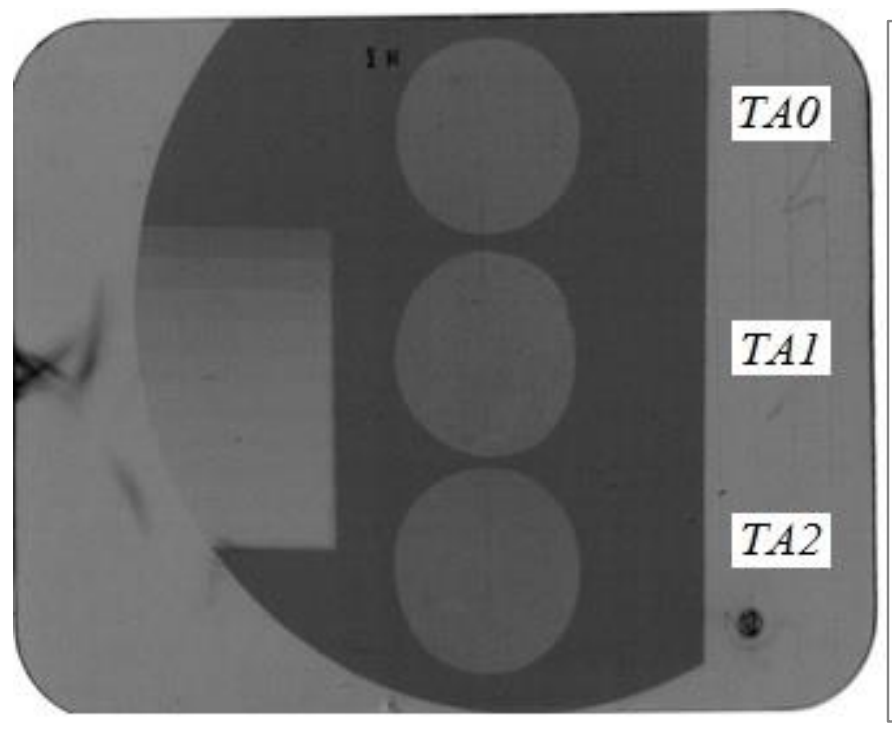

(a)

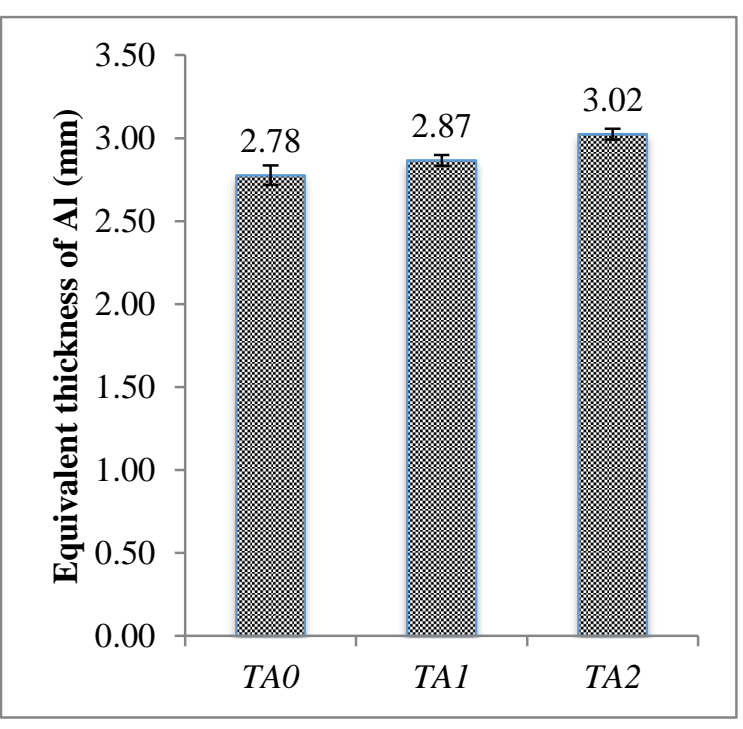

(b)

Figure 5.9: (a) Radiographic images of cement discs and the aluminum step wedge. (b) The radiopacity of the discs recorded in $m m$ Al. Error bars represent standard deviation from the mean $(n=5)$.

\subsubsection{Antimicrobial evaluation}

The antimicrobial properties of Ta-containing GPCs were assessed against both Gramnegative and Gram-positive prokaryotes (Figure 5.11), as well as eukaryotes (Figure 5.12). Figure 5.10 shows an example of the antibiotic activity of the formulated cements when tested against $S$. aureus for 1 day, post cement maturation and incubation at $37{ }^{\circ} \mathrm{C}$. All GPCs exhibited a level of both antibiotic and antimycotic activity within these experimental parameters.

Within the GPCs assessed in this chapter, $\mathrm{ZnO}$ was substituted with $\mathrm{Ta}_{2} \mathrm{O}_{5}$ (increasingly in TAO, TA1 and TA2; see Table 4.1 and Figure 5.6), and lower levels of antimicrobial activity were thus predicted, since the $\mathrm{Zn}$ ion is renowned for its antibiotic effect, whereas Ta is considered less bio-toxic [258,324]. However, the inhibition effect was comparable $(P>0.05)$ with respect to increasing $\mathrm{Ta}_{2} \mathrm{O}_{5}$ content for all bacterial species under study. Similar inhibition zones (8-9 $\mathrm{mm} \pm 0.4$ ) were obtained for one Gram-positive (S. aureus) and one Gram-negative (E. coli) strain, while a second Gram-positive bacterium (S. epidermidis) was even more susceptible to ion release by the GPCs, with an inhibition zone almost twice as large as the first two strains (15 $\mathrm{mm} \pm 0.6$ ). This species-dependent activity is in agreement with the literature [358], which indicated that factors influencing bacterial proliferation on a material surface are dependent on both the properties of the surface and the bacterial strain, particularly with regards to cell wall composition. It was reported by Wren et al. [359] that $\mathrm{Zn}^{2+}$ is particularly inhibitory against $E$. coli, and was thus the ion of interest in this study. 
However, as mentioned above, increasing levels of $\mathrm{Ta}_{2} \mathrm{O}_{5}$, accompanied by decreasing levels of $\mathrm{ZnO}$, did not demonstrate any observable influence on the antibacterial properties of the GPCs against any of the bacterial strains of interest. The uniform antibacterial effect of the materials under study could be attributed to 2 properties: (1) the increased release of Sr (see Figure 5.6) with the increased amount of $\mathrm{Ta}_{2} \mathrm{O}_{5}$ (and decreasing amounts of $\mathrm{ZnO}$ ), and/or (2) the increased wettability of the surface of Ta-containing materials, when compared to Ta-free GPCs (this will be a subject of further research). Sr is another ion with reported antimicrobial impact [257] and, although incorporated into the GPCs at the same level in TAO, TA1 and TA2, it is released at increasing levels with higher $\mathrm{Ta}_{2} \mathrm{O}_{5}$ levels due to structural changes in the glass. Thus, the increasing antimicrobial activity of $\mathrm{Sr}$ could offset the decreasing antimicrobial activity of $\mathrm{Zn}$, with the increased incorporation of Ta in the GPCs. It was reported that Ta surfaces result in lower contact angles, higher surface energy and improved antibacterial effect when compared to Ti or HA surfaces, and thus Ta itself could have indirect antimicrobial effects too [322,325,326].

During ageing, the antibacterial effect exhibited by these cements was expected to decrease as a result of the continuous cross-linking within the matrix [284], and due to potential time- and morphology-dependent adaptation of microbial species [360,361]. However the materials under study have shown that the initial antibacterial effect, presumably from ions leached into the agar, persisted for up to 30 days with no significant change $(P>0.05)$ when compared to day 1 . The release of ions into a liquid medium could significantly affect such time studies, and is an interesting potential follow-up study, particularly the antimicrobial effects of these ions in saturated biofilms, which are so relevant in nosocomial environments [360].

A single fungal eukaryotic strain, Fusarium solani, was chosen to explore the antimycotic properties of the GPCs and the results are presented in Figure 5.12. A control square fungal colony (3.6 x $7.2 \mathrm{~mm}$; sourced from the edges of a week-old colony) was transferred onto an agar plate, and its growth monitored over a period of 30 days. At day 1 (Figure 5.12a), the hyphal colony started to grow outward $(14.4 \times 8.6 \mathrm{~mm})$. At day 7 (Figure 5.12c), the control colony exhibited circular flat shape with a diameter of $52 \mathrm{~mm}$. At day 30 (Figure 5.12e), the control colony had extended prolifically to a diameter of $73 \mathrm{~mm}$. Similarly, a flat square inoculum block $(3.6 \times 7.2 \mathrm{~mm})$ was tested, with the cement substrates (TAO, TA1 and TA2) placed on the surface of the agar plate at equal distances from the central colony. At day 1, day 7 and day 30 (Figure 5.12b, d and f), fungal growth and colony morphology was clearly influenced by exposure 
to the GPCs, as compared to the control. At day 7 (Figure 5.12d), the colony was confined to the center of the plate, growing upward in a raised circular shape, morphologically distinct from the control, with a diameter of $12.5 \mathrm{~mm}$, approximately $20 \%$ of the diameter of the control at day 7 . At day 30 (Figure 5.12f), colony morphology was similarly influenced by the presence of the GPCs, constrained at 10.6, 2.5 and $4.6 \mathrm{~mm}$ away from the center of TAO, TA1 and TA2, respectively. According to the authors' knowledge, until now, no detailed studies assess the antifungal performance of GPCs or Ta-containing GPCs. It is clear from the results obtained that the formulated GPCs have antifungal properties. Unlike the antibiotic properties of these GPCs, according to these preliminary studies, the antifungal properties were shown to (1) decrease with increasing Ta content (and increasing $\mathrm{Zn}$ content), and (2) decrease with maturation. This behavior is attributed to decreasing the $\mathrm{Zn}$ content (Figure 5.6) and to the decreasing release of ions with ageing. However, after in-vivo placement of GPCs, any decreasing antimicrobial properties with age should accompany an improvement in immune response/reaction with the healing process, since the skin itself acts as a physical antibiotic barrier during the healing process [362]. Thus the initial antimicrobial activity is of greatest interest. In contrast to the antibacterial observations, increased release of $\mathrm{Sr}$, associated with increasing the Ta content, did not compensate for the decreased release of $\mathrm{Zn}^{2+}$, therefore $\mathrm{Sr}^{2+}$ is not as antifungal as $\mathrm{Zn}^{2+}$. Despite some variation, it can be seen that the formulated cement substrates have clear antibacterial and antifungal activity, as evaluated on solid media, suggesting that the substrates are promising candidates to further test long-term, liquid and in-vivo antimicrobial properties.

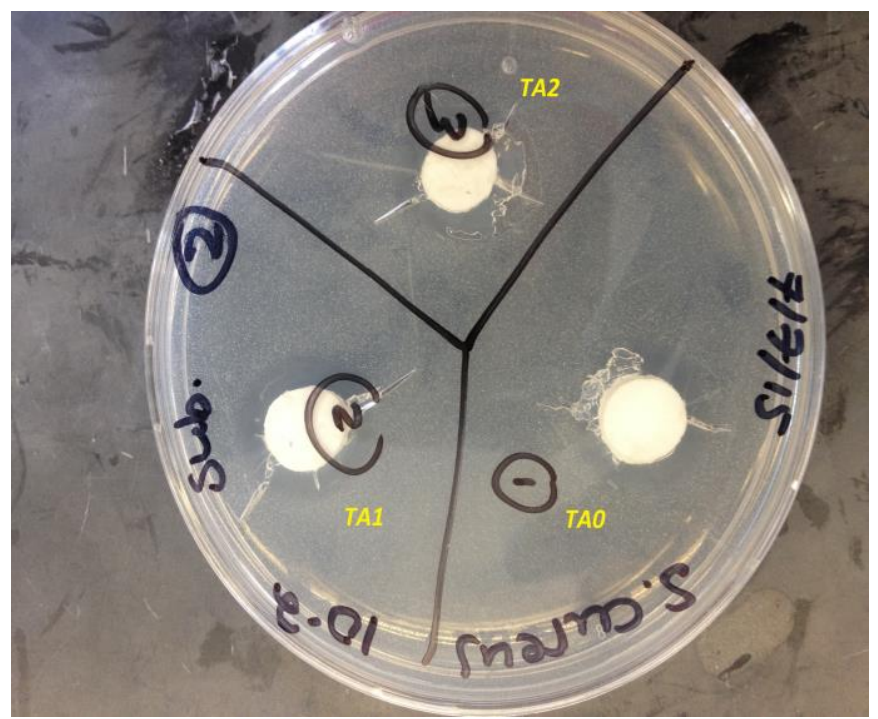

Figure 5.10: Inhibition zones of S. aureus lawn on agar media, in response to TAO, TA1 and TA2, evaluated after 1 day of maturation and incubated at $37^{\circ} \mathrm{C}$. 


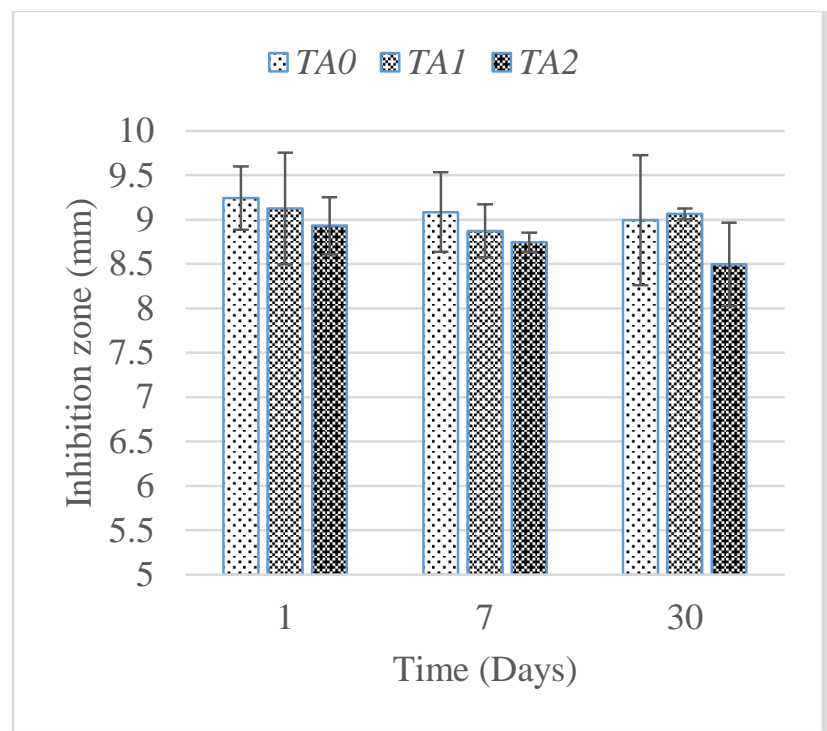

(a)

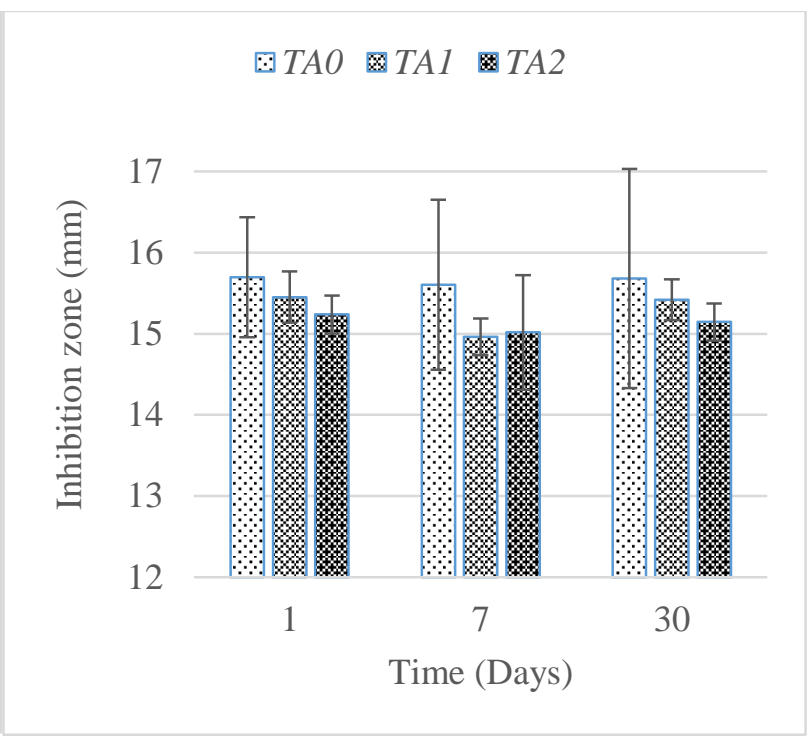

(b)

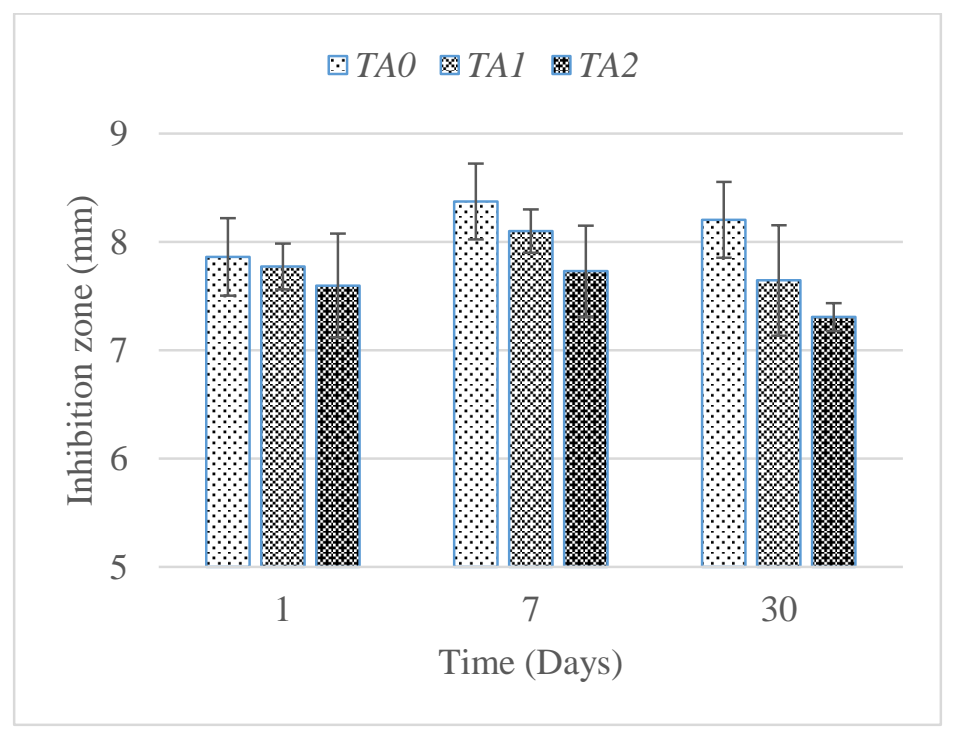

(c)

Figure 5.11: Inhibition zones of a) E. coli, b) S. epidermidis and c) S. aureus lawns on agar media, in response to TA0, TAl and $T A 2$, evaluated after 1,7 and 30 days maturation and incubated at $37^{\circ} \mathrm{C}$. Error bars represent standard deviation from the mean $(n=3)$. 


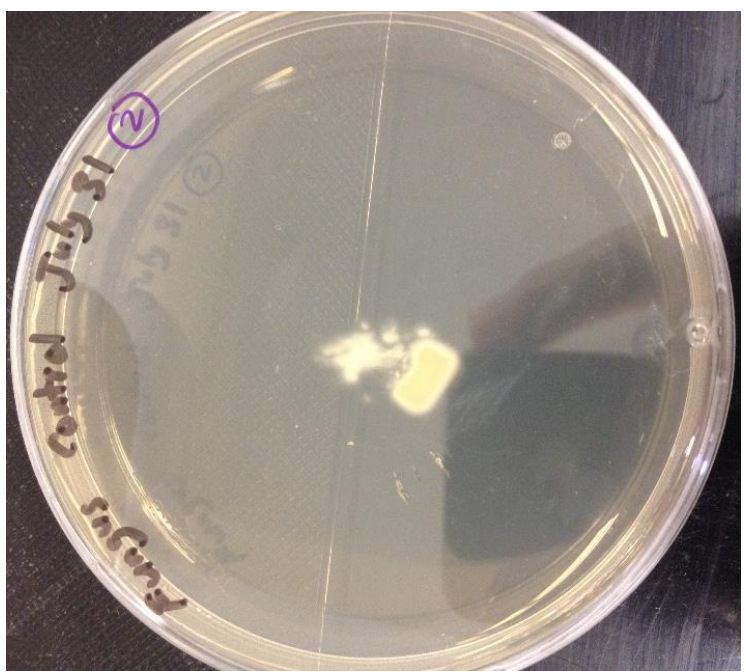

(a)

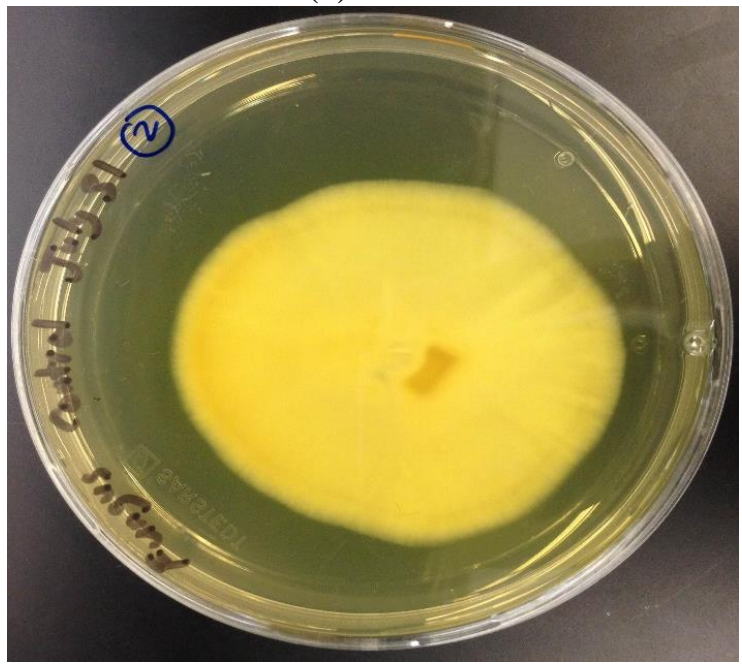

(c)

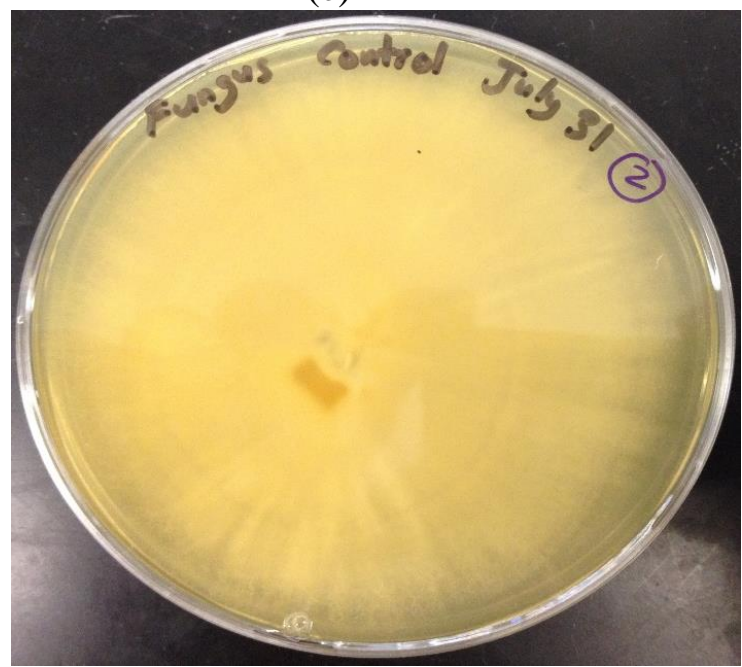

(e)

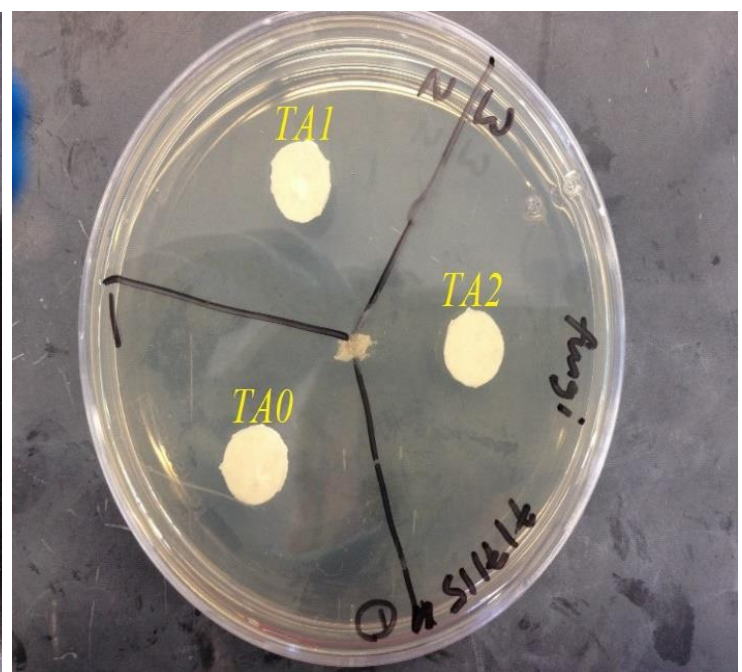

(b)

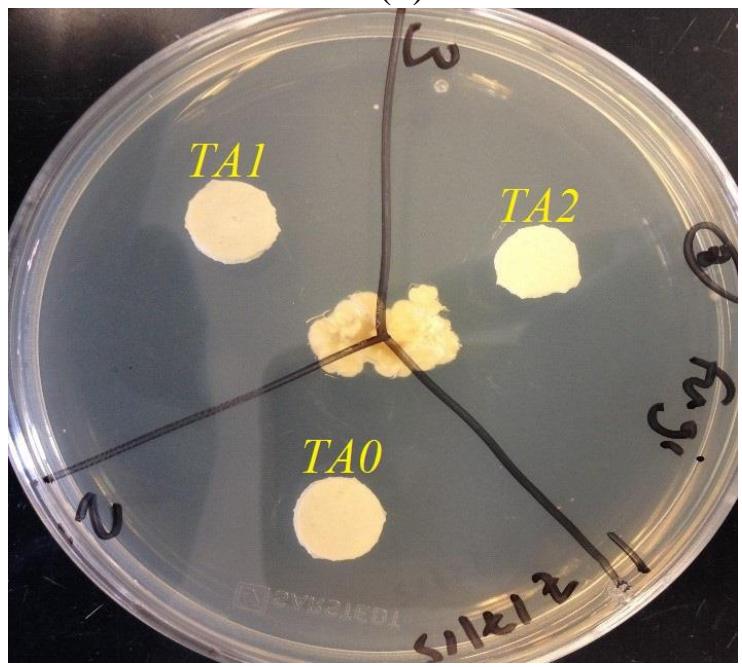

(d)

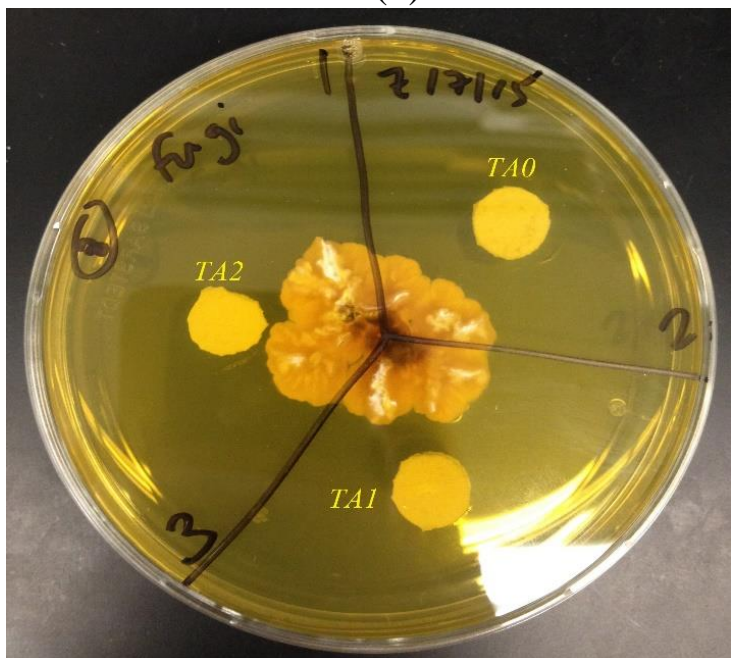

(f)

Figure 5.12: Colony morphology of Fusarium solani fungus aged with no samples (control) and tested with TAO, TA1 and TA2 over a period of 1 ( $a$ and $b), 7(c$ and $d)$ and 30 days (e and $f)$, respectively. 


\subsubsection{Cytotoxicity testing}

Figure 5.13 shows the cell viability results of each of the materials tested after 1, 3 and 7 days of culture, compared to chondrocytes seeded on tissue culture plastic (Control). All cements tested did not appear to display any cytotoxic effects as cells appeared to proliferate when cultured on the material surfaces. Cell viability on the TAO surfaces changed little $(P>0.05)$ with culture time reducing from $191 \%$ of control (day 1) to $176 \%$ (day 7). This behaviour could be attributed to the ion release products from the cement. Preliminary in-vitro biocompatibility studies by Hill et al. [363] revealed that the cytotoxic effect of a soda-lime phosphosilicate bioglass system was related to ion exchange reactions at the glass surface, resulting from the release of sodium $\left(\mathrm{Na}^{2+}\right)$ ions. Immediately after cell seeding and during the first $24 \mathrm{hrs}$ of culture, the cement releases some of its 'unbound' cations at different rates [117]. The release of $\mathrm{Si}, \mathrm{Sr}, \mathrm{Ca}, \mathrm{P}$ and $\mathrm{Sr}$ ions, unlike $\mathrm{Na}^{2+}$, would be expected to stimulate biological responses such as cell attachment and proliferation [269,364]. The cell viability results of TAl cements ranged between $221 \%$ and $349 \%$ with no apparent influence of culture time $(P>0.05)$. TA2 cements performed differently than the other cements with cell viability ranging between $174-220 \%$ (day 1 - 3) and then increasing to $760 \%$ (day 7). The substitution of $\mathrm{Ta}_{2} \mathrm{O}_{5}$ for $\mathrm{ZnO}$ may be responsible for the observed proliferative effect. Cell attachment and proliferation are primarily associated with a material's surface properties such as wettability and the material's bulk/volume composition [324]. An in-vitro study has shown that human osteoblast cells exposed to Ta and HA coatings exhibit equally excellent cellular adherence and viability [326] due to the lower contact angles and higher surface energy of Ta when compared to Ti or HA surfaces [322,326]. Therefore, Ta incorporation into bioactive glasses may not only stimulate osseo-integration but also their cellmaterial interactions and long-term mechanical stability. This is supported by a previous in-vivo study of bioactive glass coatings on $\mathrm{Ti}$ plates which resulted in enhanced initial tissue attachment, bone growth and rapid osseo-integration [365]. 


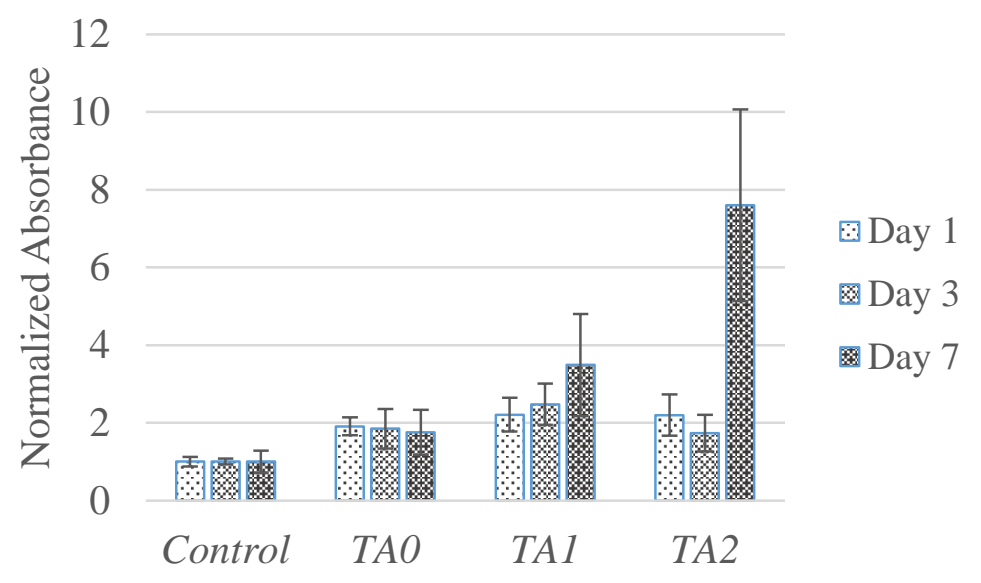

Figure 5.13: Cell viability results of the Control fibroblast cells and the formulated cements over 1, 3 and 7 days, post cement preparation and incubation. Error bars represent standard deviation from the mean $(n=3)$.

\subsubsection{Ex-vivo bond strength testing}

This study considers a preliminary adhesion test to evaluate the bond strength of the adhesive materials, when applied to bovine femoral cortical bone. Figure 5.14 shows the tensile strength results obtained at day 1 , post sample preparation and incubation. It is obvious that TAO has the highest strength $(1.6 \mathrm{MPa})$. However comparable results $(P>0.05)$ were obtained for TAl $(1.1$ $\mathrm{MPa})$ and TA2 (1.0 MPa) samples. Further studies with a larger number of samples tested over a longer ageing period may reveal statistically significant differences.

The adhesion and tissue bonding of sternal fixation devices are crucial for satisfactory performance. The results of this preliminary study confirm the mechanical testing results obtained in section 5.3.3. Generally, it can be observed that Ta-free cements result in slightly higher, but comparable, strength values at day 1. Comparable results are attributed to the little change in the former glass materials (Table 4.1). This means that further incorporation of Ta into GPCs may have unfavorable effect on their early strength values resulting from the slow reactivity of Ta with PAA. As pointed earlier, Ta is impervious to acid attack at the early stage of the reaction, therefore affecting the cation-anion chelating reactions. This however changes during cement ageing allowing for improved adhesion and mechanical stability. 


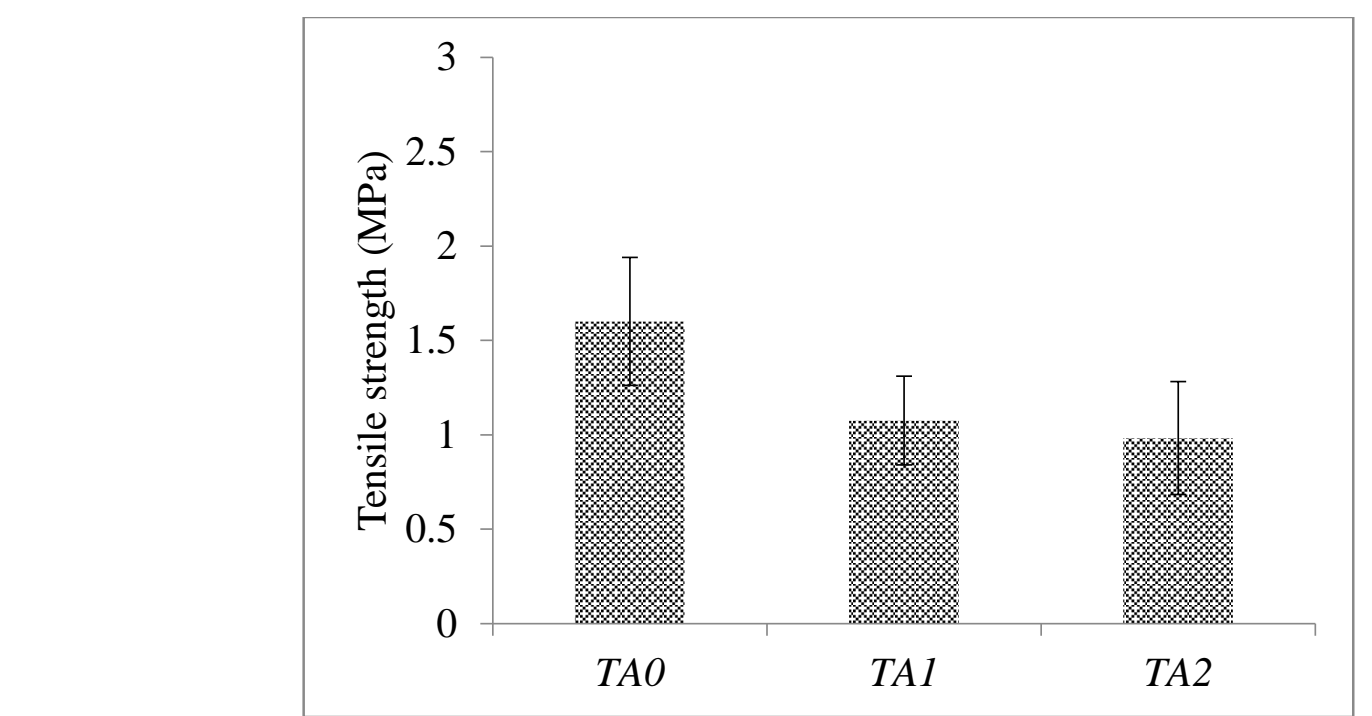

Figure 5.14: Mechanical testing results of the bovine femur cortical bones adhered using the formulated cements and aged in DI water for 1 day at $37^{\circ} \mathrm{C}$. Error bars represent standard deviation from the mean $(n=3)$.

\subsection{Summary}

The results reported here confirm that cements based on the tantalum-containing glass have rheology, strength, radiopacity, antibacterial and in-vitro behavior suitable for sternal fixation. This study has also confirmed the ability of the formulated materials to adhere to bovine femoral bone. As a permanent implant, the formulated adhesives can be used in conjunction with sternal cable ties to offer optimal fixation and reduce post-operative complications such as bacterial infections and pain from sternal displacement. Further research will involve in-vivo testing of the propriety material utilizing animals and cadaver sterna. 


\section{Conclusions and future work}

\subsection{Practical implications}

An estimated 1.3 million Canadians are living with heart disease, costing the Canadian economy in excess of $\mathrm{C} \$ 21 \mathrm{~b}$ per year in physician services and hospital costs [366]. There are over one million cardiac surgeries performed worldwide annually, with around 700,000 occurring in the US [81] and around 25,000 occurring in Canada [367]. All of the techniques that have been utilized for sternal fixation have complications limiting their widespread adoption. Our innovative technology consisting of a novel composition of matter (a wholly new, tantalumcontaining ionomeric glass mixed with aqueous acid to produce a cementitious material) may offer a novel solution to existing problems in the sternal fixation field. It provides a bioactive, anti-bacterial solution that is expected to reduce the incidence of post-operative complications and inhibit micro-motion between the dissected halves of the sternum. The novel bio-adhesive will reduce 1) rates of mortality and morbidity, 2) hospital stays, and 3) surgery and hospital costs. The developed bio-adhesive will also offer an easy to apply, sterilisable device to facilitate sternal closure and fixation after cardiac surgery.

The technology presented in this dissertation could benefit all patients who undergo sternal fixation, in the event of conventional median sternotomy and reduce post-operative complications currently associated with this surgery.

\subsection{Conclusions}

The main conclusions of this dissertation are as summarized:

* A novel series of $\mathrm{SiO}_{2}-\mathrm{ZnO}-\mathrm{CaO}-\mathrm{SrO}-\mathrm{P}_{2} \mathrm{O}_{5}-\mathrm{Ta}_{2} \mathrm{O}_{5}$ glasses were prepared using a meltquenching process.

* This dissertation has presented, for the first time, the effect of replacing $\mathrm{ZnO}$ with $\mathrm{Ta}_{2} \mathrm{O}_{5}$ in the glass system $0.48 \mathrm{SiO}_{2}-(0.36-\mathbf{X}) \mathrm{ZnO}-0.06 \mathrm{CaO}-0.08 \mathrm{SrO}-0.02 \mathrm{P}_{2} \mathrm{O}_{5}-\mathrm{XTa}_{2} \mathrm{O}_{5}$ with $\mathbf{X}$ varying from 0 mole percentage ( $\mathrm{TaO})$ to 8 mole percentage ( $\mathrm{Ta} 4$ ). The results suggest a structural model evolution in which the addition of Ta to the Si-Zn-Ca-Sr-P glass system causes a disruption in the network facilitating the insertion of octahedral $\mathrm{TaO}_{6}$ units between the $\mathrm{SiO}_{4}$ tetrahedral units through $\mathrm{Si}-\mathrm{O}-\mathrm{Ta}$ and Ta-O-Ta linkages.

* The $\mathrm{Zn}^{2+}$ ion behaves as an intermediate in the formulated glass system. Zinc may act as a network former by disrupting the $\mathrm{Si}-\mathrm{O}-\mathrm{Si}$ and probably the $\mathrm{Si}-\mathrm{O}-\mathrm{Ta}$ bonds and may act as a network modifier by acquiring more oxygen atoms. 
* Glass solubility experiments showed that minor amounts of Ta incorporation altered glass solubility, when evaluated in DI water. The ability to control glass solubility by minor compositional modifications offers great promise for the clinical applications of such bioglasses where the coordination of material solubility with bone remodelling/formation are of paramount importance.

* When mixed with PAA and DI water, the tantalum-containing bioactive glass can be used to formulate a series of GPCs. The author suggests this is the first GPC based adhesive with potential for sternal applications.

* Substituting up to 0.5 mole percentage of $\mathrm{ZnO}$ with $\mathrm{Ta}_{2} \mathrm{O}_{5}$ in the glass system $0.48 \mathrm{SiO}_{2}$ $0.36 \mathrm{ZnO}-0.06 \mathrm{CaO}-0.08 \mathrm{SrO}-0.02 \mathrm{P}_{2} \mathrm{O}_{5}$ results in the formation of adhesives that have rheology, strength, radiopacity, antibacterial and in-vitro behavior suitable for sternal fixation, when mixed with PAA and DI water. The ability of the formulated materials to adhere to bovine femur cortical bone has also been presented.

* As a permanent implant, the formulated adhesives can be used in conjunction with sternal cable ties to offer optimal fixation and reduce post-operative complications such as bacterial infections and pain from sternal displacement.

\subsection{Recommendations for future work}

The work presented in this dissertation can be extended by performing additional biological evaluation and testing of the developed materials. Following are the main recommendations to achieve this:

a) Testing the best performing materials for genotoxicity, carcinogenicity and reproductive toxicity according to part 3 of ISO 10993-1 (Biological evaluation of medical devices).

b) Performing tests for local effects after implantation and for irritation and skin sensitization according to parts 6 and 10 of ISO 10993-1 (Biological evaluation of medical devices).

c) Perform in-vivo testing of the propriety material utilizing cadaver sterna. We, in collaboration with Dr. Oleg Safir (Mount Sinai Hospital, Toronto, ON) have obtained the ethical approval to perform the human cadaver study. This will take place in Ryerson University. 
d) The human cadaver study will be followed by an animal in-vivo study. This study will be performed on a porcine model upon obtaining ethical approval and will serve to provide important information prior to implanting the novel material into human sterna.

e) The materials developed and characterized in this dissertation can be altered, by changing the P:L ratio and/or concentration, to provide a new set of adhesives with setting times that can extend from as short as $3 \mathrm{~min}$ to as long as few hours. Therefore, the developed bioadhesive could also be evaluated for its potential in other orthopedic applications such as wrist and shoulder fixation, as well as vertebroplasty and cranioplasty surgeries. 


\section{References}

[1] R. Seeley, C. VanPutte, J. Regan, A. Russo, Seeley's Anatomy and Physiology, McGraw-Hill companies, Inc., NY, USA, 2011.

[2] E.N. Marieb, Human Anatomy and Physiology, Pearson Education, Inc., San Francisco, CA, 2004.

[3] C. Le Meng Bao, E.Y. Teo, M.S.K. Chong, Y. Liu, M. Choolani, J.K.Y. Chan, Advances in Bone Tissue Engineering, in: J.A. Andrades (Ed.), Adv. Bone Tissue Eng. Regen. Med. Tissue Eng., InTech, 2013: pp. 600-601.

[4] B. Hall, Bones and Cartilage: Developmental and Evolutionary Skeletal Biology, 2nd ed., Academic Press, 2005.

[5] C. Rey, C. Combes, C. Drouet, M.J. Glimcher, Bone mineral: update on chemical composition and structure, Osteoporos. Int. 20 (2009) 1013-1021.

[6] P. Stark, D. Jaramillo, CT of the Sternum, Am. J. Roentgenol. 147 (1986) 72-77.

[7] G. Mundy, Bone remodelling and its disorders, 2nd ed., Martin Dunitz Ltd, London, U.K., 1999.

[8] S. Darke, J. Stephen, Vitamin D deficiency and osteomalacia, H.M.S.O, 1976.

[9] Royal college of physicians, Osteoporosis: Clinical guidelines for treatment and prevention, Royal College of Physicians of London, London, UK, 2000.

[10] N. Arden, Osteoporosis, 2nd ed., Remedica publishing, London, UK, 2006.

[11] P. Sambrook, Bone Structure and Function in Normal and Disease States, in: P. Sambrook, L. Schrieber, T. Taylor, A. Elis (Eds.), Musculoskelet. Syst. Basic Sci. Clin. Cond., Elsevier Health Sciences, London/GB, 2001: pp. 68-84.

[12] G. Tortora, B. Derrickson, The skeletal system: The axial skeleton, in: Princ. Anat. Physiol., 13th ed., Wiley, New Jersey, 2011.

[13] C. Wangsgard, D.J. Cohen, L. V Griffin, Fatigue testing of three peristernal median sternotomy closure techniques, J. Cardiothorac. Surg. 3 (2008) 52.

[14] D.J. Cohen, L. V Griffin, A biomechanical comparison of three sternotomy closure techniques., Ann. Thorac. Surg. 73 (2002) 563-568.

[15] A.R. Casha, L. Yang, P.H. Kay, M. Saleh, G.J. Cooper, A biomechanical study of median sternotomy closure techniques., Eur. J. Cardiothorac. Surg. 15 (1999) 365-369.

[16] S. Pai, R.M. Dunn, R. Babbitt, H.M. Strom, J.F. Lalikos, G.D. Pins, et al., Characterization of forces on the sternal midline following median sternotomy in a porcine model., J. Biomech. Eng. 130 (2008) 51004.

[17] A.R. Casha, L. Yang, G.J. Cooper, Measurement of chest wall forces on coughing with the use of human cadavers., J. Thorac. Cardiovasc. Surg. 118 (1999) 1157-1158.

[18] U.K. Dasika, D.R. Trumble, J.A. Magovern, Lower sternal reinforcement improves the stability of sternal closure., Ann. Thorac. Surg. 75 (2003) 1618-1621.

[19] D.R. Tremble, W.E. McGregor, J.A. Magovern, D.R. Trumble, W.E. McGregor, J.A. Magovern, Validation of a bone analog model for studies of sternal closure, Ann Thorac Surg. 74 (2002) 739744.

[20] J. Adams, J. Schmid, R.D. Parker, J.R. Coast, D. Cheng, A.D. Killian, et al., Comparison of force exerted on the sternum during a sneeze versus during low-, moderate-, and high-intensity bench 
press resistance exercise with and without the valsalva maneuver in healthy volunteers., Am. J. Cardiol. 113 (2014) 1045-1048.

[21] R. Parker, J.L. Adams, G. Ogola, D. McBrayer, J.M. Hubbard, T.L. McCullough, et al., Current Activity Guidelines for CABG Patients are too Restrictive: Comparison of the Forces Exerted on the Median Sternotomy during a Cough vs. Lifting Activities Combined with Valsalva Maneuver, Thorac Cardiovasc Surg. 56 (2008) 190-194.

[22] M.L. Dalton, S.R. Connally, W.C. Sealy, Julian's re-introduction of Milton's operation, Ann Thorac Surg. 53 (1992) 532-533.

[23] N. Gunja, S. Pai, N. McMahon, E. Dupak, J. Lalikos, R. Dunn, et al., A biomechanical study of a rigid plating system for sternal fixation, Bioeng. Conf. 2004. Proc. IEEE 30th Annu. Northeast. (2004) 156-157.

[24] D.B. Doty, G.B. DiRusso, J.R. Doty, Full-Spectrum Cardiac Surgery Through a Minimal Incision: Mini-Sternotomy (Lower Half) Technique, Ann. Thorac. Surg. 65 (1998) 573-577.

[25] M.J. Jurkiewicz, J. Bostwick, T.R. Hester, J.B. Bishop, J. Craver, Infected Median Sternotomy Wound: Successful Treatment by Muscle Flaps, Ann. Surg. 191 (1980) 738-743.

[26] P.W. Fedak, E. Kolb, G. Borsato, D.E. Frohlich, A. Kasatkin, K. Narine, et al., Kryptonite bone cement prevents pathologic sternal displacement, Ann Thorac Surg. 90 (2010) 979-985.

[27] S.B. Mossad, J.M. Serkey, D.L. Longworth, D.M. 3rd Cosgrove, S.M. Gordon, Coagulasenegative staphylococcal sternal wound infections after open heart operations., Ann. Thorac. Surg. 63 (1997) 395-401.

[28] J. Sjogren, M. Malmsjo, R. Gustafsson, R. Ingemansson, Poststernotomy mediastinitis: A review of conventional surgical treatments, vacuum-assisted closure therapy and presentation of the Lund University Hospital mediastinitis algorithm., Eur. J. Cardiothorac. Surg. 30 (2006) 898-905.

[29] S. Jolly, B. Flom, C. Dyke, Cabled butterfly closure: a novel technique for sternal closure., Ann. Thorac. Surg. 94 (2012) 1359-1361.

[30] C. Schimmer, W. Reents, S. Berneder, P. Eigel, O. Sezer, H. Scheld, et al., Prevention of sternal dehiscence and infection in high-risk patients: a prospective randomized multicenter trial., Ann. Thorac. Surg. 86 (2008) 1897-904.

[31] A.M. Wiley, J. Trueta, The vascular anatomy of the spine and its relationship to pyogenic vertebral osteomyelitis, J. Bone Jt. Surgery, 41-B (1959) 796-809.

[32] L. Scholl, E. Chang, B. Reitz, J. Chang, Sternal Osteomyelitis:., J. Card. Surg. 19 (2004) 453-461.

[33] M.R. Mittapalli, Primary osteomyelitis of sternum., Thorax. 34 (1979) 680-681.

[34] L.F. Lopez Almodovar, G. Bustos, P. Lima, A. Canas, I. Paredes, J.A. Buendia, Transverse plate fixation of sternum: a new sternal-sparing technique., Ann. Thorac. Surg. 86 (2008) 1016-1017.

[35] C. Schimmer, M. Ozkur, B. Sinha, J. Hain, A. Gorski, B. Hager, et al., Gentamicin-collagen sponge reduces sternal wound complications after heart surgery: a controlled, prospectively randomized, double-blind study., J. Thorac. Cardiovasc. Surg. 143 (2012) 194-200.

[36] M.N. Mavros, P.K. Mitsikostas, V.G. Alexiou, G. Peppas, M.E. Falagas, Gentamicin collagen sponges for the prevention of sternal wound infection: a meta-analysis of randomized controlled trials., J. Thorac. Cardiovasc. Surg. 144 (2012) 1235-1240.

[37] T.Y. Lee, A.L. Estrera, H.J. Safi, K.G. Khalil, Total sternal reconstruction using a titanium plate- 
supported methyl methacrylate sandwich., Ann. Thorac. Surg. 84 (2007) 664-666.

[38] K. Porter, R. Roplekar, P. Mohanna, A five year audit study on deep sternal wound infections and associated dehiscence post median sternotomy: an analysis of patient outcome, risk factors and a proposed management strategy, Int. J. Surg. 10 (2015) S16-S17.

[39] A. Khoriati, R. Rajakulasingam, R. Shah, Sternal fractures and their management, J. Emerg. Trauma. Shock. 6 (2013) 113-116.

[40] L.P. Cahalin, T.K. Lapier, D.K. Shaw, Sternal Precautions: Is It Time for Change? Precautions versus Restrictions - A Review of Literature and Recommendations for Revision., Cardiopulm. Phys. Ther. J. 22 (2011) 5-15.

[41] Physio Advisor, Sternal fracture, (n.d.). http://www.physioadvisor.com.au/injuries/upper-backchest/sternal-fracture/ (accessed June 14, 2016).

[42] C. Serry, P.C. Bleck, H. Javid, J.A. Hunter, M.D. Goldin, G.A. DeLaria, et al., Sternal wound complications. Management and results, J. Thorac. Cardiovasc. Surg. 80 (1980) 861-867.

[43] J.I. Fann, M.F. Pompili, T.A. Burdon, J.H. Stevens, F.G. St Goar, B.A. Reitz, Minimally invasive mitral valve surgery, Semin. Thorac. Cardiovasc. Surg. 9 (1997) 320-330.

[44] W.R. Burfeind, D.D. Glower, R.D. Davis, K.P. Landolfo, J.E. Lowe, W.G. Wolfe, Mitral surgery after prior cardiac operation: port-access versus sternotomy or thoracotomy., Ann. Thorac. Surg. 74 (2002) S1323-5.

[45] J.W. Asaph, J.R.J. Handy, G.L. Grunkemeier, E.C. Douville, A.C. Tsen, R.C. Rogers, et al., Median sternotomy versus thoracotomy to resect primary lung cancer: analysis of 815 cases., Ann. Thorac. Surg. 70 (2000) 373-379.

[46] J.D. Cooper, J.M. Nelems, F.G. Pearson, Extended indications for median sternotomy in patients requiring pulmonary resection., Ann. Thorac. Surg. 26 (1978) 413-420.

[47] H.C.J. Urschel, M.A. Razzuk, Median sternotomy as a standard approach for pulmonary resection., Ann. Thorac. Surg. 41 (1986) 130-134.

[48] W.H. Falor, R. Traylor, Extended indications for the median sternotomy incision, Am Surg. 48 (1982) 582-583.

[49] Y.Y. Cen, D.D. Glower, K. Landolfo, J.E. Lowe, R.D. Davis, W.G. Wolfe, et al., Comparison of survival after mitral valve replacement with biologic and mechanical valves in 1139 patients., J. Thorac. Cardiovasc. Surg. 122 (2001) 569-577.

[50] C.G. Tribble, W.A.J. Killinger, P.K. Harman, I.K. Crosby, S.P. Nolan, I.L. Kron, Anterolateral thoracotomy as an alternative to repeat median sternotomy for replacement of the mitral valve., Ann. Thorac. Surg. 43 (1987) 380-382.

[51] F.M. Follis, S.B. Pett Jr, K.B. Miller, R.S. Wong, R.T. Temes, J.A. Wernly, Catastrophic hemorrhage on sternal reentry: still a dreaded complication?, Ann. Thorac. Surg. 68 (1999) 22152219.

[52] Thinglink, Open thoracotomy, (2015). http://www.thinglink.com/scene/657200735020122113 (accessed June 5, 2016).

[53] O.C. Julian, M. Lopez-Belio, W.S. Dye, H. Javid, W.J. Grove, The median sternal incision in intracardiac surgery with extracorporeal circulation; a general evaluation of its use in heart surgery., Surgery. 42 (1957) 753-761. 
[54] A.R. Casha, S.S. Ashraf, P.H. Kay, G.J. Cooper, Routine sternal closure using interlocking multitwisted wires., Eur. J. Cardiothorac. Surg. 16 (1999) 353-355.

[55] A.R. Casha, M. Gauci, L. Yang, M. Saleh, P.H. Kay, G.J. Cooper, Fatigue testing median sternotomy closures., Eur. J. Cardiothorac. Surg. 19 (2001) 249-253.

[56] W. Cheng, D.E. Cameron, K.E. Warden, J.D. Fonger, V.L. Gott, Biomechanical study of sternal closure techniques., Ann. Thorac. Surg. 55 (1993) 737-740.

[57] O.F. Dogan, A. Oznur, M. Demircin, A new technical approach for sternal closure with suture anchors (Dogan technique)., Heart Surg. Forum. 7 (2004) E328-32.

[58] S.L. Kalush, L.I. Bonchek, Peristernal Closure of Median Sternotomy Using Stainless Steel Bands, Ann. Thorac. Surg. 21 (1976) 172-173.

[59] J.E. Losanoff, M.D. Basson, S.A. Gruber, H. Huff, F. Hsieh, Single wire versus double wire loops for median sternotomy closure: experimental biomechanical study using a human cadaveric model., Ann. Thorac. Surg. 84 (2007) 1288-1293.

[60] J.E. Losanoff, A.D. Collier, C.C. Wagner-Mann, B.W. Richman, H. Huff, F. hung Hsieh, et al., Biomechanical comparison of median sternotomy closures., Ann. Thorac. Surg. 77 (2004) 203209.

[61] R.F.J. Di Marco, M.W. Lee, S. Bekoe, K.J. Grant, G.F. Woelfel, R. V Pellegrini, Interlocking figure-of-8 closure of the sternum., Ann. Thorac. Surg. 47 (1989) 927-929.

[62] W.E. McGregor, D.R. Trumble, J.A. Magovern, Mechanical analysis of midline sternotomy wound closure., J. Thorac. Cardiovasc. Surg. 117 (1999) 1144-1150.

[63] K.D. Murray, M.K. Pasque, Routine sternal closure using six overlapping figure-of-8 wires., Ann. Thorac. Surg. 64 (1997) 1852-1854.

[64] C.-C. Shih, C.-M. Shih, Y.-Y. Su, S.-J. Lin, Potential risk of sternal wires., Eur. J. Cardiothorac. Surg. 25 (2004) 812-818.

[65] C.-M. Shih, Y.-Y. Su, S.-J. Lin, C.-C. Shih, Failure analysis of explanted sternal wires., Biomaterials. 26 (2005) 2053-2059.

[66] G. Tavilla, J.A. van Son, A.F. Verhagen, L.K. Lacquet, Modified Robicsek technique for complicated sternal closure., Ann. Thorac. Surg. 52 (1991) 1179-1180.

[67] J.J. Timmes, S. Wolvek, M. Fernando, M. Bas, J. Rocko, A new method of sternal approximation, Aorn J. 18 (1973) 1135-1137.

[68] H.R. Zurbrugg, T. Freestone, M. Bauer, R. Hetzer, Reinforcing the conventional sternal closure., Ann. Thorac. Surg. 69 (2000) 1957-1958.

[69] M.T. Grapow, L.F. Melly, F.S. Eckstein, O.T. Reuthebuch, A new cable tie based sternal closure system: description of the device, technique of implantation and first clinical evaluation, Eur $\mathbf{J}$ Cardiothorac Surg. 7 (2012) 1-5.

[70] A.P. Schulz, M. Faschingbauer, C. Jürgens, Sternal non-union-development of a novel fixation device, Inj. Extra. 36 (2005) 569-572.

[71] O. Friberg, L.G. Dahlin, B. Söderquist, J. Källman, R. Svedjeholm, Influence of more than six sternal fixation wires on the incidence of deep sternal wound infection, Thorac. Cardiovasc. Surg. 54 (2006) 468-473.

[72] J. Zeitani, A. Penta de Peppo, A. Bianco, F. Nanni, A. Scafuri, F. Bertoldo, et al., Performance of 
a novel sternal synthesis device after median and faulty sternotomy: mechanical test and early clinical experience., Ann. Thorac. Surg. 85 (2008) 287-293.

[73] L.S. Levin, A.S. Miller, A.H. Gajjar, K.D. Bremer, J. Spann, C.A. Milano, et al., An innovative approach for sternal closure., Ann. Thorac. Surg. 89 (2010) 1995-1999.

[74] W.E. McGregor, M. Payne, D.R. Trumble, K.M. Farkas, J.A. Magovern, Improvement of sternal closure stability with reinforced steel wires., Ann. Thorac. Surg. 76 (2003) 1631-1634.

[75] R.J. Baskett, C.E. MacDougall, D.B. Ross, Is mediastinitis a preventable complication? A 10-year review., Ann. Thorac. Surg. 67 (1999) 462-465.

[76] K.L. Gandy, M.J. Moulton, Sternal plating to prevent malunion of transverse sternotomy in lung transplantation., Ann. Thorac. Surg. 86 (2008) 1384-5.

[77] J. Huh, F. Bakaeen, D. Chu, M.J.J. Wall, Transverse sternal plating in secondary sternal reconstruction., J. Thorac. Cardiovasc. Surg. 136 (2008) 1476-1480.

[78] M. Ford, J. Brunelli, D. Song, P. Costello, R.M. Dunn, K. Billiar, Design of a screw-plate system to minimize loosening in sternal fixation, Bioeng. Conf. (NEBEC), 2011 IEEE 37th Annu. Northeast. (2011) 1-2.

[79] D.A. Shifrin, S.M. Sohn, C.W. Stouffer, R.L. Hooker, J.D. Renucci, Sternal salvage with rigid fixation in the setting of a massive mediastinal aortic pseudoaneurysm: a case report and review of the literature., J. Plast. Reconstr. Aesthet. Surg. 61 (2008) e17-20.

[80] A. Mitra, M.M. Elahi, G.B. Tariq, H. Mir, R. Powell, J. Spears, Composite plate and wire fixation for complicated sternal closure., Ann. Plast. Surg. 53 (2004) 217-221.

[81] D.H. Song, R.F. Lohman, J.D. Renucci, V. Jeevanandam, J. Raman, Primary sternal plating in high-risk patients prevents mediastinitis., Eur. J. Cardiothorac. Surg. 26 (2004) 367-372.

[82] O.J.J. Cicilioni, F.H. 3rd Stieg, G. Papanicolaou, Sternal wound reconstruction with transverse plate fixation., Plast. Reconstr. Surg. 115 (2005) 1297-1303.

[83] J. Raman, D.H. Song, G. Bolotin, V. Jeevanandam, Sternal closure with titanium plate fixation--a paradigm shift in preventing mediastinitis., Interact. Cardiovasc. Thorac. Surg. 5 (2006) 336-339.

[84] A. Plass, J. Grunenfelder, O. Reuthebuch, R. Vachenauer, J.-M. Gauer, G. Zund, et al., New transverse plate fixation system for complicated sternal wound infection after median sternotomy., Ann. Thorac. Surg. 83 (2007) 1210-1212.

[85] B. Voss, R. Bauernschmitt, A. Will, M. Krane, R. Kross, G. Brockmann, et al., Sternal reconstruction with titanium plates in complicated sternal dehiscence., Eur. J. Cardiothorac. Surg. 34 (2008) 139-145.

[86] S.S. Chou, M.J. Sena, M.S. Wong, Use of SternaLock plating system in acute treatment of unstable traumatic sternal fractures., Ann. Thorac. Surg. 91 (2011) 597-599.

[87] H. Fawzy, K. Osei-Tutu, L. Errett, D. Latter, D. Bonneau, M. Musgrave, et al., Sternal plate fixation for sternal wound reconstruction: initial experience (Retrospective study), J. Cardiothorac. Surg. 6 (2011) 1-7.

[88] F.R. DiMaio, The science of bone cement: a historical review., Orthopedics. 25 (2002) 1399.

[89] G. Lewis, Properties of acrylic bone cement: state of the art review., J. Biomed. Mater. Res. 38 (1997) 155-182.

[90] S.M. Kenny, M. Buggy, Bone cements and fillers: a review, J Mater Sci Mater Med. 14 (2003) 
923-938.

[91] M.J. Provenzano, K. Murphy, L.H. Riley, Bone cements: review of their physiochemical and biochemical properties in percutaneous vertebroplasty, AJNR Am J Neuroradiol. 25 (2004) 12861290.

[92] D.D. Muehrcke, P. Barberi, W.M. Shimp, Calcium phosphate cements to control bleeding in osteoporotic sternums., Ann. Thorac. Surg. 84 (2007) 259-261.

[93] T.A. Schildhauer, T.W. Bauer, C. Josten, G. Muhr, Open reduction and augmentation of internal fixation with an injectable skeletal cement for the treatment of complex calcaneal fractures., J. Orthop. Trauma. 14 (2000) 309-317.

[94] P. Lobenhoffer, T. Gerich, F. Witte, H. Tscherne, Use of an injectable calcium phosphate bone cement in the treatment of tibial plateau fractures: a prospective study of twenty-six cases with twenty-month mean follow-up., J. Orthop. Trauma. 16 (2002) 143-149.

[95] D.D. Muehrcke, W.M. Shimp, R. Aponte-Lopez, Calcium phosphate cements improve bone density when used in osteoporotic sternums., Ann. Thorac. Surg. 88 (2009) 1658-1661.

[96] Kryptonite bone void filler- biocompatibility and osseointegration, Southbury, 2009. http://www.klsmartin.com/fileadmin/Inhalte/Downloads_GA/Elektrochirurgie/90-849-0204_08_11_Biocompatibility_Osseointegration_Kryptonite.pdf.

[97] W.D. Spotnitz, Invited commentary., Ann. Thorac. Surg. 85 (2008) 293.

[98] M. Diefenbeck, T. Mückley, G.O. Hofmann, Prophylaxis and treatment of implant-related infections by local application of antibiotics., Injury. 37 Suppl 2 (2006) S95-104.

[99] A.W. Wren, A. Kidari, N.M. Cummins, M.R. Towler, A spectroscopic investigation into the setting and mechanical properties of titanium containing glass polyalkenoate cements., J. Mater. Sci. Mater. Med. 21 (2010) 2355-2364.

[100] A. Barthelemy, Post-sternotomy mediastinitis, in: Handb. Hyperb. Med., Part II., Springer, Netherlands, 2006: pp. 567-576.

[101] M.A. Kohanski, D.J. Dwyer, J.J. Collins, How antibiotics kill bacteria: from targets to networks., Nat. Rev. Microbiol. 8 (2010) 423-435.

[102] O. Friberg, L.-G. Dahlin, J. Kallman, E. Kihlstrom, B. Soderquist, R. Svedjeholm, Collagengentamicin implant for prevention of sternal wound infection; long-term follow-up of effectiveness., Interact. Cardiovasc. Thorac. Surg. 9 (2009) 454-458.

[103] D. Reser, H. Rodriguez Cetina Biefer, A. Plass, C. Ruef, B. Seifert, D. Bettex, et al., Incidence of sternal wound infection after reexploration in the intensive care unit and the use of local gentamycin., Ann. Thorac. Surg. 94 (2012) 2033-2037.

[104] D.H. Song, L.C. Wu, R.F. Lohman, L.J. Gottlieb, M. Franczyk, Vacuum assisted closure for the treatment of sternal wounds: the bridge between debridement and definitive closure., Plast. Reconstr. Surg. 111 (2003) 92-97.

[105] I.N. Boestan, D. Sarvasti, Choosing a prosthetic heart valve , Folia Medica Indones. 41 (2005) 169-181.

[106] C.S. Hollenbeak, D.M. Murphy, S. Koenig, R.S. Woodward, W.C. Dunagan, V.J. Fraser, The clinical and economic impact of deep chest surgical site infections following coronary artery bypass graft surgery, Chest. 118 (2000) 397-402. 
[107] B.E. Kent, A.D. Wilson, The properties of a glass-ionomer cement, Br Dent J. 135 (1973) 322326.

[108] A.D. Wilson, J.W. Nicholson, Acid-base cements: Their biomedical and industrial applications, Cambridge University Press, Cambridge, UK, 1993.

[109] B.M. Culbertson, Glass-ionomer dental restoratives, Prog. Polym. Sci. 26 (2001) 577-604.

[110] A.D. Wilson, B.E. Kent, Dental Silicate Cements: IX. Decomposition of the Powder, J. Dent. Res. 49 (1970) 7-13.

[111] D.R. Powis, T. Follerås, S.A. Merson, A.D. Wilson, Materials science: Improved adhesion of a glass ionomer cement to dentin and enamel, J. Dent. Res. 61 (1982) 1416-1422.

[112] G. Schmalz, D. Arenholt Bindslev, Biocompatibility of dental materials, Springer-Verlag Berlin Heidelberg, Leipzig, Germany, 2009.

[113] G. Schmalz, B. Thonemann, M. Riedel, R.J. Elderton, Biological and clinical investigations of a glass ionomer base material., Dent Mater. 10 (1994) 4-13.

[114] P. V Hatton, K. Hurrell-Gillingham, I.M. Brook, Biocompatibility of glass-ionomer bone cements, J Dent. 34 (2006) 598-601.

[115] P.R. Hornsby, Dimensional stability of glass-ionomer cements, J. Chem. Technol. Biotechnol. 30 (1980) 595-601.

[116] C. Hanting, L. Hanxing, Z. Guoqing, The setting chemistry of glass ionomer cement, J. Wuhan Univ. Technol., Mater. Sci. Ed. 20 (2005) 110-112.

[117] D.C. Smith, Development of glass-ionomer cement systems., Biomaterials. 19 (1998) 467-478.

[118] M.R. Towler, S. Kenny, D. Boyd, T. Pembroke, M. Buggy, R.G. Hill, Zinc ion release from novel hard tissue biomaterials, Biomed Mater Eng. 14 (2004) 565-572.

[119] D.A. Chen, M.A. Arriaga, Technical refinements and precautions during ionomeric cement reconstruction of incus erosion during revision stapedectomy., Laryngoscope. 113 (2003) 848852.

[120] M.P.A. Clark, I. Bottrill, SerenoCem -glass ionomeric granules: a 3-year follow-up assessment of their effectiveness in mastoid obliteration., Clin. Otolaryngol. 32 (2007) 287-290.

[121] H. Celik, S. Aslan Felek, A. Islam, M. Demirci, E. Samim, D. Oztuna, The impact of fixated glass ionomer cement and springy cortical bone incudostapedial joint reconstruction on hearing results., Acta Otolaryngol. 129 (2009) 1368-1373.

[122] E. Reusche, P. Pilz, G. Oberascher, B. Lindner, R. Egensperger, K. Gloeckner, et al., Subacute fatal aluminum encephalopathy after reconstructive otoneurosurgery: a case report., Hum. Pathol. 32 (2001) 1136-1140.

[123] W.A. Higgs, P. Lucksanasombool, R. Higgs, M. V Swain, Comparison of the material properties of PMMA and glass ionomer based cements for use in orthopedic surgery., J Mater Sci Mater Med. 12 (2001) 453-460.

[124] G.J. Mount, Glass ionomer cements: Clinical considerations, in: J.W. Clarke (Ed.), Clin. Dent., Harper \& Row, Philadelphia, 1984.

[125] A. Moshaverinia, N. Roohpour, W. Chee, S.R. Schricker, A review of powder modifications in conventional glass-ionomer dental cements, J. Mater. Chem. 21 (2011) 1319-1328. 
[126] M.J. Bertolini, R.G. Palma-Dibb, M.A. Zaghete, R. Gimenes, Evaluation of glass ionomer cements properties obtained from niobium silicate glasses prepared by chemical process, J. Non. Cryst. Solids. 351 (2005) 466-471.

[127] S. Crisp, A.D. Wilson, Reactions in glass ionomer cements: I. Decomposition of the powder, J. Dent. Res. 53 (1974) 1408-1413.

[128] B. Fennell, R.G. Hill, A. Akinmade, Failure abd fracture characteristics of glass poly(vinylphosphonate) cements, Dent Mater. 14 (1998) 358-364.

[129] M. Darling, R. Hill, Novel polyalkenoate (glass-ionomer) dental cements based on zinc silicate glasses, Biomaterials. 15 (1994) 299-306.

[130] S. Crisp, B.G. Lewis, A.D. Wilson, Characterization of glass-ionomer cements: 3. Effect of polyacid concentration on the physical properties, J. Dent. 5 (1977) 51-56.

[131] A.D. Wilson, R.G. Hill, C.P. Warren, B.G. Lewis, The influence of polyacid molecular weight on some properties of glass ionomer cements, J. Dent. Res. 68 (1989) 69-94.

[132] A.D. Wilson, S. Crisp, G. Abel, Characterization of glass-ionomer cements 4. Effect of molecular weight on physical properties, J. Dent. 5 (1977) 117-120.

[133] A.H. Dowling, G. Fleming, The influence of poly(acrylic) acid number average molecular weight and concentration in solution on the compressive fracture strength and modulus of a glass-ionomer restorative, Dent. Mater. 27 (2011) 535-543.

[134] S. Crisp, B.G. Lewis, A.D. Wilson, Characterization of glass-ionomer cements: 2. Effect of the powder: liquid ratio on the physical properties, J. Dent. 4 (1976) 287-290.

[135] A. Mitsuhashi, K. Hanaoka, T. Teranaka, Fracture toughness of resin-modified glass ionomer restorative materials: effect of powder/liquid ratio and powder particle size reduction on fracture toughness, Dent. Mater. 19 (2003) 747-757.

[136] G. Fleming, A.A. Farooq, J.E. Barralet, Influence of powder/liquid mixing ratio on the performance of a restorative glass-ionomer dental cement, Biomaterials. 24 (2003) 4173-4179.

[137] A. Moshaverinia, N. Roohpour, W. Chee, S.R. Schricker, A review of polyelectrolyte modifications in conventional glass-ionomer dental cements, J. Mater. Chem. 22 (2012) 28242833.

[138] R.A. Orwoll, Y.S. Chong, Poly(acrylic acid), in: J.E. Mark (Ed.), Polym. Data Handb., Oxford university press, Inc., New York, U.S.A., 1999: pp. 252-253.

[139] A.D. Wilson, B.E. Kent, The Glass-Ionomer Cement, a New Translucent Dental Filling Material, Appl. Chem. Biotechnol. 21 (1971) 313.

[140] B.E. Kent, A.D. Wilson, Dental Silicate Cements: VIII. Acid-Base Aspect, J. Dent. Res. 48 (1969) 412-418.

[141] R.G. Hill, A.D. Wilson, C.P. Warrens, The influence of poly(acrylic acid) molecular weight on the fracture toughness of glass-ionomer cements, J Mater Sci. 24 (1989) 363-371.

[142] S. Griffin, R. Hill, Influence of poly(acrylic acid) molar mass on the fracture properties of glass polyalkenoate cements, J Mater Sci. 33 (1998) 5383-5396.

[143] B. Fennell, R.G. Hill, The influence of poly(acrylic acid) molar mass and concentration on the properties of polyalkenoate cements Part II Young's modulus and flexural strength, J Mater Sci. 36 (2001) 5193-5202. 
[144] B. Fennell, R.G. Hill, The influence of poly(acrylic acid) molar mass and concentration on the properties of polyalkenoate cements Part IIIFracture toughness and toughness, J Mater Sci. 36 (2001) 5185-5192.

[145] E.A. Wasson, J.W. Nicholson, Study on the setting chemistry of glass-ionomer cements, Clin.Mater. 7 (1991) 289-293.

[146] E.A. Wasson, J.W. Nicholson, New aspects of the setting of glass-ionomer cements, J Dent Res. 72 (1993) 481-483.

[147] P.J. Flory, Principles of polymer chemistry, Cornell University Press, New York, 1953.

[148] W.J. King, W.L. Murphy, Bioinspired conformational changes: An adaptable mechanism for bioresponsive protein delivery, Polym. Chem. 2 (2011) 476-491.

[149] H. Morawetz, Macromolecules in solution, Inter science, John Wiley and Sons, New York, 1965.

[150] A.D. Wilson, S. Crisp, A.J. Ferner, Reactions in glass-ionomer cements: IV. Effects of chelating comonomers on setting behavior, J Dent Res. 55 (1976) 489-495.

[151] J.W. Nicholson, Chemistry of glass-ionomer cements: a review, Biomaterials. 19 (1998) 485-494.

[152] H.P. Gregor, L.B. Luttinger, E.M. Lobel, Metal-polyelectrolyte complexes. I. The polyacrylic acid-copper complex, J. Phys. Chem. 59 (n.d.) 34-39.

[153] D.A. Tanner, N. Rushe, M.R. Towler, Ultrasonically set glass polyalkenoate cements for orthodontic applications, J Mater Sci Mater Med. 17 (2006) 313-318.

[154] S. Crisp, A.D. Wilson, Reaction in glass ionomer cements: III. The precipitation reaction, J Dent Res. 53 (1974) 1420-1424.

[155] S. Matsuya, T. Maeda, M. Ohta, IR andNMR Analyses of Hardening and Maturation of Glassionomer Cement, J Dent Res. 75 (1996) 1920-1927.

[156] S. Crisp, B.G. Lewis, A.D. Wilson, Characterization of glass-ionomer cements 1. Long term hardness and compressive strength, J Dent. 4 (1976) 162-166.

[157] M.A. Cattani-Lorente, C. Godin, J.M. Meyer, Mechanical behavior of glass ionomer cements affected by long-term storage in water, Dent Mater. 10 (1994) 37-44.

[158] P. V Hatton, I.M. Brook, Characterisation of the ultrastructure of glass-ionomer (poly-alkenoate) cement, Br Dent J. 173 (1992) 275-277.

[159] G.J. Pearson, A.S. Atkinson, Long-term flexural strength of glass ionomer cements, Biomaterials. 12 (1991) 658-660.

[160] J.A. Williams, R.W. Billington, Changes in compressive strength of glass ionomer restorative materials with respect to time periods of $24 \mathrm{~h}$ to 4 months, J Oral Rehabil. 18 (1991) 163-168.

[161] B.E. Causton, The physico-mechanical consequences of exposing glass ionomer cements to water during setting, Biomaterials. 2 (1981) 112-115.

[162] S. Crisp, B.G. Lewis, A.D. Wilson, Characterization of glass-ionomer cements. 6. A study of erosion and water absorption in both neutral and acidic media, J Dent. 8 (1980) 68-74.

[163] R.G. Hill, Relaxation spectroscopy of polyalkenoate cements, J. Mater. Sci. Lett. 8 (1989) 10431047.

[164] J.P. Berry, Fracture processes in polymeric materials. II. The tensile strength of polystyrene, J Polym Sci. 50 (1961) 313-321. 
[165] M. Doi, S.F. Edwards, The theory of Polymer Dynamics, Oxford Press, New York, USA, 1986.

[166] S.F. Edwards, Statistical mechanics of polymerized material, Proc Phys Soc London. 92 (1967) 916.

[167] P.G. de Gennes, Scaling concepts in polymer physics, Cornell University Press, New York, USA, 1979.

[168] P. Prentice, Influence of molecular-weight on the fracture of poly(methyl methacrylate) (PMMA), Polymer (Guildf). 24 (1983) 344-350.

[169] P. Prentice, The influence of molecular-weight on the fracture of thermoplastic glassy-polymers, J Mater Sci. 20 (1985) 1445-1454.

[170] A. Leygue, A.N. Beris, R. Keunings, A constitutive equation for entangled linear polymers inspired by reptation theory and consistent with non-equilibrium thermodynamics, J Non-Newt. Fluid. 101 (2001) 95-111.

[171] L.T. Yan, B.H. Guo, J. Xu, X.M. Xie, Study diffusion effects on chain extention reactions based on the reptation theory, Polymers (Basel). 47 (2006) 3696-3704.

[172] K.A. Milne, N.J. Calos, J.H. O’Donnell, C.H. Kennard, S. Vega, D. Marks, Glass-ionomer dental restorative: part I: a structural study., J. Mater. Sci. Mater. Med. 8 (1997) 349-356.

[173] A.D. Wilson, Secondary reactions in glass-ionomer cements, J. Mater. Sci. Lett. 15 (1996) 275276.

[174] R.G. Hill, The fracture properties of glass polyalkenoate cements as a function of cement age, J. Mater. Sci. 28 (1993) 3851-3858.

[175] A. Sullivan, R. Hill, Influence of poly(acrylic acid) molar mass on the fracture properties of glass polyalkenoate cements based on waste gasifier slags, J Mater Sci. 35 (2000) 1125-1134.

[176] D. Boyd, M.R. Towler, The processing, mechanical properties and bioactivity of zinc based glass ionomer cements, J Mater Sci Mater Med. 16 (2005) 843-850.

[177] A.H. Dowling, G.J. Fleming, Can poly(acrylic) acid molecular weight mixtures improve the compressive fracture strength and elastic modulus of a glass-ionomer restorative?, Dent Mater. 27 (2011) 1170-1179.

[178] A.O. Majekodunmi, S. Deb, J.W. Nicholson, Effect of molecular weight and concentration of poly(acrylic acid) on the formation of a polymeric calcium phosphate cement., J Mater Sci Mater Med. 14 (2003) 747-752.

[179] A.O. Majekodunmi, S. Deb, Poly(acrylic acid) modified calcium phosphate cements: the effect of the composition of the cement powder and of the molecular weight and concentration of the polymeric acid., J Mater Sci Mater Med. 18 (2007) 1883-1888.

[180] F.O. Gomes, R.A. Pires, R.L. Reis, Aluminum-free glass-ionomer bone cements with enhanced bioactivity and biodegradability, Mater Sci Eng C. 33 (2013) 1361-1370.

[181] H.S. Kaufman, J.J. Falcetta, Introduction to polymer science and technology, John Wiley \& Sons Inc, New York, USA, 1977.

[182] H.J. Prosser, D.R. Powis, A.D. Wilson, Glass-ionomer cements of improved flexural strength., J Dent Res. 65 (1986) 146-148.

[183] J.R. Martin, J.F. Johnson, A.R. Cooper, Mechanical properties of polymers: The influence of molecular weight and molecular weight distribution, Polym. Rev. 8 (1972) 57-199. 
[184] P. de Gennes, Entangled polymers, Phys. Today. 36 (1983) 33-39.

[185] B.W. Darvel, Materials science for dentistry, Woodhead Publishing, Cambridge, UK, 2009.

[186] K.Z. Abdiyev, E.M. Shaikhutdinov, M.B. Zhursumbaeva, S.K. Khussain, Effect of polymer concentration on the surface properties of polyacid-poly(N-vinylpyrrolidone) complexes, Colloid J. 65 (2003) 399-402.

[187] R. van Noort, Introduction to Dental Materials, Mosby Ltd., London, UK, 2014.

[188] E. de Barra, R. Hill, Influence of poly(acrylic acid) content on the fracture behaviour of glass polyalkenoate cements, J Mater Sci. 33 (1998) 5487-5497.

[189] R. Guggenberger, R. May, K.P. Stefan, New trends in glass-ionomer chemistry, Biomaterials. 19 (1998) 479-483.

[190] M. Akay, Introduction to polymer science and technology, Bookboon Ventus Publishing, Denmark, 2012.

[191] D. Xie, D. Feng, I.-D. Chung, A.W. Eberhardt, A hybrid zinc-calcium-silicate polyalkenoate bone cement, Biomaterials. 24 (2003) 2749-2757.

[192] A.U.J. Yap, S. Mudambi, C.L. Chew, J.C.L. Neo, Mechanical properties of improved visible lightcured resin-modified glass ionomer cement, Oper. Dent. 26 (2001) 295-301.

[193] A.D. Neve, V. Piddock, E.C. Combe, Development of novel dental cements. I. Formulation of aluminoborate glasses, Clin.Mater. 9 (1992) 7-12.

[194] S. Crisp, A.D. Wilson, Reactions in Glass Ionomer Cements: V. Effect of Incorporating Tartaric Acid in the Cement Liquid, J. Dent. Res. 55 (1976) 1023-1031.

[195] S. Crisp, B.G. Lewis, A.D. Wilson, Characterization of glass-ionomer cements 5. The effect of the tartaric acid concentration in the liquid component, J. Dent. 7 (1979) 304-312.

[196] H.J. Prosser, C.P. Richards, A.D. Wilson, NMR spectroscopy of dental materials. II. The role of tartaric acid in glass-ionomer cements, J Biomed Mater Res. 16 (1982) 431-445.

[197] L.H. Prentice, M.J. Tyas, M.F. Burrow, The effects of boric acid and phosphoric acid on the compressive strength of glass-ionomer cements, Dent Mater. 22 (2006) 94-97.

[198] E.C. Kao, B.M. Culbertson, D. Xie, Preparation of glass ionomer cement using N-acryloylsubstituted amino acid monomers — Evaluation of physical properties, Dent Mater. 12 (1996) 4451.

[199] B.L. Rivas, G. V Seguel, Poly(acrylic acid-co-maleic acid)-metal complexes with copper(II), cobalt(II), and nickel(II): Synthesis, characterization and structure of its metal chelates, Polyhedron. 18 (1999) 2511-2518.

[200] E. Rodríguez, I. Katime, Some Mechanical Properties of Poly[(acrylic acid)-co-(itaconic acid)] Hydrogels, Macromol. Mater. Eng. 288 (2003) 607-612.

[201] L.H. Prentice, M. Tyas, M.F. Burrow, The effect of oxalic acid incorporation on the setting time and strength of a glass-ionomer cement, Acta Biomater. 2 (2006) 109-112.

[202] D.F. Williams, Definitions in biomaterials, in: Proceedings of a consensus conference of the european society for biomaterials, Chester, England, March 3-5, 1986., Elsevier, New York, U.S.A., 1987.

[203] D.F. Williams, On the mechanisms of biocompatibility, Biomaterials. 29 (2008) 2941-2953. 
[204] W.G. Brodbeck, J. Patel, G. Voskerician, E. Christenson, M.S. Shive, Y. Nakayama, et al., Biomaterial adherent macrophage apoptosis is increased by hydrophilic and anionic substrates in vivo , Proc. Natl. Acad. Sci. U. S. A. 99 (2002) 10287-10292.

[205] E. de Giglio, D. Cafagna, M.A. Ricci, L. Sabbatini, Biocompatibility of poly(acrylic acid) thin coatings electro-synthesized onto TiAlV-based implants, J Bioact Compat Pol. 25 (2010) 374391.

[206] E. de Giglio, S. Cometa, N. Cioffi, L. Torsi, L. Sabbatini, Analytical investigations of poly(acrylic acid) coatings electrodeposited on titanium-based implants: A versatile approach to biocompatibility enhancement, Anal. Bioanal. Chem. 389 (2007) 2055-2063.

[207] I.A. Mjör, Problems and benefits associated with restorative materials: side-effects and long-term cost, Adv. Dent. Res. 6 (1992) 7-16.

[208] W.F. Caughman, G.B. Caughman, W.T. Dominy, G.S. Schuster, Glass ionomer and composite resin cements: Effects on oral cells., J Prosthet Dent. 63 (1990) 513-521.

[209] W. Geurtsen, W. Spahl, G. Leyhausen, Residual monomer/additive release and variability in cytotoxicity of light-curing glass ionomer cements and compomers., J Dent Res. 77 (1998) 20122019.

[210] J. Müller, G. Bruckner, E. Kraft, W. Hörz, Reaction of cultured pulp cells to eight different cements based on glass ionomers, Dent Mater. 6 (1990) 172-177.

[211] M. Peltola, T. Salo, K. Oikarinen, Toxic effects of various retrograde root filling materials on gingival fibroblast and rat sarcoma cells, Endod Dent Traumatol. 8 (1992) 120-124.

[212] G. Schmalz, C. Schmalz, J. Rotgans, Pulp tolerance of glass ionomer and zinc oxide-phosphate cements, Dtsch Zahnärztl Z. 41 (1986) 806-812.

[213] R.S. Tobias, R.M. Browne, C.A. Wilson, Antibacterial activity of dental restorative materials, Inter. Dent. Res. 18 (1985) 161-167.

[214] M.J. Tyas, A method for the in vitro toxicity testing of dentine restorative materials, J Dent Res. 56 (1977) 1285.

[215] S.D. Meryon, R.M. Browne, In vitro cytotoxicity of a new generation, Cell Biochem. Funct. 2 (1984) 43-48.

[216] I.M. Brook, G.T. Craig, D.J. Lamb, In vitro interaction between primary bone organ cultures, glass-ionomer cements and hydroxyapatite/tricalcium phosphate ceramics, Biomaterials. 12 (1991) 179-186.

[217] H. Kawahara, Y. Imanishi, H. Oshima, Biological evaluation on glass-ionomer cement, J Dent Res. 58 (1979) 1080-1086.

[218] M. Nakamura, H. Kawahara, K. Imia, S. Tomoda, Y. Kawata, S. Hikari, Long-term biocompatibility test of composite resins and glass-ionomer cement (in vitro), Dent Mater. 1 (1983) 100-101.

[219] L.E. Tam, E. Pulver, D. McComb, D.C. Smith, Physical properties of calcium hydroxide and glass ionomer base and lining materials., Dent Mater. 5 (1989) 145-149.

[220] E.J. De Schepper, R.R. White, W. von der Lehr, Antibacterial effects of glass ionomers, Am Dent J. 2 (1989) 51-56.

[221] C.J. Palenik, M.J. Behnen, J.C. Setcos, C.H. Miller, Inhibition of microbial adherence and growth 
by various glass ionomers in vitro., Dent Mater. 8 (1992) 16-20.

[222] L. Forsten, Short- and long-term fluoride release from glass ionomers and other fluoridecontaining filling materials in vitro., Scand J Dent Res. 98 (1990) 179-185.

[223] S. Hatibovic-Kofman, G. Koch, Fluoride release from glass ionomer cement in vivo and in vitro., Swed Dent J. 15 (1991) 253-258.

[224] T. Kawase, A. Suzuki, Studies on the transmembrane migration of fluoride and its effects on proliferation of L-929 fibroblasts (Lcells) in vitro., Arch Oral Biol. 34 (1989) 103-107.

[225] Y. Li, T.W. Noblitt, A.J. Dunipace, H. Oshima, Evaluation of mutagenicity of restorative dental materials using the Ames Salmonella/microsome test., J Dent Res. 69 (1990) 1188-1192.

[226] K.S. Min, H.I. Kim, H.J. Park, S.H. Pi, C.U. Hong, E.C. Kim, Human pulp cells response to Portland cement in vitro., J Endod. 33 (2007) 163-166.

[227] N. Six, J.J. Lasfargues, M. Goldberg, In vivo study of the pulp reaction to Fuji IX, a glass ionomer cement., J Dent. 28 (2000) 413-422.

[228] R.L. Steinbrunner, J.C. Setcos, A.H. Kafrawy, Connective tissue reactions to glass ionomer cements and resin components, Am J Dent. 4 (1991) 281-284.

[229] R.C. Paterson, A. Watts, The response of the rat molar pulp to glass ionomer cement., Brit Dent J. 151 (1981) 228-230.

[230] I. and E. Council on Dental Materials, Reported sensitivity to glass ionomer luting cements, J Am Dent Assoc. 109 (1984) 476.

[231] O.H. Andersson, J.E. Dahl, Aluminium release from glass ionomer cements during early water exposure in vitro, Biomaterials. 15 (1994) 882-888.

[232] D.C. Smith, N.D. Ruse, Activity of glass ionomer cements during setting and its relation to pulp sensitivity., J Am Dent Assoc 112, 654-657. 112 (1986) 654-657.

[233] J.W. Nicholson, J.H. Braybrook, E.A. Wasson, The biocompatibility of glass-poly(alkenoate) (Glass-Ionomer) cements: a review., J Biomater Sci Polym Ed. 2 (1991) 277-285.

[234] P. Sasanaluckit, K.R. Albustany, P.J. Doherty, D.F. Williams, Biocompatibility of glass ionomer cements , Biomaterials. 14 (1993) 906-916.

[235] W.R. Lacefield, M.C. Reindl, D.H. Retied, Tensile bond strength of a glass-ionomer cement, J Prosthet Den. 53 (1985) 194-198.

[236] D.C. Smith, A new dental cement, Br Dent J. 125 (1968) 381-384.

[237] D.R. Beech, A spectroscopic study of the interaction between human tooth enamel and polyacrylic acid (polycarboxylate cement), Arch Oral Biol. 17 (1972) 907-911.

[238] A.D. Wilson, Aluminosilicate poly(acrylic acid) and related cements, Br. Polym. J. 6 (1974) 165179.

[239] D. Belton, S.I. Stupp, Adsorption and ionic crosslinking of polyelectrolytes, in: C.G. Gebelein, F.F. Koblitz (Eds.), Biomed. Dent. Appl. Polym., Springer, New York, 1980: pp. 427-439.

[240] A.D. Wilson, H.J. Prosser, D.M. Powis, Mechanism of adhesion of polyelectrolyte cements to hydroxyapatite, J Dent Res. 62 (1983) 590-592.

[241] B. Van Meerbeek, Y. Yoshida, S. Inoue, J. De Munck, K. Van Landuyt, P. Lambrechts, Glassionomer adhesion: the mechanisms at the interface, J. Dent. 34 (2006) 614-622. 
[242] Y. Yoshida, B. Van Meerbeek, Y. Nakayama, J. Snauwaert, L. Hellemans, P. Lambrechts, et al., Evidence of chemical bonding at biomaterial-hard tissue interfaces., J. Dent. Res. 79 (2000) 709714.

[243] P. Hotz, J.W. McLean, I. Sced, A.D. Wilson, The bonding of glass-ionomer cements to metal and tooth substrates, Br Dent J. 142 (1977) 41-47.

[244] R.S. Levine, D.R. Beech, B. Garton, Improving the bond strength of the polyacrylate cements to dentine. A rapid technique, Br Dent J. 143 (1977) 275-277.

[245] B.E. Causton, N.W. Johnson, The role of diffusible ionic species in the bonding of polycarboxylate cements to dentine: An in vitro study, J Dent Res. 58 (1979) 1383-1393.

[246] D. Wood, R. Hill, Glass ceramic approach to controlling the properties of a glass-ionomer bone cement., Biomaterials. 12 (1991) 164-170.

[247] I.M. Brook, P. V Hatton, Glass-ionomers: bioactive implant materials., Biomaterials. 19 (1998) $565-571$.

[248] A.O. Akinmade, J.W. Nicholson, Glass-ionomer cements as adhesives, J Mater Sci Mater Med. 4 (1993) 95-101.

[249] M. Cranfield, A.T. Kuhn, G. Winter, Factors relating to the rate of fluoride-ion release from glassionomer cement, J Dent. 10 (1982) 333-341.

[250] L. Forsten, Fluoride release from a glass ionomer cement, Scand J Dent Res. 85 (1977) 503-504.

[251] A.D. Wilson, D.M. Groffman, A.T. Kuhn, The release of fluoride and other chemical species from a glass-ionomer cement, Biomaterials. 6 (1985) 431-433.

[252] H.S. Horowitz, A review of systematic and topical fluorides for the prevention of dental caries, Community Dent Oral Epidemiol. 1 (1973) 104-114.

[253] A. Maldonado, M.L. Swartz, R.W. Phillips, An in vitro study of certain properties of a glassionomer cement, J Am Dent Assoc. 96 (1978) 785-791.

[254] D.H. Retief, E.L. Bradley, J.C. Denton, P. Switzer, Enamel and cementum fluoride uptake from a glass ionomer cement, Caries Res. 18 (1984) 250-257.

[255] M. Yamaguchi, H. Oishi, Y. Suketa, Stimulatory effect of zinc on bone formation in tissue culture , Biochem. Pharmacol. 36 (1987) 4007-4012.

[256] A. Ito, H. Kawamurab, M. Otsukac, M. Ikeuchia, H. Ohgushia, K. Ishikawad, et al., Zinc-releasing calcium phosphate for stimulating bone formation, Mater. Sci. Eng. C. 22 (2002) 21-25.

[257] A. Guida, M.R. Towler, J.G. Wall, Preliminary work on the antibacterial effect of strontium in glass ionomer cements, J Mater Sci Lett. 22 (2003) 1401-1403.

[258] A. Coughlan, K. Scanlon, B.P. Mahon, M.R. Towler, Zinc and silver glass polyalkenoate cements: an evaluation of their antibacterial nature, Biomed Mater Eng. 20 (2010) 99-106.

[259] A.W. Wren, N.M. Cummins, F.R. Laffir, S.P. Hudson, M.R. Towler, The bioactivity and ion release of titanium-containing glass polyalkenoate cements for medical applications, J. Mater. Sci. Mater. Med. 22 (2011) 19-28.

[260] L. Shen, a. Coughlan, M.R. Towler, M. Hall, Degradable borate glass polyalkenoate cements, J Mater Sci Mater Med. 25 (2014) 965-973.

[261] H.P. Gregor, M. Frederick, Potentiometric titration of polyacrylic and polymethacrylic acids with 
alkali metal and quaternary ammonium bases, J Polym Sci. 23 (1957) 451-465.

[262] X. Xu, J.O. Burgess, Compressive strength, fluoride release and recharge of fluoride-releasing materials., Biomaterials. 24 (2003) 2451-2461.

[263] L. Forsten, S. Karjalainen, Glass ionomers in proximal cavities of primary molars, Scand J Dent Res. 98 (1990) 70-73.

[264] R.R. Welbury, A.W. Walls, J.J. Murray, J.F. McCabe, The 5-year results of a clinical trial comparing a glass polyalkenoate (ionomer) cement restoration with an amalgam restoration, $\mathrm{Br}$ Dent J. 170 (1991) 177-181.

[265] A. Holst, A 3-year clinical evaluation of ketac-silver restorations in primary molars, Swed Dent J. 20 (1996) 209-214.

[266] I. Anderson-Wenckert, J.W. V Dijken van, R. Stenberg, Effect of cavity form on the durability of gIass ionomer cement restoration in primary teeth: A three year clinical evaluation, J Dent Child. 62 (1995) 197-200.

[267] A.W.G. Walls, J.F. McCabe, J.J. Murray, The effect of variation of glass polyalkenoate (ionomer) cements, Br Dent J. 164 (1988) 141-144.

[268] A.D. Wilson, D.M. Groffman, D.R. Powis, R.P. Scott, A study of variables affecting the impinging jet method for measuring the erosion of dental cements, Biomaterials. 7 (1986) 217220.

[269] A. Hoppe, N.S. Guldal, A.R. Boccaccini, A review of the biological response to ionic dissolution products from bioactive glasses and glass-ceramics., Biomaterials. 32 (2011) 2757-2774.

[270] P. Ducheyne, Bioactive ceramics: the effect of surface reactivity on bone formation and bone cell function, Biomaterials. 20 (1999) 2287-2303.

[271] M.N. Rahaman, D.E. Day, B.S. Bal, Q. Fu, S.B. Jung, L.F. Bonewald, et al., Bioactive glass in tissue engineering., Acta Biomater. 7 (2011) 2355-2373.

[272] F.T. Aquino, J.L. Ferrari, S.J.L. Ribeiro, A. Ferrier, P. Goldner, R.R. Gonçalves, Broadband NIR emission in novel sol-gel Er3+-doped $\mathrm{SiO} 2-\mathrm{Nb} 2 \mathrm{O} 5$ glass ceramic planar waveguides for photonic applications, Opt. Mater. (Amst). 35 (2013) 387-396.

[273] B. Kościelska, A. Winiarski, Structural investigations of nitrided Nb2O5 and Nb2O5-SiO2 solgel derived films, J. Non. Cryst. Solids. 354 (2008) 4349-4353.

[274] M.P.F. Graça, M.G.F. da Silva, A.S.B. Sombra, M.A. Valente, Study of the electric and dielectric properties of SiO2-Li2O-Nb2O5 sol-gel glass-ceramics, J. Non. Cryst. Solids. 352 (2006) 15011505.

[275] J.L. Ferrari, K.O. Lima, L.J.Q. Maia, R.R. Gonçalves, Sol-gel preparation of near-infrared broadband emitting Er3+-doped SiO2-Ta2O5 nanocomposite films, Thin Solid Films. 519 (2010) $1319-1324$.

[276] J.-J. Legendre, J. Livage, Vanadium pentoxide gels:, J. Colloid Interface Sci. 94 (1983) 75-83.

[277] J. Haber, M. Witko, R. Tokarz, Vanadium pentoxide I. Structures and properties, Appl. Catal. A Gen. 157 (1997) 3-22.

[278] R.J.N. K M Wetherall, P Doughty, G Mountjoy, M Bettinelli, A Speghini, M F Casula, F CesareMarincola, E Locci, The atomic structure of niobium and tantalum containing borophosphate glasses, J. Phys. Condens. Matter. 21 (2009) 37. 
[279] F. ElBatal, G. El-Bassyouni, Bioactivity of Hench Bioglass and Corresponding Glass-Ceramic and the Effect of Transition Metal Oxides, Silicon. 3 (2011) 185-197.

[280] L. Cordeiro, R.M. Silva, G.M. de Pietro, C. Pereira, E.A. Ferreira, S.J.L. Ribeiro, et al., Thermal and structural properties of tantalum alkali-phosphate glasses, J. Non. Cryst. Solids. 402 (2014) 44-48.

[281] C. Persson, L. Guandalini, F. Baruffaldi, L. Pierotti, M. Baleani, Radiopacity of tantalum-loaded acrylic bone cement., Proc. Inst. Mech. Eng. H. 220 (2006) 787-791.

[282] T. Miyaza, H.-M. Kim, T. Kokubo, C. Ohtsuki, H. Kato, T. Nakamura, Mechanism of bonelike apatite formation on bioactive tantalum metal in a simulated body fluid., Biomaterials. 23 (2002) 827-832.

[283] A.W. Wren, a. Coughlan, L. Placek, M.R. Towler, Gallium containing glass polyalkenoate anticancerous bone cements: Glass characterization and physical properties, J. Mater. Sci. Mater. Med. 23 (2012) 1823-1833.

[284] A. Alhalawani, D. Curran, B. Pingguan-Murphy, D. Boyd, M. Towler, A novel glass polyalkenoate cement for fixation and stabilisation of the ribcage, post sternotomy surgery: An exvivo study, J. Funct. Biomater. 4 (2013) 329-357.

[285] A.M.F. Alhalawani, L. Placek, A.W. Wren, D.J. Curran, D. Boyd, M.R. Towler, Influence of gallium on the surface properties of zinc based glass polyalkenoate cements, Mater Chem. Phys. 147 (2014) 360-364.

[286] M.W.G. Lockyer, D. Holland, R. Dupree, NMR investigation of the structure of some bioactive and related glasses, J. Non. Cryst. Solids. 188 (1995) 207-219.

[287] F.R. Laffir, A.W. Wren, M.R. Towler, Influence of morphology and processing on XPS characterisation of SrO-Ca-ZnO-SiO2 glass, J. Mater. Sci. 45 (2010) 3102-3105.

[288] G.M. de Pietro, C. Pereira, R.R. Gonçalves, S.J.L. Ribeiro, C.D. Freschi, F.C. Cassanjes, et al., Thermal, structural, and crystallization properties of new tantalum alkali-germanate glasses, J. Am. Ceram. Soc. 98 (2015) 2086-2093.

[289] J.C. Hurt, C.J. Phillips, Structural role of zinc oxide in glasses in the system Na2O-ZnO-SiO2, J. Am. Ceram. Soc. 53 (1970) 269-273.

[290] B.A. Sava, A. Diaconu, M. Elisa, C.E.A. Grigorescu, I.C. Vasiliu, A. Manea, Structural characterization of the sol-gel oxide powders from the $\mathrm{ZnO}-\mathrm{TiO} 2-\mathrm{SiO} 2$ system, Superlattices Microstruct. 42 (2007) 314-321.

[291] R. Hill, An alternative view of the degradation of bioglass, J. Mater. Sci. Lett. 15 (1996) 11221125.

[292] M.D. O'Donnell, R.G. Hill, Influence of strontium and the importance of glass chemistry and structure when designing bioactive glasses for bone regeneration., Acta Biomater. 6 (2010) 23825 .

[293] M. Edén, The split network analysis for exploring composition-structure correlations in multicomponent glasses: I. Rationalizing bioactivity-composition trends of bioglasses, J. Non. Cryst. Solids. 357 (2011) 1595-1602.

[294] H. Aguiar, J. Serra, P. González, B. León, Structural study of sol-gel silicate glasses by IR and Raman spectroscopies, J. Non. Cryst. Solids. 355 (2009) 475-480.

[295] J. Shelby, Introduction to glass science and technology, 2nd ed., The royal society of chemistry, 
Cambridge, UK, 2005.

[296] R.G. Hill, D.S. Brauer, Predicting the bioactivity of glasses using the network connectivity or split network models, J. Non. Cryst. Solids. 357 (2011) 3884-3887.

[297] I. Elgayar, A.E. Aliev, A.R. Boccaccini, R.G. Hill, Structural analysis of bioactive glasses, J. Non. Cryst. Solids. 351 (2005) 173-183.

[298] A. Tilocca, A.N. Cormack, N.H. de Leeuw, The Structure of bioactive silicate glasses: New insight from molecular dynamics simulations, Chem. Mater. 19 (2007) 95-103.

[299] A. Tilocca, A.N. Cormack, Structural effects of phosphorus inclusion in bioactive silicate glasses., J. Phys. Chem. B. 111 (2007) 14256-14264.

[300] A.B. Rosenthal, S.H. Garofalini, Structural role of zinc oxide in silica and soda-silica glasses, J. Am. Ceram. Soc. 70 (1987) 821-826.

[301] Y. Zhao, X. Zheng, M. Zhou, Coordination of niobium and tantalum oxides by Ar, Xe and O2: Matrix isolation infrared spectroscopic and theoretical study of $\mathrm{NbO} 2(\mathrm{Ng}) 2(\mathrm{Ng}=\mathrm{Ar}, \mathrm{Xe})$ and MO4(X) (M=Nb, Ta; X=Ar, Xe, O2) in solid argon, Chem. Phys. 351 (2008) 13-18.

[302] T. Tsuchiya, H. Imai, S. Miyoshi, P.-A. Glans, J. Guo, S. Yamaguchi, X-ray absorption, photoemission spectroscopy, and Raman scattering analysis of amorphous tantalum oxide with a large extent of oxygen nonstoichiometry., Phys. Chem. Chem. Phys. 13 (2011) 17013-17018.

[303] T. Cardinal, E. Fargin, G. Le Flem, S. Leboiteux, Correlations between structural properties of Nb2O5-NaPO3-Na2B4O7 glasses and non-linear optical activities, J. Non. Cryst. Solids. 222 (1997) 228-234.

[304] I. Kashif, A.A. Soliman, E.M. Sakr, A. Ratep, Effects of the addition of transition metal ions on some physical properties of lithium niobium borate glasses, Phys. Chem. Glas. - Eur. J. Glas. Sci. Technol. Part B. 55 (n.d.) 34-40.

[305] G. Poirier, M. Poulain, Y. Messaddeq, S.J. L Ribeiro, New tungstate fluorophosphate glasses, J. Non. Cryst. Solids. 351 (2005) 293-298.

[306] A.J. Barbosa, F.A.D. Filho, L.J.Q. Maia, Y. Messaddeq, S.J.L. Ribeiro, R.R. Gonçalves, Er 3+ doped phosphoniobate glasses and planar waveguides: structural and optical properties, J. Phys. Condens. Matter. 20 (2008) 285224.

[307] T. Kosuge, Y. Benino, V. Dimitrov, R. Sato, T. Komatsu, Thermal stability and heat capacity changes at the glass transition in K2O-WO3-TeO2 glasses, J. Non. Cryst. Solids. 242 (1998) 154164.

[308] A.W. Wren, T. Keenan, A. Coughlan, F.R. Laffir, D. Boyd, M.R. Towler, et al., Characterisation of Ga2O3-Na2O-CaO-ZnO-SiO2 bioactive glasses, J. Mater. Sci. 48 (2013) 3999-4007.

[309] J. Serra, P. González, S. Liste, C. Serra, S. Chiussi, B. León, et al., FTIR and XPS studies of bioactive silica based glasses, J. Non. Cryst. Solids. 332 (2003) 20-27.

[310] C.-C. Lin, L.-C. Huang, P. Shen, Na2CaSi2O6-P2O5 based bioactive glasses. Part 1: Elasticity and structure, J. Non. Cryst. Solids. 351 (2005) 3195-3203.

[311] H. Ono, T. Katsumata, Interfacial reactions between thin rare-earth-metal oxide films and $\mathrm{Si}$ substrates, Appl. Phys. Lett. 78 (2001).

[312] K.J. Rao, N. Baskaran, P.A. Ramakrishnan, B.G. Ravi, A. Karthikeyan, Structural and Lithium Ion Transport Studies in Sol-Gel-Prepared Lithium Silicophosphate Glasses, Chem. Mater. 10 (1998) 
3109-3123.

[313] J.R. Jones, Review of bioactive glass: from Hench to hybrids., Acta Biomater. 9 (2013) 4457-86.

[314] W.H. Zachariasen, The atomic arrangement in glass, J. Am. Chem. Soc. 54 (1932) 3841-3851.

[315] S. Grabowsky, M.F. Hesse, C. Paulmann, P. Luger, J. Beckmann, How to make the ionic Si-O bond more covalent and the $\mathrm{Si}-\mathrm{O}-\mathrm{Si}$ linkage a better acceptor for hydrogen bonding, Inorg. Chem. 48 (2009) 4384-4393.

[316] S.-P. Szu, L.C. Klein, M. Greenblatt, Effect of precursors on the structure of phosphosilicate gels: 29Si and 31P MAS-NMR study, J. Non. Cryst. Solids. 143 (1992) 21-30.

[317] A.M.F. Alhalawani, M.R. Towler, The effect of $\mathrm{ZnO} \leftrightarrow \mathrm{Ta} 2 \mathrm{O} 5$ substitution on the structural and thermal properties of SiO2-ZnO-SrO-CaO-P2O5 glasses, Mater. Charact. 114 (2016) 218-224.

[318] R.T. Sanderson, An Interpretation of Bond Lengths and a Classification of Bonds, Science. 114 (1951) 670-672.

[319] H. Darwish, S. Ibrahim, M.M. Gomaa, Electrical and physical properties of Na2O--CaO--MgO-$\mathrm{SiO} 2$ glass doped with NdF3, J. Mater. Sci. Mater. Electron. 24 (2012) 1028-1036.

[320] M. Eigen, Structural Chemistry of Glasses, Elsevier, 2002.

[321] G. Calas, L. Cormier, L. Galoisy, P. Jollivet, Structure-property relationships in multicomponent oxide glasses, Comptes Rendus Chim. 5 (2002) 831-843.

[322] V.K. Balla, S. Bodhak, S. Bose, A. Bandyopadhyay, Porous tantalum structures for bone implants: fabrication, mechanical and in vitro biological properties., Acta Biomater. 6 (2010) 3349-59.

[323] K.B. Sagomonyants, M. Hakim-Zargar, A. Jhaveri, M.S. Aronow, G. Gronowicz, Porous tantalum stimulates the proliferation and osteogenesis of osteoblasts from elderly female patients, J. Orthop. Res. 29 (2011) 609-616.

[324] V.K. Balla, S. Bose, N.M. Davies, A. Bandyopadhyay, Tantalum-A bioactive metal for implants, Jom. 62 (2010) 61-64.

[325] Y.-Y. Chang, H.-L. Huang, H.-J. Chen, C.-H. Lai, C.-Y. Wen, Antibacterial properties and cytocompatibility of tantalum oxide coatings, Surf. Coatings Technol. 259 (2014) 193-198.

[326] M. Roy, V.K. Balla, S. Bose, A. Bandyopadhyay, Comparison of tantalum and hydroxyapatite coatings on titanium for applications in load bearing implants, Adv. Eng. Mater. 12 (2010) B637B641.

[327] J. Black, Biologic performance of tantalum, Clin. Mater. 16 (1994) 167-173.

[328] A. Stamboulis, R. V Law, R.G. Hill, Characterisation of commercial ionomer glasses using magic angle nuclear magnetic resonance (MAS-NMR)., Biomaterials. 25 (2004) 3907-3913.

[329] D.S. Brauer, C. Rüssel, J. Kraft, Solubility of glasses in the system P2O5-CaO-MgO-Na2OTiO2: Experimental and modeling using artificial neural networks, J. Non. Cryst. Solids. 353 (2007) 263-270.

[330] N.Y. Mikhailenko, E.E. Stroganova, N. V Buchilin, Solubility of calcium phosphate glasses and glass ceramic materials in water and physiological media, Glass Ceram. 70 (2013) 158-163.

[331] G. Mohandas, N. Oskolkov, M.T. McMahon, P. Walczak, M. Janowski, Porous tantalum and tantalum oxide nanoparticles for regenerative medicine., Acta Neurobiol. Exp. (Wars). 74 (2014) 188-196. 
[332] J.W. Nicholson, Adhesive dental materials-A review, Int. J. Adhes. Adhes. 18 (1998) 229-236.

[333] A.M.F. Alhalawani, D.J. Curran, D. Boyd, M.R. Towler, The role of poly(acrylic acid) in conventional glass polyalkenoate cements: a review, J. Polym. Eng. 36 (2015) 221-237.

[334] J.F. McCabe, D. Watts, H.J. Wilson, H. V Worthington, An investigation of test-house variability in the mechanical testing of dental materials, J Dent. 18 (1990) 90-97.

[335] D. Boyd, M.R. Towler, A.W. Wren, O.M. Clarkin, D.A. Tanner, TEM analysis of apatite surface layers observed on zinc based glass polyalkenoate cements, J. Mater. Sci. 43 (2008) 1170-1173.

[336] M. Navarro, A. Michiardi, O. Castaño, J.A. Planell, Biomaterials in orthopaedics, J. R. Soc. Interface . 5 (2008) 1137-1158.

[337] D. Boyd, O.M. Clarkin, A.W. Wren, M.R. Towler, Zinc-based glass polyalkenoate cements with improved setting times and mechanical properties., Acta Biomater. 4 (2008) 425-431.

[338] T.M. Eidem, A. Coughlan, M.R. Towler, P.M. Dunman, A.W. Wren, Drug-eluting cements for hard tissue repair: a comparative study using vancomycin and RNPA1000 to inhibit growth of Staphylococcus aureus., J. Biomater. Appl. 28 (2014) 1235-1246.

[339] G. Lewis, M.R. Towler, D. Boyd, M.J. German, A.W. Wren, et al., Evaluation of two novel aluminum-free, zinc-based glass polyalkenoate cements as alternatives to PMMA bone cement for use in vertebroplasty and balloon kyphoplasty, J. Mater. Sci. Mater. Med. 21 (2010) 59-66.

[340] O.M. Clarkin, D. Boyd, S. Madigan, M.R. Towler, Comparison of an experimental bone cement with a commercial control, Hydroset., J. Mater. Sci. Mater. Med. 20 (2009) 1563-1570.

[341] A.M. Alhalawani, M.R. Towler, A review of sternal closure techniques., J. Biomater. Appl. 28 (2013) 483-97.

[342] R.B. Saper, R. Rash, Zinc: an essential micronutrient., Am. Fam. Physician. 79 (2009) 768-772.

[343] P.J. Marie, P. Ammann, G. Boivin, C. Rey, Mechanisms of action and therapeutic potential of strontium in bone., Calcif. Tissue Int. 69 (2001) 121-129.

[344] P. Fedak, A. Kasatkin, Enhancing sternal closure using Kryptonite bone adhesive: technical report., Surg. Innov. 18 (2011) NP8-11.

[345] M. Holland, K. King, P. Fedak, Sternal closure with kryptonite - an innovative approach to a lingering pain in the chest, Can J Cardiol. 26 (2010) 269-282.

[346] ISO 9917-1:2007, Dentistry — Water-based cements — Part 1: Powder/liquid acid-base cements, 2007.

[347] J.A. Williams, R.W. Billington, G.J. Pearson, The effect of the disc support system on biaxial tensile strength of a glass ionomer cement., Dent. Mater. 18 (2002) 376-379.

[348] W.D. Callister, D.G. Rethwisch, Materials science and engineering: An introduction, 2014.

[349] K.E. Kuettner, B.U. Pauli, G. Gall, V.A. Memoli, R.K. Schenk, Synthesis of cartilage matrix by mammalian chondrocytes in vitro. I. Isolation, culture characteristics, and morphology, J. Cell Biol. 93 (1982) 743-750.

[350] S.K. Tomlinson, O.R. Ghita, R.M. Hooper, K.E. Evans, Investigation of the dual setting mechanism of a novel dental cement using infrared spectroscopy, Vib. Spectrosc. 45 (2007) 1017.

[351] Y. Zhang, F. Zhu, J. Zhang, L. Xia, Converting layered zinc acetate nanobelts to one-dimensional 
structured $\mathrm{ZnO}$ nanoparticle aggregates and their photocatalytic activity, Nanoscale Res. Lett. 3 (2008) 201-204.

[352] S. Matsuya, Y. Matsuya, M. Ohta, Structure of bioactive glass and its application to glass ionomer cement., Dent. Mater. J. 18 (1999) 155-166.

[353] J. Rajamathi, S. Britto, M. Rajamathi, Synthesis and anion exchange reactions of a layered copperzinc hydroxy double salt, Cu1.6Zn0.4(OH)3(OAc)·H2O, J. Chem. Sci. 117 (2005) 629-633.

[354] M.. Driessen, T.. Miller, V.. Grassian, Photocatalytic oxidation of trichloroethylene on zinc oxide: characterization of surface-bound and gas-phase products and intermediates with FT-IR spectroscopy, J. Mol. Catal. A Chem. 131 (1998) 149-156.

[355] A.W. Wren, A. Coughlan, L. Placek, M.R. Towler, Gallium containing glass polyalkenoate anticancerous bone cement: Glass characterization and physcial properties, J Mater Sci Mater Med. 23 (2012) 1823-1833.

[356] A.W. Wren, a. Coughlan, M.M. Hall, M.J. German, M.R. Towler, Comparison of a SiO2-CaO$\mathrm{ZnO}-\mathrm{SrO}$ glass polyalkenoate cement to commercial dental materials: ion release, biocompatibility and antibacterial properties, J. Mater. Sci. Mater. Med. 24 (2013) 2255-2264.

[357] L. Grech, B. Mallia, J. Camilleri, Investigation of the physical properties of tricalcium silicate cement-based root-end filling materials., Dent. Mater. 29 (2013) e20-8.

[358] Y.H. An, R.J. Friedman, Concise review of mechanisms of bacterial adhesion to biomaterial surfaces., J. Biomed. Mater. Res. 43 (1998) 338-348.

[359] A.W. Wren, A. Coughlan, F.R. Laffir, M.R. Towler, Comparison of a SiO2-CaO-ZnO-SrO glass polyalkenoate cement to commercial dental materials: glass structure and physical properties. , J Mater Sci Mater Med. 24 (2013) 271-280.

[360] J.J. Harrison, M. Rabiei, R.J. Turner, E.A. Badry, K.M. Sproule, H. Ceri, Metal resistance in Candida biofilms., FEMS Microbiol. Ecol. 55 (2006) 479-491.

[361] M.R. Bruins, S. Kapil, F.W. Oehme, Microbial resistance to metals in the environment., Ecotoxicol. Environ. Saf. 45 (2000) 198-207.

[362] O.E. Sorensen, J.B. Cowland, K. Theilgaard-Monch, L. Liu, T. Ganz, N. Borregaard, Wound healing and expression of antimicrobial peptides/polypeptides in human keratinocytes, a consequence of common growth factors., J. Immunol. 170 (2003) 5583-5589.

[363] K.E. Wallace, R.G. Hill, J.T. Pembroke, C.J. Brown, P. V Hatton, Influence of sodium oxide content on bioactive glass properties., J. Mater. Sci. Mater. Med. 10 (1999) 697-701.

[364] D.H. Carter, P. Sloan, I.M. Brook, P. V Hatton, Role of exchanged ions in the integration of ionomeric (glass polyalkenoate) bone substitutes., Biomaterials. 18 (1997) 459-466.

[365] N. Moritz, E. Vedel, H. Ylanen, M. Jokinen, M. Hupa, A. Yli-Urpo, Characterisation of bioactive glass coatings on titanium substrates produced using a CO2 laser., J. Mater. Sci. Mater. Med. 15 (2004) 787-794.

[366] Heart and stroke foundation, Statistics, (2016). http://www.heartandstroke.com/site/c.ikIQLcMWJtE/b.3483991/k.34A8/Statistics.htm (accessed January 1, 2016).

[367] Heart and stroke foundation, News from the Canadian Cardiovascular Congress 2014, (2014). http://www.heartandstroke.com/site/apps/nlnet/content2.aspx?c=ikIQLcMWJtE\&b=9219173\&ct= 14291147\&printmode $=1$ (accessed June 7, 2016). 